\title{
Robot-assisted laparoscopic surgery
}

Citation for published version (APA):

Heemskerk, J. (2014). Robot-assisted laparoscopic surgery. [Doctoral Thesis, Maastricht University]. Maastricht University. https://doi.org/10.26481/dis.20140516jh

Document status and date:

Published: 01/01/2014

DOI:

10.26481/dis.20140516jh

Document Version:

Publisher's PDF, also known as Version of record

\section{Please check the document version of this publication:}

- A submitted manuscript is the version of the article upon submission and before peer-review. There can be important differences between the submitted version and the official published version of record.

People interested in the research are advised to contact the author for the final version of the publication, or visit the DOI to the publisher's website.

- The final author version and the galley proof are versions of the publication after peer review.

- The final published version features the final layout of the paper including the volume, issue and page numbers.

Link to publication

\footnotetext{
General rights rights.

- You may freely distribute the URL identifying the publication in the public portal. please follow below link for the End User Agreement:

www.umlib.nl/taverne-license

Take down policy

If you believe that this document breaches copyright please contact us at:

repository@maastrichtuniversity.nl

providing details and we will investigate your claim.
}

Copyright and moral rights for the publications made accessible in the public portal are retained by the authors and/or other copyright owners and it is a condition of accessing publications that users recognise and abide by the legal requirements associated with these

- Users may download and print one copy of any publication from the public portal for the purpose of private study or research.

- You may not further distribute the material or use it for any profit-making activity or commercial gain

If the publication is distributed under the terms of Article $25 \mathrm{fa}$ of the Dutch Copyright Act, indicated by the "Taverne" license above, 


\section{ROBOT-ASSISTED \\ LAPAROSCOPIC SURGERY}

J. HEEMSKERK 


\section{Robot-assisted Laparoscopic Surgery}

ISBN: $\quad 978-90-817698-7-7$

Text: Jeroen Heemskerk

Design and Layout: Lodewijk Imkamp

Printed by: Ars Grafisch b.v.

Cover: Detail from: Mona Lisa (La Gioconda) Oil on poplar wood, 1503-1506

The painting is thought to be a portrait of Lisa Gherardini, the wife of Francesco del giocondo. Using his famous "sfumato" painting technique, the outlines of the object become less clear, adding to the unusual lively and enigmatic look in her eyes.

Leonardo da Vinci extensively studied human anatomy and fysiology using controversial autopsy on human corpses. The knowledge he obtained resulted in the creation of this renaissance masterpiece, probably the most renaissance masterpiece, probably the most famous, copied and parodied painting in the world.

Surgical intuitive has been studying human stereoscopy and manipulation. This knowledge resulted in the creation of the daVinci ${ }^{\circledR}$ Surgical System, the only commercially available surgical "robot" at this moment. Scientific proof of the added value of this 1.5 million euro advanced telemanipulator remains controversial.

\section{PROEFSCHRIFT}

ter verkrijging van de graad van doctor aan de Universiteit Maastricht, op gezag van de Rector Magnificus, prof. dr Luc LG Soete, volgens het besluit van het College van Decanen,

in het openbaar te verdedigen op 16 mei 2014 om 14:00 uur 
Promotor:

Prof. dr C.G.M.I. Baeten

Copromotor:

Dr N.D. Bouvy

Beoordelingscommissie:

Prof. dr L.P.S. Stassen

Dr G.L. Beets

Prof. dr J.J. Jakimowicz

Prof. dr H.J.T. Rutten 


\section{Section | Introduction}

Chapter I General introduction

Chapter 2 Technical aspects of the da Vinci® ${ }^{\circledR}$ Uurgical System

Chapter 3 Outline of the thesis

\section{Section 2 Experimental studies}

Previously published as:

Heemskerk J, Zandbergen HR, Maessen JG, Greve JWM, Bouvy ND. Advantages of advanced laparoscopic systems. Surg Endosc 2006;20:730-733

Chapter 5 Learning curves in robot-assisted laparoscopic surgery

Previously published as:

Heemskerk J, van Gemert WG, de Vries J, Greve JWM, Bouvy ND. Learning curves of robotassisted laparoscopic surgery compared with conventional laparoscopic surgery. Surg Laparosc Endosc Percutan Tech 2007;17(3):171-174

\section{Section 3 Clinical studies}

\section{Chapter 6 Robotic laparoscopic cholecystectomy}

First results after introduction of the four-armed da Vinci@Surgical System in fully robotic laparoscopic cholecystectomy.

Previously published as:

Heemskerk J, van dam R, van gemert WG, Beets GL, Greve JWM, Jacobs MJHM, Bouvy ND. First results after introduction of the four-armed da Vinci@Surgical System in fully robotic laparoscopic cholecystectomy. Dig Surg 2005;22:426-43

\section{Chapter 7 Robot-assisted laparoscopic Nissen fundoplication} A comparative study on costs and time in robot-assisted versus conventional laparoscopic Nissen fundoplication

\section{Previously published as:}

Heemskerk J, van Gemert WG, Greve JWM, Bouvy ND. Robot-assisted versus conventional laparoscopic Nissen fundoplication. Surg Laparosc Endosc Percutan tech 2007:17(I); I-4
Chapter 8 Robot-assisted laparoscopic rectopexy

A comparative study on costs and time in robot-assisted versus conventional laparoscopic rectopexy

Previously published as:

Heemskerk \, de Hoog DENM, van Gemert WG, Baeten CGMI, Greve JWM, Bouvy ND. Robotassisted versus Conventional laparoscopic rectopexy for rectal prolapse: a comparative study on costs and time. Dis Colon rectum 2007;50(II):1825-30

Chapter 9 Recurrence and functional results after robot-assisted

laparoscopic Rectopexy

A comparative study on recurrences and functional results after open versus conventional laparoscopic versus robot-assisted laparoscopic rectopexy for full-thickness rectal prolapse.

Previously published as:

De Hoog DENM, Heemskerk J, Nieman FHM, van Gemert WG, Baeten CGMI, Bouvy ND. Recurrence and functional results after open versus conventional laparoscopic versus robotassisted laparoscopic rectopexy for rectal prolapse. Int I colorectal Dis 2009:9; I20|-1206

Chapter 10 Relax! It's just laparoscopy!

Surgeon's heart rhythm variability as a measure of mental strain during robot-assisted and conventional laparoscopic cholecystectomy

Section 4 Summary and general discussion

Chapter II Summary

Chapter 12 The end of robot-assisted laparoscopy?

Chapter 13 Samenvatting (Summary in Dutch)

Chapter 14 Het einde van robot-geassisteerde laparoscopie?

Dankwoord

Curriculum vitae auctoris

Publicatielijst 


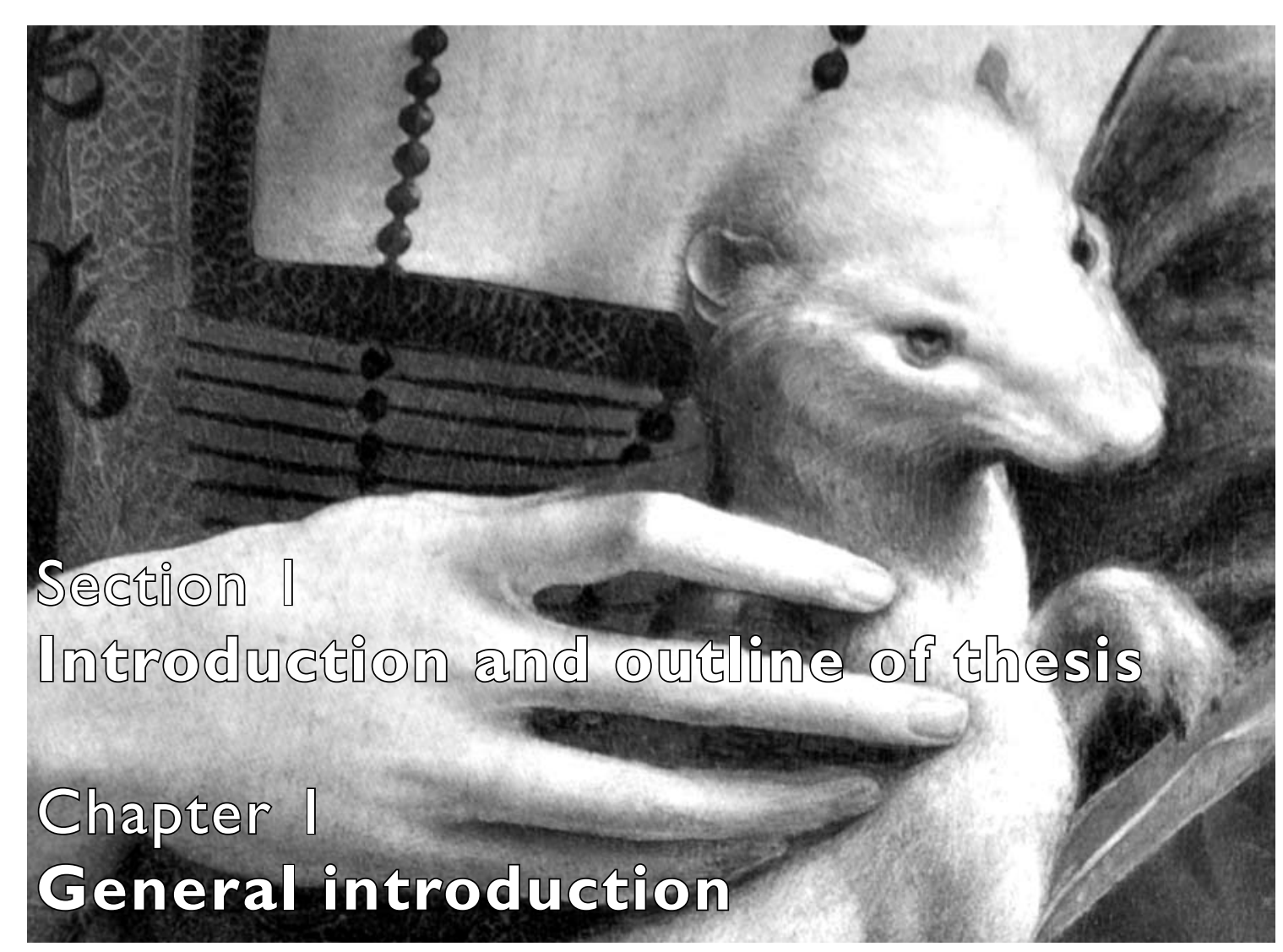

DETAIL FROM: THE LADY WITH AN ERMINE OIL ON WOODEN PANEL, I489-I490

The subject of the painting is Cecilia Gallerani, favorite mistress of Ludovico Sforza, Duke of Milan. Using a stoat in its winter coat was a traditional symbol of purity. An ermine was thought to prefer let itself be captured by hunters, than take refuge in a dirty lair, in order not to stain its white coat.

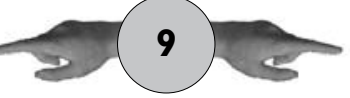




\section{HISTORY OF LAPAROSCOPY}

Laparoscopic surgery is one of the major advances in modern surgery. This technique enables surgeons to combine minimal access with maximal results, potentially offering great advantages to our patients. However, conventional laparoscopic surgery is not a new technique. In 1902, Georg Kelling of Dresden, Saxony, performed the first laparoscopic procedure in dogs. In 1910 the first laparoscopic operation on humans has been documented. Early pioneers in the field used instruments and optics that were primitive by today's standards and handling was difficult. In the 60's and 70's of the 20th century diagnostic laparoscopy became more popular, followed by merely gynaecologic therapeutic interventions such as salpingectomy and ovarian cyst enucleation. In the Netherlands, laparoscopic appendectomy was performed in the 60's by De Kok, a surgeon from Gorinchem. There was major scepticism amongst surgeons within the Dutch surgical society as to whether such minimal invasive techniques would be safe enough to introduce in general practise, and whether they should be performed by a surgeon. The first laparoscopic cholecystectomy followed in 1988. Within 10 years, laparoscopic surgery became the treatment of choice for the performance of elective cholecystectomy in The Netherlands.

Technologic advances have made the operations more efficacious, safer and easier to perform Within a few years, various devices including high-tech energy sources, 3-chip cameras and vascular and gastro-intestinal staplers have allowed surgeons to perform complex minimal invasive operations with improved confidence. However, significant concern arose soon due to a perceived increase in serious and sometimes lethal complications after minimal invasive surgery. Technical drawbacks might have been, at least partially, responsible for some of these complications. This triggered awareness within the surgical community that laparoscopy might offer a promising technique for many surgical problems, but an emphasis on extensive training in meticulous dissection and positive identification of all relevant anatomic structures is as important as ever. After all, "a fool with a tool is merely a fool" (quote: Prof. dr J.J. Jakimowicz).

\section{DRAWBACKS IN LAPAROSCOPY}

General surgery requires subtle manipulation of instruments and tissue in a complex threedimensional environment. The human arm naturally has the ability to move instruments in six degrees of freedom (DOFs), as illustrated in figure I:

1. Surging (moving forward and backward over the $\mathrm{X}$-axis)

2. Swaying (moving left and right over the Y-axis)

3. Heaving (moving up and down over the

Z-axis)

4. Rolling (tilting side to side around the $X$-axis)

5. Pitching (tilting forward and backward

around the $Y$-axis)

6. Yawing (rotation left and right around the

Z-axis)

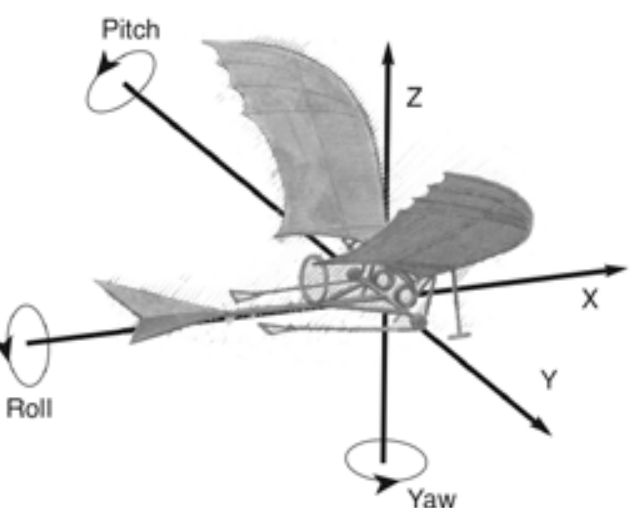

Figure I
Besides this, instruments can often be opened and closed, sometimes disputably defined as a seventh degree of freedom. Laparoscopic surgery can be demanding owing to several technical drawbacks. This attributes to a longer learning curve and might lead to increased iatrogenic complications. Limitations due to conventional laparoscopic surgery are the following:

I) Limited freedom of movement of the instruments due to the rigid instruments, introduced in the abdomen through fixed abdominal entry points. Heaving and swaying have become impossible. Surging (moving the instrument in and out the trocar) is still possible, just as rolling and pitching over a fixed entry point in the patient's abdominal wall, and yawing around the $X$-axis. This limitation makes manipulation more demanding, leading to decreased flexibility and manoeuvrability'

2) The fulcrum effect is a second effect from this combination of rigid instruments and fixed entry points in the abdominal wall. There is a movement of the tip of the instrument in the opposite direction of the handle of the instrument. Movement is both mirrored and scaled due to the point of rotation of the patient's abdominal wall. This contra-directional movement is known as the fulcrum effect, increasing learning curve and decreasing dexterity, as illustrated in figure 2 .

3) The long, inflexible instruments used in laparoscopic surgery magnify the surgeon's natural hand tremor

4 Limited tactile feedback decreases dexterity ${ }^{2,3}$

5) Two-dimensional vision using a conventional monitor jeopardizes a visual perception of depth. Misinterpretation of depth leads to decreased accuracy in performing surgical tasks, potentially leading to non-intentional damage to organs surrounding the surgical target ${ }^{4,5}$.

6) Depending on the location of the target organ and the setup of the equipment, there always is a variable disturbance of the natural eye-hand-target axis. This leads to decreased ergonomics and dexterity, subsequently leading to an increased risk of non-intentional damage.

7) Camera instability increases fatigue and degrades surgical performance ${ }^{6}$

8) Limited overview due to the small distance between the camera and the object,

These factors probably all contribute to the relatively long training period before reaching proficiency compared with traditional open surgery ${ }^{7}$. Even after extensive training, dexterity

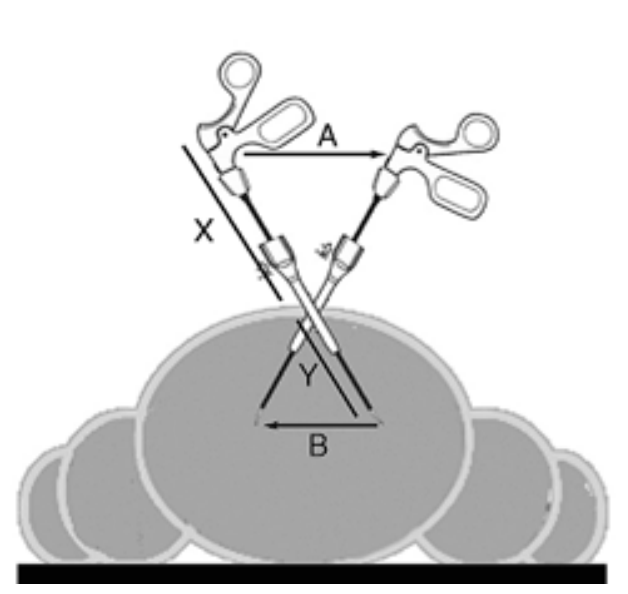
and ergonomics might remain decreased compared to open surgery, potentially leading to more complications. The use of advanced laparoscopic tools, instrument manipulating systems and visual systems might potentially address some of these shortcomings related to conventional laparoscopy, potentially leading to faster, easier, more accurate and safer minimal invasive surgery. They might also lead to a shorter learning curve ${ }^{8,9}$.

Figure 2 


\section{POTENTIAL SOLUTIONS}

I) Restoration of the full six degrees of freedom, as available in conventional manipulation, cannot be achieved with conventional laparoscopic rigid instruments. However, advanced handheld instruments, mechanical motorized telemanipulators are being developed in order to optimally restore the freedom of movement. These systems do result in improved dexterity during surgery 10,11 .

2) The presence of a fulcrum effect is inherent to the use of conventional laparoscopic long and rigid instruments, inserted to fixed abdominal entry points. Although extensive training of the surgeon leads to faster automation to the fulcrum effect ${ }^{12,13}$, only a telemanipulator system is able to fully restore intuitive movement of the instrument's tip in the direction of the surgeon's hand. 3) Automated tremor filtration using conventional laparoscopic tools has not been developed yet. At this moment, only a telemanipulator system has been shown to successfully diminish the increased natural tremor of the surgeon's hand in minimal invasive surgery ${ }^{10}$.

4) No commercially available surgical systems have been able to restore the diminished sensitivity in tactile feedback resulting from laparoscopic surgery. In fact, haptic feedback might be significantly less in conventional laparoscopic surgery as compared to open surgery, but is virtually absent in mechanical telemanipulators and totally absent in the motorized telemanipulator system available. Introduction of such haptic feedback offering motorized systems is not expected soon. 5) A variety of advanced visual systems are being developed. Traditionally, a $60 \mathrm{~Hz}$ screen refresh rate is used in television systems, resulting in an unsteady, flickering image and increased fatigue of the surgeon. The introduction of an increased screen refresh rate from $60 \mathrm{~Hz}$ to $120 \mathrm{~Hz}$ results in High Definition television (HDTV) with a smoother image in terms of motion rendering and flicker reduction. Previous studies suggest that improved resolution has a beneficial effect on surgical performance ${ }^{14}$. At the moment, this two-dimensional HDTV is considered the standard in contemporary laparoscopic surgery.

However, on the other side of the spectrum, stereoscopic systems are being developed potentially leading to convincing perception of depth. Although at this moment these stereoscopic systems rarely offer convincing depth perception ${ }^{15}$, its use has shown to be safe and feasible and it might improve laparoscopic performance, $5,16-19$

6) The disturbed eye-hand-target axis is difficult, if not impossible, to restore using conventional laparoscopic equipment. Although ergonomic monitor placement is crucial, the ideal situation positioning the surgeon on the ergonomically perfect spot and projecting the image exactly where the operation takes place is difficult (if not impossible) to achieve without the use of a headmounted display 20,21 .

7) Camera instability due to exhausting camera holding or insufficiently experienced camera holding assistants, can be restored using a variety of rigid or flexible mechanical or motorized camera holding systems.

8) The forced small distance between camera and subject and subsequent limited overview of the entire operative specimen seems inherent on the basis of single-camera video-assisted minimal invasive surgery and will not be easy to overcome.

This manuscript focuses at identification of these technical drawbacks and at defining how these difficulties could best be addressed.

\section{ADVANCED HANDHELD INSTRUMENTS}

The efficacy of a surgeon in laparoscopic surgery is highly dependent on his or her dexterity. However, conventional long and rigid laparoscopic instruments result in decreased dexterity due to the fulcrum effect, decreased degrees of freedom, magnification of the natural hand tremor of the surgeon and diminished haptic feedback as mentioned before. Rigid bend (or bendable) instruments might offer an extra possibility to allow appropriate manipulation and dissection. Recently, The introduction of Single Incision Laparoscopic Surgery (SILS) in laparoscopic surgery has attributed to the increased use of such instruments. However, a real significant improvement in instrument handling requires more than just rigid bend instruments. It requires maximal restoration of the decreased number of degrees of freedom (DOF's) . Various advanced handheld instruments have been developed in order to address some of these shortcomings.

One of these instruments (and probably the most successful one) is the Radius ${ }^{\circledR}$ Surgical System. This instrument has been developed by Tuebingen Scientific Medical GmbH, a spin-off company of Tuebingen University, Germany. The system consists of a manual manipulator with two additional degrees of freedom compared with conventional laparoscopic instruments. Extra opportunities are offered by a flexible and rotatable tip, resulting in faster, more accurate performance of laparoscopic tasks ${ }^{22,23}$. Although a variety of interchangeable instrument tips (or endo effectors) have been developed, there are still some drawbacks in the use of this instrument. Some of these drawbacks are related to the ergonomic design of this specific manipulator and its handling requiring additional training. Other drawbacks seem inherent in the use of mechanical handheld manipulators in laparoscopy such as a persisting fulcrum effect, tremor magnification and limited tactile feedback ${ }^{2,3}$

\section{MOTORIZED INSTRUMENT- OR CAMERA HOLDER}

Various companies have tried to develop motorized instrument- or camera holder systems in order to support the surgeon and redress some of the fore-mentioned technical drawbacks. The era of automated assistance in laparoscopic surgery started in 1994 with the introduction of the motorized camera-holder AESOP ${ }^{\circledR}$. This Automated Endoscopic System for Optimal Positioning has been developed by Computer Motion (Santa Barbara, CA, USA) and consists of a voiceactivated and controlled system. It does not perform automated tasks independently, but strictly follows the verbal orders of the controller, as could be expected from an instrument named after an ancient Greek slave. Therefore, the term "motorized camera holder" or "telemanipulator" seems more accurate for this device than the term "Camera Holding Surgical Robot". Potential benefits are the presence of a stable, tremor free image and a non-fatigued camera holding assistant. Use of this device might save on labour costs. However, the lack of active participation of the camera-holding assistant and subsequent suboptimal performance may lead to an increased need for necessary commands and to manual camera corrections, resulting in a loss of comfort as well as time for the operating surgeon ${ }^{24}$.

An alternative might be offered by the use of the EndoAssist ${ }^{\circledR}$ or Freehand ${ }^{\circledR}$ Camera Holding System (originally designed by Prosurgics but now further developed by Freehand $2010 \mathrm{Ltd}$, Guildford, UK). This motorized camera holder is controlled through a headset-mounted motion axis selection sensor. This might arguably lead to increased accuracy, a shorter learning curve for the surgeon and faster performance of laparoscopic tasks compared to the Aesop ${ }^{25,26}$ or conventional assistance ${ }^{27}$. However, these techniques have not been fully developed and there is no convincing evidence supporting the acquisition and use of any of these technically advanced and expensive manipulators ${ }^{28-30}$ 


\section{HIGH-DEFINITION AND STEREOSCOPIC VISUAL SYSTEM}

A variety of advanced visual systems have been developed. In the ideal situation, the use of direct view by the surgeon through a pure optical stereoscopic system offers high-quality images with an adequate perception of depth. However, this technique is only feasible if the following two conditions are met:

I) the target area is limited and camera relocation is virtually absent, allowing for fixation of the stereoscopic optic to the table, and

2) the anatomy of the patient's body does not prevent positioning of the surgeon at the ergonomically ideal location. For example: in laparoscopic surgery in the lower pelvis such as radical prostatectomy or rectum resection, the optimal location of the surgeon would probably be where the upper abdomen and the thorax of the patient are situated. Since removal of these patient body parts is not a feasible option, alternative positioning of the surgeon has to be accepted, possibly leading to the need of an alternative visual system.

At this moment, these ideal conditions are only met in Transanal Endoscopic Microsurgery (TEM) using the stereoscopic equipment developed by Prof Buess and offered by Richard Wolf $\mathrm{GmbH}^{31}$. In conventional abdominal and thoracic minimal invasive surgery, the use of a video camera and screen is unconditional. Traditionally, a mere $60 \mathrm{~Hz}$ screen refresh rate is used in both medical and consumer home television systems, resulting in an unsteady, flickering image. This leads to increased fatigue and consequently suboptimal performance of the surgeon. The introduction of an increased screen refresh rate from $60 \mathrm{~Hz}$ to $120 \mathrm{~Hz}$ results in High Definition television (HDTV) with a smoother image in terms of motion rendering and flicker reduction.

This two-dimensional HDTV is considered the standard in contemporary laparoscopic surgery ${ }^{32}$ In consumer electronics, the appearance of $240 \mathrm{~Hz}$ and even $480 \mathrm{~Hz}$ televisions suggests there might be an advantage of even higher screen refresh rates in order to prevent judder and motion blur. Whether there is a real benefit, or this is just a marketing tool ${ }^{33}$, remains unclear ${ }^{14}$.

However, on the other side of the spectrum, stereoscopic visual systems are being developed in order to mimic life-like three dimensional (3D) vision, leading to a convincing perception of depth. In order to achieve this, two slightly different images have to be produced on the retina of both eyes. In the case of a stereo endoscope, the object being viewed is captured in two slightly different orientations and, after image processing by the brain, appears as a three-dimensional object. One potential limiting factor of 3D endoscopic systems is that the normal inter-pupillary distance for human vision is approximately $60 \mathrm{~mm}$, while the maximum separation of two objective lenses in a $10 \mathrm{~mm}$ laparoscope is approximately $8 \mathrm{~mm}$. However, various endoscopic designs have accounted for this disparity, and were thus able to provide adequate capture and display of $3 \mathrm{D}$ images. Three groups of 3D visual systems have been developed: monitor-based systems, headmounted display systems and console-based systems.

The basic mechanism of 3D visual monitor-based systems consists of two separate images that are captured using a stereoscopic endoscope and alternately transmitted to a monitor at high frequency. There are three different techniques for directing the correct images to its respective eye without the other eye seeing it:

1) Using active eyewear offering two separate images from two offset sources

2) using passive eyewear offering two separate images from one monitor

3) Using an auto stereo display without eyewear.

The first method involves a surgeon wearing active eyewear. One option is the use of a head-mounted display with two separate screens (one in front of each eye) offering slightly different images to the surgeon. Examples of this system are the initial versions of the Viking 3DHD Vision System, originally developed by Viking Systems Inc, Westborough, UK and offering high-quality images with a convincing perception of depth (Figure 3). However, one of the disadvantages of this system is the relatively heavy weight of such a head-mounted display. Another problem is the inability to see anything but the image projected in front of the eyes, blinding the surgeon for other important information in the operating room.

Another possible solution using active headware consists of a head-mounted active shutter system. This system makes use of liquid crystal glasses that receive a signal from the displaying system. The transmitted signal controls the alternate optical shuttering of the glasses to enable the surgeon to receive

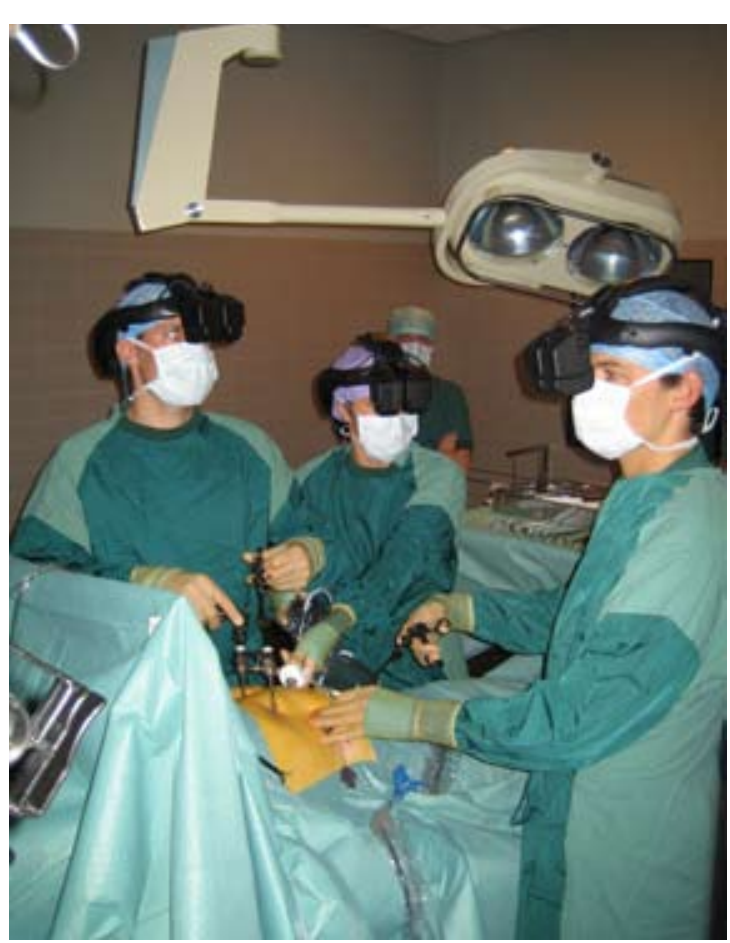

Figure 3 the two images with the respective eyes. The cerebrum merges the two separate and slightly different images as one composed 3D image. Again, head-mounted active eyewear tends to be rather bulky and heavy, preventing its successful introduction into regular practise. Development of such systems seems to be discontinued and the Viking Company has been sold to ConMed Corporation, shifting its focus to the development of $3 \mathrm{D}$ visual systems using passive eyewear.

The second method uses passive eyewear. This can be achieved using a similar shutter system. In this situation, a large liquid crystal shutter is placed in front of the monitor instead of the eye. This

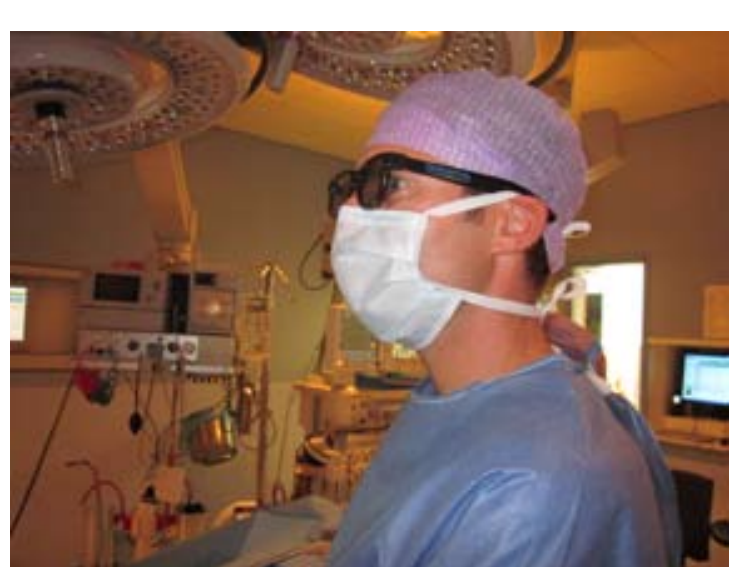
with the right and left image signals. The surgeon wears passive eyewear with a right circular polarized lens in the right eye and a left circular polarized lens in the left eye. The right eye then can only perceive a right-image signal, because it is similarly polarized, whereas the left eye can only perceive a left-image signal. Again, the 3D image is composed in the brain by merging the two slightly different images. This technique seems more promising due to its better ergonomics. Several companies are offering such systems, including Conmed and Olympus (Figure 4). The perception of depth is often reasonable or good, although the quality Figure 4 of the images rarely equals the quality offered by a good conventional HD monitor. 


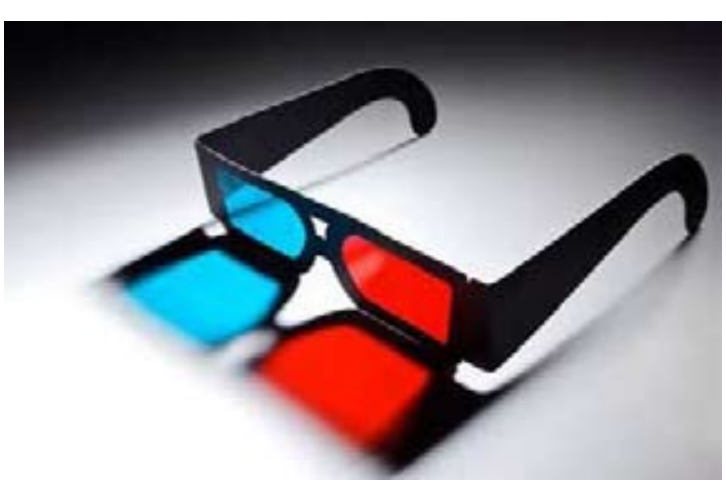

rechnique to offer two separate images to the eyes by looking at the same screen with passive eyewear, is the use of coloured glasses (the anaglyph technique) Generally, one glass is blue whilst the other is red (Figure 5). The image presented consists of two slightly different coloured images of the same object (Figure6), but each eye only receives one image. The anaglyph method has been used in microscopy successfully. However its use might lead to an unnatural sensation of the colour of the operative images. A significant Figure 5 number of individuals find it visually distressing to receive an image that is one colour in one eye, and an other colour in the other eye $\mathrm{e}^{34}$ Significant nausea and vertigo are common results of such a "colour bombardment". Due to these drawbacks, anaglyph stereoscopic systems have not become commercially available yet.

The third method uses no eyewear at all but requires an auto stereo display. These displays can basically be divided into either two-viewed, head tracked displays and multi view displays. The former allows for only one viewer to acquire a good stereoscopic image, under the condition that he is wearing a head-tracking device. The main difficulty is the head tracking itself, and adjusting the broadcasted two separate images to both separate eyes. Although some of these systems have shown to produce a reasonable perception of depth, the quality of the image and the fact that only one viewer can see the stereoscopic image makes this method not feasible for daily use.

Using a multi-view display could possibly solve some of the practical drawbacks of auto stereo displaying. However, this technique is still in its infancy and the quality of the image is not nearly adequate enough. Therefore, auto stereoscopy should not be considered a viable option soon.

Despite the development of these different visual systems, the stereoscopic systems available rarely offer a combination of HDTV with a high screen refresh rate and convincing stereoscopic perception of depth $^{15}$. Its use might improve laparoscopic performance performing tasks in a laboratory environment ${ }^{5,16-19}$. If this use of stereoscopy leads to faster, safer or more accurate surgery in daily practise, is subject of debate ${ }^{18}$.

Technically, this might in daily practise lead to a trade-off where a pragmatic choice will have to be made between HDTV or Stereoscopic view. Future research will have to clarify whether this offers significant advantages for the surgeon and the patient, potentially leading to a new standard in laparoscopic surgery.

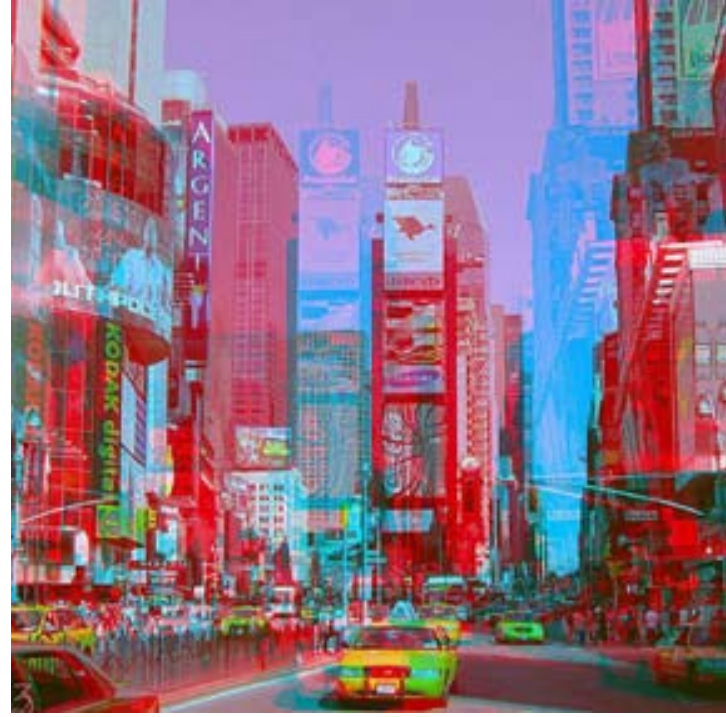

Figure 6

\section{INTEGRATED TELEMANIPULATOR AND VISUAL SYSTEMS}

Various companies have tried to develop an integrated system offering both motorized automated manipulator arms and High-Definition stereoscopic view in order to support the surgeon and address some of the fore-mentioned technical drawbacks. Some of these more complex and automated surgical systems have incorrectly been named "robotic" systems. The term "robot" was first used in 1921 by the Czech play writer Karel Capek and is derived from the Czech word "robota" which means forced labour. A robot is defined as "a mechanical contraption which can perform a variety of automated tasks on its own". The integrated systems available at this moment consist of a master-slave unit. The surgeon (master) is seated at a console and his movements of the instrument handles are digitized and imported in a computer. This computer can process these raw data in order to improve precise manipulation. Possible corrections made by the computer are the filtering of the surgeon's innate tremor. Also considerable downscaling occurs, reducing the relatively gross movements of the surgeon's hands. The adjusted information is then translated to relatively small but highly precise and accurate movement of the robotic (slave) arms.

The term "robotic surgery" is currently often used to refer to such telemanipulation technology. However, this might incorrectly give the impression that the system is performing the operation autonomously, suggesting a totally new and original concept. In advertisement, it is used (or abused) as a term suggesting a safer surgical environment, free of potential human errors. Research is being done in order to create a control system based on artificial intelligence, allowing for a real autonomous system performing save and reliable surgery. However, a major obstacle is that surgery per se is not readily formalizable. Therefore, all current systems are designed to merely seamlessly replicate the movement of the surgeon's hands with the tips of microinstruments, not to make decisions or move without the surgeon's direct input. Automated performance of limited surgical tasks such as taking image-guided biopsies ${ }^{35}$ or other interventions in specific surgical fields is still in its infancy and real automated surgery of entire procedures is not expected soon. Therefore, the consequent use of the term "telemanipulator" addressing the current robotic systems would add to clarification of its real nature. However, the term "robot" is being used so frequently by the manufacturer, users and patients alike, that this term has more or less become synonym with such an integrated visual and telemanipulator system. For the sake of readability, we will comply to the current use of the word "robot" and use the terms robot and telemanipulator interchangeable.

The ZEUS-AESOP ${ }^{\circledR}$ Robotic Surgical System was the first integrated and therefore "robotic" system especially designed for laparoscopic surgery by Computer Motion (Santa Barbara, CA, USA). The system was originally developed under a NASA Small Business Innovation Research (SBIR) contract to invent robots able to perform tasks requiring precise movements that exceed human dexterity. These automated systems were intended to facilitate remotely controlled operations in a hostile environment, for example during space repair missions or in a battlefield. The ZEUS ${ }^{\circledR}$ Robotic Surgical System was developed as a two-armed extension of the AESOP ${ }^{\circledR}$ motorized camera holder. It was first used in experimental surgery in 1998 re-anastomosing fallopian tubes after sterilisation. In $200 \mathrm{I}$ it was cleared by the Food and Drug Administration (FDA) for use by surgeons in a variety of laparoscopic and thoracoscopic procedures. The ultimate proof showing the feasibility of this remotely controlled precise movements, was delivered during the Lindbergh operation in the year $200 \mathrm{I}$. A remote controlled robotic laparoscopic cholecystectomy was performed in a patient with symptomatic cholelithiasis. Surgeons were in New York (USA) while the patient was several thousand miles away in Strasbourg (FR) ${ }^{36}$. Despite this spectacular telesurgical operation and a few cases of telementoring ${ }^{37}$, commercial success of the Zeus ${ }^{\circledR}$ Robotic Surgical System was limited. 


\section{THE DAVINCI ${ }^{\circledR}$ SURGICAL SYSTEM}

In 1999, Intuitive surgical Inc. introduced the da Vinci ${ }^{\circledR}$ Surgical System. This system is described by the manufacturer as being "a sophisticated robotic platform designed to expand the surgeon's capabilities - and for the first time - offer a minimal invasive option for major surgery" 38,39 . Again, the system has been designed to copy the movement of the surgeon, not to perform an operation autonomously. The system combines an ergonomic console based working place for the surgeon with a four-armed motorized instrument and camera holder. Positioning of the camera and instruments is performed by the surgeon's fingers grasping the master controls below the display, allowing an optimal restoration of the eye-hand-target axis. The view offered by the console consists of High-definition stereoscopic vision for the surgeon, allowing for a convincing perception of depth. An extensive technical description of the da $\mathrm{Vinci}^{\circledR}$ Surgical System is available in Chapter 2. Operation of this system seems quite intuitive. In the year 2000 it became the first robotic surgical system cleared by the FDA for general laparoscopic surgery. After a period of serious competition with the rival medical robotics company Computer Motion (offering the ZEUS ${ }^{\circledR}$ system), a variety of lawsuits were filed against Intuitive Surgical Inc. for allegedly infringing on Computer Motion's patents related to robotic technology. In March 2003, Intuitive Motion Inc acquired its principal (if not only) competitor, combining their intellectual potency and their efforts in developing robotic surgical systems.

At this moment, the da Vinci ${ }^{\circledR}$ Surgical System is the only integrated surgical system commercially available, combining advanced High-Definition stereoscopic view with motorized manipulator arms. Since its introduction to the market, Surgical intuitive has expanded impressively. The market for robotic systems is booming and at the time of writing, over 1800 da Vinci ${ }^{\circledR}$ Surgical Systems have been installed in more than 1450 hospital sites world wide where they are being used for a broad variety of cardiac, thoracic urologic, gynaecologic, colorectal, general surgical and paediatric operations. In the past few years, numerous manuscripts have been published on the advantages and disadvantages of the use of robotic assistance in laparoscopic surgery. Enthusiasts have proclaimed a clear benefit in terms of a shorter learning curve and an increased speed and accuracy performing laparoscopic tasks. This is supposed to result in improved operative results in terms of better functional results and less complications performing actual surgery. However, opponents have stated that the decrease in learning curve is mainly a significant finding in inexperienced individuals $\mathrm{s}^{40-43}$, not in expert surgeons performing actual surgery The increased speed of performing laparoscopic tasks as found in various laboratory studies ${ }^{44,45}$, might not result in an actual reduction of operation time, since installation of the da Vinci ${ }^{\circledR}$ Surgical System can be time consuming and cumbersome. Various studies show the use of robotic assistance is without any doubt feasible in both adults ${ }^{46-50}$ and in children ${ }^{51,52}$, but whether robotic assistance really leads to significant improved results compared to conventional laparoscopic or even open surgery remains under debate ${ }^{53-55}$ Studies suffering from publication bias might even further blur a clear view on advantages and disadvantages. Advantages might be minimal and certainly not justifying the increased financial costs, working in an era where cost reduction seems to become one of the primary goals in medicine. Critical surgeons have already stated that the da Vinci ${ }^{\circledR}$ Surgical System is an insignificant tool for surgery, but a great tool for marketing purposes. Whether the da Vinci ${ }^{\circledR}$ Surgical System should be categorized as "an invaluable extension of the surgical armamentarium" or as "toys for boys and tools for fools" remains subject to debate.
To clarify the role of advanced surgical systems, a four-armed da Vinci ${ }^{\circledR}$ Surgical System was acquired at Maastricht University Hospital in the year 2003. Since then, various studies have been conducted both in a dry lab environment and in clinical practise. This manuscript describes the studies conducted and the results and conclusions that might be taken. An outline of the thesis can be found in Chapter three.

\section{REFERENCES}

I Hodgson AJ, Person JG, Salcudean SE, et al. The effects of physical constraints in laparoscopic surgery. Med Image Anal 1999;3(3):275-83

2 Shamsunder SC, Manivannan M. Haptic guided laparoscopy simulation improves learning curve. Stud Health Technol Inform 2008;132:454-6

3 Panait L, Akkary E, Bell RL, et al. The Role of haptic feedback in laparoscopic simulation training. J Surg Res 2009;156(2):312-6

4 Peitgen K, Walz MV, Walz MV, et al. A prospective randomized experimental evaluation of three-dimensional imaging in laparoscopy. Gastrointest Endosc 1996;44(3) :262-7

5 Taffinder N, Smith SG, Huber J, et al. The effect of a second-generation 3D endoscope on the laparoscopic precision of novices and experienced surgeons. Surg Endosc 1999;13(11) :1087-92

6 Gallagher AG, Al-Akash M, Seymour NE, et al. An ergonomic analysis of the effects of camera rotation on laparoscopic performance. Surg Endosc 2009;23(I2):2684-9I

7 Subramonian K, DeSylva S, Bishai P, et al. Acquiring surgical skills: a comparative study of open versus laparoscopic surgery. Eur Urol 2004;45(3):346-5 I

8 Hanly EJ, Talamini MA. Robotic abdominal surgery. Am J Surg 2004; |88(4ASuppl) : I9S-26S

9 Hazey JW, Melvin WS. Robot-assisted general surgery. Semin Laparosc Surg 2004; I I (2) $: 107-12$

10 Moorthy K, Munz Y, Dosis A, et al. Dexterity enhancement with robotic surgery. Surg Endosc. 2004; I8(5) :790-5

II Usui S, Inoue H, Yoshida T, et al. Preliminary report of multi degrees of freedom forceps for endoscopic surgery. Surg laparosc Endosc percutan Tech. 2004;14(2) :66-72

12 Crothers IR, Gallagher AG, McClure N, et al. Experienced laparoscopic surgeons are automated to the "fulcrum effect": an ergonomic demonstration. Endoscopy 1999;3 I (5) :365-9

13 Jordan JA, Gallagher AG, McGuigan J, et al. Randomly alternating image presentation during laparoscopic training leads to faster automation to the "fulcrum effect". Endoscopy 2000;32(4):317-21

14 Van Bergen P, Kunert W, Buess GF. The effect of high-definition imaging on surgical task efficiency in minimally invasive surgery: an experimental comparison between threedimensional imaging and direct vision through a stereoscopic TEM rectoscope. Surg Endosc $2000 ; 14(1): 71-4$

15 Hofmeister J, Frank TG, Cuschieri A, et al. Perceptual aspects of two-dimensional and stereoscopic display techniques in endoscopic surgery: review and current problems. Semin Laparosc Surg 200I;8(I): 12-24

16 Cheah WK, Lenzi JE, So J, et al. Evaluation of a headmounted display (HMD) in the performance of a simulated laparoscopic task. Surg endosc 1999;15(9):990-I

17 Herron DM, lantis JC 2nd, Maykel J, et al. The 3-D monitor and head-mounted display. A quantitative evaluation of advanced laparoscopic viewing technologies. Surg Endosc 1999;। $3(8): 751-5$ 
18 Mueller MD, Camartin C, Dreher E, et al. Three-dimensional laparoscopy. Gadget or progress ? A randomized trial on the efficacy of three-dimensional laparoscopy. Surg endosc 1999;13(5): :469-72

19 van Bergen P, Kunert W, Buess GF. Three-dimensional (3-D) videosystems: bi-channel or single-channel optics? Endoscopy 1999;31(9):732-7

20 Berguer R, Forkey DL, Smith WD. The effect of laparoscopic instrument working angle on surgeon's upper extremity workload. Surg Endosc 2001;15(9):1027-9

PEmam TA, Hanna G, Cuschieri A. Ergonomic principles of task alignment, visual display, and direction of execution of laparoscopic bowel suturing. Surg Endosc 2002;16(2):267-7I

21 Di Lorenzo N, Camperchioli I, Gaspari AL. Radius surgical system and conventional

laparoscopic instruments in abdominal surgery: application, learning curve and ergonomy. Surg Oncol 2007;16 Suppl 1:S69-72

22 Frede T, Hammady A, Klein J, et al. The Radius surgical system - a new device for complex minimally invasive procedures in urology? Eur Urol 2007;5 I (4) : 1015-22

23 Kraft BM, Jäger C, Kraft K, et al. The AESOP robot system in laparoscopic surgery: increased risk or advantage for surgeon and patient? Surg Endosc 2004;18(8) :1216-23

24 Nebot PB, Jain Y, Haylett K, et al. Comparison of task performance of the camera-holder robots Endo-Assist and Aesop. Surg Laparosc Endosc Percutan Tech 2003;13(5) :334-8

25 Wagner AA, Varkarakis IM, Link RE, et al. Comparison of surgical performance during laparoscopic radical prostatectomy of two robotic camera holders, EndoAssist and AESOP: a pilot study. Urology 2006;68(I):70-4

26 Aiono S, Gilbert JM, Soin B, et al. Controlled trial of the introduction of a robotic camera assistant (EndoAssist) for laparoscopic cholecystectomy. Surg Endosc 2007;16(9):1267-70

27 Kalteis M, Pistrich R, Schimetta W, et al. Laparoscopic cholecystectomy as solo surgery with the aid of a robotic camera holder: a case-control study. Surg laparosc Endosc Percutan Tech 2007;17(4) :277-82

28 Gurusamy KS, Samraj K, Fusai G, et al. Robot assistant for laparoscopic cholecystectomy. Cochrane Database Syst Rev 2009; I:CD006578

29 Gurusamy KS, Samraj K, Fusai G, et al. Robot assistant versus human or another robot assistant in patients undergoing laparoscopic cholecystectomy. Cochrane database Syst Rev 2012;9:CD006578

30 Buess G, Kipfmüller K, Hack D, et al. Technique of Transanal endoscopic microsurgery. Surg Endosc 1988;2(2):71-5

31 Hagiike M, Philips EH, Berci G. Performance differences in laparoscopic surgical skills between true high-definition and three-chip CCD video systems. Surg Endosc 2007;21 ( I0:1849-54

32 Feng C, Rozenblit JW, Hamilton AJ. A computerized assessment to compare the impact of standard, stereoscopic, and high-definition laparoscopic monitor displays on surgical technique. Surg Endosc 2010;24(II):2743-8

33 Barber VC, Brett DA. "Colour Bombardment" - a human visual problem that interferes with the viewing of anaglyph stereo material. Scan Electron Microsc 1982; $(\mathrm{Pt} 2): 495-8$

34 Muntener M, Patriciu A, Petrisor D, et al. Transperineal prostate intervention: robot for fully automated MR imaging - system description and proof of principle in a canine model. Radiology 2008;247(2):543-9

35 Marescaux J, Leroy J, Rubino F, et al. Transcontinental robot-assisted remote telesurgery: feasibility and potential applications. Ann Surg 2002;235(4):487-92

36 Bove P, Stoianovici D, Micli S, et al. Is telesurgery a new reality? Our experience with laparoscopic and percutaneous procedures. J Endourology 2003;17(3):137-42

37 Website www.davincisurgery.com
38 Website www.intuitivesurgical.com

39 Deane LA, Lee HJ, Box GN, et al. Robotic versus standard laparoscopic partial/wedge nephrectomy: a comparison of intraoperative and perioperative results from a single institution. J Endourol 2008;22(5) :947-52

40 Yohannes $P$, Rotariu $P$, pinto $P$, et al. Comparison of robotic versus laparoscopic skills: is there a difference in the learning curve? Urology 2002;60(I):39-45

4I Prasad SM, Maniar HS, Soper NJ, et al. The effect of robotic assistance on learning curves for basic laparoscopic skills. Am J Surg. 2002;183(6):702-7

42 Hanly EJ, Marohn MR, Bachman SL, et al. Multiservice laparoscopic surgical training using the daVinci surgical system. Am J Surg 2004;187(2):309-15

43 Garcia-Ruiz A, Gagner M, Miller JH, et al. Manual vs robotically assisted laparoscopic surgery in the performance of basic manipulation and suturing tasks. Arch Surg. 1998;133(9) :957-61

44 Sarle R, Tewari A, Shrivastava A, et al. Surgical robotics and laparoscopic training drills. J Endourol 2004;18(I):63-6

45 Ruurda JP, van Dongen KW, Dries J, et al. Robot-assisted laparoscopic choledochojejunostomy. Surg Endosc 2003;17(12):1937-42

46 Ruurda JP, Broeders IA, Simmermacher RP, et al. Feasibility of robot-assisted laparoscopic surgery: an evaluation of 35 robot-assisted laparoscopic cholecystectomies. Surg Laparosc endosc Percutan tech 2002; I2(I) :4I-5

47 Ruurda JP, Draaisma WA, van Hillegersberg R, et al. Robot-assisted endoscopic surgery: a four-year single-center experience. Dig surg 2005;22(5) :3। 3-20

48 Wykypiel H, Wetscher GJ, Klaus A, et al. Robot-assisted laparoscopic partial posterior fundoplication with the daVinci system: initial experiences and technical aspects. Langenbecks Arch Surg 2003;387( I I- I 2) :4 I I-6

49 Melvin WS, Needleman BJ, Krause KR, et al. Computer-enhanced vs standard laparoscopic anti-reflux surgery. J gastrointest Surg 2002;6(I) :II-5

50 Knight CG, Lorincz A, Gidell KM, et al. Computer-assisted robot-enhanced laparoscopic fundoplication in children. J pediatr Surg 2004;39(6):864-6

5I Atug F, Woods M, Burgess SV, et al. Robot-assisted laparoscopic pyeloplasty in children. Jurol 2005; 174(4 Pt I) :1440-2

52 Barakat EE, Bedaiwy MA, Zimberg S, et al. Robotic-assisted, laparoscopic and abdominal myomectomy: a comparison of surgical outcomes. Obstet Gynecol 201 I; II7(2 Pt I) :15665)

53 Gettman MT, Blute ML, Chow GK, et al. Robotic-assisted laparoscopic partial nephrectomy: technique and initial clinical experience with daVinci robotic system. Urology 2004;64(5) :914-8

54 Ruurda JP, Visser PL, Broeders IA. Analysis of procedure time in robot-assisted surgery: comparative study in laparoscopic cholecystectomy. Comput Aided Surg 2003;8(I) :24-9 


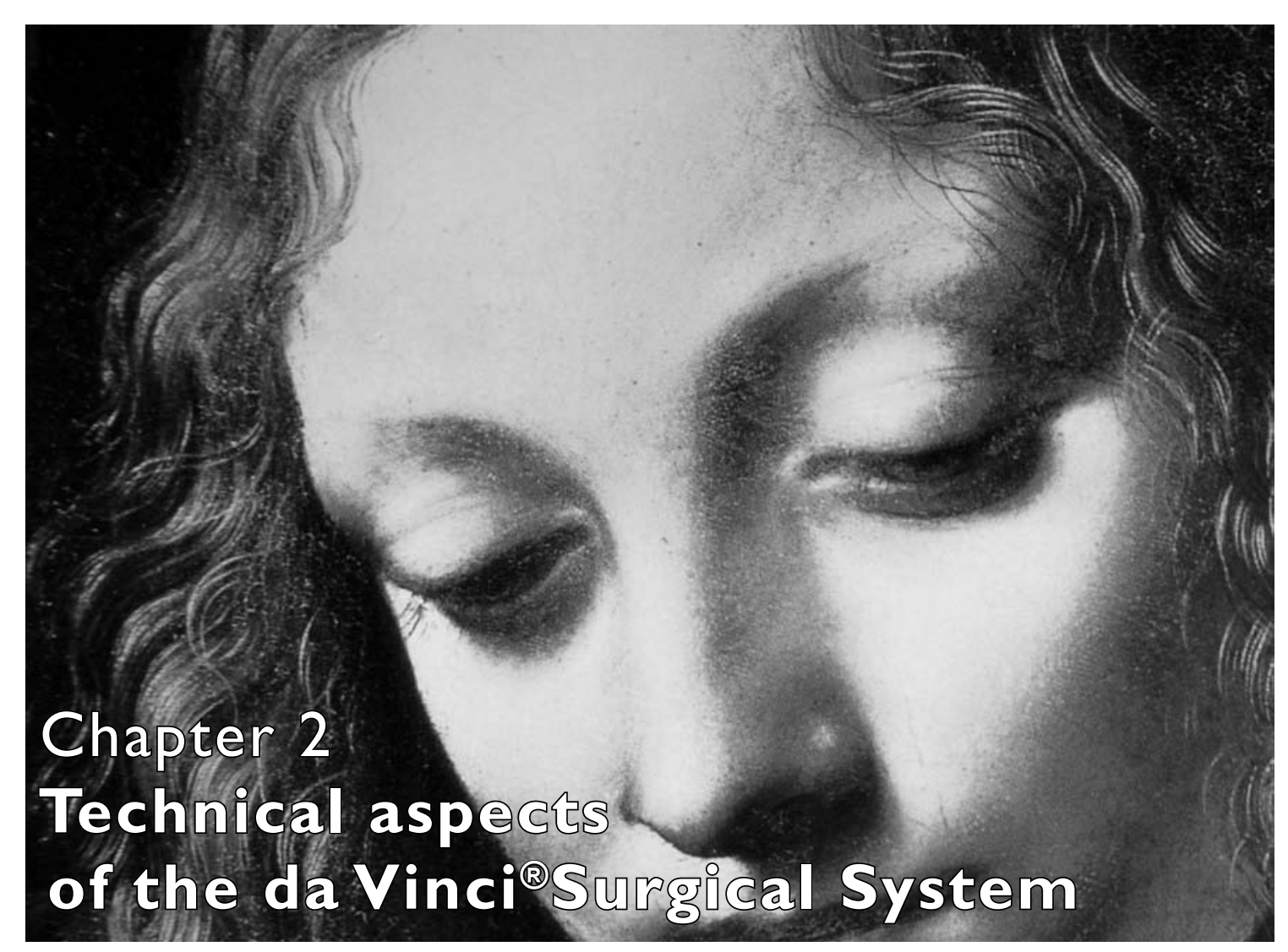

DETAIL FROM: VIRGIN OF THE ROCKS OIL ON PANEL, I483-I 486

The subject of the painting is the Virgin Mary with the Christ child being adored by John the Baptist, Patron Saint of Florence. 


\section{TECHNICAL ASPECTS}

Robotic system or stereoscopic telemanipulator?

As described before, the da Vinci ${ }^{\circledR}$ Surgical System became the first telesurgical system cleared by the FDA for general laparoscopic surgery in the year 2002. Since the company acquired its principal (if not only) rival competitor in 2003, it is the only company currently offering an integrated visual and telemanipulatory surgical system. In order to comply with the most common used terms, we will use the words "robot" and "telemanipulator" interchangeable, although the system is not able to perform tasks independently. The system merely copies the exact movements of the surgeon and translates them (after downscaling and tremor filtration), to a movement of the manipulator arms. The system combines an ergonomic console based stereoscopic working place for the surgeon with a four-armed motorized instrument and camera holder.

\section{THE SURGEON'S CONSOLE}

During surgery, the surgeon is seated in a comfortable ergonomic console, restoring optimal posture and minimizing strain (Figure I).

His eyes are faced downwards to see the operative field. The positioning of the camera and instruments is performed by the surgeon's fingers grasping the master controls located directly below the display. This allows for an optimal restoration of the eye-hand-target axis where hands and wrists are positioned naturally relative to the surgeon's eyes (Figure 2). Operating this system

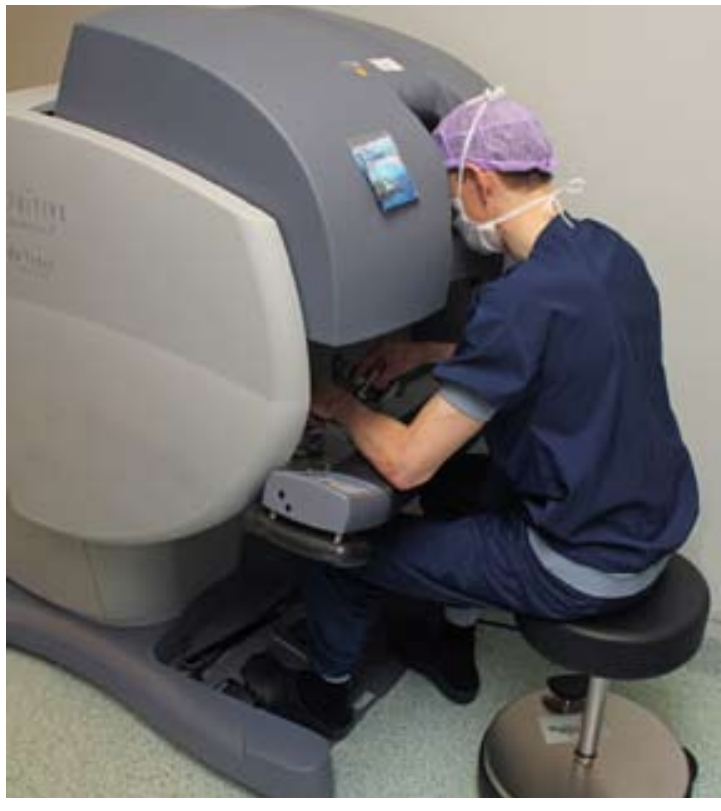

Figure I. The surgeon is seated in an ergonomic console, restoring optimal posture and minimizing strain.

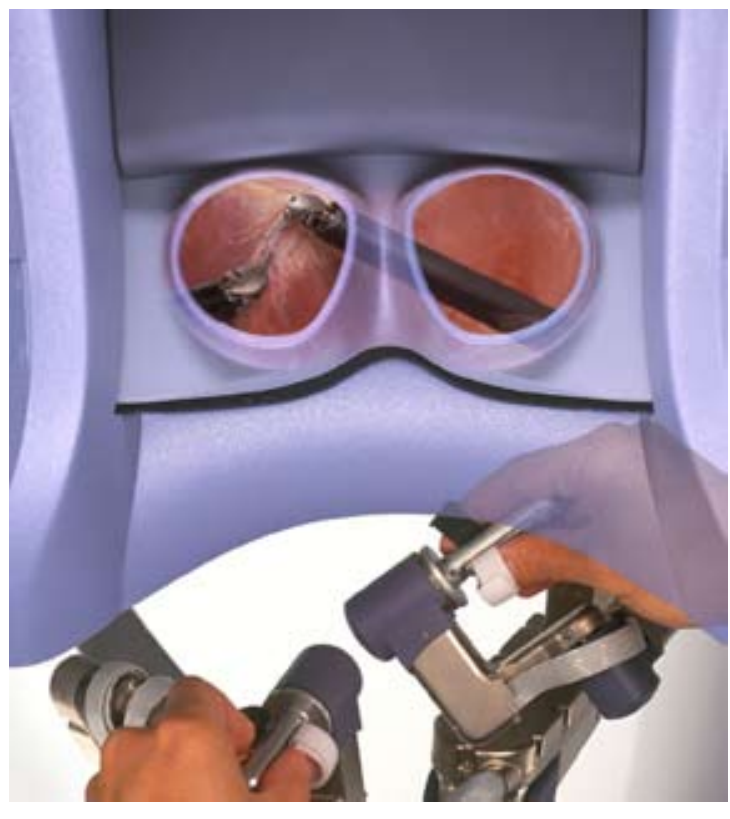

Figure 2. The tips of the instruments are projected on the location where the finger tips of the surgeon are, allowing optimal restoration of the eye-hand-target axis. The controls allow for a natural forceps-like grip.

seems more natural and intuitive compared to conventional laparoscopy, but also compared to the previous joystick-controlled ZEUS ${ }^{\circledR}$ Robotic Surgical System. The da Vinci ${ }^{\circledR}$ system automatically and fully compensates for the so-called fulcrum effect, normally present in minimal access surgery. The intuitive motion potentially leads to easier and faster surgery. The surgeon's fingers are positioned in the manipulators in a quite natural forceps-like grip. Motions performed by the surgeon are detected by sensors and indirectly translated to movement of the tips of the robotic instruments adjusted to the patient side cart.

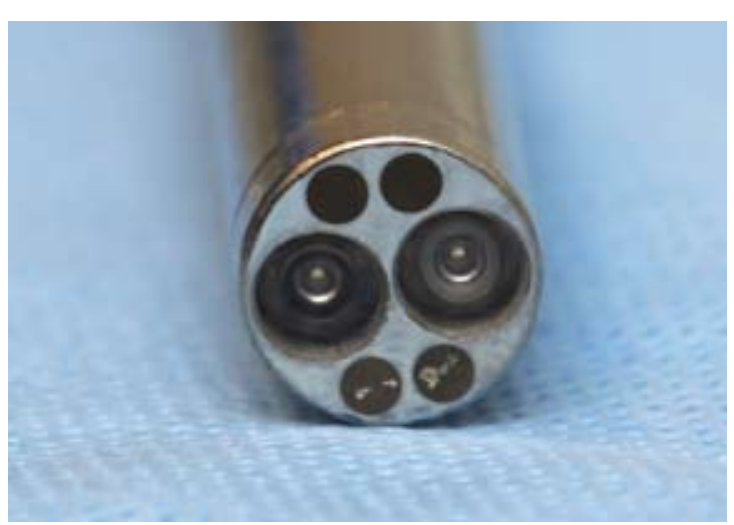
A double-channel stereoscopic $12 \mathrm{~mm}$ videoendoscope (Figure 3 ) contains two lenses approximately $8 \mathrm{~mm}$ separate from each other. It generates two slightly different images that are transposed through two separate vision canals. After correcting the images for the mean inter papillary distance of $60 \mathrm{~mm}$, the images are sent to two separate High-Definition displays in the console.

Figure 3. A double-channel videoscope captures two slightly different images.

Both eyes are offered a slightly different image in the console, allowing for a convincing perception of depth (Figure 4).

The console holds a number of foot pedals (Figure 5). The most lateral left foot pedal is the clutch and allows for control of the position of the master controls without moving the instruments or camera holder. Once pressed, the specially designed robotic instruments are fixed in its current position whilst movement of the manipulators at the tips of the surgeon's fingers allow the surgeon for repositioning his hands and forearms to an ergonomically optimal position. The second pedal allows for camera control. Once pressed, the surgical instruments are fixed in its current position and any movement of the manipulators results in a subsequent movement of the automated camera holder. This allows for a perfectly stable tremor-filtrated

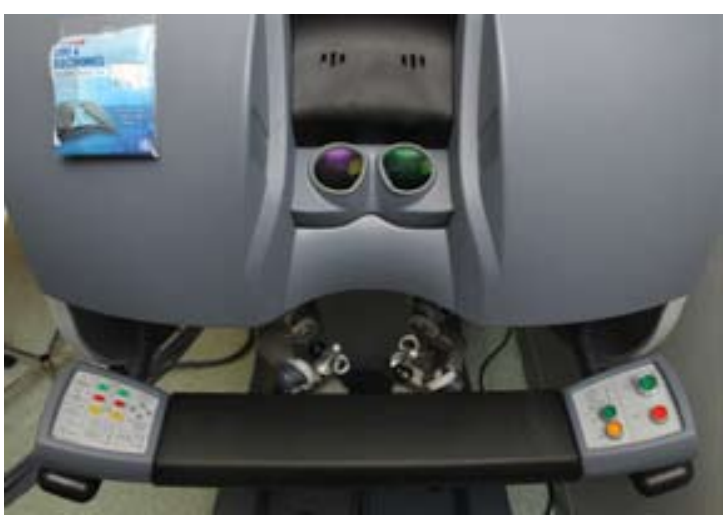

Figure 4. The two separate displays in the console offer the different images to the surgeon. view, directed exactly at the location of interest of the surgeon. The middle pedal allows for focus control. The median right foot pedal is reserved for new applications, such as activation of newly designed bipolar or ultrasonic sealing instruments. The lateral right foot pedal controls activation of monopolar diathermy.

Besides these foot pedals and the manipulators, two control panels are integrated in the console. One allows for adjustment of working distance and scaling factor (Figure 6). The indirect translation of the movement of the master control to a movement of the instrument tips, allows for automated downscaling to a preferred scale. 


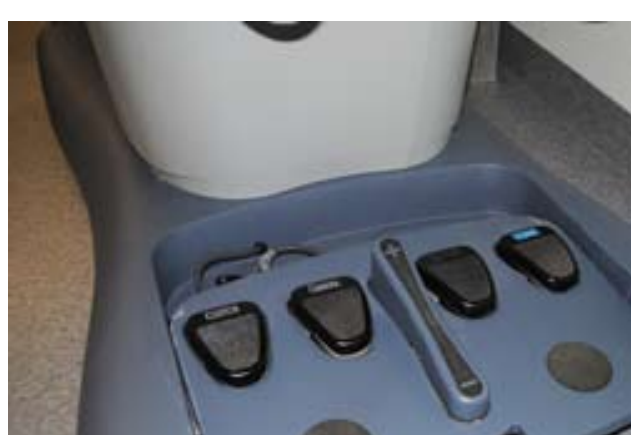

Figure 5. The console holds a number of foot pedals, allowing for adjustments of the manipulating and visual systems.

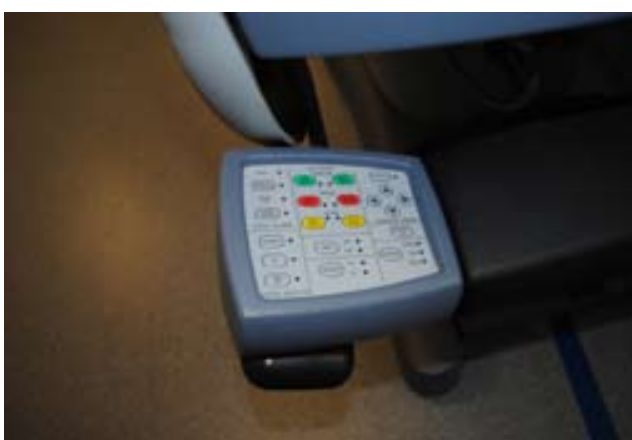

Figure 6. Control panel A

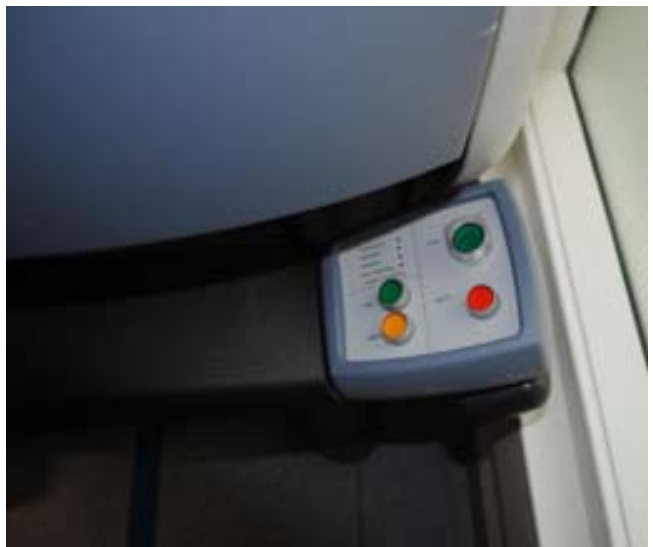

Figure 7. Control panel B
This gives the surgeon the opportunity to operate with a precision and dexterity unprecedented by the natural human hand. The last integrated control panel (Figure 7) allows selection and calibration of the stereoscopic High-definition endoscope.

\section{THE PATIENT-SIDE CART}

The patient is situated on the operating table. A patient-side cart (Figure 8) with four telemanipulator arms is positioned next to the table, allowing the arms to reach the operating area. It is imperative to choose the position of the cart in relation to the operating table well, in order to prevent clashes of robotic arms. The camera-arm

is connected to the $11 \mathrm{~mm}$ endoscope and a $12 \mathrm{~mm}$

trocar. The three other robotic arms are connected

to the robotic instruments and to specially

designed robotic trocars. Once the trocars have

been inserted into the patient's body and are well

connected to the patient side cart, robotic surgery

can begin. Control of the operation can be switched

from the surgeon standing next to the operating

table to the surgeon sitting in the console. This

console can be located at considerable distance from the operative field, potentially at the other side of the globe. The tableside surgeon and the rest of the attending surgical team can follow the progress of the operation looking at a conventional monitor, located on a video cart. This video cart holds the standard accessories for conventional laparoscopy, including an insufflator, light source and camera controls.

The motions of the surgeon's fingers are indirectly translated to motion of the tips of the specially designed robotic instruments (Figure 9), allowing for downscaling and tremor filtration. Despite the limitations of minimal access surgery, the use of

"endowrist" instruments allows for a full six degrees of freedom and an impressive dexterity and range of motion. A wide selection of specially designed instruments allows for a broad range of surgical procedures. New energised robotic instruments are being developed allowing the use of monopolar and bipolar cautery, ultrasonic and advanced bipolar dissection and sealing, and even laser surgery.

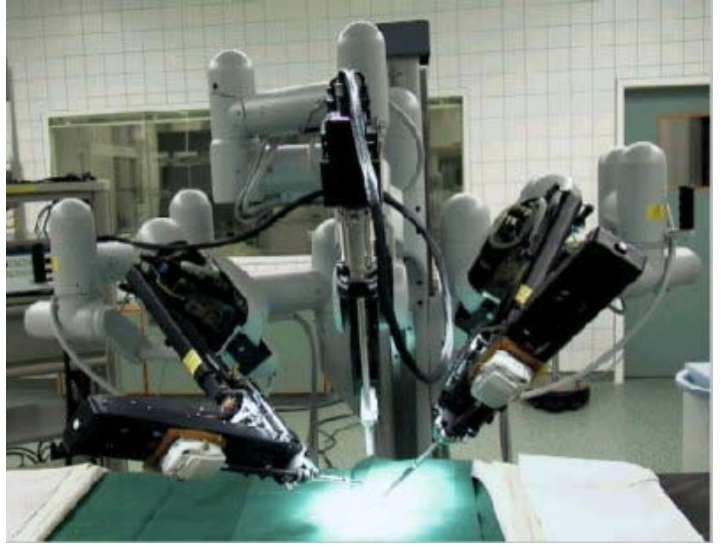

Figure 8. The patient-side cart holds one arm for the visual system and three arms for manipulation

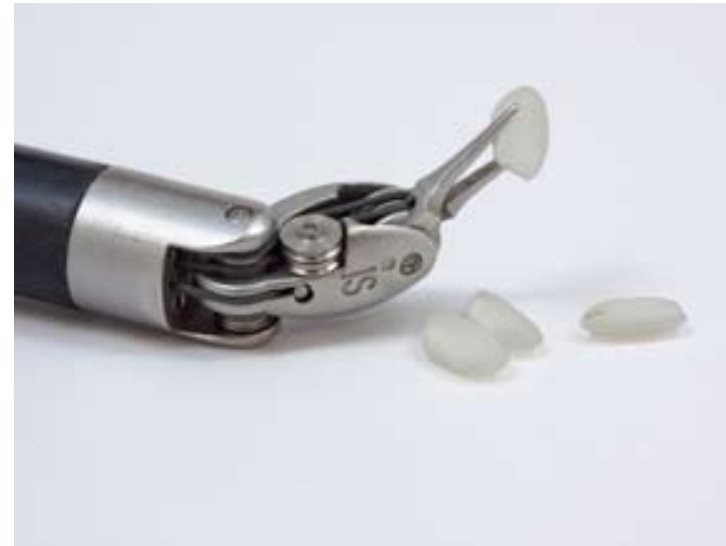

Figure 9. The specially designed robotic instrument tips offer six degrees of freedom and allow for intuitive manipulation. 


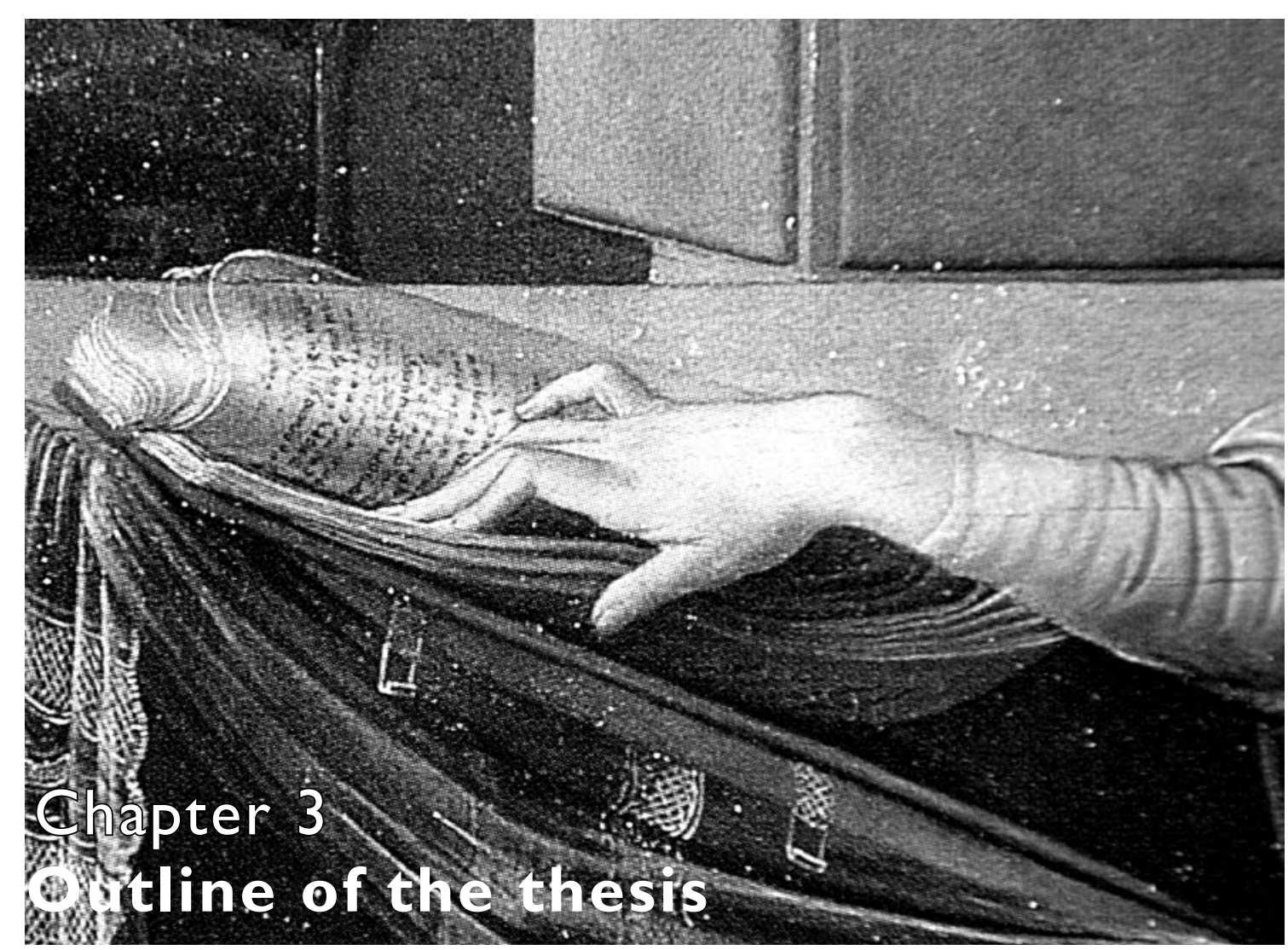

DETAIL FROM: ANNUNCIATION OIL AND TEMPERA ON WOODEN PANEL

Madonna receives the annunciation of her immaculate conception. Her right hand on the marble table probably quotes the tomb of Piero and Giovanni de'medici in the Basilica of San Lorenzo, Florence, which Verrocchio had sculpted during this same period. 


\section{OUTLINE OF THE THESIS}

I In order to clarify the role of advanced surgical systems, a four-armed da Vinci ${ }^{\circledR}$ Surgical System was acquired at Maastricht University Hospital in the year 2003. Since then, various studies have been conducted both in a dry lab environment and in clinical practise. This manuscript describes the studies conducted and the results and conclusions that might be taken.

2 The questions that were attempted to answer in this thesis are

Is it possible to use the da Vinci ${ }^{\circledR}$ Surgical system as a research tool in order to clarify whether this integrated system really facilitates the performance of laparoscopic tasks. Is it possible to differentiate what part of this integrated system offers clear benefits? Is it the stereoscopic 3-dimensional view? Is it due to the high-definition image? Is it the restoration of the eye-hand-target-axis or the intuitive movement of the instruments with 6 degrees of freedom?

3 In Chapter four of this thesis we focus on the advantages (and disadvantages) of these separate parts of the da Vinci ${ }^{\circledR}$ telemanipulator in the performance of laparoscopic tasks in a dry lab environment.

4 Is there a difference in learning curve between conventional laparoscopy and robot-assisted laparoscopy? A significant part of medical complications and mistakes is caused during the learning curve of the surgeon or surgical resident. If use of the da Vinci ${ }^{\circledR}$ Surgical System would lead to a significant shorter learning curve, this could lead to safer medical care. In Chapter five of this thesis we focus on the learning curves of inexperienced individuals, learning how to perform laparoscopic tasks using conventional laparoscopy or Robotassisted laparoscopy. Looking at the time needed to perform a certain laparoscopic task and the accuracy or number of technical mistakes while performing this task, we try to determine whether there is a significant difference in learning curve between both groups.

5 Is the use of robotic assistance feasible in actual laparoscopic surgery? Does it lead to advantages for the patient such as a decreased operating time? Does it lead to advantages to the health care system such as a decrease in costs involved?

6 In Chapter six, seven and eight, we evaluated the role of this telemanipulator system while performing actual laparoscopic surgery. We selected a variety of frequently-performed laparoscopic operations. Chapter six focuses on cholecystectomy, Chapter seven focuses on Nissen fundoplication and Chapter eight focuses on rectopexy. Secondary end points in these studies were operative complications and duration of admission.

7 Does the use of robotic assistance lead to advantages for the patient such as an improved functional result or a lower recurrence rate?

In Chapter nine we focus on the long-term results and recurrence rates after conventional open, conventional laparoscopic and robot-assisted laparoscopic rectopexy.

8 Does the use of robotic assistance lead to a more ergonomic working situation? Does it lead to less mental strain with the surgeon and therefore to less exhaustion, less potentially harmful operative mistakes and less stress-induced illnesses with the surgeon?

This is a quite uncommon focus for medical research. The effects of newly developed surgical techniques are generally measured mainly (if not exclusively) by their direct effects on the patient (in terms of post-operative pain and complications, tissue damage, timeto-recovery, functional and aesthetic results, Quality Of Life and chance of recurrence ) or they are focused on the impact on the health system (in terms of costs, operative time and duration of admission). However, we know that newly developed, minimal invasive techniques might be advantageous for our patients but may be quite demanding, exhausting and harmful to the surgeon. Increased mental strain to the minimal invasive surgeon is closely associated with decreased heart rate variability (HRV), impaired health and limited life expectancy. Although adverse health effects to the surgeon are difficult to measure, the physical effects of mental strain can be measured as a precursor for stress-induced health risk.

9 Chapter 10 focuses on the question whether the use of "robotic" assistance during laparoscopic surgery does actually lead to increased HRV and therefore diminished mental strain as compared to conventional laparoscopic performance of these same operation.

10 In Chapter II we will summarize the conclusions of the previous separate studies performed. A critical discussion on these conclusions and a systematic review to evaluate the current status of robotic assistance in a variety of surgical fields is the subject of Chapter 12. In this Chapter we will also focus on future perspectives. 


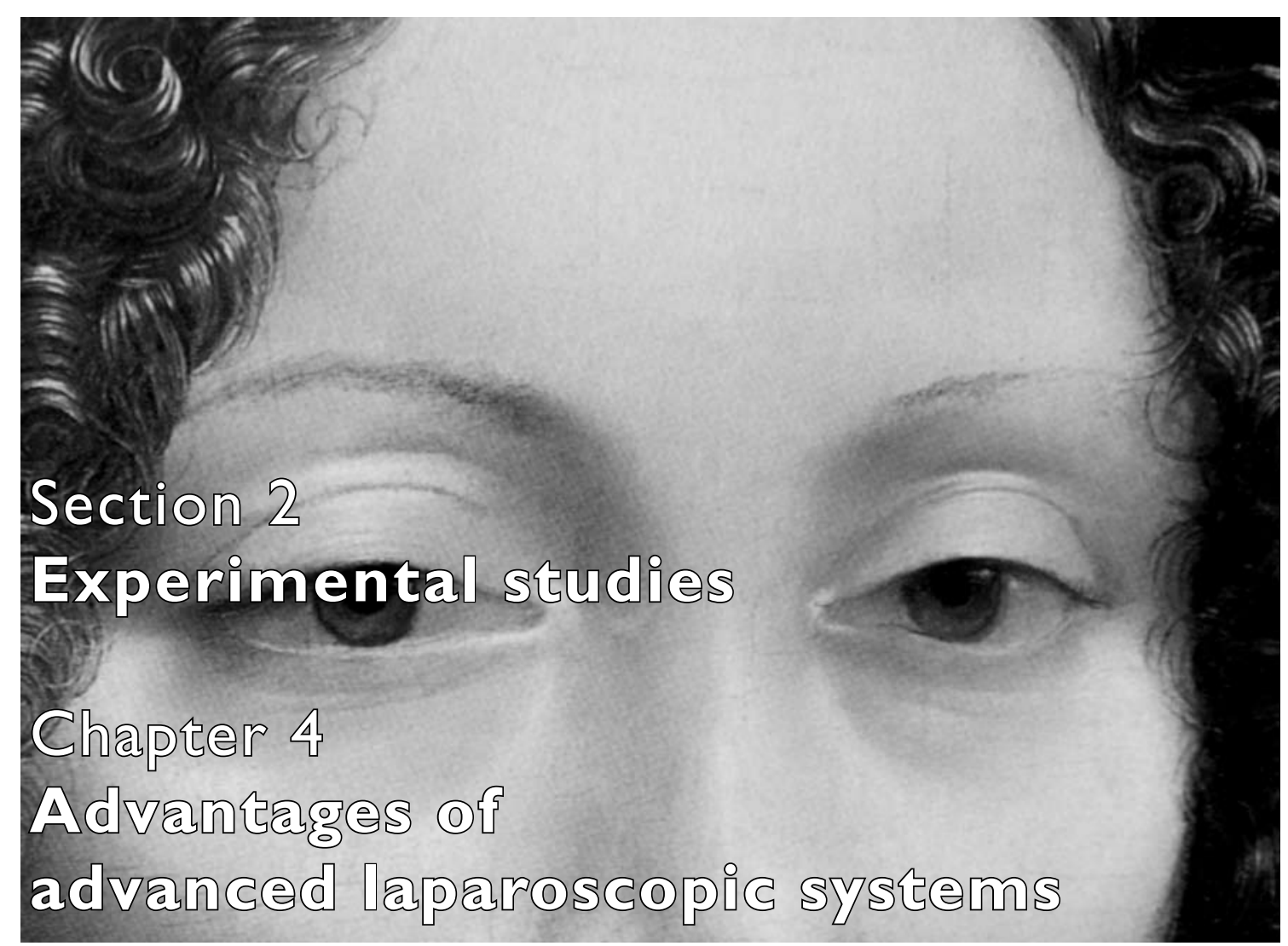

Previously published as:

Advantages of advanced laparoscopic systems

Heemskerk J, Zandbergen HR, Maessen JG, Greve JWM, Bouvy ND.

Surg Endosc 2006;20:730-733

DETAIL FROM: GINEVRA DE' BENCI OIL ON WOODEN PANEL, I474-I 478

A young, sad looking woman is being depicted in front of juniper tree, symbol of sorrow, loss and pain. The subject might be Ginevra de'Benci, wife of Amerigo de'Benci. Other sources suggest the woman depicted is Fioretta Gorini, the widow of the murdered Giuliano de'Medici. 


\section{ABSTRACT}

Background: Conventional laparoscopy offers great benefits to our patients, but suffers from major technical drawbacks. Advanced laparoscopic systems are being developed addressing some of these drawbacks.

Methods: We performed a training-box based study, performing laparoscopic tasks using conventional laparoscopy and advanced laparoscopic systems in order to assess the influence of these technical drawbacks in order to predict where the biggest advantages of newly developed surgical systems can be expected.

Results: The most significant technical drawbacks were two-dimensional vision, disturbed eyehand-target axis and (possibly to a lesser extent) the rigid instruments with a limited four degrees of freedom.

Conclusion: Major advances in advanced laparoscopy might only be expected using console-based robot-arm manipulated systems like the da Vinci ${ }^{\circledR}$ Surgical System, or a combination of a highquality 3-dimensional vision system, restoration of the eye-hand-target axis and the use of an advanced handheld instrument offering six degrees of freedom such as the Radius ${ }^{\circledR}$ Surgical System.

\section{INTRODUCTION}

Minimal invasive surgery is one of the great advances in medicine in recent decades, aiming at maximal reduction of surgical trauma. However, laparoscopic surgeons sacrifice dexterity to provide patients with less invasive surgery. The following are major drawbacks of laparoscopy:

I Two-dimensional (2D) vision using a conventional monitor reduces perception of depth

2 A disturbed eye-hand-target axis decreases ergonomics and dexterity.

3 The long, inflexible instruments used in laparoscopic surgery magnify the surgeon's natural hand tremor.

4 The rigid instruments with four degrees of freedom limit the surgeon's natural range of motion, decreasing dexterity.

5 Fixed abdominal entry points result in limited freedom of motion and movement of the tip of the instrument to the opposite direction of the outer pat of the instrument, a technical drawback known as the fulcrum effect.

6 Camera instability increases fatigue.

7 Limited tactile feedback decreases dexterity.

These factors probably all contribute to the relatively long learning curve in laparoscopic surgery'. Advanced stereoscopic and instrument manipulating surgical systems are being developed in order to address some of the shortcomings related to conventional laparoscopy, potentially leading to faster and more accurate laparoscopy $y^{2,3}$

A variety of stereoscopic systems are being developed. Although stereoscopy rarely offers convincing depth perception ${ }^{4}$, its use might improve laparoscopic performance ${ }^{5-9}$.

The disturbed eye-hand-target axis is difficult to restore using conventional laparoscopic equipment. Although ergonomic monitor placement is crucial, the ideal situation of projecting the image exactly where the operation takes place is difficult to achieve without a consolebased surgical system ${ }^{10,11}$. Tremor can be diminished using a robot arm manipulated system with tremor filtration ${ }^{12}$. Both handheld and console-based surgical systems offer the full six degrees of freedom, increasing dexterity ${ }^{12,13}$. The fulcrum effect is difficult to address using conventional laparoscopic instruments. Although extensive training leads to faster automation to the fulcrum effect ${ }^{14,15}$, only robot arm manipulated systems can restore intuitive movement of the instrument's tip in the direction of the surgeon's hand, increasing dexterity. Camera instability due to exhausting camera holding can be restored using a variety of mechanical or robot arm manipulated systems. No commercially available surgical systems have been able to restore normal sensitivity in tactile feedback.

We performed a training box-based study, describing time consumption and accuracy in both inexperienced users and expert laparoscopic surgeons performing laparoscopic tasks using conventional laparoscopy, the Radius ${ }^{\circledR}$ Surgical System (Tuebingen Scientific, Tuebingen, Germany) and the da Vinci ${ }^{\circledR}$ Surgical System (Intuitive Surgical, Mountain View, CA, USA) in a variety of settings. The aim of the study was to assess the significance of the previously described technica drawbacks for laparoscopic surgery in order to predict where the major advantages of newly developed surgical systems can be expected. 


\section{MATERIAL AND METHODS}

\section{Participants}

Ten inexperienced and 10 experienced volunteers were selected to perform laparoscopic tasks using various laparoscopic systems. The inexperienced group consisted of 10 volunteers without any previous laparoscopic experience. The experienced group consisted of 10 expert laparoscopic and thoracoscopic surgeons from the Departments of Surgery and Cardio-thoracic Surgery of Maastricht University Hospital. All of them had extensive experience in laparoscopy or thoracoscopy, having performed more than 100 laparoscopic or thoracoscopic procedures.

\section{Conventional laparoscopy}

All conventional laparoscopic tasks were performed using a pelvic trainer with one $12 \mathrm{~mm}$ video port and two $12 \mathrm{~mm}$ trocar ports (Versaport, US Surgical Corporation, Norwalk, CT, USA). A $10 \mathrm{~mm} 0^{\circ}$ digital video camera (Endoeye, Olympus, Hamburg, Germany) was used, and the image was displayed on a 14 -inch high-resolution $100 \mathrm{~Hz}$ monitor. Camera handling was done using a simple rigid standard. Manual laparoscopic drills were performed using disposable $5 \mathrm{~mm}$ laparoscopic instruments (Endo Clinch II, Autosuture, Norwalk, CT, USA) and a $5 \mathrm{~mm}$ laparoscopic needle driver (Storz 26173SC laparoscopic needle driver, Karl Storz Endoskope, Tuttlingen, Germany).

\section{Radius ${ }^{\circledR}$ Surgical System}

All radius-assisted laparoscopic tasks were performed in the same pelvic trainer using the same trocars described previously. The Radius ${ }^{\circledR}$ handheld manipulator (Radius Surgical Systems, Tuebingen Scientific Medical GmbH, Tuebingen, germany) was used instead of conventional laparoscopic instruments. This laparoscopic instrument enables the surgeon to perform laparoscopic tasks offering a full six degrees of freedom instead of the four degrees of freedom on conventional laparoscopy, potentially increasing dexterity and improving performance. Unfortunately, the tip of the Radius instrument was not suitable to grasp the beads used in task 1 . therefore, this task was not done using the Radius ${ }^{\circledR}$ Surgical System.

\section{da Vinci®Surgical System}

All da Vinci $^{\circledR}$-assisted laparoscopic tasks were performed in the same pelvic trainer as described previously using a $12 \mathrm{~mm}$ video port and two $7 \mathrm{~mm}$ trocars. We used three arms of the fourarmed da Vinci ${ }^{\circledR}$ Surgical System. This robotic surgical system consists of a surgeon's console, patient side cart, Endowrist ${ }^{\circledR}$ instruments and InSite ${ }^{\circledR}$ Vision System. The surgeon's console offers an ergonomic position to the surgeon, translating the surgeon's intuitive movements into precise, real-time movements of the instruments. The patient side cart offers four robot arms, executing the surgeon's commands while offering tremor filtration and movement downscaling if desired.

The Endowrist ${ }^{\circledR}$ instruments attached to the patient side cart offer the full six degrees of freedom. The InSite ${ }^{\circledR}$ Vision System provides high-quality stereoscopic stable vision, projecting the tip of the instruments where the fingertips of the surgeon are located.

Three arms of the four-armed da Vinci ${ }^{\circledR}$ system were used. One arm handled the camera and the other two arms manipulated two Endowrist ${ }^{\circledR}$ laparoscopic Debakey forceps. The da Vinci ${ }^{\circledR}$ tasks were performed using the da Vinci ${ }^{\circledR}$ Surgical System in stereoscopic 3D InSite ${ }^{\circledR}$ vision, in 2D InSite ${ }^{\circledR}$ vision, and in a conventional monitor-viewed modus.

Tasks

Three laparoscopic tasks were devised to test dexterity, two-handed coordination, and suturing. Each participant was instructed about the main features of the endoscopic tasks to be performed and on how to use the surgical systems. The participants were allowed to manipulate each surgical system for five minutes become familiar with the controls and setup. Questions were allowed before and during the tests, but no assistance was provided. The same order of tasks was performed for every participant, but the sequence of the use of the different surgical systems changed in order to prevent a learning curve from interfering with the results.

\section{Task I: pick up and drop}

A comparable laparoscopic drill was used in other studies ${ }^{16-18}$, in which a receptacle $(40 \mathrm{~mm}$ opening and $10 \mathrm{~mm}$ high) containing five beads was used. The task was to pick up a bead from the receptacle with the right-handed instrument and transfer it halfway to a second receptacle. The bead had to be taken over with the left-handed instrument and dropped into the second receptacle. Time was recorded from starting position with the instrument in focus but outside the initial receptacle to the fifth bead dropped into the final receptacle. Inaccuracy was defined as 10 points for every bead accidentally dropped outside the receptacle. The task was performed eight times - twice per suitable instrument. The tip of the Radius ${ }^{\circledR}$ instrument was unfit for this task.

\section{Task 2: cap the needle}

This task was performed as described previously ${ }^{15}$ using a 19-gauge $\times 1,5$-inch aspiration needle with Luer Lock (Terumo Europe NV, Leuven, Belgium) and its cap. The task was to cap the needle after grasping both pieces from the floor of the training box, keeping both cap and needle above the box floor. Time was recorded from starting position with the instruments in focus but $5 \mathrm{~cm}$ from the needle and its cap to the moment when te needle and cap were securely coupled and held by one instrument. Inaccuracy was defined as 10 points for every cap or needle accidentally dropped or touching the box floor. The task was performed 10 times - twice per instrument.

\section{Task 3: suturing and knot tying}

This task was previously described ${ }^{16,18,19}$, and it consists of using a size eight latex glove and a Vicry 3-0 polyglactin suture with FS-I $24 \mathrm{~mm} 3 / 8$ circular needle (Johnson\&Johnson, New Brunswick,

$\mathrm{NJ}$, USA). The task was to pass the needle through two separated five $\mathrm{mm}$ dots on the glove and then tie a double knot. Time was recorded from starting position with the instruments in focus but five $\mathrm{cm}$ away from the needle to the moment when the suture was securely tied. Inaccuracy was defined as 10 points per $\mathrm{mm}$ distance between the black dot and the needle entry through the glove. Twenty points was added if the knot was too loose or the suture broke. The task was performed 10 times - twice per setup.

\section{Statistical analysis}

Data were stored in an Excel XP database (Microsoft, Redmond, WA, USA) and analysed using SPSS version II.0.I (SPSS, Chicago, IL, USA). Comparison of groups was done using Pearson's chi-square test. Comparison of two related samples was done using a non-parametric Wilcoxon signed rank test. A p value $\leq 0.05$ was defined as statistically significant.

\section{RESULTS}

Study population

The median age of the study population was 32 years (range, $21-52$ ), 36 years in the experienced group (range, 32-52) and 23 years in the inexperienced group (range, 2I-35). In total, 20 participants performed two tasks twice using five different setups. One task was performed twice using four setups, leading to a total of 560 tasks. Performing every task, time consumption, and accuracy were registered, leading to a total of I, I20 analyzable data points. 
Time and accuracy

Time consumption was compared by performing different tasks using various instruments and setups. Inexperienced participants took significantly more time to complete a task than the experienced surgeons. Conventional laparoscopy was most time-consuming, whereas the $\mathrm{daVinci}{ }^{\circledR}$ system with stereoscopy was the fastest. Task 3 was far more time-consuming than tasks I and 2. The benefit of using advanced surgical systems seemed less for experienced users compared to inexperienced users. Accuracy was compared using the different surgical systems. Higher numbers of failures and mistakes resulted in higher inaccuracy scores. Inexperienced participants had higher inaccuracy scores than expert surgeons. Conventional laparoscopy and the use of the da Vinci ${ }^{\circledR}$ system with monitor-viewed vision resulted in the highest inaccuracy scores, whereas use of the daVinci ${ }^{\circledR}$ system with stereoscopic InSite ${ }^{\circledR}$ vision resulted in the lowest inaccuracy scores and thus the best results. Table I shows mean time consumption and inaccuracy scores for the total group and for the inexperienced and experienced subgroups separately.

\begin{tabular}{|c|c|c|c|c|c|c|}
\hline & Task & Conventional & Radius & daVinci 3-D & daVinci 2-D & daVinci-M \\
\hline \multirow[t]{6}{*}{ Time } & Task 1, first trial & $171(233,108)$ & - & $85(108,62)$ & $96(111,82)$ & $140(189,90)$ \\
\hline & Task 1 , second trial & $121(167,74)$ & & $65(74,56)$ & $92(107,76)$ & $118(143,94)$ \\
\hline & Task 2, first trial & $138(220,55)$ & $100(156,43)$ & $40(44,35)$ & $64(74,55)$ & $105(121,89)$ \\
\hline & Task 2, second trial & $103(158,49)$ & $62(80,44)$ & $55(40,70)$ & $64(52,77)$ & $109(137,80)$ \\
\hline & Task 3, first trial & $332(500,164)$ & $304(477,132)$ & $122(165,79)$ & $158(192,124)$ & $182(238,127$ \\
\hline & Task 3, second trial & $323(515,132)$ & $240(335,148)$ & $87(105,69)$ & $155(200,110)$ & $186(251,120$ \\
\hline \multirow[t]{5}{*}{ Inaccuracy } & $\begin{array}{l}\text { Task , first trial } \\
\text { Task I second trial }\end{array}$ & $\begin{array}{l}188(28,7) \\
11(17,5)\end{array}$ & $=$ & $\begin{array}{l}9(13,4) \\
6(6,5)\end{array}$ & $\begin{array}{r}10(16,3) \\
9(16,2)\end{array}$ & $\begin{array}{l}24(44,4) \\
14(26,2)\end{array}$ \\
\hline & Task 2, first trial & $23(37,9)$ & $14(20,8)$ & $15(10,20)$ & $23(21,24)$ & $\begin{array}{l}30(26,34) \\
30(26)\end{array}$ \\
\hline & Task 2, second trial & $16(27,4)$ & $9(9,8)$ & $17(12,22)$ & $24(19,28)$ & $37(37,36)$ \\
\hline & Task 3, first trial & $23(44,2)$ & $27(41,13)$ & $0(0,0)$ & $4(7,1)$ & $7(11,2)$ \\
\hline & Task 3, second trial & $27(46,7)$ & $24(45,2)$ & $2(3,0)$ & $5(9,0)$ & $12(24,0)$ \\
\hline
\end{tabular}

Comparing instruments

Using the Radius ${ }^{\circledR}$ Surgical System, two tasks were performed twice each, describing time consumption, accuracy, and score. This resulted in 12 data samples. Using a non-parametric Wilcoxon signed rank test, related samples could be compared in order to assess significant superiority of one setup or the other. Results are depicted in table 2.

Table 2. Number of significantly better results comparing first instrument versus second instrument (number of camparing data samples)

Conventional vs Radius Conventional vs da Vinci 3-D Conventional vs da Vinci 2-D Conventional vs da Vinci M Radius vs da Vinci 3-D Radius vs da Vinci 2-D Radius vs da Vinci $M$

da Vinci 3-D vs da Vinci 2-D

da Vinci 3-D vs da Vinci $M$ da Vinci 2-D vs da Vinci $M$

$\begin{array}{ll}\text { Total Group } & \text { Inexperienced } \\ 0 \text { vs I (8) } & 0 \text { vs } 2(8) \\ 0 \text { vs } 9(12) & 0 \text { vs I0 (I2) } \\ 0 \text { vs } 5(12) & 0 \text { vs } 8(12) \\ \text { I vs } 0(12) & 0 \text { vs } 2(12) \\ 0 \text { vs } 5(8) & 0 \text { vs } 7(8) \\ \text { I vs } 4(8) & 0 \text { vs } 5(8) \\ \text { I vs I (8) } & \text { I vs I (8) } \\ 5 \text { vs } 0(12) & 3 \text { vs } 0(12) \\ \text { I } 2 \text { vs } 0(12) & 10 \text { vs } 0(12) \\ 5 \text { vs } 0(12) & 4 \text { vs } 0(12)\end{array}$

Experienced 0 vs 0 (8) 0 vs I ( $(12)$ I vs $0(12)$ 2 vs $0(12)$ 0 vs $2(8)$ I vs 0 (8) 3 vs 0 (8) 4 vs $0(12)$ 6 vs $0(12)$ 0 vs $0(12)$

\section{DISCUSSION}

Conventional laparoscopy suffers from seven technical drawback as described previously. This study was conducted in order to assess these drawbacks.

The role of 2D vision was assessed by comparing results of da Vinci ${ }^{\circledR}$ in $2 \mathrm{D}$ InSite ${ }^{\circledR}$ vision mode with daVinci ${ }^{\circledR}$ in stereoscopic InSite ${ }^{\circledR}$ mode. The daVinci ${ }^{\circledR}$ system in 3D mode seemed faster and more accurate in all 12 data samples (table I). This difference was significant in 5 of 12 data samples (table 2), suggesting stereoscopic vision does indeed lead to faster and better performance of laparoscopic tasks. The role of the disturbed eye-hand-target axis was assessed by comparing the results of $d a V_{i n c i}{ }^{\circledR}$ in the $2 D$ InSite ${ }^{\circledR}$ vision mode with $\mathrm{daVinci}^{\circledR}{ }^{\text {in }}$ the monitorviewed mode. Two-dimensional InSite ${ }^{\circledR}$ vision seemed faster and more accurate in all 12 data samples (table 1). This difference was significant in five of 12 data samples (table 2), suggesting restoration of the disturbed eye-hand-target axis does improve performance of laparoscopic tasks. The role of limited degrees of freedom in conventional laparoscopy was assessed by comparing conventional laparoscopy with the Radius ${ }^{\circledR}$ Surgical System. Although the tip of the Radius ${ }^{\circledR}$ instrument was not fit for task I, the other tasks seemed to be performed faster and more accurate using the radius ${ }^{\circledR}$ instrument in seven of eight data samples (table I). This suggests that offering six degrees of freedom might improve laparoscopic performance.

The roles of tremor enhancement, fulcrum effect, and limited tactile feedback could not be assessed separately in this study. However, comparing the radius ${ }^{\circledR}$ system, which suffers from tremor enhancement, fulcrum effect, and limited tactile feedback, with the da Vinci ${ }^{\circledR}$ system in monitor-viewed mode, no significant difference was present (tables $I$ and 2). This suggests these three drawback do not play a crucial role and might not require a technical solution.

The role of camera instability was not assessed in this study, since camera holding was done by a rigid standard or robot arm.

Analysis of the experienced and inexperienced subgroups showed a more significant advantage of the use of advanced laparoscopic systems in the inexperienced group. This suggests that extensive training in laparoscopy may reduce the need for advanced stereoscopic or manipulating laparoscopic systems.

We conclude that the most significant improvements with regard to the previously mentioned technical drawbacks in conventional laparoscopy are high-definition 3D vision, restoration of the disturbed eye-hand-target axis and (possibly to a lesser extent) the use of instruments offering the full six degrees of freedom. Major improvements in laparoscopic surgery may only be expected from either a console-based surgical system, such as the da Vinci ${ }^{\circledR}$ Surgical System, or a combination of a high-definition 3D vision system with ergonomic monitor placement (or a headmounted display), with a handheld, six degrees of freedom instrument, such as the Radius ${ }^{\circledR}$ Surgical System.

Advanced laparoscopic surgery is still in its infancy, and major improvements in the availability of specifically designed surgical systems are expected soon, offering great opportunities for the future. However, more research is needed in order to develop affordable and feasible instruments offering high-quality 3D vision, a restoration of the eye-hand-target axis, and six degrees of freedom. 


\section{REFERENCES}

I Subramonian K, DeSylva S, Bishai P, et al. Acquiring surgical skills: a comparative study of open versus laparoscopic surgery.Eur Urol 2004;45(3):346-5 I

2 Hanly EJ, Talamini MA. Robotic abdominal surgery. Am J Surg 2004; 188(4ASuppl):19S-26S

3 Hazey JW, Melvin WS. Robot-assisted general surgery. Semin Laparosc Surg 2004; I I (2): 1 07- 12

4 Hofmeister J, Frank TG, Cuschieri A, et al. Perceptual aspects of two-dimensional and stereoscopic display techniques in endoscopic surgery: review and current problems. Semin Laparosc Surg 2001;8(1):12-24

5 Cheah WK, Lenzi JE, So J, et al. Evaluation of a headmounted display (HMD) in the performance of a simulated laparoscopic task. Surg endosc 1999;15(9):990-I

6 Herron DM, lantis JC 2nd, Maykel J, et al. The 3-D monitor and head-mounted display. A quantitative evaluation of advanced laparoscopic viewing technologies. Surg Endosc 1999; |3(8):75I-5

7 Mueller MD, Camartin C, Dreher E, et al. Three-dimensional laparoscopy. Gadget or progress? A randomized trial on the efficacy of three-dimensional laparoscopy. Surg endosc 1999; I 3(5):469-72

8 Taffinder N, Smith SG, Huber J, et al. The effect of a second-generation 3D endoscope on the laparoscopic precision of novices and experienced surgeons. Surg endosc 1999;13(II):1087-92

9 van Bergen P, Kunert W, Buess GF. Three-dimensional (3-D) videosystems: bi-channel or single-channel optics? Endoscopy 1999;31(9):732-7

10 Berguer R, Forkey DL, Smith WD. The effect of laparoscopic instrument working angle on surgeon's upper extremity workload. Surg Endosc 2001;15(9):1027-9

II Emam TA, Hanna G, Cuschieri A. Ergonomic principles of task alignment, visual display, and direction of execution of laparoscopic bowel suturing. Surg Endosc. 2002; 16(2):267-71

12 Moorthy K, Munz Y, Dosis A, et al. Dexterity enhancement with robotic surgery. Surg Endosc. 2004; 18(5):790-5

13 Usui S, Inoue H, Yoshida T, et al. Preliminary report of multi degrees of freedom forceps for endoscopic surgery. Surg laparosc Endosc percutan Tech. 2004; I 4(2):66-72

14 Crothers IR, Gallagher AG, McClure N, et al. Experienced laparoscopic surgeons are automated to the "fulcrum effect": an ergonomic demonstration. Endoscopy 1999;3 | (5):365-9

15 Jordan JA, Gallagher AG, McGuigan J, et al. Randomly alternating image presentation during laparoscopic training leads to faster automation to the "fulcrum effect". Endoscopy 2000;32(4):3|7-2|

16 Garcia-Ruiz A, Gagner M, Miller JH, et al. Manual vs robotically assisted laparoscopic surgery in the performance of basic manipulation and suturing tasks. Arch Surg. 1998; | 33(9):957-61

17 Prasad SM, Maniar HS, Soper NJ, et al. The effect of robotic assistance on learning curves for basic laparoscopic skills. Am J Surg. 2002;183(6):702-7

Scott DJ, Young WN, Tesfay ST, et al. Laparoscopic skills training. Am J Surg. 2001;182(2):137-42

18 Yohannes P, Rotariu P, pinto P, et al. Comparison of robotic versus laparoscopic skills: is there a difference in the learning curve? Urology 2002;60(I):39-45

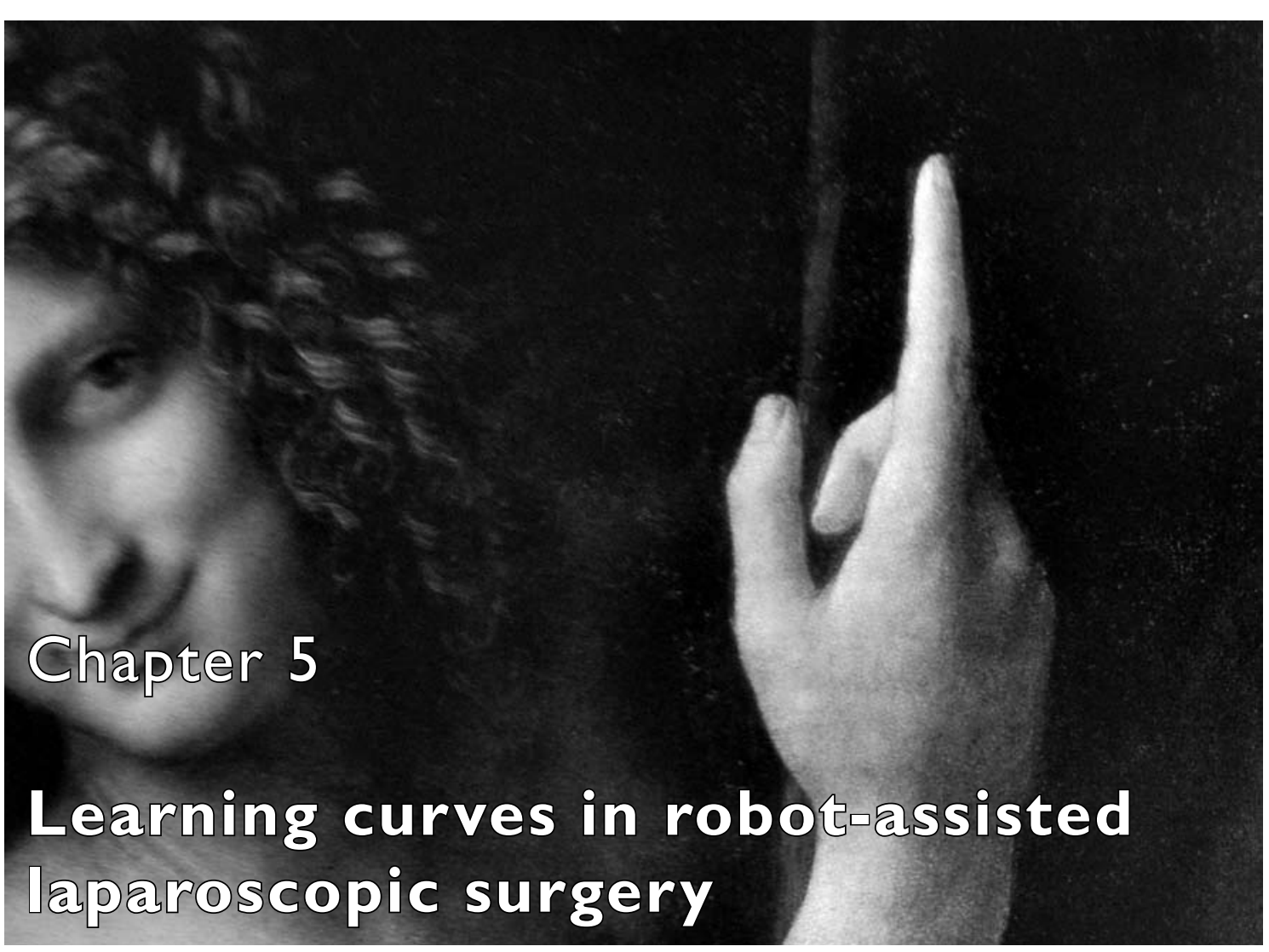

Previously published as:

Learning curves of Robot-assisted Laparoscopic Surgery Compared With Conventional Laparoscopic Surgery

Heemskerk J, van Gemert WG, de Vries J, Greve JWM, Bouvy ND.

Surg Laparosc Endosc Percutan tech 2007; 17(3): I7I-4

DETAIL FROM: ST. JOHN THE BAPTIST OIL ON WOODEN PANEL I5I3-1516

This piece depicts St John in isolation. The pointing gesture towards heaven suggests the importance of salvation through baptism. Others suggest an esoteric symbolique referring to the first principle of the Emerald Table of Alchemy. 


\section{ABSTRACT}

Background: Laparoscopic surgery can be demanding, resulting in a longer operating time and a longer time before reaching proficiency compared with open surgery. Robotic assistance allows stereoscopic vision and improves dexterity; potentially leading o faster and safer laparoscopic surgery and a shortening of the learning curve.

Methods: Duration and accuracy were measured in inexperienced participants, performing basic and advanced laparoscopic tasks using both conventional laparoscopy and the da Vinci ${ }^{\circledR}$ Surgical System.

Results: Eight participants performed 176 laparoscopic tasks. Robotic assistance resulted in faster and more accurate performance of laparoscopic tasks. However, conventional laparoscopy showed faster skill acquisition.

Conclusion: Robotic assistance resulted in faster and more accurate performance of laparoscopic tasks. However, learning curve favored conventional laparoscopy. These data suggest robotic assistance might be most beneficial in inexperienced subjects. The relatively flat learning curve in robot-assisted laparoscopy suggests robotic assistance might be less (or marginally) beneficial in experienced surgeons. This could explain why robotic assistance has failed to show clear benefit in several clinical studies. Extensive conventional laparoscopic training might lead to faster, safer and less expensive surgery, further marginalizing the role for robotic assistance in laparoscopic surgery.

\section{INTRODUCTION}

Laparoscopic surgery offers great advantages to our patients but can be demanding owing to several technical drawbacks. Limitations include 2-dimensional vision jeopardizing visual perception of depth, disturbance of the eye-hand-target axis, fulcrum effect, rigid instruments with limited degrees of freedom and limited tactile feedback. These factors might attribute to the required relatively long training period before reaching proficiency compared with traditional open Surgery'.

Robotic assistance improves dexterity and offers stereoscopic vision in combination with a restored eyehand-target axis, allowing complex laparoscopic tasks to be performed faster and more accurate compared with conventional laparoscopy ${ }^{2-6}$. Disadvantages of robot-assisted laparoscopy are higher costs, longer preparation time, complex technology, and lack of tactile feedback. In several clinical studies, the use of robotic assistance in laparoscopic surgery has been proven safe and feasible, but failed to offer major advantages over standard laparoscopic surgery ${ }^{7}$ 10. Data comparing learning curves of participants performing laparoscopic tasks are limited, possibly favoring robot-assisted surgery"1.

We performed a training-box-based study, describing speed and accuracy in volunteers performing basic and complex laparoscopic tasks using both conventional laparoscopy and using the da

Vinci ${ }^{\circledR}$ Surgical System. Aim of the study was to assess differences in both performance and in skill acquisition of inexperienced users using both conventional and robotic laparoscopy.

\section{MATERIAL AND METHODS}

Participants

To obtain reliable learning curves, eight medical students with no experience in conventional laparoscopic surgery or robot-assisted laparoscopic surgery performed four laparoscopic tasks, using both conventional laparoscopy $(C L)$ and robot-assisted laparoscopy $(R L)$ in randomized order.

Materials

All CL tasks were performed using a pelvic trainer with two 10-mm trocar ports (Versaport, United States Surgical Corporation, Norwalk, CT, USA) and a $10-\mathrm{mm}$ video port. A IOmm 0 -degree I-chip video camera (Karl Storz Endoscopy, Tuttlingen, Germany) was used, and the image was displayed on a 14-inch monitor. Conventional laparoscopic drills were performed using disposable $5 \mathrm{~mm}$ laparoscopic instruments (Endo Clinch II, AutoSuture, Norwalk, CT, USA). The $C L$ suturing task was performed using a $5 \mathrm{~mm}$ laparoscopic needle driver (Storz 26173SC laparoscopic needle driver, Karl Storz Endoscopy, Tuttlingen, Germany).

All RL tasks were performed using a pelvic trainer with two $7 \mathrm{~mm}$ trocar ports and a $12-\mathrm{mm}$ video port. We used 3 arms of the 4-armed da Vinci ${ }^{\circledR}$ Surgical System (Intuitive surgical, Mountain view, CA). One arm handled the 0 -degree video camera and the other two manipulated laparoscopic Debakey forceps. Standardized instructions about the use of instruments and the endoscopic tasks to be performed, were given to the participants on an individual basis. The participants were allowed to manipulate both systems for two minutes to become familiar with its controls and setup. However, no time was allowed to practice any of the tasks. 
Tasks

A variety of tasks were devised to test dexterity, two-handed coordination and suturing. Using a cross-over technique, participants started alternating using $\mathrm{CL}$ or the da $\mathrm{Vinci}^{\circledR}$ system. The same order of tasks was followed for every participant. The same robotic tools were always used for a given task. Two basic laparoscopic tasks were used and two advanced laparoscopic tasks.

\section{Task I (Pick up and Drop)}

This basic laparoscopic drill was comparable to the tasks described previously by Prasad et al. An initial receptacle $(40 \mathrm{~mm}$ opening, $10 \mathrm{~mm}$ high) contained five beads $(2 \times 4 \mathrm{~mm})$. The task involved picking up the beads with the right-handed instrument, one at a time, and then transferring them to the second receptacle. Upon successful transfer, participants were asked to reverse the transfer using the left handed instrument, and return the beads one at a time to the first receptacle. The total time for the exercise was recorded, starting from a position with the instruments in focus but outside the first receptacle, and finishing when the last bead was returned to the final receptacle. Accuracy was defined as the number of beads accidentally dropped outside the receptacle or damaged owing to excessive force. The task was performed six times: three times by $C L$, and three times by RL.

\section{Task 2 (Give Over the Bead)}

In this exercise, the same receptacle and beads were used as described before. The initial receptacle contained five beads. Participants were asked to pick up the beads with the right handed instrument, one at a time, and transfer them halfway to the final receptacle. Then they had to be taken over with the left handed instrument and dropped inside a second receptacle. Time and accuracy were recorded as in the previous task. The task was performed six times: three times by $C L$ and three times by RL.

\section{Task 3 (Cap the Needle)}

This advanced laparoscopic drill was comparable to the needle capping task as described by Garcia-Ruiz et al. A 19 Gauge x I.5-inch aspiration needle with luer lock (Terumo Europe NV, Leuven, Belgium) and its cap were used. The purpose was to cap the needle after grasping both pieces from the floor of the training box. The Only requirement was to cap the needle above the box floor. Time was recorded from starting position with the instruments in focus and $5 \mathrm{~mm}$ from the needle and its cap to the moment when needle and cap were securely coupled and held by one instrument. Accuracy was defined as the number of accidental needle or cap droppings. The task was performed six times: three times by $C L$ and three times by $R L$

\section{Task 4 (Suturing and Knot Tying)}

This suturing task was comparable to tasks described before by others. ${ }^{1-5}$. In this exercise participants were asked to suture and tie a double knot on a latex glove size 8 using a Vicryl 3-0 polyglactin suture with a FS-I $24.0 \mathrm{~mm} 3 / 8$ circular needle (Johnson \& Johnson, New Brunswick) The suture had to pass through two separated $5 \mathrm{~mm}$ dots on the glove. Time was recorded from a starting position with the instruments in focus and $5 \mathrm{~mm}$ away from the needle to the moment the suture was securely tied. Accuracy was defined as number of times the suture broke owing to excessive force, or was tied too loose. Task 4 was performed three times in the RL-group. Owing to limited availability of equipment, the task could not be performed three times in the CL-group. For comparison of $\mathrm{RL}$ versus $\mathrm{CL}$, only the first trial of robot-assisted laparoscopic suturing was compared with the first trial of conventional laparoscopic suturing.
Statistical Analysis

Data were analyzed using SPSS version II.0.I (SPSS, Inc). A multivariate analysis of variance for repeated measures was used. A $p$ value of $\leq 0.05$ was defined as being statistically significant.

\section{RESULTS}

Eight inexperienced participants, four men and four women aged between 22 and 26 years, performed in total 176 laparoscopic tasks.

Time and Accuracy Scores

Time and accuracy score were compared performing laparoscopic tasks using $C L$ and the $d a$ Vinci ${ }^{\circledR}$ Surgical System (RL). RL performed all four tasks faster than $C L$, reaching statistical significance in three out of four tasks. Accuracy scores favored RL over CL in three out of four exercises, reaching statistical significance in two of them. Results are shown in table I.

Table I.

Time and Accuracy performing laparoscopic tasks using both robot assisted and conventional laparoscopy

$\begin{array}{llll} & \text { Robot } & \text { Conventional } & \text { P } \\ \text { Time } & & & <0.00 I^{*} \\ \text { Task I } & 92.10 & 147.80 & <0.00 I^{*} \\ \text { Task 2 } & 62.20 & 253.67 & 0.009^{*} \\ \text { Task 3 } & 49.20 & 83.80 & \text { NS } \\ \text { Task 4 } & 306.00 & 441.10 & \\ & & & \text { NS } \\ \text { Accuracy } & & & <0.00 I^{*} \\ \text { Task I } & 0.25 & 0.29 & <0.00 I^{*} \\ \text { Task 2 } & 0.21 & 1.67 & \text { NS } \\ \text { Task 3 } & 0.38 & 1.75 & \\ \text { Task 4 } & 0.75 & 0.00 & \end{array}$

$\mathrm{P}$ value $<0.05$ was considered statistically significant

\section{Learning curve}

To assess an effect of repetition on time necessary to perform a task, a comparison was made between the first, second and third time a task was performed. The first time a task was performed always took more time than the second or third time. However, a multivariate analysis of variance did not show a significant difference between different runs in speed $(p=0.438)$ or in accuracy $(p=0.082)$. Results are shown in Figures $I$ and 2 .

\section{DISCUSSION}

Conventional laparoscopy can be quite demanding owing to several technical drawbacks. In this study, robotic assistance allowed laparoscopic tasks to be performed faster and more accurately than $\mathrm{CL}$ as described before. ${ }^{2-6}$ Other variables potentially representing the extent of proficiency and/or skill acquisition, such as electromyogram or efficiency of movement," have not been measured in our study. Both $C L$ and $R L$ seemed to show improvement after repetition in speed and accuracy score. This improvement was not always statistically significant, which probably 
reflects our limited sample size. Learning curves in time and accuracy for $C L$ and $R L$ were not comparable for all exercises. In some drills, eg, task I, both curves seemed to run parallel, indicating a continuous persistent advantage of robotic assistance independent of training. In other exercises, for example, task 2 , the learning curve for $C L$ seemed to run more steeply, approaching and possibly reaching the learning curve for $R L$ after further training. Subgroup analysis by task was not performed to prevent type 2 error. These results are contradictory to the findings of Chang et al, ${ }^{13}$ favoring the learning curve in robotic surgery. However, their study used participants with extensive experience in conventional laparoscopy, but without experience in robot-assisted surgery, making their differences in learning curves more of a challenge to interpret. The declining advantage of robotic assistance after repetition, found in our study, could be owing to the initial inferior performance of our study objects using CL. Those participants who make a slow or inaccurate start to the technically more demanding $C L$ have significant room for improvement, and thus are more likely to demonstrate a steeper learning curve. Those who initially perform well on RL have minimal room for subsequent improvement. One interpretation of the steeper learning curve in conventional laparoscopy might be that robotic assistance is advantageous mainly in inexperienced subjects as suggested before by Sarle et al ${ }^{3}$ and Scott et $\mathrm{al}^{14}$. This could explain why most clinical studies have not been able to show the benefit from the use of robotic assistance in terms of time or costs, as could be expected from various training-boxbased studies ${ }^{2-6}$. Adequate and extensive conventional laparoscopic training might lead to faster, better, and less expensive laparoscopy, further marginalizing the advantages of robotic assistance. The advantages of RL over CL, including improved dexterity, tremor filtration, and stereoscopic vision, resulting in increased accuracy and technical feasibility, may be more pronounced in more complex laparoscopic procedures. More research is required to assess the advantages and disadvantages of the use of robotic assistance by experienced laparoscopic surgeons performing complex laparoscopic surgery, ultimately leading to the creation of clear guidelines for the appropriate use of robotic assistance in laparoscopic surgery.

\section{REFERENCES}

I Subramanian K, Desylva S, Bishai P, et al. Acquiring surgical skills: a comparative study of open versus laparoscopic surgery. Eur J Urol. 2004;45(3):346-35I.

2 Heemskerk J, Zandbergen HR, Maessen JG, et al. Advantages of advanced laparoscopic systems. Surg Endosc. 2006;20(5):730-3

3 Sarle R, Tewari A, Shrivastava A, et al. Surgical robotics and laparoscopic training drills. J Endourol. 2004; I8(I):63-66.

4 Hanly EJ, Marohn MR, Bachman SL, et al. Multiservice laparoscopic surgical training using the daVinci Surgical System. Am J Surg. 2004;187(2):309-315.

5 Yohannes P, Rotariu P, Pinto P, et al. Comparison of robotic versus laparoscopic skills: is tbere a difference in the learning curve? Urology. 2002;60(I):39-45.

6 Prasad SM, Maniar HS, Soper NJ, et al. The effect of robotic assistance on learning curves for basic laparoscopic skills. Am J Surg. 2002:183(6):702-707.

7 Ruurda JP, Visser PL, Breeders IA. Analysis of procedure time in robot-assisted surgery: a comparative study in laparoscopic cholecystectomy. Comput Aided Surg. 2003;8(I):24-29.

8 Heemskerk J, van Dam R, van Gemert WG, et al. First results after introduction of the four-armed daVinci Surgical system in fully robotic laparoscopic Cholecystectomy. Dig Surg. 2006;22(6);426-43I.

9 Ruurda JP, Broeders IA, Simmermacher RP, et al. Feasibility of robot-assisted laparoscopic surgery: an evaluation of 35 robotassisted laparoscopic cholecystectomies. Surg Laparosc Endosc Percut Tech. 2002; 12(I):41-45.

10 Melvin WS, Needleman BJ, Krause KR, et al. Computer-enhanced vs standard I aparoscopic antireflux surgery. J Gastrointestinal Surg. 2002;6(I): I I-I5.

I Narazaki K, Oleynikov D, Stergiou N. Robotic surgery training and performance. Identifying objective variables for quantifying the extent of proficiency. Surg Endosc. 2006;20(I):96103.

12 Garcia-Ruiz A, Gagner M; Miller JH, et al. Manual versus robotically assisted laparoscopic surgery in the performance of basic manipulation and suturing tasks. Arch Surg. 1998; 133(9):957-6I.

13 Chang L, Satava RM, Pellegrini CA, et al. Robotic surgery: identifying the learning curve through objective measurement of skill. Surg Endosc. 2003;17(II): 1744-1748.

14 Scott DJ, Young WN, Tesfay ST, et al. Laparoscopic skills training. Am J Surg. 200I; I82(2):I37-42. 


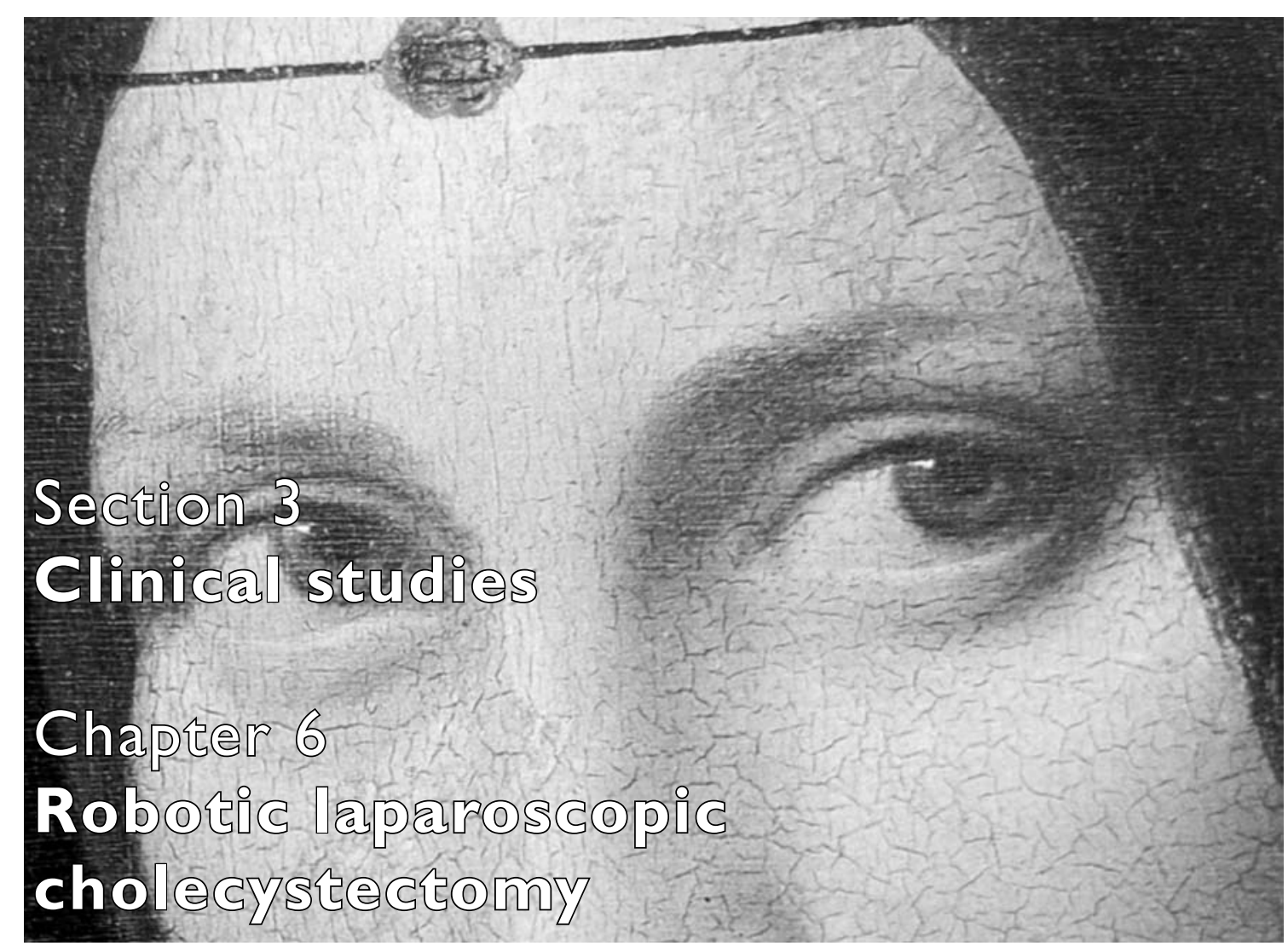

Previously published as:

Heemskerk J, van dam R, van Gemert WG, Beets GL, Greve JWM, Jacobs MJHM, Bouvy ND. First results after introduction of the four-armed daVinci Surgical System in fully robotic laparoscopic cholecystectomy. Dig Surg 2005;22:426-43।

\section{DETAIL FROM: LA BELLE FERRONNIÈRE.}

The painting's title discreetly alludes to a reputed mistress of king Francis I of France. She was the unfaithful wife of an ironmonger (a ferronnier). When the aggrieved husband found this out, he took revenge by intentionally infecting himself with syphilis, indirectly passing it through his wife to the king. 


\section{ABSTRACT}

Background: Laparoscopic cholecystectomy offers less post-operative pain, less complications, and faster recovery compared with open cholecystectomy. However, laparoscopic surgery can be demanding because of several technical drawbacks. Robotic surgery allows dexterity skills to be performed faster and shortens the learning curve, possibly leading to faster and safer laparoscopic surgery.

Methods: In this paper, we report the results of our first 12 cases of fully robotic laparoscopic cholecystectomy using the da Vinci ${ }^{\circledR}$ Surgical System, comparing them with 12 cases of conventional laparoscopic cholecystectomy. Using a fourth arm in robotic laparoscopy enables the surgeon to perform surgery without the use of a tableside assistant, leading to non-tiring, tremblefree assistance and reducing salary costs. Primary end points are operating time and costs. Secondary end points are operative complications and duration of admission.

Results: Fully robotic cholecystectomy was completed in all 12 cases without increased complication rate and without conversions. However, robotic assistance results in an increased overall operating room stay.

Conclusion: Fully robotic laparoscopic cholecystectomy is safe and feasible but seems more expensive and time consuming at this moment.

\section{INTRODUCTION}

Laparoscopic cholecystectomy has become the standard treatment for symptomatic and complicated cholelithiasis ${ }^{1,2}$ and for acute cholecystitis ${ }^{3}$, leading to less complications and faster recovery compared with traditional cholecystectomy $y^{4,5}$. However, the benefits for the patient might be smaller than expected and might not justify the additional costs ${ }^{6,7}$. Conventional laparoscopic surgery can be demanding, potentially attributing to the relatively long learning curve ${ }^{8}$. Robotic assistance in laparoscopy enables stereoscopic vision, improves dexterity 9,10 , and has been proven safe and feasible in a wide variety of surgical procedures including cholecystectomy ${ }^{11-15}$. However, whether robotic surgery leads to increased costs or time loss remains unclear ${ }^{16-18}$.

We describe our first cases of fully robotic laparoscopic cholecystectomy using the four-armed da Vinci ${ }^{\circledR}$ Surgical System. The use of an additional fourth instrumentation arm has proven useful in anti-reflux surgery ${ }^{19}$, potentially diminishing the need for a tableside assistant. Our results are compared with conventional laparoscopic cholecystectomies, performed during the same period. Primary end points are operating time and costs. Secondary end points are post-operative complications and duration of hospital stay.

\section{MATERIAL AND METHODS}

Patients

Between I September 2003 and I February 2004, I 2 fully robotic laparoscopic cholecystectomies were performed and matched with 12 conventional laparoscopic cholecystectomies. No specific criterion was used selecting patients for fully robotic surgery other than availability of the da Vinci ${ }^{\circledR}$ Surgical System and an experienced laparoscopic surgeon. The indication for cholecystectomy was symptomatic cholecystolithiasis, defined as one or more episodes of colic pain in the right upper abdomen in the presence of cholelithiasis objectivated by ultrasound. Exclusion criterion was the presence of acute cholecystitis.

\section{Procedures}

Conventional laparoscopic cholecystectomy (LC) was performed after open introduction of a $10 \mathrm{~mm}$ trocar at the level of the umbilicus for insufflation. A $10 \mathrm{~mm} 0^{\circ}$ three-chip video camera (Karl Storz Endoscopy, Tuttlingen, Germany) was introduced, followed by a second $10 \mathrm{~mm}$ trocar under the xyphoid. Additionally, two $5 \mathrm{~mm}$ trocars were used for introduction of $5 \mathrm{~mm}$ instruments (Endo Grasp, Auto-Suture, Norwalk, CT, USA) to retract and manipulate the gallbladder. Dissection started at the neck of the gallbladder using a curved Maryland dissector. After dissection of Calot's triangle and clear identification of the cystic duct and artery, both were clipped (Hemoclip, Auto-Suture, Norwalk, CT, USA) and cut using $5 \mathrm{~mm}$ Endo Shears (AutoSuture). After this, both blunt and diathermic dissection was performed to free the gallbladder from the liver bed. The gallbladder was removed through the sub-umbilical port. If there were signs of cholecystitis or operative bile spill, the gallbladder was inserted into a disposable plastic bag (Medinorm, Quierschied, Germany) before removal. In case of intra-abdominal spill of bile, suction was used and irrigation if deemed necessary.

The operating team for LC consisted of one operating surgeon or surgical resident performing the dissection, one assisting surgeon or surgical resident handling the camera and retracting the gallbladder through the most lateral trocar, and a scrub nurse.

Robotic Cholecystectomy (RC) was performed after open introduction of a $12 \mathrm{~mm}$ trocar at the level of the umbilicus. A second $12 \mathrm{~mm}$ trocar was introduced in the paramedian left region of the epigastric space. Additionally, two $7 \mathrm{~mm}$ trocars were inserted at the standard trocar sites. The 
trocars were connected to the four-armed da Vinci ${ }^{\circledR}$ Surgical System patient side cart (Intuitive Surgical, Mountain View, CA, USA) and the surgeon was seated behind the da Vinci ${ }^{\circledR}$ console.

Dissection, removal of the gallbladder, and wound closure were performed in the same manner as was done in LC.

The operating team consisted of one operating surgeon and a scrub nurse. No assisting surgeon or surgical resident was used during this stage of surgery. The assisting scrub nurse replaced instruments and placed clips during cholecystectomy. Although all RC procedures were performed by experienced surgeons in general surgery, none of them had extensive experience in RC. The number of previously performed robotic cholecystectomies ranged between zero and three.

\section{Measurements}

Discharge criteria were identical for all patients. Patients were discharged one day after surgery if sufficiently recovered and if pain and nausea had resided. All patients were seen for examination and reassessment at the outpatient clinics two weeks after surgery. Laboratory tests were only performed on indication.

Primary endpoints were operating time and costs. Operating time was recorded separately for different stages of surgery. The overall operating room stay was defined as the total time a patient was in the operating room. This was divided in pre-operative anesthesia induction time (from arrival in the operating room until the end of anesthesia induction), preparation time (from the end of anesthesia induction until the first incision) and real operating time (from incision until placement of the last closing suture). In the RC group, real operating time could be divided into operating time previous to robotic assistance, operating time with robotic assistance, and wound closure time.

Costs per patient were calculated using costs of hospital stay, costs for diagnostic tests, material costs for laparoscopic cholecystectomy, accessory costs for sterile draping and robotic instruments if applicable, salary costs (wages per hour for attending surgeons, residents and nurses, multiplied by overall operating room stay), and outpatient clinics pre-operative assessment and post-operative follow-up.

Secondary endpoints were length of hospital stay and complications.

\section{Statistical analysis}

Data were stored in an Excel 97 database (Microsoft Corporation, Redmond, WT, USA) and analysed using SPSS version II.0.I (SPSS Inc., Chicago, III, USA). The results were analysed by the intention to treat principle. No conversions were performed in this study population. Groups were compared using Pearson's $X^{2}$ test for nominal differences. Age, Laboratory test results, and duration of operation of both groups were compared using a Mann-Whitney $U$ nonparametric test for independent samples or a Spearman's rank correlation test for non-parametric correlations. A p -value $\leq \mathbf{0 . 0 5}$ was defined as statistically significant.

\section{Results}

Pre-operative patient characteristics

Twelve consecutive patients undergoing fully RC were matched for age and gender with 12 patients undergoing a standard LC in the same hospital during the same period. The total study population was 24 patients.

The indication for surgery was symptomatic cholecystolithiasis without acute cholecystitis or previous biliary complications in 23 cases (96\%). One patient in the RC group underwent cholecystectomy "à froid" four months after an episode of acute cholecystitis without cholestasis. None of the patients met the criteria of acute cholecystitis at the time of hospital admission. Pearson's $\mathrm{X}^{2}$ test for nominal differences showed no difference between both groups in sex, indication for operation, or indicators for acute cholecystitis or cholestasis. However, there was a significant difference in the consistence of the operating team. In the RC group, all operations were performed by an experienced general surgeon, assisted by a scrub nurse. Experience in robotic surgery was limited in all six individual surgeons. None of them had experienced more than three RC procedures and one of them had no previous experience in laparoscopic cholecystectomy at all. In the LC group, only one cholecystectomy was performed by an experienced general surgeon. The other II operations were performed by a surgical resident. The Mann-Whitney $U$ test showed no significant difference between both groups in age and pre-operative laboratory results. Pre-operative characteristics of the study population are displayed in table 1.

Intra-operative complications

No major intra-operative complications occurred. There were no cases of intra-operative bleeding, bile duct damage, or conversion. Nine patients had per-operative intra-abdominal bile spill, four in the CC group and five in the RC group. Pearson's $X^{2}$ test showed no difference between both groups.

Table I. Pre-operative characteristics of the study population

$\begin{array}{llllll} & \text { Total study Group } & & \text { LC } & \text { RC } & \\ \text { value } & & & & \\ & (\mathrm{n}=24) & (\mathrm{n}=12) & (\mathrm{n}=12) & \\ \text { Sex, \% male } & 4 & 8 & 0 & 0.307 \\ \text { Mean age, years } & 47.8 & 48 & 47.7 & 0.977 \\ \text { Median age, years (range) } & 45.5(19-77) & 46.5(19-77) & 45(24-73) & 0.977 \\ \text { Operated by surgeon \% } & 54 & 8 & 100 & <0.00 I^{*} \\ \text { Pre-op abd tenderness, \% } & 0 & 0 & 0 & 0.680 \\ \text { Pre-op leucocytosis } & 7.7(5.3-11.4) & 7.7(5.3-11.4) & 7.6(5.4-9.0) & 0.862 \\ \text { Pre-op CRP } & 5(1-195) & 8.4(2-195) & 3.2(1-16) & 0.056 \\ \text { Pre-op bilirubine } & 12.4(7.3-24) & 13.5(10.1-24.0) & 12(7.3-23.0) & 0.174 \\ \text { Pre-op Alk. phosphatase } & 84(53-152) & 94(64-138) & 75(53-152) & 0.009 * \\ \text { Pre-op GGT } & 22(7-126) & 32(9-126) & 19(7-64) & 0.078 \\ \text { Cholelithiasis on US, \% } & 100 & 100 & 100 & 1.000 \\ \text { Thick wall on US, \% } & 17 & 17 & 17 & 1.000 \\ \text { Pericystic oedema on US\% } 4 & 8 & 0 & 0.320 \\ & & & & \end{array}$

Duration of the operation

The duration of the overall operating room stay was significantly longer in the RC group compared with the LC group (2:30 vs. I :59). No significant difference could be found between the groups in anesthesia induction time, preparation time, or real operating time.

Time consumption of different stages of RC was compared with the number of previously performed robotic procedures in our hospital as an indicator for our experience with the robotic system. In the group of 12 patients, no significant correlation could be found between our previous robotic laparoscopic experience and anesthetic induction time $(p=0.23)$, preparation time $(p=0.12)$, operating time previous to robotic assistance $(p=0.31)$, operating time with robotic assistance $(p=0.5 \mathrm{I})$, or wound closure time $(p=0.76)$ using Spearman's test for nonparametric correlations. Therefore, no statistical significant decrease in operating time due to a progression in learning curve could be shown at the moment. 
Post-operative recovery

Four patients developed post-operative complications. Three of them (all in the RC group) had a superficial wound infection. One patient in this group developed urinary bladder retention. Admission was 2.5 days (range 2-4), i.e. 2.7 days versus 2.3 days for the RC and CC groups respectively $(p=0.21)$. Pathologic examination of resected gallbladder showed no difference between both groups.

\section{Costs}

Total costs per patient were calculated. In our total study group, mean costs of admission were $€ \mathrm{I}, 402.17$, accessory costs $€ 567.47$, and wage costs $€ 274$.I7. Added to the costs of outpatient clinics $(€ 47.80)$ and, if applicable, the costs of the da Vinci ${ }^{\circledR}$ Surgical System ( $€ 889.18$ excluding acquisition and maintenance of the robotic system), the total costs were $€ 2,738.76$ per patient. Using a Mann-Whitney $U$ non-parametric test for independent samples, no statistically significan difference in costs of hospital admission, outpatient clinics, accessory diagnostics, or operation theatre rent and materials used, excluding specific da Vinci ${ }^{\circledR}$ instruments, were present between both groups.

Salary costs of the LC group were calculated adding the salary costs of one surgeon, one surgical Table 2. Operative and post-operative characteristics of the study population

\section{Total study Group}

Overall operating room stay (range)

3:10) $0.042 *$

Anesthesia induction

0.280

Preparation time

0.760

Real operating time

0.170

Bile spill, \%

0.673

Wound infection, \%

0.064

Duration of admission, days

0.208

Costs for hospital stay

0.219

Costs for accessory tests

Costs for da Vinci®System

Salary costs

Outpatient follow-up

1.00

Total Costs

$<0.001 *$

\section{LC}

$(\mathrm{n}=24)$

2:14 (1:09-3:14)

$0: 11$

$0: 13$

I:43

38

12

2.5

\section{$€ \mathrm{I}, 402.17$}

$€ 567.47$

$€ 444.59$

$€ 274.16$

$€ 47.80$

$€ 2,738.76$
$\mathrm{RC}$
$(\mathrm{n}=12)$

$P$ value

$(n=12)$

I:59 (I:09-3:14) 2:30 (I:24-

$0: 13$

0:09

$0: 15$

$0: 10$

$1: 30$

I:55

33

0

2.3

$€ 1,308.83$

$€ 1,495.50$

$€ 552.01 € 582.920 .567$

$€ 0.00 \quad € 889.18<0.001$ *

$€ 273.74 € 274.570 .980$ $€ 47.80$

$€ 47.80$

$€ 2,148.45$

$€ 3,329.07$ $p$ value $<0.05$ was considered statistically significant resident, and two theatre nurses, multiplied by the overall operating room stay. This resulted in costs of $€ 137.39$ per hour during I:59h and therefore in a total of $€ 273.74$. Using the da Vinci ${ }^{\circledR}$ robotic system with a fourth arm, there was no need for an assisting surgical resident. Salary costs were calculated adding only the costs of one surgeon and two nurses, multiplied by the overall operating room stay. This resulted in costs of $€ 113.31$ per hour during 2:30h and therefore in a total of $€ 274.57$. Consequently, total salary costs for LC and RC were equal, despite a significant longer overall operating room stay in the latter group. Including the extra material costs of the specific da Vinci ${ }^{\circledR}$ Surgical System instruments $(€ 889.18$ ), this resulted in significantly higher total costs $(€ 3,329.07$ versus $€ 2,148.45$; $p<0,00 I)$ compared with LC, with a difference of $€ \mathrm{I}, 180.62$. Characteristics of both groups are displayed in table 2 .

No correlation could be found between complications and costs.

\section{DISCUSSION}

Robotic laparoscopic surgery provides multiple potential advantages over conventional laparoscopy. We compared our first 12 cases of fully robotic laparoscopic cholecystectomy with 12 conventional laparoscopic cholecystectomies performed during the same period in the same hospital. Primary end points were duration of the operation and costs.

Statistical analysis showed that robotic laparoscopic cholecystectomy, at this moment, is relatively time consuming. A faster operating time in the robotic group could be expected due to the potentially beneficial aid of the robotic system and the use of experienced laparoscopic surgeons in comparison with several relatively inexperienced residents in the conventional laparoscopic group. However, despite improved three-dimensional optics, improved camera stability, and increased dexterity, the use of robotics in laparoscopic surgery lead to a significant increased time consumption of $3 \mathrm{I}$ min compared with conventional laparoscopy in our study.

Increased time consumption was described before by Ruurda et $\mathrm{a}^{16}$ and Delaney et al ${ }^{17}$. whereas a beneficial effect of robotic assistance on time consumption was previously described by Sarle et $\mathrm{al}^{18}$. Probably, part of this increase in time consumption is due to the relative extensive effort exchanging robotic instruments, the increased time necessary to position the bulky patient-side cart, and due to our relative limited experience with robotic surgery at the moment.

Robotic assistance in laparoscopic cholecystectomy results in accessory costs of $€ 1,180.62$ per patient. The real costs might be even higher, since increased wage costs for the anesthesiologist during this time consuming operation were not taken into account. Using the fourth robotic arm of the da Vinci ${ }^{\circledR}$ Surgical System enabled us to perform surgery with one assistant less, thereby decreasing salary costs per hour compared with the three armed robotic systems. Whether the absence of a surgeon at the operating room table side is a potential hazard in case of acute complications remains subject to debate. However, absence of a tableside surgeon (or resident) did lead to decreased salary costs per hour. Consequently, salary costs for conventional laparoscopic cholecystectomy and for robot-assisted laparoscopic cholecystectomy were similar. despite a significantly longer overall operating room time in the robotic group. Since financial resources in contemporary medicine are limited, a comparative assessment of costs and benefits should be made. Therefore, clear benefits for the patient should be indicated in order to warrant the additional costs. In more complex laparoscopic surgery, the benefits of robotic assistance may result in faster and safer performance of laparoscopic tasks ${ }^{18}$, potentially leading to decreased operating room stay, less complications, faster recovery after surgery, and shorter admission. Eventually, these improvements may lead to decreased costs.

Secondary end points were peri-operative complications and hospital stay. In our study group, complications were rare and no differences were found between LC and RC. Hospital admission was similar in both groups. Therefore, RC using the four armed da Vinci ${ }^{\circledR}$ Surgical System was a 
safe and feasible procedure that could be performed by general surgeons with limited experience in robotic surgery. However, no convincing benefits of robotic assistance were identified that could justify the associated increased costs and increased consumption of time. Safety and feasibility were described before by other authors in a variety of robotic and robot-assisted laparoscopic procedures $11-13,17$. However, to the best of our knowledge, no previous study has been reported describing the results of fully robotic laparoscopic cholecystectomy using the fourarmed da Vinci ${ }^{\circledR}$ Surgical System.

The advantages of three-dimensional optics and increased dexterity offered by the robot to, for example, intra-corporal suturing and micro-suturing are not required for laparoscopic cholecystectomy. In more complex laparoscopic surgery, these advantages may result in more technical possibilities, less complications, and decreased time consumption. Therefore, in complex procedures, robot-assisted laparoscopic surgery is more likely to become cost-effective than in relatively simple procedures such as laparoscopic cholecystectomy. In our opinion, fully robotic laparoscopic cholecystectomy should be considered as a learning tool for complex robot-assisted procedures, not as a potential standard operative procedure for symptomatic cholelithiasis. Contemporary robotic and robot-assisted laparoscopic surgery is still in its infancy, and major improvements in the availability of tactile feedback and specifically designed instruments are expected soon, offering great opportunities for the future. However, more research needs to be done in order to define exact indications for robotic assistance in order to justify the increased costs and increased time consumption compared with standard laparoscopic surgery.

\section{REFERENCES}

I Bass EB, Pitt HA, Lillemoe KD: Cost-effectiveness of laparoscopic versus open cholecystectomy. Am J Surg 1993;165(4):466-7I.

2 Boerma D, Rauws EA, Keulemans YC, et al. Wait-and-see policy of laparoscopic cholecystectomy after endoscopic sphincterotomy for bile-duct stones: a randomised trial. Lancet 2002;360(9335):761-5

3 Kiviluoto T, Siren J, Luukkonen P, et al. Randomised trial of laparoscopic versus open cholecystectomy for acute and gangrenous cholecystitis. Lancet 1998;35 I(9099):32I-5.

4 Koperna T, Kisser M, Schulz F: Laparoscopic versus open treatment of patients with acute cholecystitis. Hepatogastroenterology 1999;46(26):753-7.

5 Berggren U, Gordh T, Grama D, et al. Laparoscopic versus open cholecystectomy: hospltalization, sick leave, analgesia and trauma responses. Br J Surg 1994;8I(9):1362:5

6 Calvert NW, Troy GP, Johnson AG: Laparoscopic cholecystectomy: a good buy? A cost comparison with small incision (mini) cholecystectomy. Eur J Surg 2000;166(10):782-6

7 Brazier JE, Johnson AG: Economics of surgery. Lancet 2001;358(9287): 1077-81

8 Voitk AJ, Tsao SG, Ignatius S: The tail of the learning curve for laparoscopic cholecystectomy. Am J Surg 200I;182(3):250-3

9 Yohannes P, Rotariu P, Pinto P, et al. Comparison of robotic versus laparoscopic skills: is there difference in learning curve? Urology 2002;60(I):39-45

10 Hernandez JD, Bann SD, Munz Y, et al. Qualitative and quantitative analysis of the learning curve of a simulated surgical task on the da Vinci ${ }^{\circledR}$ System. Surg endosc 2004;18(3):372-8

I I Giulianotti PC, Coratti A, Ahelini M, et al. Robotics in general surgery : personal experience in a large community hospital. Arch Surg 2004:138(9):777-84

12 Roeyen G, Chapelle T, Ysebaert D: robot assisted choledochotomy: Feasibility. Surg Endosc 2004;18(I):165-6

3 Undre S, Munz Y, Moorthy. Robot assisted adrenalectomy: preliminary UK results. BJU Int 2004;93(3):357-359

14 Nio D, Bemelman WA, Busch OR, et al. Robot-assisted laparoscopic cholecystectomy versus conventional laparoscopic cholecystectomy: a comparative study. Surg Endosc 2004;18(3):379-82
15 Ruurda JP, Broeders IA, Simmermacher RP, et al. Feasibility of robot-assisted laparoscopic surgery: an evaluation of 35 robot-assisted laparoscopic cholecystectomies. Surg Laparosc Endosc Percutan Techn 2002; I2(I):4I-5

16 Ruurda JP, Visser PL, Broeders IA. Analysis of procedure time in robot-assisted surgery: comparative study in laparoscopic cholecystectomy. Comput Aided Surg. 2003;8(I):24-9

17 Delaney CP, Lynch AC, Senagore A], et al. Comparison of robotically performed and traditional laparoscopic colorectal surgery. Dis Colon Rectum 2003:46(I2):1633-9

I8 Sarle R, Tewari A, Shrivastava A, et al. Surgical robotics and laparoscopic training drills. J Endourol 2004; I8(I):63-6

19 Newlin ME, Mikami DJ, Melvin SW. Initial experience with the four-arm computer-enhanced telesurgery device in foregut surgery. J Laparoendosc Adv Surg Tech A 2004; I4(3):I2I-4 


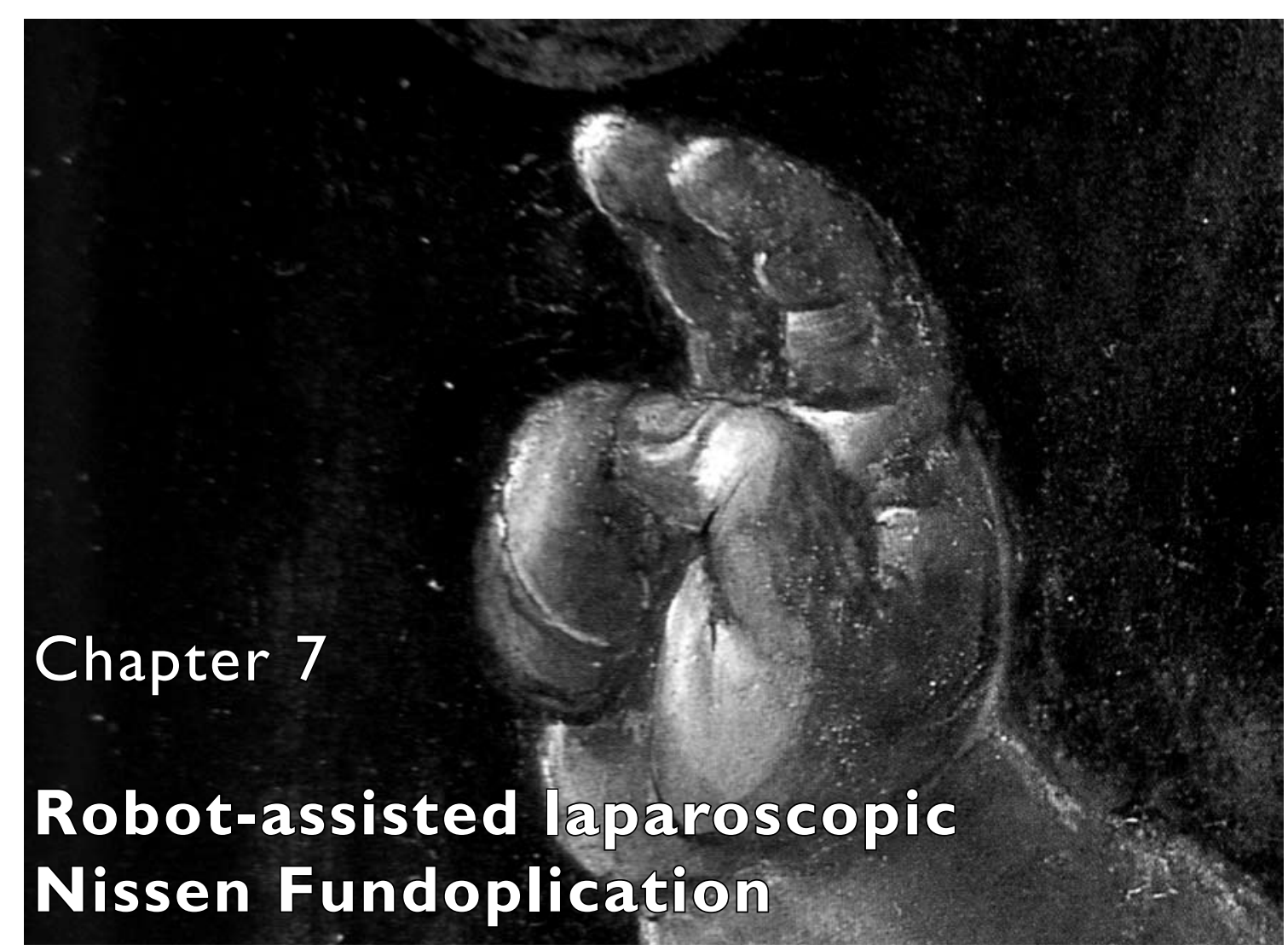

Previously published as:

Heemskerk J, van Gemert WG, Greve JWM, Bouvy ND. Robot-assisted versus Conventional laparoscopic Nissen Fundoplication. Surg Laparosc Endosc Percutan tech 2007; I (1): I-4

DETAIL FROM: VIRGIN OF THE ROCKS

OIL ON PANEL, I $483-$ I 486

The Christ child sits towards the front of the picture, and raises his right hand in a sign of benediction towards the kneeling John the Baptist. 


\section{ABSTRACT}

Background: Laparoscopic Nissen fundoplication offers clear benefits for our patients, but requires advanced laparoscopic skills. Robotic assistance in laparoscopic antireflux surgery improves dexterity skills and shortens learning curve, possibly leading to faster, more precise, and safer laparoscopic surgery.

Methods: We review our first II cases of robot-assisted laparoscopic Nissen fundoplication using the 4-armed da Vinci ${ }^{\circledR}$ Surgical System, comparing them with patients who underwent conventional laparoscopic Nissen fundoplication for gastroesophageal reflux disease in the same period.

Results: Robot-assisted laparoscopic Nissen fundoplication did not result in more complications. However, the use of robotic assistance took an extra 47 minutes to complete the operation and costs were raised with an accessory $€ 987.47$.

Conclusion: The use of robotic assistance in laparoscopic antireflux surgery is safe and feasible, but results in longer operating time and higher costs compared with conventional laparoscopic surgery without proven benefit at this moment.

\section{INTRODUCTION}

Since Dallemagne et al' first described minimal invasive antireflux surgery, laparoscopy has become the golden standard for the surgical treatment of gastroesophageal reflux disease with good-to-excellent quality of life and functional results after long-term follow-up ${ }^{2,3}$. laparoscopic Nissen fundoplication results in comparable functional results ${ }^{4}$ but faster convalescence and less postoperative pain compared with open Nissen fundoplication ${ }^{5,6}$, allowing antireflux surgery in day care $^{7}$.

However, laparoscopic fundoplication requires advanced laparoscopic skills, probably attributing to the relatively long learning curve ${ }^{8}$. Robotic assistance in laparoscopic surgery allows dexterity skills to be performed faster and shortens the learning curve in simple laparoscopic tasks ${ }^{9-13}$, possibly leading to faster and safer laparoscopic surgery. Robot-assisted antireflux surgery has been proven safe and feasible ${ }^{14-16}$, but has up until now failed to show convincing benefits over conventional laparoscopy ${ }^{17-19}$.

In this retrospective study we describe our first II cases of robot-assisted laparoscopic Nissen fundoplication (RF), comparing our results with historical data of patients undergoing conventional laparoscopic Nissen fundoplication (LF) in the same hospital and in the same period.

\section{Material and methods}

\section{Patients}

Between the first of September 2003 and the first of July 2004, 22 patients underwent minimal invasive Nissen fundoplication for gastroesophageal reflux disease. Patients were non-randomly assigned to Robot-assisted surgery (RF) or conventional laparoscopic surgery (LF). Groups were matched for age and sex. The indication for Nissen fundoplication was gastroesophageal reflux, objectivated by gastroscopy, esophageal manometry, and 24-hour $\mathrm{pH}$ monitoring. Exclusion criterion was age under 18 years or Nissen fundoplication for esophageal disrupture (Boerhave syndrome or iatrogeneous rupture during endoscopy).

\section{Procedures}

Conventional LF was performed using a 5 -trocar technique as described by Dallemagne $e^{1,20}$. A slight modification was used, placing the $12 \mathrm{~mm}$ subcostal trocar at the right midclavicular line instead of the left midclavicular line. The operating team consisted of one surgeon, two assisting residents, and a scrub nurse. RF was performed using a similar 5-trocar technique. The operating team consisted of one surgeon, one assisting resident, and a scrub nurse. Using a four-armed da Vinci ${ }^{\circledR}$ robotic system (Intuitive Surgical, Inc, CA, USA), there was no need for a second assistant. A $12 \mathrm{~mm}$ trocar was placed in the midline on $2 / 3$ from the xyphoid to the umbilicus for insertion of the 30-degree da Vinci ${ }^{\circledR}$ camera with stereoscopic vision. A second $12 \mathrm{~mm}$ trocar just below the right subcostal margin in the anterior axillary line was used for insertion of a conventional laparoscopic liver retractor. A $7 \mathrm{~mm}$ trocar just below the right subcostal margin in the midclavicular line was used for insertion of an atraumatic grasper and instruments for dissection. A second $7 \mathrm{~mm}$ trocar was placed in the epigastrium, just below the xyphoid. A third $7 \mathrm{~mm}$ trocar below the left subcostal margin was used for insertion of the needle and hemostatic clips, and introduction of dissecting and suturing devices including the $5 \mathrm{~mm}$ handheld Atlas Ligasure ${ }^{\circledR}$ vessel sealing system (Valleylab, Tyco Healthcare Group, Boulder, CL, USA). All trocars except the right subcostal $12 \mathrm{~mm}$ trocar containing the liver retractor were connected to the da Vinci ${ }^{\circledR}$ Surgical System. After positioning the patient in mild anti-trendelenberg position, the surgeon was seated behind the console and performed the operation, controlling the camera and three instruments. Manipulation of the liver retractor was done by the assistant. Replacement of instruments was done by the scrub nurse. 
After mobilization and retraction of the left liver lobe, the gastric fundus was pulled to the left. The gastrohepatic ligament was divided along the lesser curvature of the stomach thus providing exposure of the right crus of the diaphragm. After identification of the anterior edge of the right diaphragmatic crus, the overlying peritoneum was incised. The incision was continued anterior to the esophagus to the left crus. The right crus was detached from the esophagus, leaving the posterior vagal nerve attached to the esophagus. After totally dissecting the gastroesophageal junction and the distal esophagus up into the mediastinum, a window was made by blunt dissection, inferior to the right crus. The distal esophagus was encircled using a rubber tube to manipulate the esophagus without the risk of further trauma. Dissection of the short gastric vessels was performed using the Atlas ${ }^{\circledR}$ instrument, inserted through the left subcostal trocar. The hiatal crura were approximated using two to four 2-0 prolene non-absorbable sutures. A $56 \mathrm{Fr}$ gastric tube was kept in the esophagus during approximation of the hiatal crura to prevent accidental critical narrowing of the hiatus.

The gastric fundus was pulled through the window behind the esophago-gastric junction to produce a floppy 360-degree wrap. The wrap was secured with three 2-0 prolene non-absorbable sutures using the da Vinci ${ }^{\circledR}$ needle driver. After completion of the fundoplication and control of hemostasis, closure of the abdominal wall was done using vicryl polyglactin absorbable suture (Johnson\&Johnson healthcare, Piscataway, NY, USA). Skin closure was done intracutanously.

\section{Measurements}

Discharge criteria were identical for all patients. Patients were discharged two days after surgery if sufficiently recovered. All patients were seen for examination and reassessment at the out-patient clinics two weeks after surgery. Accessory laboratory tests, endoscopy, or radiologic examinations were only performed on indication.

Primary end points were length of hospital stay and complications. Secondary end points were operating time and costs. Operating time was recorded separately for different stages of surgery. The overall operating room stay was defined as the total time a patient was in the operating room. This was divided into preoperative anesthesia induction time, preparation time, real operating time, and postoperative recovering time. Setup of the da Vinci ${ }^{\circledR}$ Surgical System was performed during both preoperative anesthesia induction time and preparation time. Costs per patient were calculated using costs of hospital admission and treatment, material costs for open, laparoscopic, or robot-assisted surgery and salary costs (wages per hour for attending surgeons, residents, and nurses, multiplied by total operating room stay).

\section{Statistical Analysis}

Data were stored in an Excel 97 database (Microsoft Corporation, Redmond, USA) and analysed using SPSS version II.0.I (SPSS, Inc, Chicago, III, USA). The results were analysed by the intention to treat principle. Groups were compared using Pearson's $X^{2}$ test for nominal differences. Age, laboratory test results, duration of operation, and costs were compared using a Mann-Whitney $U$ non-parametric test for independent samples. A $p$ value $\leq 0.05$ was defined as being statistically significant.

\section{RESULTS}

\section{Preoperative Characteristics}

Twenty-two patients with symptomatic gastroesophageal reflux were non-randomly assigned to undergo either LF or RF. Patients were matched for age and sex. Preoperative patient characteristics are listed in table I. One patient in the LF had previously undergone transabdominal uterus extirpation. Previous abdominal surgery in the robot-assisted group consisted of laparoscopic cholecystectomy (one patient) and conventional open appendectomy (twice). No intra-operative complications, bleeding, or conversion to another technique occurred.

\section{Postoperative Period}

In total, six patients developed postoperative complications. No wound infections occurred. One patient in the da Vinci ${ }^{\circledR}$ group developed an intestinal pseudo-obstruction due to motility dysfunction under high-dose morfinomimetics. After reduction of the analgesics, motility returned and further recovery was uncomplicated. Two patients developed early dysphagia, improving under conservative therapy. Three patients developed late dysphagia or bloating after surgery, one after RF and two after LF. One of them required surgical intervention: the LF was converted to a partial posterior Toupet's fundoplication.

\section{Table I}

Patient pre-operative characteristics, showing the total study population (Total), the conventional laparoscopic group (LF) and the robot-assisted Group (RF)

\begin{tabular}{|c|c|c|c|}
\hline & $\begin{array}{l}\text { Total } \\
(n=22)\end{array}$ & $\begin{array}{l}\text { LF } \\
(n=I I)\end{array}$ & $\begin{array}{l}R F \\
(n=I I)\end{array}$ \\
\hline Age, median (range) & $40(22-65)$ & $41(22-58)$ & $39(26-65)$ \\
\hline Sex, \% male & 64 & 64 & 64 \\
\hline Weight, mean in kg & 79 & 77 & 80 \\
\hline Length, mean in $\mathrm{cm}$ & 172 & 175 & 170 \\
\hline Pre-op reflux of food & 90 & 82 & 100 \\
\hline Pre-op heartburn & 100 & 100 & 100 \\
\hline Previous abdominal surgery & 4 & I & 3 \\
\hline
\end{tabular}

There were no significant differences between these groups

Total operating room stay was divided in preoperative anesthesia induction time (Anesth Ind Time), preparation time (Prep Time), real operating time (Operating Time), and postoperative anesthesia recovering time (Anesth Recov Time). No significant differences were found between the two different groups in preparation time, operating time, or recovering time. However, total operating room stay was significantly longer in the robot assisted group ( 220 vs. $173 \mathrm{~min} ; \mathrm{p}=0.028$ ). Total costs for each group were calculated adding costs for hospital admission, postoperative diagnostic tests, material costs for surgery and salary costs of attending surgeon, assistant, and nurses. RF resulted in higher material costs than LF. Although RF could be performed with one assistant less than LF, the longer total operating room stay resulted in marginally higher salary costs, attributing to higher total costs (€ 4,363.82 vs. $€ 3,376.35$; $p=0.033)$. Therefore, $L F$ is not only the fastest, but also the most economical option. Results are shown in Table 2. When we compare our first five cases of RF with our last five cases, total operating room stay decreased from 266 to 197 minutes $(p=0.115)$ and operating time decreased from 222 to 150 minutes $(p=0.059)$, both being not significantly different. 
Table 2

Patient post-operative characteristics, showing the total study population (Total), the conventional laparoscopic group (LF) and the robot-assisted Group (RF)

\begin{tabular}{|c|c|c|c|c|}
\hline & Total & $\begin{array}{l}\mathrm{LF} \\
(\mathrm{n}=22)\end{array}$ & $\begin{array}{l}R F \\
(n=I I)\end{array}$ & $\begin{array}{l}P \text { - value } \\
(n=I I)\end{array}$ \\
\hline Days of admission & 4 & 4 & 4 & 0.928 \\
\hline No. of complications & 6 & 3 & 3 & 0.901 \\
\hline Early dysphagia & 2 & I & I & 0.867 \\
\hline ate dysphagia & 3 & 2 & I & 0.893 \\
\hline Anesth Ind time & 13 & 10 & 16 & 0.210 \\
\hline Prep time & 18 & 20 & 15 & 0.166 \\
\hline Operating time & 156 & 135 & 176 & 0.094 \\
\hline Anest rec time & 11 & 8 & 13 & 0.236 \\
\hline Total time & 197 & 173 & 220 & $0.028 *$ \\
\hline $\begin{array}{l}\text { Admission costs } \\
\text { Diagnostics costs } \\
\text { Materials costs } \\
\text { Wage costs }\end{array}$ & $\begin{array}{l}€ 2,244.00 \\
€ 22.36 \\
€ 1,272.50 \\
€ 331.23\end{array}$ & $\begin{array}{l}€ 2,244.00 \\
€ 21.87 \\
€ 780.00 \\
€ 330.48\end{array}$ & $\begin{array}{l}€ 2,244.00 \\
€ 22.84 \\
€ 1,765.00 \\
€ 331.98\end{array}$ & $\begin{array}{l}0.405 \\
0.430 \\
<0.001 * \\
0.669\end{array}$ \\
\hline Total costs & $€ 3,870.09$ & $€ 3,376.35$ & $€ 4,363.82$ & $0.033 *$ \\
\hline
\end{tabular}

Complications are listed in absolute numbers, anesthesia insuction time, preparation time, operating time, anesthesia recovery time and Total time are noted in minutes. Costs are noted in Euros.

*p value $<0.05$ was considered statistically significant

\section{DISCUSSION}

Robotic assistance in advanced laparoscopy potentially attributes to safety and feasibility. In this study, we compared conventional laparoscopic with robot-assisted laparoscopic Nissen fundoplication. Statistical analysis showed pre-operative characteristics, duration of admission, and complication rate were comparable in both groups, suggesting RF is safe and feasible. However, group size was limited and complications were rare, making it impossible to find a statistically significant decrease in complication rate.

The use of robotic assistance in antireflux surgery led to a significant increased time consumption of 47 minutes compared with standard conventional laparoscopy in our study. Increased time consumption was described before by other authors in advanced laparoscopy ${ }^{17-19}$, in contrast to the beneficial effect of robotic assistance on time consumption in the performance of aparoscopic training drills as described before by us and by others ${ }^{11,13}$.

Probably, part of this increase in time consumption is due to the relative extensive effort exchanging robotic instruments and due to our relative limited experience with robotic surgery at this moment. Comparing our first and our last five cases of RF showed a possible decrease in operating time and total operating room stay, although this difference was not statistically significant. Possibly, operating time will decrease further after gaining more extensive experience in robot-assisted surgery.

Robotic assistance in minimal invasive Nissen fundoplication results in accessory material costs of $€ 985.00$ during surgery. However, using the fourth robotic arm of the da Vinci ${ }^{\circledR}$ robotic system enabled us to perform surgery with one assistant less, thereby decreasing salary costs with $€ 24.08$ per hour as compared with conventional laparoscopy and three-armed robotic systems. This resulted in total accessory costs for the four-armed surgical system of $€ 987.47$ 
13 Heemskerk J, Zandbergen HR, Maessen JG, et al. Advantages of advanced laparoscopic systems. Surg Endosc 2006;20(5):730-3.

14 Wykypiel H, Wetscher GJ, Klaus A, et al. Robot-assisted laparoscopic partial posterior fundoplication with the daVinci system: initial experiences and technical aspects. Langenbecks Arch Surg 2003;387(II-I2):4II-6.

I5 Melvin WS, Needleman BJ, Krause KR, et al. Computer-enhanced vs. standard laparoscopic antireflux surgery. I Gastrointest Surg 2002;6(I): I I-5.

16 Knight CG, Lorinez A, Gidell KM, et all. Computer-assisted robot-enhanced laparoscopic fundoplication in children. J Pediatr Surg 2004;39(6):864-6.

17 Cadiere GB, Himpens B, Vertruyen M, et al. Evaluation of telesurgical (robotic) NISSEN fundoplication. Surg Endosc 200I; I5(9): 918-23

18 Costi R, Himpens J, Bruyns J, el al. Robotic fundoplication: from theoretic advantages to real problems. J Am Coll surg 2003; 197(3):500-7

19 Hanly EJ, Talamini MA. Robotic abdominal surgery. Am J Surg 2004; 188(4A suppl): 19S-26S

20 Dallemagne B: GERD: laparoscopic Nissen Fundoplication. Available at: www.websurg.com

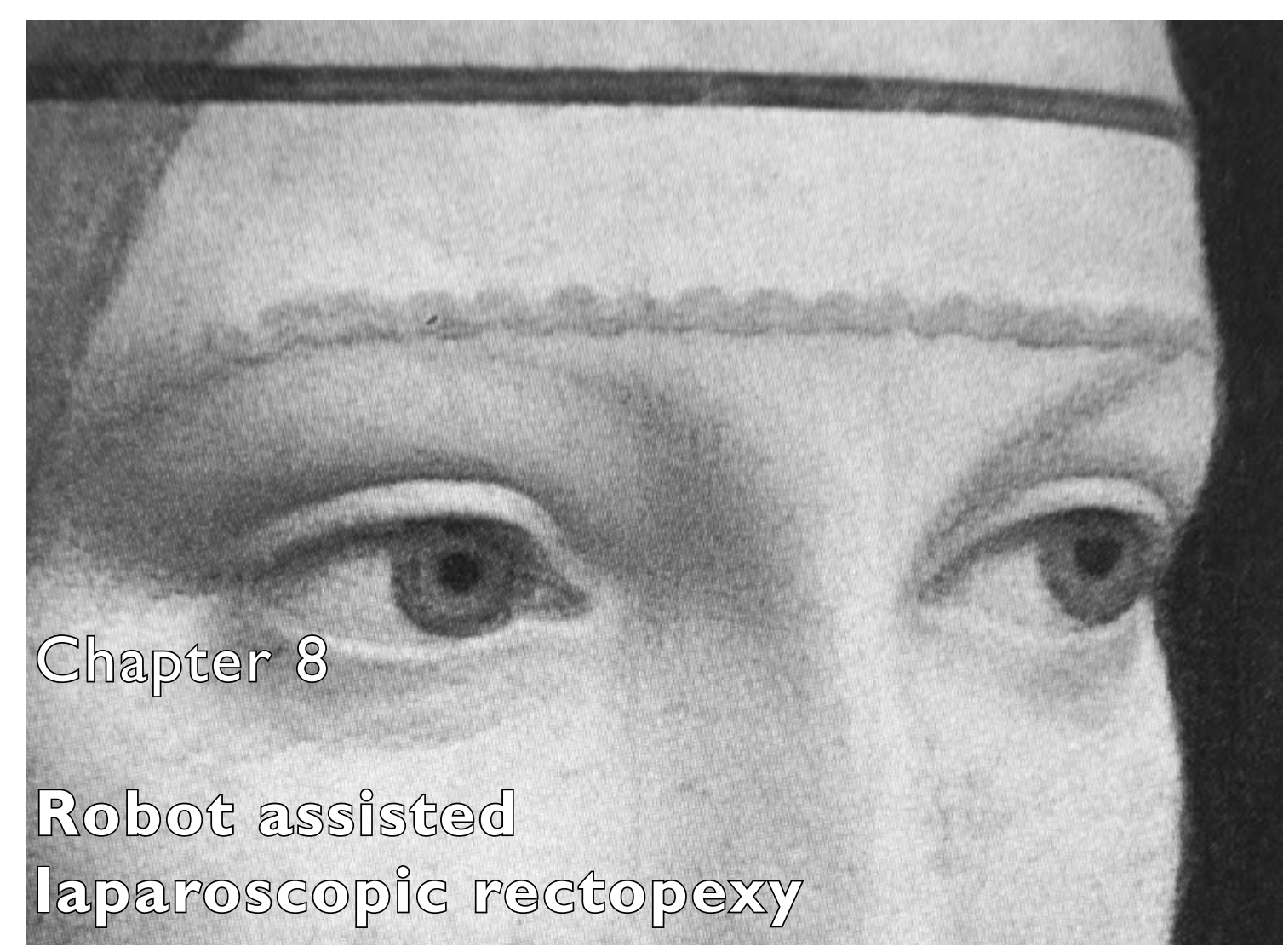

Previously published as:

Heemskerk J, de Hoog DENM, van Gemert WG, Baeten CGMI, Greve JWM, Bouvy ND. Robotassisted versus Conventional laparoscopic rectopexy for rectal prolapse: a comparative study on costs and time.

Dis Colon rectum 2007;50(II):1825-30

DETAIL FROM: THE LADY WITH AN ERMINE OIL ON WOODEN PANEL, I489-1490

Cecilia Gallerani was neither wealthy nor noble. At the time the portrait was painted, she was about 16 years old and renowned for her beauty, het scholarship and her poetry. She was betrothed at the age of 10 to a young nobleman of the house of Visconti, but the marriage was called off. Cecilia became the mistress of Lodovica Sforza, Duke of Milan and bore him a son, but he chose to marry a woman from a nobler family, Beatrice d'Este. 


\section{ABSTRACT}

Background: Laparoscopic rectopexy has become one of the most advocated treatments for full-thickness rectal prolapse, offering good functional results compared with open surgery and resulting in less postoperative pain and faster convalescence. However, laparoscopic rectopexy can be technically demanding. Once having mastered dexterity, with robotic assistance, laparoscopic rectopexy can be performed faster. Moreover, it shortens the learning curve in simple laparoscopic tasks. This may lead to faster and safer laparoscopic surgery. Robot-assisted rectopexy has been proven safe and feasible; however, until now, no study has been performed comparing costs and time consumption in conventional laparoscopic rectopexy vs. robot-assisted rectopexy.

Methods: Our first 14 cases of robot-assisted laparoscopic rectopexy were reviewed and compared with 19 patients who underwent conventional laparoscopic rectopexy in the same period.

Results: Robot-assisted laparoscopic rectopexy did not show more complications. However, the average operating time was 39 minutes longer, and costs were $€ 557,29$ higher.

Conclusion: Robot-assisted laparoscopic rectopexy is a safe and feasible procedure but results in increased time and higher costs than conventional laparoscopy.

\section{INTRODUCTION}

Since Edmond Delorme first described a perineal mucosal-stripping procedure to treat rectal procidentia in 1899', controversy exists regarding the preferred surgical technique for the treatment of rectal prolapse. Not a single procedure has been considered a standard, because all treatment modalities show failures. In all studies, patient groups are heterogeneous and therefore incomparable, and, often, long-term recurrence has not been observed in adequate numbers. However, most authors agree that perineal procedures might be less invasive than abdominal procedures, offering successful treatment in frail elderly patients with extensive comorbidity-5. A transabdominal procedure is generally considered more effective in healthy patients ${ }^{6.8}$ and can be combined with uteropexy or colpopexy when necessary. Laparoscopic repair-11 seems as effective as open surgery and results in faster convalescence and less postoperative pain ${ }^{12-15}$ Therefore, this approach has been advocated by many authors as probably the preferred technique. Whether standard sigmoid resection should be performed to prevent constipation remains debatable ${ }^{16-20}$. Division of the lateral ligaments should be avoided to prevent rectal dysfunction ${ }^{21}$. Whether anterior rectopexy leads to better functional results than posterior rectopexy, and mesh repair results in better effect and fewer complications than suture repair, remains unclear ${ }^{22}$.

Laparoscopic rectopexy, irrespective of the technique used, can be technically demanding. Robotic assistance in laparoscopic surgery may shorten the operating time as well as the learning curve in simple laparoscopic tasks ${ }^{23-26}$. Robot-assisted rectopexy has been proven safe and feasible ${ }^{27-28}$, but until now, no study has been performed comparing costs and time consumption in conventional laparoscopic rectopexy vs. robot-assisted rectopexy.

\section{MATERIAL AND METHODS}

Patients

From January I, 2004 through May I, 2006, 33 patients underwent laparoscopic rectopexy for rectal procidentia. They were non-randomly assigned to conventional laparoscopic (LR) or robotassisted (RR) laparoscopic surgery, using the four-armed da Vinci ${ }^{\circledR}$ surgical system if available. The indication for rectopexy was full-thickness rectal prolapse in all cases. Exclusion criteria were: younger than aged 18 years, patients unfit to undergo laparoscopic surgery, or "hostile abdomen" meaning patients with a medical history of extensive abdominal surgery, probably with multiple adhesions, which make them less accessible for laparoscopic surgery. Previous simple abdominal surgery was not considered a contraindication per se, nor was previous antiprolapse surgery. Both $L R$ and $R R$ were performed by the same surgical team.

\section{Procedure}

In the first II cases, a laparoscopic Wells'29 posterior sling procedure was performed. Since July I, 2004, general policy in our department shifted toward performing a minimal invasive d'Hoore's procedure $^{10}$ in order to minimize postoperative constipation. This change in technique was used irrespectively of the use of $L R$ vs. RR. In LR, a five-trocar technique was used. The rectosigmoid junction was retracted to the left and a peritoneal incision was made over the right side of the sacral promontory and extended in an inverted J-form along the rectum. The right hypogastric nerve was left undamaged while opening Denonvillier's fascia in male patients or the rectovagina septum in females. No lateral mobilization or lateral dissection was performed to maximally preserve rectal innervation. In Wells' procedure, a piece of polypropylene mesh (Dacron ${ }^{\circledR}$ ) vascular prosthesis is stapled to the sacral promontory using the Endopath ${ }^{\circledR}$ EMS tacker (Ethicon 
Endo-Surgery, Norderstedt, Germany) and wrapped at two sides around the lifted rectum where it is fixed on the anterolateral side, using GORE-TEX ${ }^{\circledR}$ sutures. In females with coexisting vaginal vault prolapse, the top of the vagina is fixed to the $\mathrm{Dacron}^{\circledR}$ mesh and the peritoneum is closed over the mesh. In d'Hoore's rectopexy, a $3 \mathrm{~cm} \times 17 \mathrm{~cm}$ strip of Dacron ${ }^{\oplus}$ is fixed to the sacral promontory by using an endofascial tacker device (Endopath ${ }^{\circledR}$ EMS) and then sutured to the ventral aspect of the distal rectum. The posterior vagina fornix is elevated and sutured to the anterior aspect of the mesh, closing the rectovaginal septum. The peritoneum is closed over the mesh.

In RR, the same procedure is performed by using the four-armed da Vinci ${ }^{\circledR}$ Surgical System (Intuitive Surgical Inc., Sunnyvale, CA, USA). The patient is positioned in a French steep Trendelenburg position. The four-armed robotic cart is positioned between the legs of the patient. Port placement is similar to that in LR, using a $12-\mathrm{mm}$ robotic camera port in the infraumbilical position and three $7 \mathrm{~mm}$ robotic ports controlled by the surgeon from behind the console. Another $12 \mathrm{~mm}$ trocar is placed supra-pubically to allow the assistant to retract the bladder and use the EMS stapler to fix the mesh to the promontory. Dissection and fixation is done as described in LR.

\section{Measurements}

Discharge criteria were identical for all patients. Patients resumed oral feeding within 24 hours if tolerated. They were discharged two days after surgery if sufficiently recovered and normal defecation had occurred. Laxatives were given when indicated. Accessory laboratory and radiologic examinations were only performed on indication. Primary end points were procedure time, hospital stay, and costs. Costs were calculated by using costs for hospital admission and treatment, material costs during surgery, salary costs (wages per hour for attending surgeons, anesthesiologists, residents and nurses, multiplied by the time spent in the operating room). Secondary end points were morbidity and mortality.

Statistical analysis was performed by using SPSS ${ }^{\circledast} 12$ (SPSS Inc., Chicago, III, USA). Pearson's $X^{2}$ test was used to compare nominal data between groups. A Mann-Whitney U non-parametric test for two independent samples was used to compare age, time, and costs. A p $\leq 0.05$ was defined as being statistically significant.

\section{RESULTS}

Preoperative characteristics

Thirty-three patients (22 females) with symptomatic full-thickness rectal prolapse were nonrandomly assigned to undergo LR or RR. In the LR group, 19 patients were included; 7 underwent a Wells' procedure and 12 underwent a d'Hoore's rectopexy. In the RR group, a Wells' rectopexy was performed in four patients and a d'Hoore's procedure in ten patients. Pre-operative, operative and post-operative characteristics are listed in tables I and 2. In the d'Hoore's rectopexy group, eight patients had undergone previous uterus extirpation vs. none in the Wells rectopexy group.
Table I.

Conventional laparoscopic versus Robot-assisted Rectopexy

\begin{tabular}{|c|c|c|c|c|}
\hline & $\begin{array}{l}\text { Total } \\
(\mathrm{n}=33)\end{array}$ & $\begin{array}{l}L R \\
(n=19)\end{array}$ & $\begin{array}{l}R R \\
(n=14)\end{array}$ & $P$ - value \\
\hline \multicolumn{5}{|l|}{ Pre-op characteristics } \\
\hline Gender, \% male & $33 \%$ & $29 \%$ & $37 \%$ & 0.618 \\
\hline Mean age, yrs & 52 yrs & $47 \mathrm{yrs}$ & 55 yrs & $0.021 *$ \\
\hline Previous abdominal surgery & $58 \%$ & $71 \%$ & $47 \%$ & 0.167 \\
\hline Previous prolapse surgery & $21 \%$ & $29 \%$ & $16 \%$ & 0.375 \\
\hline Previous uterus extirpation & $24 \%$ & $36 \%$ & $16 \%$ & 0.187 \\
\hline ASA-classification & 1.6 & 1.6 & 1.6 & 0.307 \\
\hline \multicolumn{5}{|l|}{ Operative characteristics } \\
\hline Operating time & $135 \mathrm{~min}$ & $113 \mathrm{~min}$ & $152 \min$ & $0.040 *$ \\
\hline Conversion & $3 \%$ & & $5 \%$ & 0.383 \\
\hline \multicolumn{5}{|l|}{ Post-op characteristics } \\
\hline Admission, days & 3.9 & 4.3 & 3.5 & 0.527 \\
\hline First post-op defaecation, days & 1.9 & 1.9 & 1.8 & 0.857 \\
\hline Post-op constipation $>5$ days & $15 \%$ & $14 \%$ & $16 \%$ & 0.905 \\
\hline Incontinence Gr 0 & $88 \%$ & $93 \%$ & $84 \%$ & 0.635 \\
\hline Incontinence Gr I & $3 \%$ & $0 \%$ & $5 \%$ & \\
\hline Incontinence Gr 2 & $9 \%$ & $7 \%$ & $11 \%$ & \\
\hline Procedure, \% d'Hoore & $67 \%$ & $71 \%$ & $63 \%$ & 0.618 \\
\hline \multicolumn{5}{|l|}{ Costs } \\
\hline Costs (salary) & $€ 463.22$ & $€ 386.35$ & $€ 519.87$ & $0.040 *$ \\
\hline Costs (instruments) & $€ 780.00$ & $€ 780.00$ & $€ 780.00$ & 1.000 \\
\hline Costs (use of da Vinci®) & $€ 511.95$ & $€ 0.00$ & $€ 889.18$ & $<0.005^{*}$ \\
\hline Costs (lab/X-ray etc) & $€ 18.44$ & $€ 18.04$ & $€ 18.73$ & 0.700 \\
\hline Costs (outpatient clinic) & $€ 47.80$ & $€ 47.80$ & $€ 47.80$ & 1.000 \\
\hline Costs (admittance) & $€ 1,615.00$ & $€ 1,883.36$ & $€ 1,417.26$ & 0.441 \\
\hline Costs (total) & $€ 3,436.4 I$ & $€ 3,115.55$ & $€ 3,672.84$ & $0.012 *$ \\
\hline
\end{tabular}

\section{Operative and postoperative characteristics}

Preoperative and postoperative complication rates were similar in the LR and RR groups, and also in the d'Hoore's and Wells' rectopexy group. However, average operation time is longer in robotic-assisted rectopexy (152 vs. II3 minutes) compared with conventional laparoscopy. D'Hoore's rectopexy is faster than Wells' procedure (I22 vs. 162 minutes). When comparing the costs of the procedures, it is clear that RR is more expensive than LR, both in salary and robot-associated costs, leading to higher total costs $(€ 3,672.84 \mathrm{vs.} € 3,115.55 ; \mathrm{p}=0.012)$. When comparing Wells' procedure vs. d'Hoore's rectopexy, the salary costs are higher in Wells' procedure $(€ 555.12$ vs. $€ 417.27 ; p=0.039)$, but the total costs remain unchanged $(€ 3,446.61$ vs. $€ 3,431.32 ; p=0.620)$.

Postoperative constipation was defined as the inability to pass stool more than five days after surgery. Postoperative incontinence was measured using the Parks-Browning classification for fecal incontinence. Grade I is full continence. Grade 2 is incontinence to flatus, Grade 3 is incontinence to liquid stool, and Grade 4 is incontinence to solid stool. Operative and postoperative characteristics are shown in tables I and 2 . 
Table 2.

Wells' versus d'Hoore's laparoscopic Rectopexy

$$
\begin{aligned}
& \text { Total } \\
& (n=33)
\end{aligned}
$$

d'Hoore

P - value

Pre-op characteristics

Gender, \% male

Mean age, yrs

Previous abdominal surgery

Previous prolapse surgery

Previous uterus extirpation

ASA-classification

$33 \%$

52 yrs

$58 \%$

$21 \%$

1.6

$135 \mathrm{~min}$

$3 \%$

Operating time

Conversion

Post-op characteristics

Admission, days

First post-op defaecation, days

Post-op constipation $>5$ days

Incontinence Gr 0

ncontinence $\mathrm{Gr}$

Procedure, \% da Vinci®

Costs

Costs (salary)

Costs (instruments)

Costs (use of da Vinci@)

Costs (lab/X-ray etc)

Costs (outpatient clinic)

Costs (admittance)

Costs (TOTAL)

$A S A=$ American Society of Anest

*

* $P$ value $<0.05$ was considered statistically significan

\section{DISCUSSION}

Robotic assistance in advanced laparoscopy leads to high-definition stereoscopic vision and intuitive tremor-filtrated movement of instruments, potentially attributing to safety and feasibility. In this study, we compared conventional laparoscopic vs. robot-assisted rectopexy. Statistical analysis showed that pre-operative characteristics, admissions, and complication rates were

similar between both groups, suggesting robot-assisted laparoscopic rectopexy is safe and feasible. However, the group size is limited, making it impossible to show a statistically significant decrease in complication rate. A follow-up study assessing functional results and complications is being performed, and results are expected soon. If robotic assistance does lead to a lower complication rate or better functional results, this could result in higher cost-effectiveness.

Robotic assistance in laparoscopic rectopexy results in a significantly increased operating time of 39 minutes. Increased time consumption in robot-assisted advanced laparoscopy was described previously ${ }^{30-32}$ in contrast to the beneficial effect of robotic assistance on time consumption in the performance of laparoscopic excercises ${ }^{23,24,26}$. Probably, part of this increase in time is caused by the relatively laborious effort to change robotic instruments and to the limited experience with robotic surgery at this moment.
The use of robotic assistance leads to increased salary costs (caused by increased time consumption) and increased material costs, which results in a total increase of $€ 557.29$ compared with LR. Along with the increasing experience with robotic surgery, the time needed to perform the operation is expected to decrease, resulting in diminished salary costs. Whether material costs will decrease in time remains unclear.

The Wells' procedure seemed more time consuming than the slightly less complex modified D'Hoore's rectopexy. However, because the Wells' rectopexy was performed before July I, 2004, whereas d'Hoore's rectopexy was performed after this date, the decreased operating time also might partly be a result of the proficiency curve. We did not find a statistically significant decreased number of patients with postoperative constipation performing d'Hoore's rectopexy compared with Wells' rectopexy, as might have been expected ${ }^{22}$.

\section{CONCLUSIONS}

Robotic assistance in laparoscopic rectopexy is a safe and feasible procedure but leads to a longer operating time and higher costs compared with conventional laparoscopy. Although robotic assistance has excellent vision and intuitive manipulation of instruments during surgery, this study did not show objective arguments to support the routine use of robotic assistance at this time. A follow-up study that assesses functional results and recurrences after robot assisted vs. conventional laparoscopic rectopexy is being conducted, and results are expected in a few months. Further prospective comparative trials are needed to assess the role of robotic assistance in laparoscopic surgery.

\section{ACKNOWLEDGEMENT}

The authors thank Mrs. Karin Baeten for assistance.

Rose SM. Classic articles in colonic and rectal surgery. Edmond Delorme 1847-1929. Dis Colon 


\section{REFERENCES}

Rectum 1985;28(7):544-53.

Williams JG, Rothenberger DA, Madoff RD, et al. Treatment of rectal prolapse in the

2 elderly by perineal rectosigmoidectomy. Dis Colon Rectum 1992;35(9):830-4.

Lasheen AE, Khalifa S, El Askry SM, et al. Closed rectopexy with transanal resection for

3 complete rectal prolapse in adults. J Gastrointest Surg 2005;9(7):980-4.

Watkins BP, Landercasper J, Belzer GE, et al. Longterm follow-up of the modified Delorme

4 procedure for rectal prolapse. Arch Surg 2003; I38(5):498-502.

Altemeier WA, Giuseffi J, Hoxworth P. Treatment of extensive prolapse of the rectum in

5 aged or debilitated patients. AMA Arch Surg 1952;65(I):72-80.

Chow PK, Ho YH. Abdominal resection rectopexy versus Delorme's procedure for

6 rectal prolapse: comparison of clinical and physiological outcomes. Int J Colorectal Dis 1996; I I (4):20I-2.

Penninckx F, D'Hoore A, Sohier S, et al. Abdominal resection rectopexy versus Delorme's

7 procedure for rectal prolapse: a predictable outcome. Int I Colorectal Dis 1997; I (I):49-50. Steele SR, Goetz LH, Minami S, et al. Management of recurrent rectal prolapse: surgical

8 approach influences outcome. Dis Colon Rectum 2006;49(4):440-5.

Zittel TT, Manncke K, Haug K, et al. Functional results after laparoscopic rectopexy for

9 rectal prolapse. J Gastrointest Surg 2000;4(6):632-4I.

D'Hoore A, Cadoni R, Penninckx F. Long-term outcome of laparoscopic ventral rectopexy

10 for total rectal prolapse. Br J Surg 2004;9I(II): 1500-5.

Rose J, Schneider C, Scheidbach H, et al. Laparoscopic treatment of rectal prolapse:

II experience gained in a prospective multicentre trial. Langenbeck's Arch Surg 2002;387(34): $130-7$.

Solomon MJ, Young CJ, Eyers AA, et al. Randomized clinical trial of laparoscopic versus

12 open abdominal rectopexy for rectal prolapse. Br.J Surg 2002;89(I):35-9.

Kairaluoma MV, Viljakka MT, Kellokumpu IH. Open vs. laparoscopic surgery for rectal

13 prolapse: a casecontrolled study assessing short-term outcome. Dis Colon Rectum 2003;46(3):353-60.

Purkayastha S, Tekkis P, Athanasiou T, et al. A comparison of open vs. laparoscopic

14 abdominal rectopexy for full-thickness rectal prolapse: a meta-analysis. Dis Colon Rectum 2005;48(10):1930-40.

Kariv Y, Delaney CP, Casillas S, et al. Long-term outcome after laparoscopic and open

15 surgery for rectal prolapse: a case-controlled study. Surg Endosc 2006;20(I):35-42. Benoist S, Taffinder N, Gould S, et al. Functional results two years after laparoscopic

16 rectopexy. Am J Surg 200I;182(2):168-73.

Heah SM, Hartley JE, Hurley J, et al. Laparoscopic suture rectopexy without resection is

17 effective treatment for full-thickness rectal prolapse. Dis Colon Rectum 2000;43(5):638-43. Lechaux JP, Atienza P, Goasguen N, et al. Prosthetic rectopexy to the pelvic floor and

18 sigmoidectomy for rectal prolapse. Am J Surg 200 ; 182(5):465-9.

Basse L, Billesbolle $\mathrm{P}$, Kehlet $\mathrm{H}$. Early recovery after abdominal rectopexy with multimodal

19 rehabilitation. Dis Colon Rectum 2002;45(2): 195-9.

Ashari LH, Lumley JW, Stevenson AR, et al. Laparoscopically-assisted resection rectopexy

20 for rectal prolapse: ten year's experience. Dis Colon Rectum 2005;48(5):982-7.

Scaglia M, Fasth S, Hallgren T, et al. Abdominal rectopexy for rectal prolapse. Influence of
21 surgical technique on functional outcome. Dis Colon Rectum 1994:37(8):805-13.

Schiedeck TH, Schwandner O, Scheele J, et al. Rectal prolapse: which surgical option is

22 appropriate? Langenbecks Arch Surg 2005;390(I):8-I4.

Yohannes P, Rotariu P, Pinto P, et al. Comparison of robotic versus laparoscopic skills: is

23 there a difference in the learning curve? Urology 2002;60(I):39-45.

Hernandez JD, Bann SD, Munz T, et al. Qualitative and quantitative analysis of the learning

24 curve of a simulated surgical task on the da Vinci ${ }^{\circledR}$ system. Surg Endosc 2004; 18(3):372-8 Sarle R, tewari A, Shrivastava A, et al. Surgical robotics and laparoscopic drills. J Endourol

$25 \quad 2004 ; 18(I): 63-6$

Heemskerk J, Zandbergen HR, Maessen JG, et al. Advantages of advanced laparoscopic

26 systems. Surg Endosc 2006;20(5):730-3

Munz Y, Moorthy K, Kudchadkar R, et al. Robotic assisted rectopexy. Am J Surg

27 2004; I87(I):88-92

Ayav A, Bresler L, Hubert J, et al. Robotic-assisted pelvic organ prolapse surgery. Surg

28 Endosc 2005;19(9):1200-3

Himpens J, Cadiere GB, Bruyns J, et al. Laparoscopic rectopexy according to Wells. Surg

29 Endosc 1999; |3(2):|39-4|

Heemskerk J, van Dam R, van Gemert WG, et al. Robot-assisted versus conventional

30 laparoscopic Nissen fundoplication. A comparative retrospective study on costs and time consumption. SLEPT 2007;17(I): I-4

Morino M, Pellegrino L, Giaccone C, et al. Randomized clinical trial of robot-assisted versus

31 laparoscopic Nissen fundoplication. Br J Surg 2006;93(5):553-8

Morino M, Beninca G, Giraudo G, et al. Robot-assisted vs. laparoscopic adrenalectomy: a

32 prospective randomized controlled trial. Surg Endosc 2004:18(I2):1742-6 


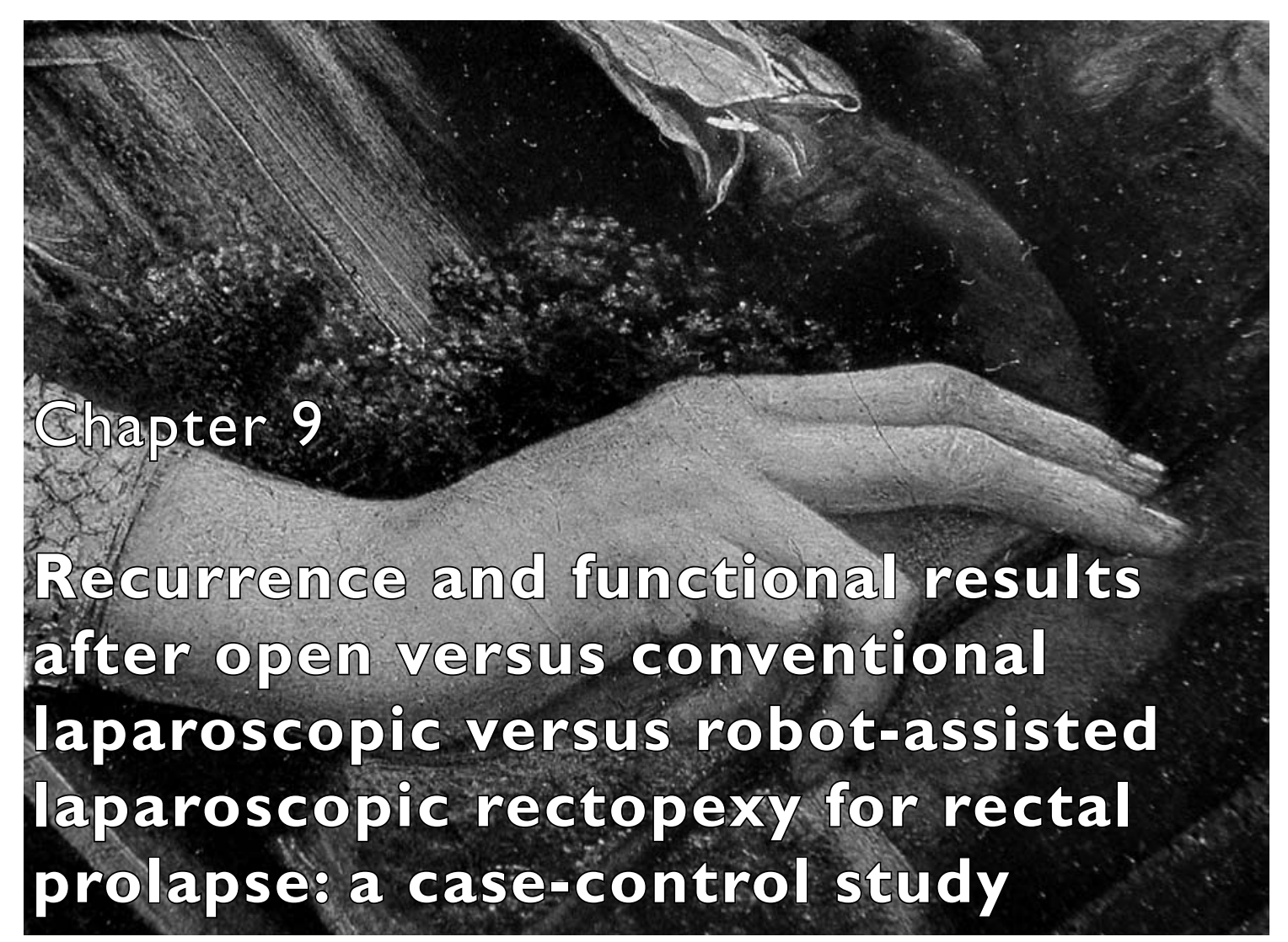

Previously published as:

Recurrence and functional results after open versus conventional laparoscopic versus robotassisted laparoscopic rectopexy for rectal prolapse: a case-control study De Hoog DENM, Heemskerk J, Nieman FHM, van Gemert WG, Baeten CGMI, Bouvy ND. Int J Colorectal Dis 2009;24(I0): I 201-6

DETAIL FROM: ANNUNCIATION

OIL AND TEMPERA ON WOODEN PANEL

The angel holds a Madonna lily, a symbol of Mary's virginity and of the city of Florence. 


\section{ABSTRACT}

Background: This study was designed to evaluate recurrence and functional outcome of three surgical techniques for rectopexy: open (OR), laparoscopic (LR), and robot-assisted (RR). A casecontrol study was performed to study recurrence after the three operative techniques used for recta I procidentia. The secondary aim of this study was to examine the differences in functional results between the three techniques.

Methods: All consecutive patients who underwent a rectopexy between January 2000 and September 2006 enrolled in this study. Peri-operative data were collected from patient records and functional outcome was assessed by telephonic questionnaire.

Results: Eighty-two patients (7I females, mean age 56.4 years) underwent a rectopexy for rectal procidentia. Nine patients (II\%) had a recurrence; one $(2 \%)$ after OR, four $(27 \%)$ after LR, and four $(20 \%)$ after RR. RR showed significantly higher recurrence rates when controlled for age and follow-up time compared to OR, $(P=0.027)$, while $L R$ showed near significant higher rates $(P$ $=0.059)$. Functional results improved in all three operation types, without a difference between them.

Conclusion: $L R$ and $R R$ are adequate procedures but have a higher risk of recurrence. A RCT is needed assessing the definitive role of (robotic assistance in) laparoscopic surgery in rectopexy.

\section{INTRODUCTION}

Rectal procidentia frequently occurs in older women. The male-to-female ratio is 1:6 with a peak incidence between 50 and 60 years of age'. Patients usually present with obstructed defecation or fecal incontinence.

Controversy exists regarding the preferred surgical technique for the treatment of rectal procidentia. The transabdominal procedure is generally considered more effective in healthy patients compared to perineal procedures ${ }^{2-5}$. Laparoscopic repair seems as effective as open surgery ${ }^{6-9}$ with possible advantages such as faster recovery, less blood loss, lower medical costs, and less post-operative pain ${ }^{10-13}$. Therefore, many authors have advocated this approach as the preferential technique $10,11,14$.

At our hospital robot-assisted laparoscopic rectopexy (RR) has been performed since 2003. The $\mathrm{daVinci}{ }^{\circledR}$ robot combines the advantages of the laparoscopic technique, such as faster recovery and less post-operative pain, with the advantages of open surgery, namely the high-quality threedimensional vision, restoration of the eye-hand-target axis and the use of an advanced instrument offering a full six degrees of freedom in handling ${ }^{15-17}$. However, there is a suspicion of a higher recurrence rate in the minimal invasive procedure as compared to the conventional procedure most likely due to the differences in fixation of the rectum to the promontory. This study was performed to investigate the effectiveness of laparoscopic rectopexy (LR) and RR compared to open rectopexy (OR) in terms of recurrence rates. The secondary goal was to determine the difference in functional outcome. This was done by measuring differences between these procedures in terms of constipation, fecal incontinence, and the impact on the patients' daily life.

\section{MATERIAL AND METHODS}

\section{Patients}

Eighty-two patients underwent a rectopexy for rectal procidentia at Maastricht University Medical Center between January 2000 and September 2006. They were non randomly assigned to open, conventional laparoscopic, or robot-assisted rectopexy. The inclusion criterion for rectopexy was full thickness rectal prolapse in all cases. Exclusion criteria for the study were age under 18 or patient unfit for surgery. Patients with a "hostile abdomen" after extensive abdominal surgery were excluded from the study as they were deemed eligible for an OR only. Previous abdominal surgery was not considered a contra-indication for LR or RR per se, nor was previous antiprolapse surgery. All operations were performed by the same team with all extensive experience in advanced minimal invasive techniques, including laparoscopic d'Hoore's rectopexy. Patients were post-operatively asked to participate in a structured interview. Results of the questionnaire were used for analysis after informed consent was obtained.

\section{Procedure}

In the first 42 patients, a Wells' procedure was performed. After rectal mobilization a posterior mesh rectopexy was performed (first described by Wells in 1959) ${ }^{18}$. Since July 2004, the genera policy in our department shifted from a modified Wells' procedure towards a d'Hoore's ventral mesh rectopexy in order to minimize the risk for autonomic neural damage and therefore postoperative constipation6. Ventral mobilization of the rectum was performed with fixation of the mesh to the promontory through suture or staple. The mesh was then sutured on the ventral side of the stretched rectum. In females, this procedure included fixation of the mesh to the top of the vagina or uterus.

LR and RR were performed as previously described by our unit ${ }^{19}$. In RR, we used the four- 
armed da Vinci ${ }^{\circledR}$ Surgical System (Intuitive Surgical Inc., CA, USA). The patient is positioned in a French steep Trendelenburg position. The four-armed robotic patient-side cart is positioned between the legs of the patient. The port placement is similar in LR and RR. A I $2 \mathrm{~mm}$ port is placed in the infra-umbilical position for the camera. Three $5 \mathrm{~mm}$ ports are placed in LR, and $7 \mathrm{~mm}$ robotic ports are placed in $\mathrm{RR}$ and controlled by the surgeon from behind the console. Another $12 \mathrm{~mm}$ trocar is placed supra-pubic to allow the assistant to retract the bladder and use a tacker (Endopath ${ }^{\circledR}$ EMS tacker, Ethicon Endo-Surgery, Norderstedt, Germany) to fix the mesh (polypropylene mesh, Dacron ${ }^{\circledR}$ ) to the promontory. Dissection and fixation is done as described by d'Hoore'.

Discharge criteria were equal for all patients. Patients resumed oral feeding within $24 \mathrm{~h}$ if tolerated. Laxatives were given when indicated. Discharge was only approved after sufficient recovery, no intravenous analgesia, defecation, and adequate oral intake.

\section{MEASUREMENTS}

The primary outcome of the study was the recurrence rate after the various surgical techniques. Secondary outcome parameters were complications, post-operative recovery, functional results, and quality of life. The standardized Wexner constipation score was used to investigate the level of constipation before and after the operation ${ }^{20}$. The Parks-Browning classification was used to grade fecal incontinence ${ }^{21}$

The impact of the surgical procedures on daily life as judged by the patient was scored on an ordinal scale ( 0 is unbearable/maximally incapacitated to 10 which is no impact at all), further referred to as the IDL score.

\section{STATISTICS}

Metric data, if normally distributed, are presented as means and standard deviations and categorical data as frequencies and percentages. To test for normality of distributions the Kolmogorov-Smirnov test is used. In univariate statistics for recurrence loglikelihood chisquares, odds ratios and its $95 \%$ confidence intervals $(95 \% \mathrm{Cl}$ ) are presented for (risk) factors and variables examined in the study (table I). A multivariate logistic regression analysis is used to search for statistical significance of effects belonging to these risk factors and variables. Backward elimination technique and change in loglikelihood chi-squares is used to find the best-fitting model. The final model for recurrence containing only statistically significant effects is presented as a table with net odds ratios and $95 \% \mathrm{Cl}$ (table 2). To test for differences in operating time between the three types of operations the Univariate overall analysis of variance (ANOVA) F ratio is used, and $P$ values for separate $t$ tests are Bonferroni-adjusted in multiple comparisons. To test for differences in post-operative hospital stay between the three types of operations the Kruskal-Wallis (K-W) test is used. For the analysis of (differences in) pre-operative and postoperative Wexner-scores (or IDL scores) paired $t$ tests and repeated measures ANOVA were done and $F$ ratios, df's and $p$ -values are presented. Statistical analysis was performed using SPSS I5 (SPSS Inc., Chicago, USA). A $p$-value $<0.05$ was defined as being statistically significant.

\section{RESULTS}

A total of 82 patients (7I females, $87 \%$ ) with a mean age of 56.4 years (range, $2 \mathrm{I}-88$ ) were included and underwent OR $(n=47,57 \%), L R(n=15,18 \%)$, or $R R(n=20,24 \%)$ for rectal procidentia. Eighty-two patients were eligible for follow-up. Seventy-two $(90 \%)$ patients answered the questionnaire (M:F=10:62). Reasons for not taking part were: inaccessibility (four), psychological illness (three), and unwillingness to participate (one). Two patients died during follow-up as a result of non-related causes.

\section{Pre-operative characteristics}

Forty-one (50\%) patients had fecal incontinence (including grade 4 incontinence in 35 patients). Other complaints were constipation $(n=29,35 \%)$. Fifty-one of the 71 women $(72 \%)$, have had hysterectomy. Indication for previous hysterectomy was prolapse of the uterus in 25 patients $(35 \%)$

\section{Operative characteristics}

Mean operation time was $77 \pm 33 \mathrm{~min}$ in OR, $119 \pm 31 \mathrm{~min}$ in $L R$, and $154 \pm 47 \mathrm{~min}$ in RR (ANOVA $F=33.37$ by 2 and $79 \mathrm{df} ; \mathrm{p}<0.00 \mathrm{I}$ ). Bonferroni-adjusted $\mathrm{p}$-values for multiple tests are: OR-LR $p=0.00 I$, OR-RR $p<0.00$ I, LR-RR $p=0.020$. Median follow-up time in the study was 1.95 years (mean 2.6; range 0.2-8.0). There was no statistical significant difference in operation time between the Wells' and the d'Hoore's rectopexy (99 versus $107 \mathrm{~min} ; \mathrm{p}=0.192$ ).

Thirty-five patients had a rectopexy through EMS fixation. Five patients $(14.3 \%)$ in this group had a recurrence. Three out of five $(60 \%)$ had documented failure of the fixation. In contrast, four out of 47 patients $(8.5 \%)$ in the sutured group had a recurrence. None was documented as a release of the suture from the promontorium.

\section{Post-operative characteristics}

Patients were discharged from the hospital after a median of three days (range I-30, SD 3.94). Mean length of stay per operation type were: OR 5.7 days (range 2-30), LR 3.5 days (range I-14), and RR 2.6 days (range $1-6 ; p<0.00 \mathrm{I}$ ). After surgery, there was a large number of complications $(42.7 \%)$ : urine retention $(3.7 \%)$, cystitis $(20.7 \%)$, wound infection $(4.9 \%)$, bowel obstruction $(6.1 \%)$ and incisional hernia $(2.4 \%)$

\section{Recurrences}

Nine (I I\%) of the 82 patients developed a recurrence. Recurrences (Table I) were more frequent after both minimal invasive rectopexy types compared to open surgery (respectively LR $27 \%$ and $R R 20 \%$ versus OR $2 \%$; $p=0.008$ ). Recurrence occurs significantly more often in younger patients in childbearing age $(p=0.003)$, especially below the age of $40(50 \%$ vs. $6 \%$ above the age of $60 ; p=0.002)$. Males are more likely to get a recurrence $(p=0.013)$, and fixation of the vaginal vault (in patients with previous hysterectomy) protect against recurrence $(p=0.009)$. Patients under the age of 40 were more likely to undergo conventional laparoscopic procedures (six out of ten). From the age of 40 OR is significantly more present (44\% in the age $40-60$ years and $73 \%$ above 60 ).

Logistic regression analysis was performed with backward elimination procedure using - next to operation type - age, previous abdominal surgery, and previous uterus surgery as possible risk factors for recurrence. Multivariate analysis was repeated for all patients $(n=82)$, using-next to operation type and follow-up time, gender, age, and previous abdominal surgery as risk factors. The final model now includes - next to operation type and follow-up time - only age. Results of this model are presented in Table 2.

\section{Functional results}

The mean Wexner score decreased from $13.4 \pm 7.5$ to $10.3 \pm 7$.I post-operatively $(p<0.001)$. The mean IDL score decreased from $8.3 \pm 1.5$ to $4.8 \pm 2.7$ post-operatively $(\mathrm{p}=0.04 \mathrm{I})$. Repeated measures ANOVA was performed to test for differences in IDL- and Wexner trends for the three operation types. To test for homogeneity of the decrease in Wexner score over the 


\begin{tabular}{|c|c|c|c|c|c|c|c|}
\hline Paramcter & Cancgory & N & three & $x_{L}^{2}$ & $p$ value & Odds ratio & $95 \% \mathrm{Cl}$ \\
\hline \multirow[t]{3}{*}{ Operation type } & OR & 47 & 2.1 & 9.652 & $0.008^{*}$ & - & - \\
\hline & LR & 15 & 26.7 & & & 16.73 & $1.68-164.88$ \\
\hline & $\mathrm{RR}$ & 20 & 20.0 & & & 11.50 & $1.195-110.641$ \\
\hline \multirow[t]{2}{*}{ Operation type dichotony } & O,en & 47 & 2.1 & 9.438 & $0.002^{*}$ & & \\
\hline & Minimally imvasive & 35 & 22.9 & & & 13.63 & $1.62-114.98$ \\
\hline Follow-up time (yeans) & - & - & - & 0.116 & 0.734 & 1.07 & $0.73-1.56$ \\
\hline \multirow[t]{2}{*}{ Procedure } & Well's & 40 & 12.5 & 0.186 & 0.666 & 0.737 & $0.183-2.966$ \\
\hline & D'Hoore & 42 & 9.5 & & & & \\
\hline \multirow[t]{2}{*}{ Gender } & Female & 71 & 7 & 6.152 & $0.013^{*}$ & 7.543 & $1.636-34.774$ \\
\hline & Make & 11 & 36.4 & & & & \\
\hline Age (yean) & & & & $8.94 k$ & $0.003^{*}$ & $0.92 \mathrm{~B}$ & $0.881-0.978$ \\
\hline \multirow[t]{3}{*}{ A } & $\leq 40$ & 10 & 50.0 & & & 15.500 & $2336-102.848$ \\
\hline & $40-60$ & 39 & 5.1 & & & 0.838 & $0.111-6.298$ \\
\hline & $>60$ & 33 & 6.1 & 12.015 & $0.002^{*}$ & - & - \\
\hline \multirow[t]{3}{*}{ ASA } & 1 & 29 & 13.8 & 0.646 & 0.724 & - & - \\
\hline & 2 & 37 & 10.8 & & & $0.75 \mathrm{~s}$ & $0.172-3.328$ \\
\hline & 3 & 16 & 63 & & & 0.417 & $0.042-4.085$ \\
\hline \multirow[t]{2}{*}{ Abdominal surgery in history } & No & 28 & 21.4 & 4.476 & $0.034^{*}$ & 0.216 & $0.049-0.941$ \\
\hline & Yes & 54 & 36 & & & & \\
\hline \multirow[t]{2}{*}{ Constipetion in history } & No & 53 & 113 & 0.018 & 0.892 & 0.904 & $0.209-3.917$ \\
\hline & Yes & 29 & 10.3 & & & & \\
\hline
\end{tabular}

"irec percentage of recurreche

" $p<0$ os Statistically significan

"Reference group is age $>60$ yean of age

different operation types the $F$ ratio is 0.001 by 2 and 69 degrees of freedom $(p=0.999)$. The $F$ ratio for decrease in IDL differences between the three operation types is I. 183 by 2 and 69 degrees of freedom $(p=0.313)$. Therefore, no differences were found for either decrease in Wexner score or IDL score between the three operation types (table 3).

Urinary incontinence increased after rectopexy (22 patients suffered from stress, urge, or mixed incontinence before versus 27 patients after the operation). Fecal incontinence was still present in

Table 2. Final model logistic analysis results for recurrence $(n=82)$

$\quad 95 \% \mathrm{Cl}$

Follow-up time

Operation

LR vs. OR

RR vs. OR

1.54

0.103

$0.92-2.59$

Age

13.94
24.41

0.08

0.059

0.027

0.93

0.024

$0.90-215.58$

$1.45-410.65$

$0.87-0.99$
27 patients (33\%). In 15 of the $42(36 \%)$ patients the fecal incontinence improved after rectopexy. Fifty percent of the patients needed laxatives during admission. Twenty-nine percent of the patients were still using laxatives at time of the questionnaire. The use of the rectal irrigation pump for intractable constipation and/or fecal incontinence increased from $4 \%$ during hospital stay to $21 \%$ at time of the questionnaire.

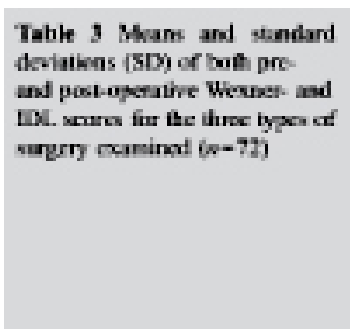

\begin{tabular}{|c|c|c|c|c|c|c|c|c|c|}
\hline \multirow[b]{2}{*}{ Operatin bpe } & \multicolumn{2}{|c|}{ mewex } & \multicolumn{2}{|c|}{ post-wet } & \multicolumn{2}{|c|}{ pre-1DC } & \multicolumn{2}{|c|}{$p 0 s-1 D t$} & \multirow[b]{2}{*}{$N$} \\
\hline & Man & SD & Mean & SD & Mean & SD & Mean & so & \\
\hline oR & 14.30 & 6.003 & 11.15 & 6.702 & 8.25 & 1.881 & 5.10 & 2.408 & 40 \\
\hline L.R & 13.98 & 8.039 & 10.60 & 9.206 & 8.42 & 1.379 & 3.92 & 3.343 & 12 \\
\hline RR & 11.90 & $8: 909$ & 8.20 & 6.355 & 8.35 & 1.309 & 4.75 & 2.552 & 20 \\
\hline Toul & 13.43 & 9.477 & $10.2 \mathrm{~s}$ & 7.059 & 8.31 & $1 .+60$ & 4.31 & 2.646 & $n$ \\
\hline
\end{tabular}

\section{DISCUSSION}

In this study we compared conventional laparoscopic, robot-assisted laparoscopic, and open rectopexy. However, it remains difficult to really determine the influence of either technique on the outcome in a limited population. Open surgery seems to lead to less recurrences. Several reasons may explain the disappointing results after minimal invasive rectopexy. A possible explanation might be the use of different fixation instruments or techniques.

Besides the differences in results due to technical failure, there is a possibility that OR leads to more adhesions, resulting in a more firm fixation of the rectum to the promontory and subsequently less recurrences. However, if recurrence rates are statistically corrected for age, the differences in recurrence rate for the various operative techniques become statistically nonsignificant. One explanation of this difference in outcome between females in childbearing age and older patients might be the fact that there was no combined rectovaginopexy with fixation of the top of the vagina in the younger group. LR and RR result in a significant increased operating time compared to OR, respectively 42 and 77 min more.

Increased time consumption in robot-assisted advanced laparoscopy was described before ${ }^{13,22,23}$ in contrast to the beneficial effect of robotic assistance on time consumption in the performance of laparoscopic training drills ${ }^{15,24,25}$. Probably, part of this increase in time consumption is due to the relative extensive effort exchanging robotic instruments and due to still relative limited experience with robotic surgery at this moment.

The use of laparoscopic techniques leads to similar functional results when comparing the different parameters measured as described before, such as the constipation, incontinence, and IDL scores pre- and post-operatively.

\section{CONCLUSION}

Minimal invasive techniques (conventional laparoscopic and robotic assisted) for rectopexy can be performed safely with similar functional results but possibly at the expense of higher recurrence rates. Fixation of the top of the vagina or uterus results in better fixation and therefore less recurrences. Rectovaginopexy was performed mainly on older patients. Wellpowered randomized controlled trials are needed to eliminate selection bias and assess the definite role of (robotic assistance in) laparoscopic surgery in rectopexy. 


\section{REFERENCES}

I van Lanschot JJB, Gouma DJ, Schouten WR, et al. Gastro-intestinale chirurgie en gastroenterologie in onderling verband. 1999. Bohn Stafleu Van Loghum, Houtem.

2 Altemeier WA, Giuseffi J, Hoxworth P. Treatment of extensive prolapse of the rectum in aged or debilitated patients. AMA Arch Surg 1952;65(I):72-80

3 Chow PK, Ho YH. Abdominal resection rectopexy versus Delorme's procedure for rectal prolapse: comparison of clinical and physiological outcomes. Int J Colorectal Dis 1996; I I (4):20I-2

4 Penninckx F, D'Hoore A, Schier S, et al. Abdominal resection rectopexy versus Delorme's procedure for rectal prolapse: a predictable outcome. Int J Colorectal Dis 1997; I (I):49-50

5 Rose SM. Classic articles in colonic and rectal surgery. Edmond Delorme 1847-1929. Dis Colon Rectum 1985;28(7):544-53.

6 D'Hoore A, Cadoni R, Penninckx F. Long-term outcome of laparoscopic ventral rectopexy for total rectal prolapse. Br J Surg 2004;9 ( I I): I500-5

7 Rose J, Schneider C, Scheidbach H, et al. Laparoscopic treatment of rectal prolapse: experience gained in a prospective multicenter study. Langenbecks Arch Surg 2002;387(34): $130-7$

8 Solomon MJ, Young CJ, Eyers AA, et al. Randomized clinical trial of laparoscopic versus open abdominal rectopexy for rectal prolapse. Br J Surg 2002;89( I ):35-9

9 Zittel TT, Manncke K, Haug S, et al. Functional results after laparoscopic rectopexy for rectal prolapse. J Gastrointest Surg 2000;4(6):632-4I

10 Kairaluoma MV, Viljakka MT, Kellokumpu IH. Open vs. laparoscopic surgery for recta prolapse: a case-controlled study assessing short-term outcome. Dis Colon Rectum 2003;46(3):353-60

II Kariv Y, Delaney CP, Casillas S, et al. Long-term outcome after laparoscopic and open surgery for rectal prolapse: a case-control study. Surg Endosc 2006;20(I):35-42

12 Purkayastha S, Tekkis P, Athanasiou T, et al. A comparison of open vs. laparoscopic abdominal rectopexy for full-thickness rectal prolapse: a meta $\urcorner$ analysis. Dis Colon Rectum 2005;48(10): 1930-40

I3 Heemskerk J, van Gemert WG, Greve JW, et al. Robot 7 assisted versus conventional aparoscopic Nissen fundoplication: a comparative retrospective study on costs and time consumption. Surg Laparosc Endosc Percutan Tech 2007;17(1):1-4

14 Kessler H, Hohenberger W. Laparoscopic resection rectopexy for rectal prolapse. Dis Colon Rectum 2005;48(9): 1800-1

15 Heemskerk J Zandbergen HR, Maessen JG, et al. Advantages of advanced laparoscopic systems. Surg Endosc 2006;20(5):730-3

I6 Ayav A, Bresler L, Hubert J, et al. Robotic-assisted pelvic organ prolapse surgery. Surg Endosc 2005; 19 (9): 1 200-3

17 Munz Y, Moorthy K, Kudchadkar R, et al. Robotic assisted rectopexy. Am J Surg 2004; I87(I):88-92

18 Wells C. New operation for rectal prolapse. Proc R Soc Med 1959;52:602-3

19 Heemskerk J, de Hoog DE, van Gemert WG, et al. Robot-assisted vs. conventiona laparoscopic rectopexy for rectal prolapse: a comparative study on costs and time. Dis Colon Rectum 2007;50(1 I): 1825-30

20 Agachan F, Chen T, Pfeifer J, et al. A constipation scoring system to simplify evaluation and management of constipated patients. Dis Colon Rectum 1996;39(6):68I-5

Browning GG, Parks AG. Post-anal repair for neuropathic faecal incontinence: correlation of clinical result and anal canal pressures. Br J Surg 1983;70(2): I0I-4
2I Morino M, Beninca G, Giraudo G, et al. Robot-assisted vs laparoscopic adrenalectomy: a prospective randomized controlled trial. Surg Endosc 2004; I 8( I 2): I 742-6

22 Morino M, Pellegrino L, Giaccone C, et al. Randomized clinical trial of robot-assisted versus aparoscopic Nissen fundoplication. Br J Surg 2004;93(5):553-8

23 Hernandez Fernandez C. Finalidad de los cursos de adiestramiento practico. (Purpose of the practical training courses). Actas Urol Esp 2006;30(5):46I-3

24 Yohannes P, Rotariu P, Pinto P, et al. Comparison of robotic versus laparoscopic skills: is there a difference in the learning curve? Urology 2002;60(I):39-45 


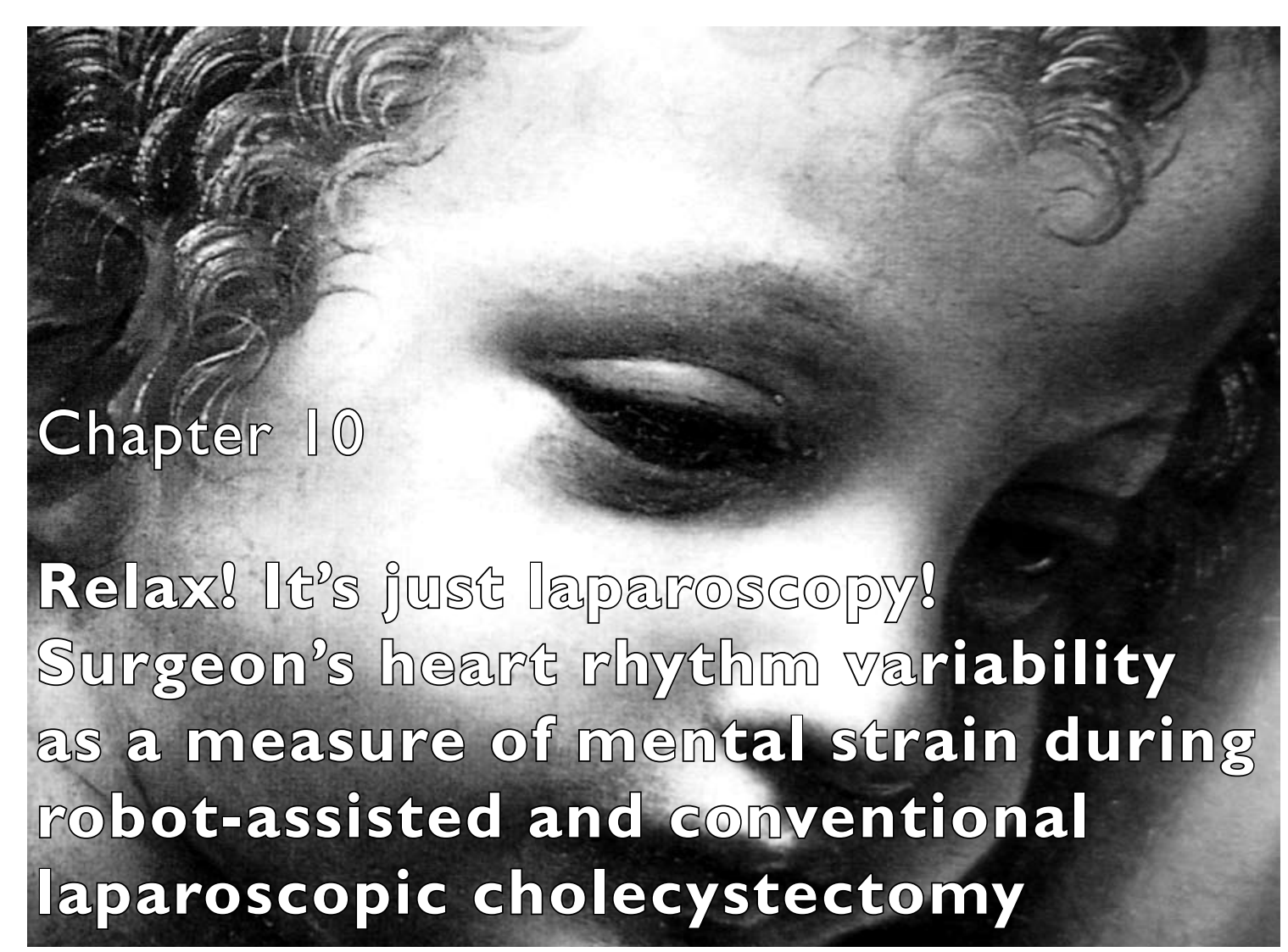

\section{Submitted as:}

Relax, it's just laparoscopy!

A prospective randomized trial on Heart Rate Variability of the Surgeon in Robot-assisted versus Conventional Laparoscopic Cholecystectomy.

Heemskerk J, Zandbergen HR, Keet S, Martijnse I, van Montfort G, Peters RJA, Bouwman RA, Baeten CGMI, Bouvy ND 


\section{ABSTRACT}

Background: Laparoscopic surgery might be beneficial for the patient, but it imposes increased physical and mental strain on the surgeon. Robot-assisted laparoscopic surgery addresses some of the laparoscopic drawbacks and may potentially reduce mental strain. This could reduce the risk of surgeon's fatigue, mishaps and stress-induced illnesses, which may eventually improve the safety of laparoscopic surgical procedures.

Methods: To test this hypothesis, a randomized study was performed, comparing both heart rate and heart rate variability (HRV) of the surgeon as a measure of total and mental strain respectively, during conventional- and robot-assisted laparoscopic cholecystectomy.

Results: Both heart rate and the low frequency band/high frequency band ratio (LF/HF ratio) were significantly decreased using robotic assistance.

Conclusions: These data suggest the use of the $\mathrm{daVinci}^{\circledR}$ Surgical System leads to less physical and less mental strain of the surgeon during surgery. However, assessing significant mental strain by means of heart rate variability is cumbersome since there is no clear cut-off point or scale for critical mental strain during surgery.

\section{INTRODUCTION}

The demanding nature of surgery poses significant physical and mental strain on surgeons. Increased sympathetic activity increases mean heart rate over 120/min during surgery. Peak heart rates well over 150/min secondary to catecholamine release have been reported'. Although laparoscopic surgery is beneficial for patients in terms of post-operative pain, convalescence and duration of hospital admission, various drawbacks may contribute to increased mental and physical strain for the surgeon. Drawbacks include impaired visual perception of depth, use of long inflexible instruments and the fulcrum effect (movement of the tips of the instruments in the opposite direction of the movement of the handles of the instrument). In particular, advanced laparoscopic procedures compared to conventional open surgery are more time consuming and exhausting, and may thus contribute to an increase in mental strain ${ }^{2}$. Mental strain has been identified as a risk factor for the development of myocardial infarction, hypertension, atherosclerosis, arrhythmia, heart failure and sudden death. This might account for the impaired health of physicians and other professionals suffering from high work-related mental strain ${ }^{3-6}$.

Robotic assistance in laparoscopic surgery addresses some of these drawbacks potentially leading to faster, more accurate and less exhausting surgery. However, despite numerous comparative studies these expected clinical benefits of robot-assisted laparoscopy over conventional laparoscopy in terms of time consumption, complication rate or cost-effectivity have not been demonstrated. Improved ergonomics from robotic assistance may reduce operative mental strain of the surgeon, leading to reduced fatigue, less complications and perhaps to a better outcome. In addition, it might reduce stress-induced illness of the surgeon.

While stress comprises all objective environmental factors influencing an individual, strain is defined as the physical and psychological effects of this stress on the individual ${ }^{2}$. A variety of conditions or stressors (even under defined stress conditions) may give rise to different physical responses and different perceived levels of strain. This depends on coping mechanisms, previous experience, level of training and the emotional status of the surgeon at a specific time. Therefore, perceived mental strain seems to be more relevant than stress. Although total strain is probably best assessed by measuring heart rate and physical strain is best measured by physical activity, mental strain can be best assessed by measuring heart rate variability (HRV) of the surgeon ${ }^{7}$. HRV is the quantitative assessment of beat-to-beat variation in heart rate reflecting parasympathetic and sympathetic control of the sino-atrial node. The autonomic nervous system is a major determinant of the functional properties of the heart in that it alters spontaneous sinus node depolarization and cardiac rhythm. Increased mental strain leads to a more regular heart rhythm and thus decreased HRV ${ }^{8-10}$. In particular, the low-frequency component (LF) increases whilst the highfrequency component (HF) decreases. Previously, intra-operative HRV-measurements in surgeons performing general" or thoracic surgery ${ }^{12}$ showed significant increased heart rate and a decreased HRV in surgeons.

In this study, we investigated the level of experienced mental strain of the surgeon performing robot-assisted laparoscopic surgery compared to conventional laparoscopic surgery. In particular, we decided to differentiate between stress and strain. We hypothesized that the use of roboticassisted laparoscopy might improve ergonomics and therefore might decrease mental strain compared to conventional laparoscopy, bringing heart rate variability levels back to similar levels as in open surgery while still offering the benefits of laparoscopic surgery to the patient. 


\section{MATERIAL AND METHODS}

Participants

In order to minimize inter-individual variations, only two surgeons (one female and one male) participated in this study (IM and GvM). In order to reduce external influences as much as possible, pre-operative activities were standardized ${ }^{13,14}$. The procedures were performed after at least 7 hours of sleep the night before. Participants refrained from smoking, alcohol and caffeine-containing beverages from 24 hours before the surgical procedure. The participants were cardiovascular healthy and used no cardiac modifying medication.

\section{ECG recording}

R-R intervals were obtained from standard bipolar ECG leads connected to a recorder. The electrocardiogram recorded continuously with a sample rate of $400 / \mathrm{s}$. All digital data were transferred to a personal computer after surgery for off-line analysis. Using one baseline and six well-defined stages in the surgical procedure as explained in table I, seven interval tachograms of five minutes were selected and analysed.

\section{HRV analysis}

Since mental strain is difficult to measure, HRV was chosen as the primary end point. HRV analysis was performed according to the recommendations of the Task Force of the European

Figure I. Heart rate variability in a relaxed state and under severe mental strain. ECG

indicates electrocardiogram; VLF, very-lowfrequency component; LF, low-frequency component; and HF, high-frequency component.

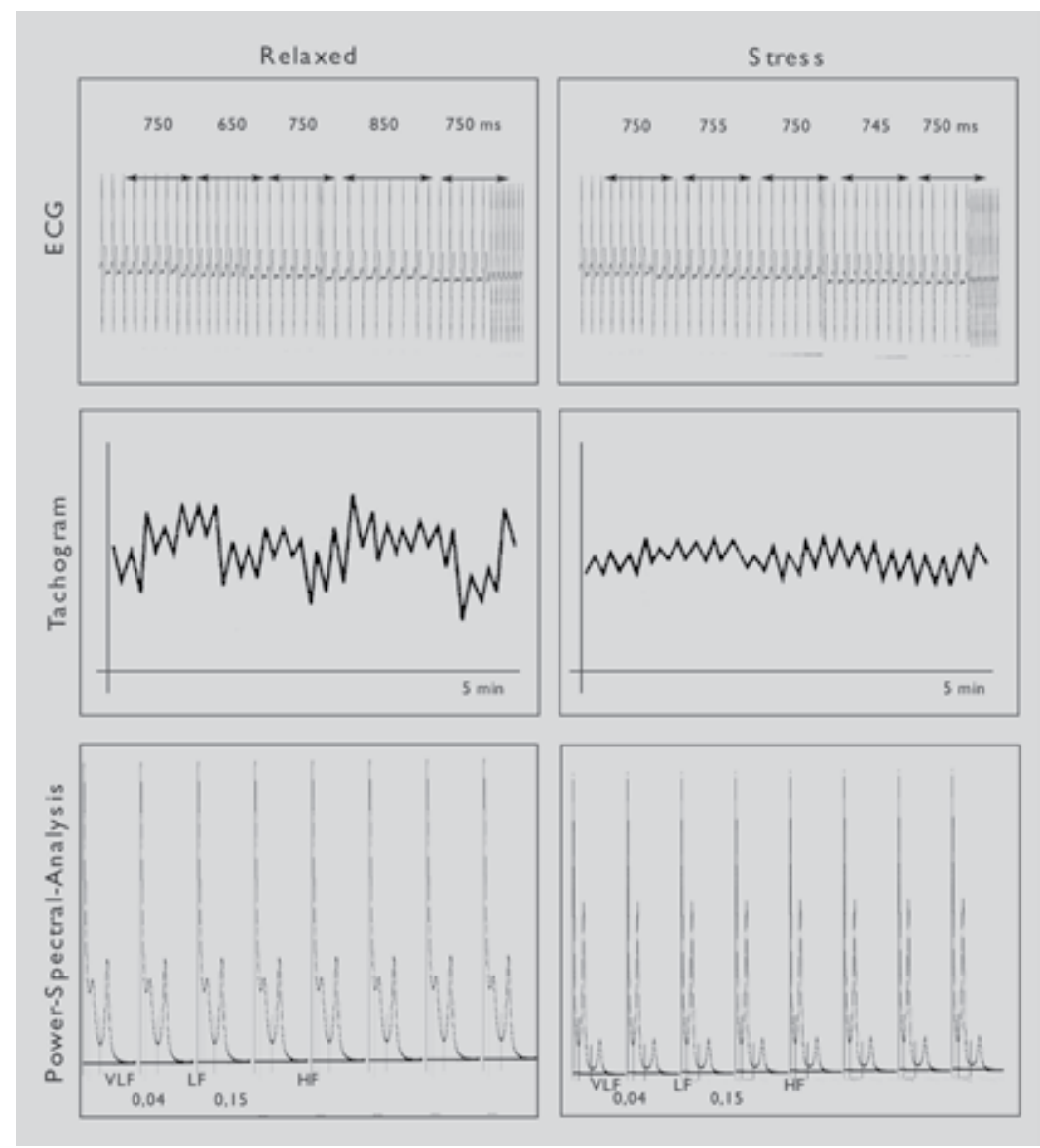

Society of Cardiology and the North American Society of Pacing and Electrophysiology ${ }^{15}$. Signals were visually inspected for premature beats, arrhythmias and movement artifacts and further analysed using free available software (Kubios HRV version 2.0, University of Kuopio, Finland) ${ }^{16}$. Mean heart rate and R-R intervals were analysed. From the recorded R-R intervals, this software performs spectral analysis using fast Fourier transformation, and translates the overall variability into its composing frequencies. This provides insight into what extent a frequency contributes to the overall variability of the signal. The power spectrum of HRV has been shown to consist of three peaks: the very low frequency $(\mathrm{VLF})$ band $(<0.04 \mathrm{~Hz})$, the low-frequency (LF) band $(0.04-$ $0.12 \mathrm{~Hz}$ ) and the high-frequency $(\mathrm{HF})$ band $(0.12-0.40 \mathrm{~Hz})^{14,17}$. Increased mental strain is closely associated with increased sympathetic and decreased parasympathetic (vagal) activity, leading to an increased LF component, a decreased HF component and an increased LF/HF Ratio ${ }^{18}$ as explained in Figure 1.

\section{Study protocol}

In order to obtain reliable, well-comparable data, selection of a well-standardized procedure with limited variation in operation-induced mental strain to the surgeon was necessary. Therefore, only elective laparoscopic cholecystectomy procedures were studied. Procedures in patients with (a history of) acute cholecystitis were excluded. The type of procedure (conventional vs. robot-assisted laparoscopic cholecystectomy) was randomized on the day of the operation.

Laparoscopic cholecystectomy was performed using a 4-trocar technique. In case of robot-assisted cholecystectomy, the daVinci ${ }^{\circledR}$ four-armed telemanipulator was used as described by Heemskerk et $\mathrm{a}^{\prime}{ }^{\prime 9}$. Before surgery, the surgeon was connected to the Holter portable recording unit and a 5-minute baseline ECG was obtained during rest and continuously throughout the surgical procedure. One observer continuously documented any environmental factors that could influence the surgeon. Laparoscopic cholecystectomy was divided in seven well-defined stages in order to evaluate the most demanding stages of the procedure, and to allow for a proper comparison between procedures, as has been shown in table 1 .

\section{Table I.The seven stages of laparoscopic cholecystectomy}

Baseline

First incision and insertion of the trocars

Dissection of Calot's Triangle

Clip and Cut of the cystic duct and artery

Dissection of the gallbladder from the liverbed

Removal of the gallbladder

Closure of the incisions

\section{Statistical Analysis}

Sample size was derived by power analysis, assuming a mean LF/HF ratio of II in laparoscopy surgery and a mean LF/HF ratio of 7 in robot-assisted surgery. If we assume that robotic assistance leads to a HRV comparable to open surgery in surgeons with comparable expertise ${ }^{2}$ and we accept a type I error alpha of 0.05 and a type II error beta of 0,80 , a sample size $n$ of II per group was calculated.

Statistical analysis was done using SPSS 19 (SPSS Inc., Chicago, IL, USA). Univariate differences between two groups were analyzed using the Student T-test for the parametric and the Mann- 


\begin{tabular}{|c|c|c|c|c|c|c|c|c|c|c|c|c|c|c|c|}
\hline & \multicolumn{3}{|c|}{ Hevrt Rete mean (St Dssy) } & \multirow{2}{*}{\multicolumn{3}{|c|}{ VLF median irangec) }} & \multicolumn{3}{|c|}{ Lf modiun (rarage) } & \multirow{2}{*}{\multicolumn{3}{|c|}{ HF nodian (ranes) }} & \multirow{2}{*}{\multicolumn{3}{|c|}{ LF/HF Fatio medion (range) }} \\
\hline & $A C$ & $c c$ & 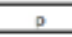 & $\mathrm{AC}$ & & $p$ & AC & & 0 & & & $p$ & $\mathrm{BC}$ & & $p$ \\
\hline 1 - Boselne & $84.6(10.4)$ & $84,9(5,6)$ & 0.93 & $1,987(605-39,739)$ & $1354[633-3737)$ & 0.28 & $761(204-2,349)$ & $941(370-2,755)$ & 0.36 & $266(45-2,263)$ & $277(145-1,102)$ & $a n$ & $2.67(0.38-8.82)$ & $2.70(154.7 .51)$ & 0.62 \\
\hline 2. Trocer plesement & $82.75 .9)$ & $89.2(7,3)$ & 0.01 & $699(271 \cdot 6.006)$ & $1268(166-4117)$ & 0.87 & $965(572-1.916)$ & $730(285-2.630)$ & 0.31 & 447 (168:3,073) & $176(83 \cdot 1,381)$ & 0.01 & $2.23(0.31-5.75)$ & $3.30(1.439 .45)$ & 0.18 \\
\hline 3 Dissection calot & $78.7(0.9)$ & $928(6.9)$ & $<0.001$ & $1,746(501-3,506)$ & $526(159-930)$ & 0.01 & $956(309-3,682)$ & $436(233-832)$ & 0.01 & $308(153-1,623]$ & $218(05-404)$ & a.os & $2.26(0.65-4.57)$ & $2.26(1.05-6.08)$ & 0.67 \\
\hline 4. Clp and cut & 75.769.4) & $97,2(6.7)$ & $<0.001$ & 1,180 (792-11,631) & $581(209-934)$ & 60.001 & $506(255-4,846)$ & $592(198-1.057)$ & 0.47 & $418(184-6,037)$ & $170(51-374)$ & 0.01 & $1.21(0.31-2.21)$ & $2988(1.655 .560)$ & $<0.001$ \\
\hline 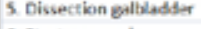 & $m 53(x .9)$ & $96,2(6,7)$ & $<0.001$ & 1,4a86 (399--11,1777) & $704(107-1370)$ & 0.03 & $513(021-3,861)$ & $416(194-1,136)$ & 0.36 & $569(157-3,062)$ & $171(53-691)$ & a.o & $1.60(0.25-3.28)$ & $3.12(a n-4.46)$ & 0.01 \\
\hline 6 Start removal & $766(11.1)$ & $95,6(7,4)$ & $<0.001$ & 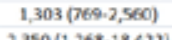 & $864(372-1938)$ & 0.02 & $902(270-2,220)$ & $487(148 \cdot-1,076)$ & 0.05 & $600(164.5,000)$ & $158(59.444)$ & a.o1 & $1.48(0.39 .2 .62)$ & $271(134.850)$ & 0.01 \\
\hline 7 Closure & $70.35 .6)$ & $913(49)$ & $<0.001$ & $2,750(1,268 .-18,422)$ & Sas (151-1194) & $\varepsilon 0.001$ & $1, \pi>0(k) 1-5,494)$ & $\sin (227-1,218)$ & 20.01 & $500(179-3,500)$ & $152(26-268)$ & $<0001$ & $2.90(1.41-5.99)$ & $3<8$ (1 (155-7.48) & 0.38 \\
\hline
\end{tabular}

Whitney $U$ test for the non-parametric data. Primary outcome of interest was defined as LF/ $\mathrm{HF}$ ratio of the surgeon. We tested the null hypothesis that robot-assisted laparoscopic cholecystectomy (RC) does not lead to an altered HRV with the surgeon, compared to conventional laparoscopic cholecystectomy (CC). The alternative hypotheses was that RC does change HRV compared to CC. Secondary outcome parameters were Heart Rate and VLF, LF and $\mathrm{HF}$ components during the surgical procedure, and duration of the operative procedure.

\section{RESULTS}

Operating time was measured, starting from first skin incision until the final suture. Robot-assisted laparoscopic cholecystectomy (RC) did take significantly longer to perform than conventional laparoscopic cholecystectomy (CC) $(86$ vs. 48 minutes, $p=0.003)$. Intra-operative complications did not occur and there were no conversions in either group. The postoperative course of all patients was uneventful.

Heart rate registration and heart rate variability analysis were performed, comparing the RC and the CC group. Results are shown in table 2 .

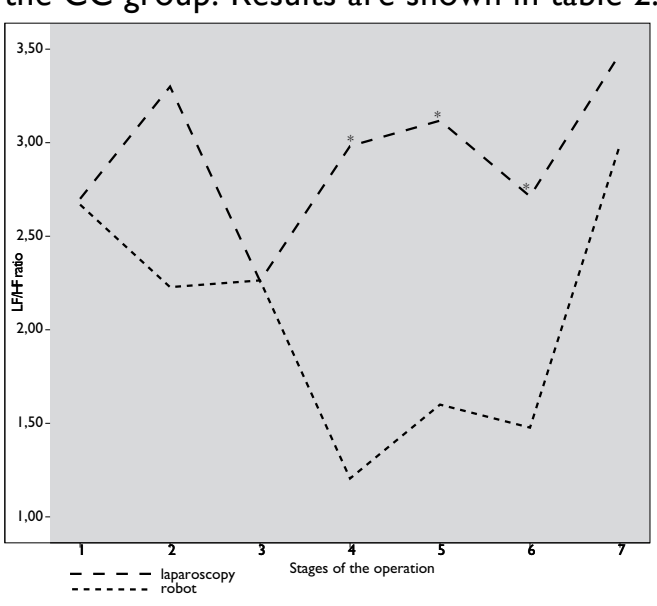

Figure 2. Heart rate during the seven stages of the operation.

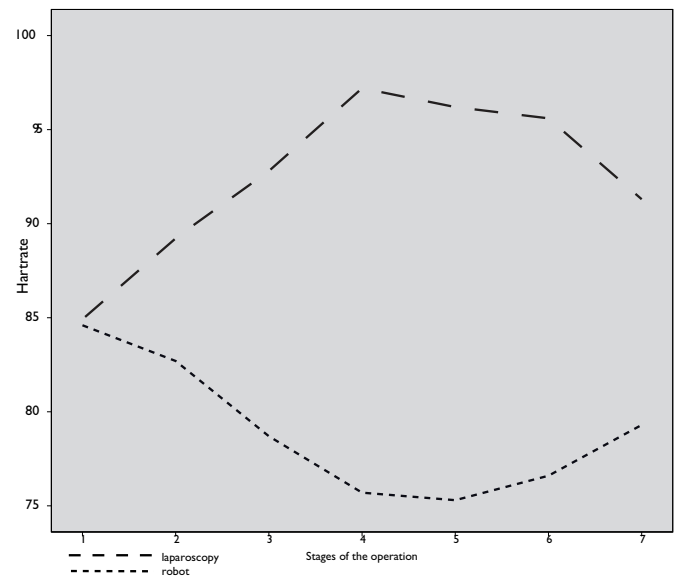

Figure 3. LF/HF ratio during the seven stages of the operation.

Interestingly, the LF/HF ratios performing RC are significantly lower then those performing CC during stage four, five and six of the operation, even despite the rather small numbers of operations.
Table 2. Mean heart Rate and VLF, LF, HF and LF/HF ratio during the seven stages of the operation. VLF, very-low frequency component; LF, low-frequency component; HF, high-frequency component; and LF/HF ratio, ratio between low-frequency and high-frequency components. RC means robot-assisted laparoscopic cholecystectomy and CC means conventional laparoscopic cholecystectomy.

Figure 2 shows the mean heart rate for both groups during the seven stages of the operation. Baseline is equal for both groups, but in the course of the operation, CC leads to a significant higher mean heart rate compared to baseline level, whereas RC leads to a lower HR compared to baseline level. As an example, during stage four (clipping and cutting of cystic artery and duct), mean heart rate increases from 84.9 at baseline to 97.2 when performing CC. However, when using robotic assistance, mean heart rate decreases from 84.9 at baseline to 75.7 .

Figure 3 shows the LF/HF ratio for both groups over the seven stages of the surgical procedure. Again, baseline is similar for both groups, but during the operation, CC leads to a significant higher $\mathrm{LF} / \mathrm{HF}$ ratio than RC. Figure 3 exemplifies the significant differences in LF/HF ratio during the different stages.

\section{DISCUSSION}

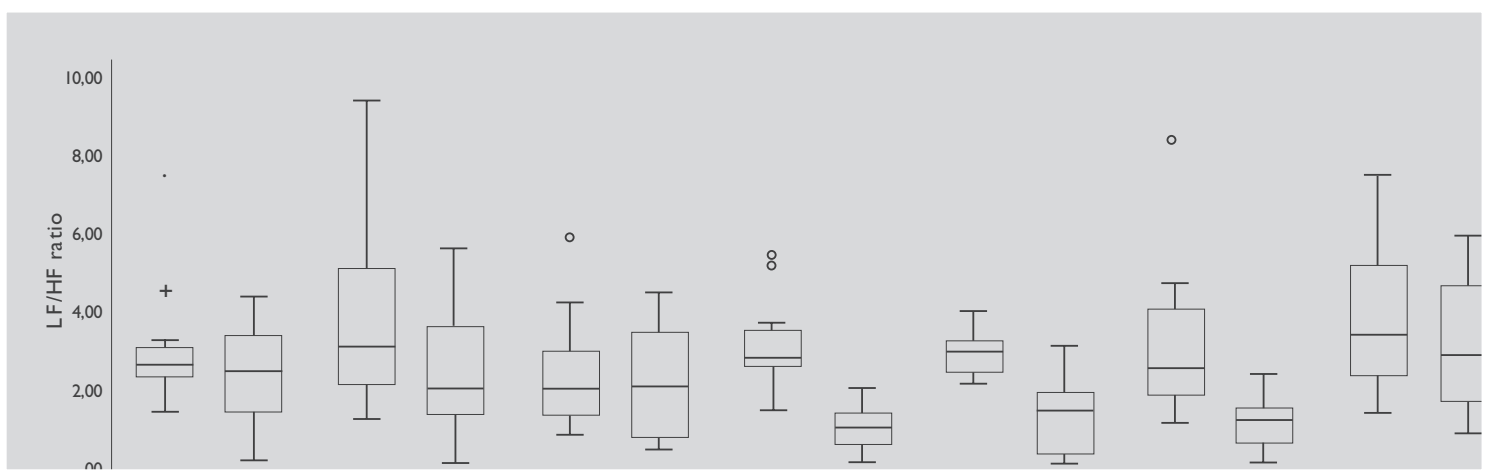

Figure 4. Boxplot diagram of the LF/HF ratio during the seven stages of the operation. RC means robot-assisted laparoscopic cholecystectomy and CC means conventional laparoscopic cholecystectomy. 
robot-assisted laparoscopic cholecystectomy. Our results show that the mean heart rate during robotic assisted laparoscopic cholecystectomy is lower compared to conventional laparoscopic cholecystectomy. This suggests that the use of robotic assistance for this procedure reduces total strain, which is the combined physical and mental strain. However, mean heart rate differences alone cannot differentiate between physical and mental strain. We therefore performed HRV analysis and were able to show a significant lower LF/HF ratio in the robot-assisted procedure. This suggests that even in a common and generally considered hardly stressful laparoscopic procedure, performing a CC leads to significant mental strain and the use of robotic assistance significantly reduces this mental strain.

Surgeons generally evaluate a procedure based on the advantages and disadvantages for their patients. It is rather unconventional to assess the drawbacks imposed on the surgeon, such as increased physical or mental strain and fatigue. Our present results were quite comparable with previous publications ${ }^{1,20,21}$, that demonstrate that increased mental and physical strain during surgery can significantly increase the surgeons heart rate till well up to 150 beats $/ \mathrm{min}$. Importantly, these excessive tachycardic rhythms were not limited to generally considered "high risk operations", but they also included generally considered "low risk and low strain" operations such as cholecystectomy and hernia surgery. Whether experienced surgeons really are as well adapted to this kind of stress as stated before ${ }^{22}$ remains under debate. The fact that the vast majority of surgeons reaches these extreme fast heart rhythms during their daily occupational activities, and the fact that surgeons are at a significantly increased risk of death from ischemic heart disease compared to general practitioners ${ }^{23}$ might suggest that even experienced surgeons might overestimate their own capability of coping with occupational strain.

Interestingly, the LF/HF ratio was lower when the surgeon used robot-assistance for the cholecystectomy. This suggests that a common and hardly stressful laparoscopic procedure leads to significant mental strain and that the use of robotic assistance seems to be able to significantly reduce this mental strain. The more ergonomic position of the surgeon and the motorized manipulation offered by robotic-assistance may reduce physical strain on the surgeon, and may explain our findings. This line of reasoning is supported by evidence of Klein et al", who suggest that optimal ergonomics in the operating room are able to reduce mental strain in the operating surgeon. They clearly show a decrease in postoperative physical strain and pain measurements in the surgeon working in a modern, ergonomically optimized operating room compared to the surgeon working in a standard operating room. However, other parameters substantiated their conclusions as differences in HRV parameters were not detected because of high inter- and intraindividual variation. In our study, we therefore limited our surgeons to two individuals performing well-standardized operations, leading to a lower inter- and intra-individual variation.

Looking at the different stages of the operation, it is interesting to notice that the significant difference in LF/HF ratio between CC and RC is present in stage four (clip and cut of the cystic artery and duct), stage five (dissection of the gallbladder from the liver bed) and stage six (removal of the gallbladder). During stage three (dissection of Calot's triangle) there was no significant difference. This is quite remarkable, since stage three could generally be considered one of the most stressful stages of the operation. An explanation could be, that the measurable physical effects of decreased heart rate variability due to increased sympathetic activity caused by increased mental strain, do occur only after a delay of a few minutes. In that case, the interval tachograms should probably have been selected only after a delay of three to five minutes. Previous studies comparing HRV in conventional open surgery versus laparoscopic surgery have been published before. However, to our knowledge there have been no previous publications comparing conventional laparoscopic surgery versus robot-assisted surgery. Therefore, we are the first to show that the use of high-tech surgical solutions such as the daVinci ${ }^{\circledR}$ Surgical System seems to be able to reduce the increased mental strain that is being put on the surgeon during the performance of minimal invasive surgical procedure. This suggests the use of robotics in minimal invasive surgery might well lead to improved ergonomics, less fatigue, and a better health of the surgeon.

\section{LIMITATIONS}

Several limitations need to be taken into account with the interpretation of the present results. Assessing mental strain by means of heart rate variability is cumbersome. This is partly due to the fact that interpretation of HRV is challenging and subject to bias. As we measured only a limited amount of participants and focused on HRV changes in time, we circumvented several of the potential sources of bias of HRV analysis. Second, previous studies have shown before that laparoscopic surgery is more demanding than conventional open surgery and puts a higher mental strain on surgeons ${ }^{2}$. Our study suggests that the use of robotic assistance in laparoscopic surgery might (partially) compensate for this increase in mental strain being put on the surgeon. Although reference values for short-term heart rate variability in healthy adults have been determined ${ }^{24}$, there is no clear cut-off point or scale for critical mental strain during surgery. Furthermore, as the effects of daily recurrent increased mental strain and the potentially associated health risk for the surgeon are unclear, the exact relevance of the observation on the difference in LF/HF ratio for clinical practice remains speculative. Third, from our present results we cannot exactly discriminate the relative contribution of mental strain versus physical activity on our findings regarding HRV. However previous studies comparing laparoscopic versus open procedures have been using the HRV parameter similarly².

During both procedures we found remarkable high heart rates at baseline. It could be questioned whether this is a normal physiologic phenomenon, or whether the measurements were biased by the extra mental strain caused by the study-circumstances. Surgeons may not recognize this anticipative strain in themselves, but we may be underestimating the effects of surgery on the surgeon's body and mind. This is nicely illustrated by the previous publication by Foster et al'. In this study it was demonstrated that all surgeons that participated in their study did have significant tachycardia during surgery, even while performing quite routinely low-stress operations such as hernia repair and cholecystectomy. Interestingly, a significant rise in heart rate well over $100 / \mathrm{min}$ began as soon as scrubbing for an operation was commenced. The mean heart rate for the whole group in their study was over $120 / \mathrm{min}$ with peak heart rates over $150 / \mathrm{min}$. These data suggest that significant preoperative anticipative mental strain and intraoperative mental strain do occur on a regular basis in general surgery. Considering these observations, the surgeons in our present study were not more stressed compared to the other surgeons studied before ${ }^{\prime l}$.

Future studies

Our study was limited to surgeons performing laparoscopic cholecystectomy, generally considered a relative low-stress well-standardized operation. It would be very interesting to see if the differences in HRV would increase if a more stressful operation would be selected such as laparoscopic total mesorectal resection or surgery for aortic aneurysm.

At this moment, the exact impact of decreased HRV on the health status of the surgeon is difficult to measure, although previous studies have shown a significant increase in potentially lethal health issues after prolonged exposure to decreased $\mathrm{HRV}^{25}$. More research should be performed in order to clarify whether a decrease in HRV does impose an unacceptable health risk on the surgeon and therefore should warrant stress-reducing measures such as the acquaintance of high-tech, costly, ergonomy improving tools such as the daVinci ${ }^{\circledR}$ Surgical System. 


\section{CONCLUSION}

We conclude that the use of robotic assistance in laparoscopic surgery leads to significant decrease in mean heart rate and an increase in heart rate variability of the surgeon during surgery, strongly suggesting a reduction in intra-operative mental strain.

A decrease in mental strain of the surgeon could potentially lead to less fatigue, less surgical mistakes and less stress-induced illnesses to the surgeon. The continuous drive to introduce new, less invasive techniques for our patients leads to an ongoing exposure of more stress-inducing techniques to our surgeons. In an era where mean life expectancy increases and the length of the medical carrier elongates accordingly with it, prevention of work-related stress-induced illnesses might gain importance. The use of robotics could therefore potentially prove to be beneficial for the health of both patients and surgeons. Preventing work-related illnesses and associated work incapacity, the acquisition and use of a robotic surgical system might prove to be a cost-effective strategy to enable surgeons to perform minimal-invasive surgery until their retirement at old age.

The associated disadvantages such as increased operative time and increased costs have to be taken into account before a decision can be made to use or abandon robotic surgery. Until then, surgeons should be aware that if they try to accomplish multiple, prolonged and demanding procedures per day, they will probably risk the health of their patients resulting from exhaustioninduced surgical mishaps, as well as risk their own health.

\section{REFERENCES}

I Foster, GE, Evans DF, Hardcastle JD. Heart-rates of surgeons during operations and othe clinical activities and their modification by oxprenolol. The lancet 1978; I (8078): 1323-5

2 Böhm B, Rötting N, Schwenk W et al. A prospective randomized trial on heart rate variability of the surgical team during laparoscopic and conventional sigmoid resection. Arch Surg 200I;I36(3):305-10

3 Vrijkotte TG, vanDoornen LJ, de Geus EJ. Effects of work stress on ambulatory blood pressure, heart rate, and heart rate variability. Hypertension, 2000. 35(4): p. 880-6.

4 Lynch J, Krause N, Kaplan GA, et al. Workplace demands, economic reward, and progression of carotid atherosclerosis. Circulation. 1997;96(I):302-7

5 Siegrist J, Peter R, Junge A et al. Low status control, high effort work and ischemic heart disease: prospective evidence from blue-collar men. Soc Sci med. 1990;3 I (10): I I 27-34.

6 Bosma H, Peter R, Siegrist J et al. Two alternative job stress models and the risk of coronary heart disease. Am J Public health 1998;88(I):68-74

7 Pagani M, Furlan R, Pizzinelli P, et al. Spectral analysis of R-R and arterial pressure variabilities to assess sympatho-vagal interaction during mental stress in humans. J Hypertens Suppl. 1989;7(6):SI4-5

8 Hjortskov N, Rissen D, Blangsted AK, et al. The effect on mental stress on heart rate variability and blood pressure during computer work. Eur J Appl Physiol 2004;92(I-2):84-9

9 Nieminen T, Kähönen M. Kööbi T, et al. Hear rate variability is dependent on the level of heart rate. Am Heart J. 2007; I54(I):el3

10 Nunan D, Sandercock GR, Brodie DA. A quantitative systematic review of normal values for short-term heart rate variability in healthy adults. Pacing Clin Electrophysiol. 1010;33(II):1407-17

II Klein M, Andersen LP, Alamili M et al. Psychological and physical stress in surgeons operating in a standard or modern operating room. Surg Laparosc Endosc Percutan tech. 2010;20(4):237-42
12 Song $\mathrm{MH}$, Tokuda $\mathrm{Y}$, Nakayama $\mathrm{T}$ et al. Intraoperative heart rate variability of a cardiac surgeon himself in coronary artery bypass grafting surgery. Interact Cardiovasc Thorac Surg 2009;8(6):639-4।

13 Gerritsen J, TenVoorde BJ, Dekker JM, et al. Measures of cardiovascular autonomic nervous function: agreement, reproducibility, and reference values in middle age and elderly subjects. Diabetologia. 2003;46(3):330-8

I4 Keet SW, Bulte CS, Boer C, et al. Reproducibility of non-standardised autonomic function testing in the pre-operative assessment screening clinic. Anaesthesia 201 I;66(I):10-4

15 Task Force of the European Society of cardiology. heart Rate Variability: standards of measurement, physiological interpretation, and clinical use. Circulation. 1996;93:1043-1065

16 Niskanen JP, Tarvainen MP, Ranta-Aho PO, et al. Software for advanced HRV analysis. Computer Methods Programs Biomed. 2004;76(I):73-8I

17 Vinik Al, Ziegler D. Diabetic cardiovascular autonomic neuropathy. Circulation 2007; I I5(3):387-97

I8 Akselrod S, Gordon D, Ubel FA et al. Power spectrum analysis of heart rate fluctuation: a quantitative probe of beat-to-beat cardiovascular control. Science 198I;2I3(4504):220-2

19 Heemskerk J, van dam R, van Gemert WG et al. First results after introduction of the four-armed daVinci Surgical System in fully robotic laparoscopic cholecystectomy. Dig Surg 2005;22(6):426-31

20 Payne RL, Rick JT. Heart rate as an indicator of stress in surgeons and anaesthesists. J Psychosom Res. 1986;30:41I-20

21 Czyzewska E, Kicka K, Czarnecki A, et al. The surgeon's mental load during decision making at various stages of operations. Eur j Appl Physiol. 1983;5 I:44I-446

22 Becker WG, Ellis $\mathrm{H}$, Goldsmith $\mathrm{R}$ et al. Heart rates of surgeons in theatre. Ergonomics. 1983;26(8):803-7

23 Arnetz BB, Andreasson S, Strandberg $M$ et al. Comparison between surgeons and general practitioners with respect to cardiovascular and psychosocial risk factors among physicians. Scand J Work Environ health. 1988; I 4(2): I I8-24

24 Keet SWM, Bulte CSE, Garnier RP, et al. Reference values for short-term heart rate variability in healthy adults. Anaesthesia 2013 April 08. Epub ahead of print. http://www. respond2articles.com/ana/forums/thread/1376.aspx

25 Hillebrand S, Gast KB, de Mutsert R, et al. Heart rate variability and first cardiovascular event in populations without known cardiovascular disease: meta-analysis and doseresponse meta-regression. Eurospace 2013 Jan 30. Epub ahead of print. 


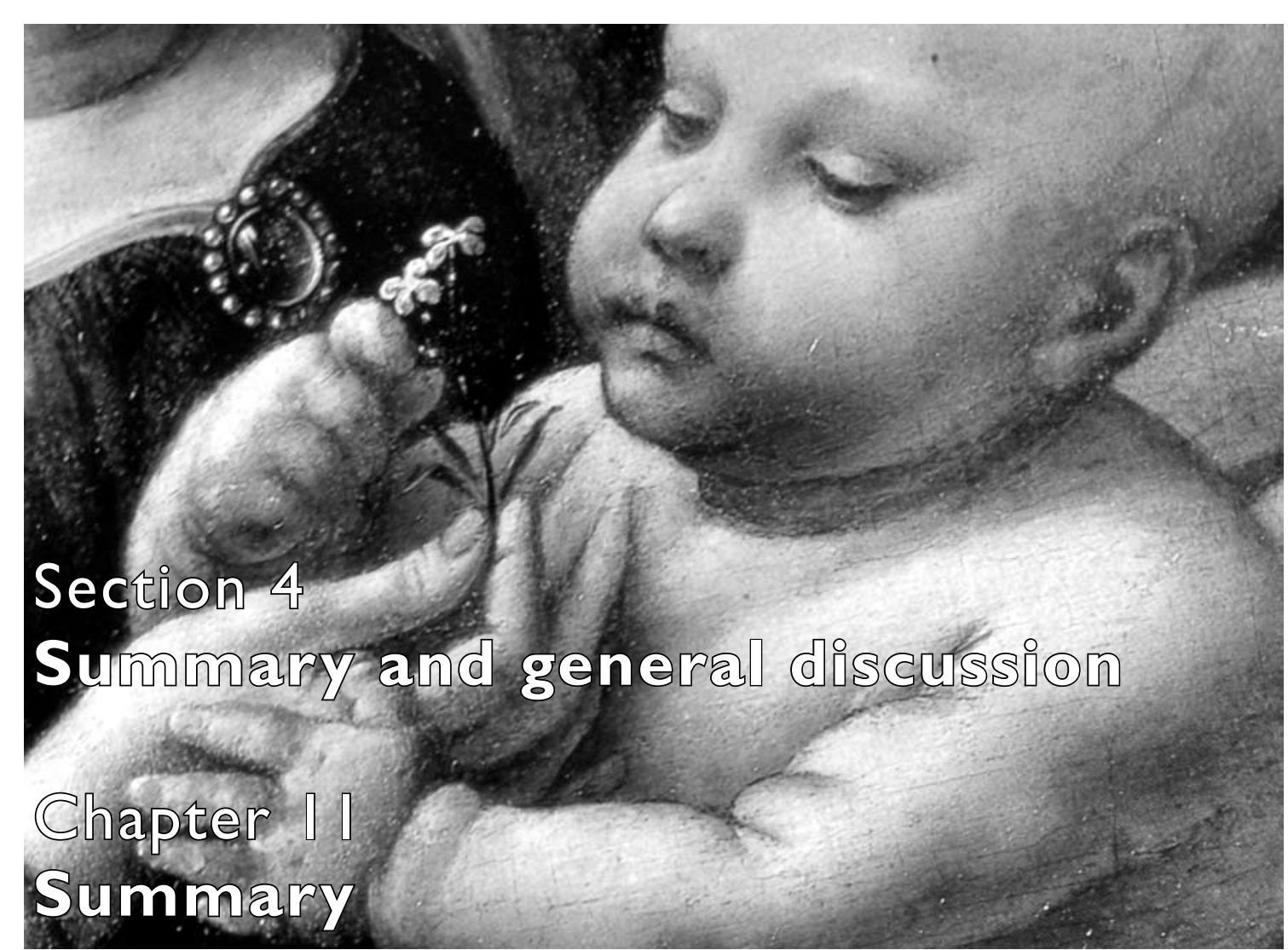

DETAIL FROM: BENOIS MADONNA

OIL ON CANVAS, 1478

Probably the first work painted by Leonardo independently from his master Verrocchio. The painting suggests the artists was concentrating on the idea of sight. It was thought that human eyes exhibited rays to cause vision, with a central beam being the most important. The child is thought to be guiding his mother's hands into his central vision. 


\section{SUMMARY}

The initial introduction of laparoscopy into general surgical practise has met major scepticism Three decades later, laparoscopic surgery has become the standard technique in some fields of surgery such as cholecystectomy. In many other surgical fields it has become an attractive alternative to traditional open surgery, still gaining popularity. Patients benefit from reduced postoperative pain, fewer pulmonary complications, less incisional hernias and faster recovery after surgery. However, surgeons do suffer from a longer learning curve, decreased ergonomics and increased intra-operative mental strain.

Robotic surgical systems address some of these drawbacks and might facilitate endoscopic surgery. Using a master-slave concept, the surgeon still performs the operation but downscaling of movement and tremor filtration allow for increased dexterity beyond the possibilities of the human hand. The objectives of this thesis were to clarify the role of robotic assistance in laparoscopic surgery and to determine if and where the use of robotics offers significant advantages. We performed a variety of studies, both in a dry lab environment and in clinical practise.

In chapter four we focused on the advantages (and disadvantages) of the separate parts of the $\mathrm{daVinci}^{\circledR}$ telemanipulator in the performance of laparoscopic tasks in a dry lab environment. We concluded that the most significant drawbacks in conventional laparoscopy compared to robotassisted laparoscopy were:

a) the lack of stereoscopic vision adequate restoration of the eye-hand-target axis

b) (possibly to a lesser extent) the use of rigid instruments with limited degrees of freedom Major advances in laparoscopic surgery might only be expected if these drawbacks are adequately addressed. This seems possible using console-based telemanipulator systems such as the daVinci ${ }^{\circledR}$ Surgical System, or using a combination of a high-definition stereoscopic visual system with adequate restoration of the eye-hand-target axis such as the Viking ${ }^{\circledR}$ System in a combination with a handheld instrument offering six degrees of freedom such as the Radius ${ }^{\circledR}$ System.

The difference in learning curve between conventional and robot-assisted laparoscopic surgery in a dry lab environment was studied in chapter five. Since it is rather impossible to find experienced surgeons with equal experience in conventional laparoscopy and in robot-assisted laparoscopy, we selected inexperienced users. The presence of a relatively long learning curve in conventional laparoscopy is relevant for daily clinical practise, since learning curves are associated with prolonged operating time, increased patient morbidity and higher costs. We found that the use of robotic assistance in laparoscopic surgery leads to faster and more accurate performance of laparoscopic tasks. However, conventional laparoscopy showed a steeper learning curve and therefore faster skill acquisition. This might suggest that the advantages offered by the use of robotic assistance might be significant in inexperienced users. However, whether this leads to a faster acquisition of an adequate level of proficiency in surgeons acquiring new surgical skills in actual surgery remains under debate.

Laparoscopic cholecystectomy is one of the most common laparoscopic procedures, if not the most common laparoscopic procedure performed worldwide. In cholecystectomy, laparoscopy is generally considered the gold standard. In chapter six, we asked ourselves the question whether fully robotic laparoscopic cholecystectomy would be feasible in daily clinical practise. The use of the fourth arm of the telemanipulator enabled us to perform surgery with one assistant less. Fullyrobotic cholecystectomy proved to be safe and feasible. However, operating time was 31 minutes 
practise. Previous studies have shown that conventional laparoscopic surgery leads to significant increase in heart rate and LF/HF ratio, suggestive of increased mental strain. The use of robotic assistance during laparoscopic cholecystectomy resulted in an significant decrease in heart rate and an increase of heart rate variability during various stages of surgery. This strongly suggests a significant reduction of intra-operative physical and mental strain. At this moment, interpretation of these results is challenging since the exact impact of decreased heart rate variability on the health status of the surgeon is difficult to measure. However, previous studies have shown a

significant increase in potentially lethal health issues after prolonged exposure to decreased heart rate variability. These results suggest that surgeons should be aware that if they try to accomplish multiple prolonged demanding laparoscopic procedures per day without the use of robotic

assistance, they will probably risk the health of their patients resulting from exhaustion-induced surgical mishaps, as well as risk their own health.

\section{CONCLUSION}

The studies described above suggest that the use of robotic assistance in a dry lab environment leads to faster and more accurate performance of laparoscopic tasks. However, in daily clinical practise, the advantages of the use of robotics are disappointing. Robotic surgery takes longer to perform and is more expensive. The most significant advantage of the use of robotics, might be the increased ergonomics and subsequent reduction in mental strain of the surgeon. This might potentially lead to a reduction in operative complications for the patient and a decrease in potentially lethal health issues for the surgeon.

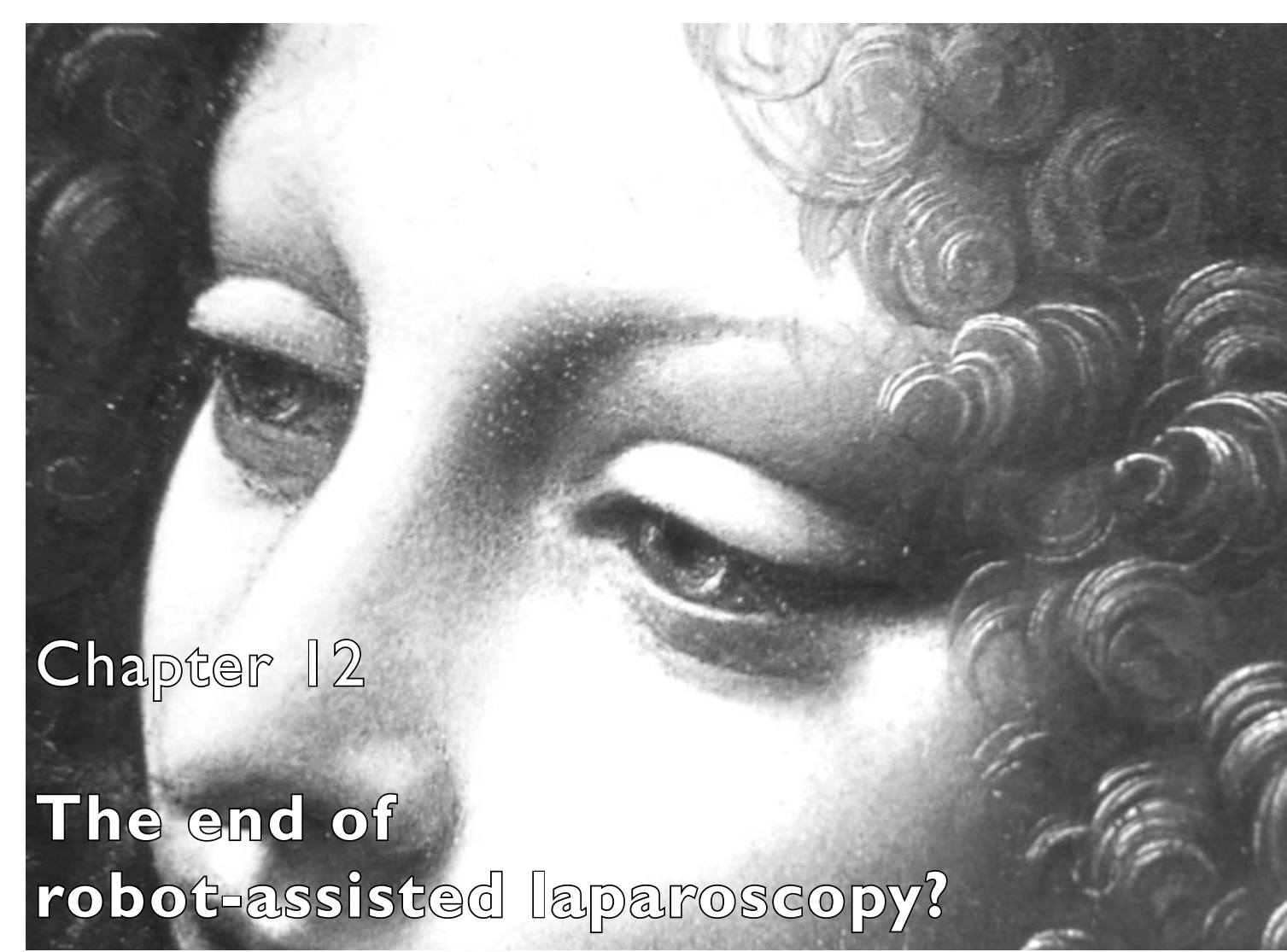

Previously published as:

The end of robot-assisted laparoscopy? A critical appraisal of scientific evidence on the use of robot-assisted laparoscopic surgery.

Heemskerk J, BouvyND, Baeten CGMI. Surg Endosc. (epub ahead of print)
DETAIL FROM: VIRGIN OF THE ROCKS

OIL ON WOODEN PANEL, I483-1486

The Virgin of the Rocks (or Madonna of the Rocks) is the name used for two similar paintings by Leonardo da Vinci. The version belonging to the National Gallery in London, shows the eyes of the angel turned down in a contemplative manner. The other version of the painting, belonging to the Louvre Museum, Paris, shows the eyes of the angel staring at the direction of the viewer. 


\section{ABSTRACT}

Robot-assisted laparoscopy has been used in a wide variety of surgical fields. However, the financial costs involved are high and convincing proof of superiority in terms of Quality of life, cost-effectiveness and survival is often lacking. However, there might be small benefits for the patient or for the surgeon's health that might warrant the use of robotics in limited fields of surgery. In an era of world-wide economic crisis, it is about time to start a critical discussion whether we should drastically limit, or even abandon, the use of robot-assisted laparoscopic surgery and focus on more cost-effective strategies of health care improvement.

\section{INTRODUCTION}

The era of telemanipulator systems in minimal invasive surgery started with the introduction of the Automated Endoscopic System for Optimal Positioning (AESOP). In 1994 this system was approved by the US FDA as the first surgical "robot" ever. Since the introduction, many prototype advanced manipulator systems have been developed. However, introduction to the field of surgery and delivering solid proof of its added value remains cumbersome.

In 2000 the daVinci ${ }^{\circledR}$ Surgical System was approved by the US FDA for general laparoscopic surgery, and at this moment it is the only commercially available "robotic" system offering an integrated stereoscopic visual system with a motorized telemanipulator. The term "robot" might, semantically speaking, be outplaced here, since this suggests the presence of an automated process instead of a technically advanced distance-controlled integrated visual and manipulator system. However, over the last decade, this term has been (mis)used at such an extend in the field of advanced minimal invasive surgery in order to address the daVinci ${ }^{\circledR}$ Surgical System, that the two terms have become synonymous. Therefore, we will use both terms interchangeable in this manuscript.

Almost 2000 daVinci systems have been installed worldwide and the number of indications seems to grow rapidly in a wide variety of field, including urology, gynaecology and general, cardiothoracic, paediatric and gastrointestinal surgery. The use of the system has been proven safe and feasible, but costs are high and clear medical benefits are difficult to prove. In the Netherlands alone, eighteen hospitals have already invested significant sums to acquire twenty robotic systems. After more than 10 years of extensive use and living in an era where an economic crisis forces us to optimize resource utilization and critically reconsider every penny we spend on health care, the role of robotic assistance in laparoscopic surgery merits robust evaluation.

Introducing new technology in medicine is intended to improve disease management either by leading to an increased survival, an enhanced Quality of Life (QOL) or reduced costs. In considering the cost-effectiveness of robotics, one must first consider what the potential benefits are and then determine whether these additional benefits justify the additional costs. Looking at the extensive field of indications, it is practically impossible to evaluate every operation in every field of surgery. Therefore we will try to limit ourselves to some of the most used and best evaluated operations.

\section{CURRENT STATUS OF}

\section{THE STANDARD DAVINCI ${ }^{\circledR}$ SURGICAL SYSTEM}

General Surgery

Thyroidectomy has been used for benign and malign lesions of the thyroid gland. Minimal invasive thyroidectomy has been introduced in order to minimize visible scar formation in the neck. The main advantage compared to conventional thyroidectomy seems to be the improved cosmesis and patient satisfaction, while leading to a safe and radical excision of the thyroid. Minimal invasive thyroidectomy (either via the axillary, the anterior neck or a combined approach) leads to a longer operative time and more postoperative pain'. The open operation is generally considered the gold standard.

Robotic assistance has been used but there is no sound proof whether this leads to a faster ${ }^{2}$ or slower ${ }^{3-5}$ operative procedure compared to minimal invasive surgery. No significant medical advantages have been identified resulting from the use of robotics in minimal invasive thyroidectomy. Compared to open thyroidectomy, there is little evidence of superiority except for possibly improved cosmesis ${ }^{6,7}$

\section{Gastro-intestinal Surgery}

Colon resections are performed frequently for the treatment of colon carcinoma. Laparoscopic Colon resection has been performed and studied extensively following the introduction and success of laparoscopic cholecystectomy. Numerous well-developed Randomised Clinical Trials have shown that conventional laparoscopic colectomy is safe and feasible if performed by a well-trained surgeon, offering short term benefits and a faster recovery after surgery without compromising oncologic outcome $\mathrm{e}^{8-12}$. There is no consensus whether laparoscopic or open colectomy should be considered the gold standard.

The use of robotics in laparoscopic colectomy is safe and feasible ${ }^{13-16}$ but seems more time consuming and more expensive $e^{4,16-18}$ without significant medical advantages over conventional laparoscopy.

Laparoscopic rectum resection is generally considered to be technically more demanding than laparoscopic colon resection. Working in a small confined space where nerves could risk inadverted damage, the potential benefits of the daVinci ${ }^{\circledR}$ Surgical System could possibly be higher. However, laparoscopic rectum resections have been performed safe and feasible without robotic assistance and with results at least equal to open surgery ${ }^{15,19-21}$. The use of Robotic assistance leads to a comparable or longer ${ }^{22-25}$ operative time and to similar oncologic outcome and postoperative complications compared to conventional laparoscopic surgery $26-29$. Recovery and return of sexual function might be equal or possibly slightly faster after robotic surgery ${ }^{30}$

Abdominal rectopexy has been performed as a treatment for full-thickness rectum prolapse. In western Europe, the laparoscopic anterior mesh technique as described by d'Hoore ${ }^{31}$ is one of the most frequently used, resulting in excellent long term results with minimal complications ${ }^{32-34}$. Generally, laparoscopic rectopexy is considered the gold standard.

Robotic assistance has proven safe and feasible ${ }^{35}$ with a comparable recurrence rate, complication rate and functional results compared to laparoscopic surgery ${ }^{36}$. However, the operative time seems to be longer and costs are higher in robot-assisted laparoscopic rectopexy ${ }^{35}$.

Nissen fundoplication has been performed as an anti-reflux procedure extensively. The laparoscopic Nissen fundoplication is generally considered the gold standard for anti-reflux surgery over the last few years, offering a successful treatment for adults and children ${ }^{37}$, 
potentially performed in day care. Both short-term results ${ }^{38}$ and in long-term follow-up ${ }^{39-41}$, results are excellent while recovery after laparoscopic surgery is faster ${ }^{42,43}$ than after open surgery. Incisional hernia appeared significantly more frequent after open surgery as compared to laparoscopic surgery ${ }^{44,45}$. Introduction of the daVinci ${ }^{\circledR}$ Surgical System leads to similar results ${ }^{46}$, but is more expensive ${ }^{47-51}$

Roux-en-y Gastric Bypass has been performed as a bariatric procedure. The laparoscopic procedure has taken an impressive flight in the last few years as one of the most effective and frequently performed bariatric operations. In expert centres, hundreds or even thousands of these operations are performed annually with limited morbidity and mortality. Laparoscopic

RYGB results in a faster recovery, shorter length of stay, lower morbidity, lower mortality and lower costs compared to its open counterpart and should be considered the gold standard at this time T2-54 $^{52}$

The use of robotic assistance results in similar postoperative functional results and complications ${ }^{55}$. There is no agreement whether the use of the daVinci ${ }^{\circledR}$ Surgical System leads to a shorter ${ }^{56}$ or longer ${ }^{57-59}$ operation time. The costs associated with the use of robotics are generally considered higher ${ }^{58-60}$, although some studies suggest lower $\operatorname{costs}^{61}$. This difference might be due to a difference in operative techniques, use of staplers and other surgical devices, and a difference in complication risk and length of stay.

\section{Thoracic surgery}

Thymectomy for Myasthenia Gravis is an invasive operation, traditionally performed by transsternal approach. Using Video-Assisted Thorascopic Surgery (VATS), the procedure can be performed equally effective with a decreased need for post-operative ventilation and decreased length of stay in both adults ${ }^{62-64}$ and children ${ }^{65,66}$. The use of the daVinci ${ }^{\circledR}$ system is safe and feasible, offering enhanced post-operative recovery compared to transsternal approach ${ }^{67-71}$ Unfortunately, no randomized trials have been published, comparing the results of traditional VATS thymectomy with robot-assisted thymectomy.

Lobectomy for early stage non-small cell lung cancer is a frequently performed procedure. The traditional open approach using a thoracotomy is considered painful, potentially attributing to frequent pulmonary complications and a relatively long length of stay. VATS-lobectomy is safe and feasible ${ }^{72}$, leading to similar ${ }^{73-76}$ or even better ${ }^{7-79}$ oncologic results as the open approach, in combination with faster recovery.

The use of robotic assistance is feasible ${ }^{80-83}$ and does arguably lead to similar ${ }^{84}$, better or worse ${ }^{85}$ results. Adequately powered well-balanced studies comparing VATS with robot-assisted lobectomy are lacking 86

\section{Gynaecology}

Hysterectomy has been used for benign indications and for the treatment of early stage cervical cancer. In general, operative times for laparoscopic resection seem longer than for open surgery, but recovery after surgery is faster and oncologic outcome is similar ${ }^{87,88}$. The use of the daVinci $i^{\circledR}$ Surgical System has been used and evaluated repeatedly. The robotic procedure is safe and feasible ${ }^{89}$ and blood loss might possibly be marginally less ${ }^{90}$, but operative time seems longer ${ }^{90-94}$ without significant advantages in postoperative outcome compared to conventiona laparoscopic surgery. In general, robotic assistance seems significantly more expensive $e^{91,92,94}$

Sacrocolpopexy has been developed as a treatment for management of apical prolapse. Abdominal suspension of the vaginal apex results in superior results compared to transvaginal procedures.
Laparoscopic sacrocolpopexy results in significantly less blood loss and less postoperative pain compared to abdominal surgery, leading to faster convalescence ${ }^{95}$. Therefore, laparoscopic sacrocolpopexy should be considered the gold standard. It is not clear whether the use of robotic assistance leads to a faster ${ }^{96}$ or slower ${ }^{97}$ operative procedure compared to conventiona laparoscopy. Including the set-up time of the daVinci ${ }^{\circledR}$ Surgical System, time consumption seems more. Costs are significantly higher when using robotics ${ }^{97}$. In a comparison of robot-assisted sacrocolpopexy vs open sacrocolpopexy, the latter technique seems more expensive due to a longer admission ${ }^{98,99}$

\section{Urology}

Laparoscopic nephrectomy has been used as a less invasive alternative to open (and often painful) nephrectomy in renal cancer ${ }^{100}$, leading to similar oncologic results ${ }^{101-103}$. The use of a daVinci ${ }^{\circledR}$ telemanipulator has been studied in mainly small and underpowered trials ${ }^{104,105}$ but seems to result in a more time-consuming operation compared to open ${ }^{106}$ or laparoscopic ${ }^{107}$ surgery. The results and complications seem comparable ${ }^{106-110}$, but costs seem significantly higher $104,108-110$

Laparoscopic radical prostatectomy (LRP) for prostate cancer has been introduced as a technically demanding but less invasive operation compared to the open retropubic radical prostatectomy

(RRP), leading to less blood loss and similar oncologic results compared to retropubic surgery 111 However, conventional LRP is considered an extremely demanding operation and only few urologists are capable of performing this kind of surgery safe without robotic assistance. Comparing LRP to Robot-Assisted Radical prostatectomy (RARP), oncologic results seem similar ${ }^{1 / 2-1 / 4}$ but long term results of RARP concerning urinary continence and erectile function I year after surgery might possibly be slightly better $114-116$

An adequate comparison between RARP and LRP is difficult to perform, as many urologists do not perform LRP. Compared to RRP, the use of a robot seems to lead to equivalent oncologic results 1 12,116-118. Recovery of potency and urinary continence might be marginally better after robotic surgery 119 although scientific evidence is weak. Generally, RARP is considered more expensive than both open and conventional laparoscopic prostatectomy ${ }^{120-123}$

\section{New developments in robot-assisted laparoscopy}

The daVinci ${ }^{\circledR}$ S Surgical System: The next generation has arrived!

Intuitive Surgical has developed a new generation robotic systems, offering improved manoeuvrability and increased working space. There are several advantages of the newly developed daVinci ${ }^{\circledR} S$ and daVinci ${ }^{\circledR}$ Si Surgical Systems over the current standard daVinci ${ }^{\circledR}$ system. The new generation robotic systems has undergone significant structural and functional modifications, affecting their respective applications. Some of the major differences are: - An increased range of motion. The arms of the standard daVinci ${ }^{\circledR}$ system allow for a rotationalaxis-range-of-motion (yaw) of 180 degrees. The newly designed and optimized instrument arm design of the daVinci ${ }^{\circledR} \mathrm{S}$ and Si yields a yaw of 336 degrees, increasing manoeuvrability and instrument workspace. Workspace refers to the total physical area that can be reached by an Endowrist ${ }^{\circledR}$ instrument once it has been attached to one arm of the patient side cart.

- An increased instrument length. The newly developed instruments are five centimetres longer than the standard daVinci ${ }^{\circledR}$ instruments. In combination with the increased range of motion, the use of these longer instruments leads to an impressively increased instrument working space by over a factor three. To reach the same anatomy as the standard daVinci ${ }^{\circledR}$ system, the new systems require less patient cart and arm adjustments.

- Improved third arm access. The new generation patient-side cart contains the third instrument 
arm on the top, allowing for better manoeuvrability and less instrument collisions. - Slim telescopic arms. The new generation patient-side cart has been equipped with instrument arms with a slim profile and telescopic design, minimizing intra-operative interference and collisions.

\section{The daVinci®i Surgical System:}

Single incision laparoscopy made easy

One of the recent developments in laparoscopic surgery, is the trend to minimize the number of trocars used during surgery. Theoretically, the use of less trocars might reduce postoperative pain and trocar-related complications. Ultimately, this leads to a form of surgery using only one trocar, generally referred to as Single-port, Single-access or Single-incision laparoscopic surgery. At this moment, single access surgery using conventional laparoscopic (or slightly adjusted) instruments is considered technically demanding due to frequent collisions of instruments and limited workspace. Although there are no convincing studies showing significant clinical benefit from single access surgery over conventional laparoscopy, development of this technique is booming. The use of robotics might prove to be indispensable in the performance of technically demanding single access procedures.

The daVinci ${ }^{\circledR}$ Si system has specially been developed in order to be used in single-access minimal invasive surgery. The use of robotics might lead to easier adaptation of this technically demanding technique, potentially minimizing tissue damage and leading to faster convalescence.

The Firefly ${ }^{\circledR}$ Fluorescence Imaging System: enhanced visualization of crucial structures The image offered by the standard daVinci ${ }^{\circledR}$ Surgical System consists of high-definition stereoscopic vision. A further increase in the number of pixels (in order to increase sharpness of the image) of image refresh rate (in order to decrease flickering and reduce eye strain) is generally considered not significantly useful in improving surgical performance. One development that could contribute to increased safety and better surgery, is the application of image enhancement. Using fluorescence, vital structures can be made visible that could not be seen with the human eye using plain white light.

Intuitive Surgical has developed a new tool named the Firefly ${ }^{\circledR}$ fluorescence imaging system. By switching from conventional white light to fluorescency, crucial anatomical structures such as hepato-biliary structures can be made easily visible, potentially leading to safer surgery and preventing inadverted common bile duct lesions. This optional tool could for example be used for assistance in single access cholecystectomy using the daVinci ${ }^{\circledR} \mathrm{Si}$ system.

\section{DISCUSSION}

Since the introduction of the $\mathrm{daVinci}^{\circledR}$ Surgical System, the number of robotic systems has risen dramatically in countries across the world. Despite the extensive experience in the past years in various fields of surgery, gynaecology and urology, there is little evidence of superiority of the robot-assisted procedures over conventional laparoscopy. Well-designed and adequately powered, blinded, randomised controlled trials are scarce and the risk for publication bias is significant ${ }^{124,125}$

Historically, the implementation of new technology in medicine has always outpaced the available sound data to support its rapid adoption. However, in the contemporary situation of an economic crisis disturbing the economies in Europe and (probably to a lesser extend) the rest of the world, it will be considered absolutely inacceptable to introduce these new and highly expensive techniques in any field of medicine as the new standard of care, without offering or at least searching for robust evidence of significant improved survival, cost-effectivity or Quality of Life. The use of robotics adds approximately between 600 and 3000 Euro per procedure compared to conventional laparoscopy. This is an impressive cost without evidence of improved outcome. Our patients and the society in general, would be better off if only a fraction of that sum would be spend on additional training and further differentiation of surgeons and residents who could perform laparoscopic procedures without robots more cost-effectively. Comparative-effectiveness studies are indispensable before standard widespread adoption of robot-assisted surgery can be considered.

Besides considering the added financial costs associated with robotic surgery, a second concern is safety and the generally prolonged duration of the operation. Although the daVinci ${ }^{\circledR}$ system has been FDA approved as a surgical tool for minimal invasive surgery, the lack of tactile feedback associated with this system does potentially cause a serious threat to our patients. Besides this, there is no general agreement on the exact mean time added to the operative procedure when robotic assistance is used, but most publications show a longer duration of the operation in robotic surgery and therefore an increased exposure to anaesthesiology-associated risks and sideeffects without significant benefit of robotic assistance.

Various arguments have been used to advocate the contemporary trend to increase the use of robotic devices. Patient demand has often been used as one of the most common mentioned arguments, or as an excuse, to the growing use of robotics. Even in professional literature, it has recently been stated that "well developed randomized controlled trials comparing conventional laparoscopy with robot-assisted laparoscopy have not been performed yet. Unfortunately, that ship has sailed. At this moment, such trials seem infeasible to conduct since our patients will choose robot-assisted laparoscopy based on the information available"| 26.

However, in an era of evidence-based medicine, such a patient demand cannot be granted if not supported by sound evidence. The source of this patient demand is more likely to be industrydriven and hospital-driven marketing, than the limited evidence of clinical superiority that is now available. Prof. dr IA Broeders has stated that "in countries where the health care system is more commercial than in The Netherlands, the daVinci robot is being used as a marketing tool" 26 .

It does not seem unthinkable that exact the same marketing potential is being used (or abused) in our country, although possibly to a slightly lesser extent. Only in the field of minimal invasive radical prostatectomy for prostatic cancer, scientific evidence suggest a slight potential advantage in improved sexual function and possible better urinary continence postoperative after the use of robotic assistance. Whether a potential marginal improvement of sexual function in an individual 70-year old patient should justify a mayor increase in health care costs to the society should be subject to an honest and open debate.

A second argument that seems to play a significant role in the contemporary Dutch medica society, is the "Fear Of Missing Out", also known as FOMO. Medical professionals feel a continuous drive to improve the care and cure they deliver. They are constantly looking for new techniques and methods. Failure to become and stay a trendsetter or early adjuster does result in the fear of being left behind in important new developments. This might initially sound somewhat overdone, but it certainly is not an unrealistic fear. Contemporary developments in the Dutch healthcare system, stimulating competition between different health care providers, do actively stimulate such behaviour.

Various organisations including the Dutch Health Care Inspectorate, Health insurance companies and patient support groups have developed an attitude of "Quantity equals Quality", requiring certain minimal numbers of specific operations per hospital and per surgeon in order to improve 
quality. Despite scientific lack of proof supporting such regulations, various hospitals perceive difficulty in reaching the required minimum numbers of these operations, potentially leading to an interdiction to deliver such care irrespective of the real quality of the delivered care. Hospitals are directly threatened in their existence, and so are the jobs of medical professionals working in these institutions. A failure to attract sufficient numbers of patients with a strong marketing tool such as an operating robot, can make the difference between a thriving referral medical centre and a marginalized insignificant clinic balancing on the edge of bankruptcy. This is not a theoretical doom scenario for small hospitals, it is every day practise. Only a health care system that would refuse to reimburse the increased costs associated with robotic surgery in all surgical fields where its value has not been sufficiently scientifically proven, would stimulate the realistic use of the daVinci ${ }^{\circledR}$ Surgical System where it is medically useful. It would be used as a research tool and (probably in limited cases) as an advanced surgical tool, not as a marketing tool. The contemporary system leads to a situation where relative small hospitals cease to deliver specific forms of care, leading to an increased scale of the larger institutions. Only a few relative large Medical Centres, assured of sufficient numbers of patients, can easily afford to withstand the pressure to comply to the demand of such "False innovation" or "Pseudo-innovation", as it is named by oncologist Ezekiel Emanuel in the New York Times ${ }^{127}$. In the Academic Medical Centre Amsterdam, the deliberate decision has been made not to invest in robotic surgery. The managing director has stated "Such false innovations, or probably better named exnovations, should not be implemented in an effective and efficient health care system" 128

The third argument to advocate the use of robotics is its magnificent potential benefits of stereoscopic magnification, increased precision, miniaturization, tremor filtration and articulation beyond human manipulation, potentially leading to improved outcome in the future. In a truly open-minded scientific atmosphere, leading forms of technology should be offered the possibility to be pursued within a critical context. Yes, we do believe new technologies should be developed and carefully introduced to medical practice. It is definitely not our intention to thwart technical and scientific progress in the field of surgery. On the contrary. It is our goal to aim for a scientific atmosphere where our limited financial resources are spend thoughtfully, leading to optimal efficacy of every penny spend on health care and on research. Therefore, as long as evidence of superiority is lacking, introduction of these tremendous costly technologies should be limited to research facilities within well-designed research projects and should not be extended to normal daily practise. There is no good argument why new surgical technologies should not be subject to the same strict rules as applied to newly developed medication. Well powered studies are mandatory before the widespread adoption of robot-assisted laparoscopy over conventional laparoscopy or even open surgery can be justified.

A fourth argument often used, is that the costs involved in robotic surgery will decrease with increased use. During the introduction of conventional laparoscopic surgery in the late 1980s, the initially increased costs of surgical treatment were considered a potential drawback. Thirty years later, conventional laparoscopy has proved to be cost-effective in various fields of surgery. We should not make the same erroneous assumptions used back then, by focussing mainly on the capital costs while overlooking the greater cost savings to the health system due to decreased length of hospital stay, decreased wound related costs, decreased use of analgesics and decreased cost to the society. We definitely do not argue that the costs for the use of robotic surgery will probably decrease in time and with increased experience. However, whether this will lead to cost-effective treatment should be subject to debate. Introducing conventional laparoscopy in the ' 80 s of the 20 th century, the operative procedure changed significantly from open to minimal access surgery, thereby potentially leading to smaller wounds, less pain, less wound infections, less incisional hernia, decreased pulmonary impairment, less postoperative infections, faster convalescence and a shorter length of hospital stay. Therefore, the initial capital costs might have been high, but the potential savings were considerable. Introducing robotic surgery, a new and expensive minimal invasive approach is offered for many indications as an alternative for conventional laparoscopy. In that case, the operative procedure might change, but the potential benefits in terms of smaller wounds, less pain, faster convalescence and shorter hospital admission seem absent. This makes it rather unlikely that the costs for robotic surgery will become lower than those for conventional laparoscopy.

A last (and hardly ever mentioned) argument could be that the benefits for the patients might be limited, but benefits for the surgeon are significant. Surgeons performing conventional laparoscopy do not only suffer from high perceived mental strain levels ${ }^{129}$, they also seem to suffer from an increased stress-induced health risk compared to other health professionals ${ }^{130}$. Therefore, it seems that the minimal invasive surgeon, who is fighting for the health of his patient, might well be risking his own health. In robotic surgery, the excellent view and increased ergonomics lead to an experience to the surgeon of decreased physical and mental strain ${ }^{131}$. This might lead to less lower back, neck and shoulder pain ${ }^{132-134}$, decreased fatigue and decreased stress-related health risks to the surgeon. Training-box based studies trying to objectivate this decrease in mental strain in robot-assisted laparoscopy as compared to conventional laparoscopy, has indeed shown a significant increase in beat-to-beat variability of the heart rate during performance of robotassisted laparoscopic tasks, suggesting a decreased mental strain in the robot-assisted group ${ }^{13}$ We performed a clinical study showing an impressive increase in heart rate variability, suggesting decrease in mental strain, using robotic assistance during laparoscopic surgery. This occurred even during surgery performing laparoscopic cholecystectomy, an operative procedure generally considered hardly stressful to the surgeon ${ }^{135}$. In technically more demanding procedures such as laparoscopic rectum resection and laparoscopic radical prostatectomy, the positive effect of the use of robotic assistance on mental strain, could well be expected more profound. Unfortunately, it is quite difficult to measure the exact effect of a certain amount of job-related mental strain on multifactorial caused (but partially stress-induced) impaired health status such as hypertension, myocardial infarction, acute cardiac death and diabetes mellitus.

At this moment in time, it is considered rather unconventional or even unprecedented to spend significant funds on development of new surgical techniques, improving the health of our surgeons instead of the health of our patients. However, if we stop seeing robotic assistance as a brand new technique, and we address it as merely a protective tool against job related health issues, the use of robotics might in the future be seen as just as normal as the use of the operation gloves and gown, surgeons have been using for ages in order to protect themselves from various transmittable diseases. Such protective measures do not need to lead to superior survival or quality of life to our patients, and might be disputably cost-effective. However, they do offer health professionals protection against job-related illnesses. Unfortunately, as long as strong evidence is lacking, supporting the health claims made by advocators of the use of robotics, the significantly associated increased costs cannot be accepted. 


\section{CONCLUSION}

At this moment, proof of superior outcome after robot-assisted surgery for both the patient and the surgeon is less than convincing. The Dutch National Health Care Insurance Board has stated that "All scientific evidence available is consistent. Robot-assisted laparoscopic prostatectomy is equally effective as conventional laparoscopic and open prostatectomy. Therefore, such intervention should be reimbursed". The insurance board does unfortunately not state whether the extra, and probably unnecessary costs associated with the use of robotics should be reimbursed too. Individual health insurance companies follow different reimbursement policies. Some of the largest companies, such as Achmea and Menzis, have decided to pay for the regular open of conventional laparoscopic procedure, but they refuse to pay extra for the use of robotics. Other companies such as CZ do continue to offer financial support to hospitals for acquisition, maintenance and use of operative robots. This disparity leads to an inequality in the treatment of patients suffering from the same disease, which seems not recommendable. However, it seems difficult or virtually impossible to approve to consensus in a national guideline. Every debate on health issues suggesting certain new expensive techniques should not be afforded because of financial arguments, leads to extreme sensitive reactions of the public out of a fear of getting a "second-best" or even insufficient treatment ${ }^{124,125,136-138}$. A true open and honest public discussion on whether robotic surgery should be reimbursed, and under what conditions, is needed urgently in the Netherlands. At this moment, such debate is still in its infancy ${ }^{|39-14|}$ Invalid arguments as stated above are frequently used by authorities in this field of surgery, in order to serve other goals such as the protection of their intellectual, time and financial investments in robotics.

If we are really serious in our efforts to constrain the rapidly increasing costs in the Dutch health system in an era of financial crisis, and we really want to offer the best medical care we are able to afford, there is only one conclusion that can be drawn here. The extremely increased costs do not warrant the implementation of robotic laparoscopy as standard care at this moment. The use of robotic-assisted surgery should be restricted to well-designed and adequately powered randomized controlled trials. The areas where robotic surgery seems most likely to show any benefit, are limited. Research projects should probably best be aimed at the following targets:

1) The use of the currently available standard daVinci ${ }^{\circledR}$ Surgical System in improving Quality of Life, nerve preservation, sexual function, urologic continence and oncologic outcome after technically demanding procedures such as minimal invasive radical prostatectomy or rectum resection.

2) The use of the standard daVinci® ${ }^{\circledR}$ system in decreasing mental and physical strain of the surgeon performing technically demanding laparoscopic procedures. Measurement of strain and of its effects on the physical health status of the surgeon would be very interesting in order to decide whether a robot-induced decrease in such strain does prevent potentially lethal profession-related health issues.

3) The advantages of improved manoeuvrability and increased working space using the new generation daVinci ${ }^{\circledR}$ S and Si Surgical Systems.

4) Implementation of $\mathrm{daVinci}{ }^{\circledR} \mathrm{Si}$ in single-access minimal invasive surgery.

5) Implementation of the Firefly ${ }^{\circledR}$ fluorescence imaging system, potentially improving visualization of crucial anatomical structures and decreasing the risk of inadverted bile duct lesions performing (single access) laparoscopic cholecystectomy using the daVinci ${ }^{\circledR} \mathrm{Si}$ system.

Besides these randomized controlled trials, it would be very interesting and probably enlightening to organize a nation-wide registration for advanced laparoscopic surgery, organized by the Dutch Institute for Clinical Auditing (DICA). Such a registration should include radical prostatectomy, rectum resection and cystectomy, and should include registration of the technique used (open surgery, conventional laparoscopy or robot-assisted laparoscopy). A registration could be used for monitoring and evaluating the role of robotic assistance in laparoscopic surgery. Until such research and registration has been performed and looking at the tremendous recent technical developments in robot assisted laparoscopic surgery, it becomes clear that the speed of technical progress dramatically exceeds the speed of scientific proof of efficacy. Historically, the implementation of new technology in medicine has always outpaced the available sound data to support its rapid adoption. This gap between newly developed surgical possibilities on one side, and scientifically proven effective standard surgical care on the other side, seems bigger than ever. If we want to keep good medical care affordable for our patients, we will have to make choices. Comparative-effectiveness studies are indispensable before standard adoption of robot-assisted surgery can be considered. Until than, we strongly believe that the use of robotic surgery should be restricted to well-designed trials and nation-wide registrations aimed at the targets mentioned above.

Does this mean we suggest or even promote the end of this promising technical development, mainly based on pragmatic financial reasons? We certainly do not. Is this the end for robotassisted laparoscopic surgery? We certainly hope not. We do sincerely believe that the contemporary technical developments offer potential interesting advantages that might lead to successful cost-effective robot-assisted surgery in the near future, or to the development of lateral spin-off of such as stereoscopic conventional laparoscopy and the development of advanced handheld instruments. If we may quote Sir Winston Churchill :"Now, this is not the end. It is not even the beginning of the end. But it is, perhaps, the end of the beginning" 


\section{REFERENCES}

I Tan CT, Cheah WK, Delbridge L. "Scarless" (in the neck) endoscopic thyroidectomy (SET): an evidence-based review of published techniques. World J Surg 2008;32(7):1349-57

2 Lee J, Lee JH, Nah KY, et al. Comparison of endoscopic and robotic thyroidectomy. Ann Surg Oncol $2011 ; 18(5): 1439-46$

3 Fan LJ, Jiang J. Present and future of robot-assisted endoscopic thyroid surgery. Chin Med J (Engl) 2012; I 25(5):926-3।

4 Yoo H, Chae BJ, Park HS, et al. Comparison of surgical outcomes between endoscopic and robotic thyroidectomy. J Surg Oncol 20I2; 105(7):705-8

5 Vriens MR, Kist JWK, Lodewijk L, et al. Robotgeassisteerde transaxillaire schildklieroperatie. Ned Tijdschr Geneeskd 2013;157:A584I

6 Landry CS, Grubbs EG, Warneke CL, et al. Robot-assisted transaxillary thyroid surgery in the United States: is it comparable to open thyroid lobectomy? Ann Surg Oncol 20I2; I 9(4): I 269-74

$7 \mathrm{Kim}$ WW, Kim JS, Hur SM, et al. Is robotic surgery superior to endoscopic and open surgeries in thyroid cancer? World J Surg 201 I;35(4):779-84

8 Soop M, Nelson $\mathrm{H}$. Is laparoscopic resection appropriate for colorectal adenocarcinoma? Adv Surg 2008;42:205-17

9 Fleshman J, Sargent DJ, Green E, et al. Laparoscopic colectomy for cancer is not inferio to open surgery based on 5-year data from the COST Study Group Trial. Ann Surg 2007;246(4):655-62

10 Veldkamp R, Kuhry E, Hop WC, et al. Laparoscopic surgery versus open surgery for colon cancer: short-term outcomes of a randomised trial. Lancet Oncol 2005;6(7):477-84

II Guillou PJ, Quirke P, Thorpe H, et al. Short-term endpoints of conventional versus laparoscopic-assisted surgery in patients with colorectal cancer (MRC CLASICC trial): multicentre, randomised controlled trial. Lancet 2005;365(9472): I 1 18-26

12 Hewett PJ, Allardyce RA, Bagshaw PF, et al. Short-term outcomes of the Australasian randomized clinical study comparing laparoscopic and conventional open surgical treatments for colon cancer: the ALSSaS trial. Ann Surg 2008;248(5):728-38

13 Trastulli S, Desiderio J, Farinacci F, et al. Robotic right colectomy for cancer with intracorporeal anastomosis: short-term outcomes from a single institution. Int J Colorectal Dis 2013;28(6):807-14

I4 Park JS, Choi GS, Park SY, et al. Randomized clinical trial of robot-assisted versus standard laparoscopic right colectomy. Br J Surg 2012;99(9):1219-26

15 Antoniou SA, Antoniou GA, Koch OO, et al. Robot-assisted laparoscopic surgery of the colon and rectum. Surg Endosc 20I2;26(I): I-II

16 deSouza AL, Prasad LM, Park JJ, et al. Robotic assistance in right hemicolectomy: is there a role? Dis Colon Rectum 2010;53(7): 1000-6

17 Delaney CO, Lynch AC, Denagore AJ, et al. Comparison of robotically performed and traditional laparoscopic colorectal surgery. Dis Colon Rectum 2003;46(I2):1633-9

18 Fung AK, Aly EH. Robotic colonic surgery: is it advisable to commence a new learning curve? Dis Colon rectum 2013;56(6):786-96

19 Kellokumpu IH, Kairaluoma MI, Nuorva KP, et al. Short- and long-term outcome following laparoscopic versus open resection for carcinoma of the rectum in the multimodal setting.

20 Dis Colon Rectum 2012;55(8):854-63

Stamopoulos P, Theodoropoulos GE, Papailiou J, et al. Prospective evaluation of sexual function after open and laparoscopic surgery for rectal cancer. Surg Endosc 2009;23(I2):2665-74
$21 \mathrm{Ng}$ SS, Leung KL, Lee JF, et al. Long-term morbidity and oncologic outcomes of laparoscopic-assisted anterior resection for upper rectal cancer: ten-year results of a prospective, randomized trial. Dis Colon Rectum 2009;52(4):558-66

22 deSouza AL, Prasad LM, Ricci J, et al. A comparison of open and robotic total mesorectal excision for rectal adenocarcinoma. Dis Colon Rectum 20 I I;54(3):275-82

23 deSouza AL, Prasad LM, Marecik SJ, et al. Total mesorectal excision for rectal cancer: the potential advantage of robotic assistance. Dis Colon rectum 20 I0;43(I2): I6 I I-7

24 Park JS, Choi GS, Lim KH, et al. Robotic-assisted versus laparoscopic surgery for low rectal cancer: a case-matched analysis of short-term outcomes. Ann Surg Oncol 2010;17(I2):3195 202

25 Kim JC, Yang SS, Jang TY, et al. Open versus robot-assisted sphincter-saving operations in rectal cancer patients: techniques and comparison of outcomes between groups of 100 matched patients. Int J Med Robot 20I2;8(4):468-75

26 Trastulli S, Farinella E, Cirocchi R, et al. Robotic resection compared with laparoscopic rectal resection for cancer: systematic review and meta-analysis of short-term outcome. Colorectal Dis 20I2; I4(4):el34-56

27 Kwak JM, Kim SH, Kim J, et al. Robotic vs laparoscopic resection of rectal cancer: shortterm outcomes of a case-control study. Dis Colon Rectum 201 I;54(2):15 I-6

28 Park SY, Choi GS, Park JS, et al. Short-term clinical outcome of robot-assisted intersphincteric resection for low rectal cancer: a retrospective comparison with conventional laparoscopy. Surg Endosc 2013;27(1):48-55

29 Memon S, Heriot AG, Murphy DG, et al. Robotic versus laparoscopic proctectomy for rectal cancer: a meta-analysis. Ann Surg oncol 2012;19(7):2095-10

$30 \mathrm{Kim} \mathrm{JY,} \mathrm{Kim} \mathrm{NK,} \mathrm{Lee} \mathrm{KY,} \mathrm{et} \mathrm{al.} \mathrm{A} \mathrm{comparative} \mathrm{study} \mathrm{of} \mathrm{voiding} \mathrm{and} \mathrm{sexual} \mathrm{function} \mathrm{after}$ total mesorectal excision with autonomic nerve preservation for rectal cancer: laparoscopic versus robotic surgery. Ann Surg oncol 2012;19(8):2485-93

3I D'hoore A, Penninckx F. Laparoscopic ventral recto(colpo)pexy for rectal prolapseL surgical technique and outcome for 100 patients. Surg Endosc 2006;20(I2):1919-23

32 D'hoore A, Cadoni R, Penninckx F. Long-term outcome of laparoscopic ventral rectopexy for rectal prolapse. Br J Surg 2004;9I(I I): I500-5Zittel TT, Manncke K, Haug S, et al. Functional results after laparoscopic rectopexy for rectal prolapse. J gastrointest Surg 2000;4(6):632-4

33 Rose J, Schneider C, Scheidbach H, et al. Laparoscopic treatment of rectal prolapse: experience gained in a prospective multicenter study. Langenbecks Arch Surg 2002;387(34): I 30-7

34 Heemskerk J, de Hoog DE, van Gemert WG, et al. Robot-assisted vs. conventional laparoscopic rectopexy for rectal prolapse: a comparative study on costs and time. Dis Colon Rectum 2007;50(II): 1825-30

35 De Hoog DE, Heemskerk J, Nieman FH, et al. Recurrence and functional results after open versus conventional laparoscopic versus robot-assisted laparoscopic rectopexy for rectal prolapse: a case control study. Int I Colorectal Dis 2009;24(I0): | 20|-6

36 McHoney M, Wade AM, Eaton S, et al. Clinical outcome of a randomized controlled blinded trial of open versus laparoscopic Nissen fundoplication in infants and children. Ann Surg 20I I;254(2):209-16 
37 Draaisma WA, Buskens E, Bais JE, et al. Randomized clinical trial and follow-up study of cost-effectiveness of laparoscopic versus conventional Nissen fundoplication. Br J Surg 2006;93(6):690-7

38 Draaisma WA, Rijnhart-de Jong HG, Broeders IA, et al. Five-year subjective and objective results of laparoscopic and conventional Nissen fundoplication: a randomized trial. Ann Surg 2006;244(I):34-4I

39 Salminen P, Hurme S, Ovaska J. Fifteen-year outcome of laparoscopic and open Nissen fundoplication: a randomized clinical trial. Ann Thorac Surg 2012;93(I):228-33

40 Salminen PT, Hiekkanen HI, Rantala AP, et al. Comparison of long-term outcome of laparoscopic and conventional Nissen fundoplication: a prospective randomized study with an II-year follow-up. Ann Surg 2007;246(2):20I-6

$4 \mathrm{I}$ Ackroyd R, Watson DI, Majeed AW, et al. Randomized clinical trial of laparoscopic versus open fundoplication for gastro-oesophageal reflux disease. Br J Surg 2 2004;9I(8):975-82

42 Laine S, Rantala A, Gullichsen R, et al. Laparoscopic vs conventional Nissen fundoplication. A prospective randomized study. Surg Endosc 1997; I I (5):44|-4

43 Broeders IA, Rijnhart-de Jong HG, Draaisma WA, et al. Ten-year outcome of laparoscopic and conventional Nissen fundoplication: randomized clinical trial. Ann Surg 2009;250(5):698 706

44 Pelgrims N, Closset J, Sperduto N, et al. What did the laparoscopic Nissen approach of the gastro-oesophageal reflux really change for the patient 8 years later? Acta Chir Belg 200I;I0I (2):68-72

45 Draaisma WA, Ruurda JP, Scheffer RC, et al. Randomized clinical trial of standard laparoscopic versus robot-assisted laparoscopic Nissen fundoplication for gastrooesophageal reflux disease. Br J Surg 2006;93(II): I35 I-9

46 Copeland DR, Boneti C, Kokoska ER, et al. Evaluation of initial experience and comparison of the daVinci ${ }^{\circledR}$ Surgical System with established laparoscopic and open pediatric Nissen fundoplication surgery. JSLS 2008; I 2(3):238-40

47 Muller-Stich BP, Reiter MA, Wente MN, et al. Robot-assisted versus conventional laparoscopic fundoplication: short-term outcome of a pilot randomized controlled trial. Surg Endosc 2007;2I(10): 1800-5

48 Morino M, Pellegrino L, Giaccone C, et al. Randomized clinical trial of robot-assisted versus laparoscopic Nissen fundoplication. Br J Surg 2006;93(5):553-8

49 Heemskerk J, van Gemert WG, Greve JW, et al. Robot-assisted versus conventional laparoscopic Nissen fundoplication: a comparative retrospective study on costs and time consumption. Surg Laparosc Endosc Percutan Tech 2007; I7(I): I-4

50 Wang Z, Zheng Q, Jin Z. Meta-analysis of robot-assisted versus conventional laparoscopic Nissen fundoplication for gastro-oesophageal reflux disease. ANZ J Surg 2012;82(3): I I 2-7

$5 \mathrm{I}$ Masoomi H, Kim H, Reavis KM, et al. Analysis of factors predictive of gastro-intestinal tract leak in laparoscopic and open gastric bypass. Arch Surg 201 I; 146(9): 1048-5 I

52 Nguyen NT, Masoomi H, Laugenour K, et al. Predictive factors of mortality in bariatric surgery: data from the Nationwide Inpatient Sample. Surgery 20I I; I50(2):347-5 I

53 Tian HL, Tian JH, Yang KH, et al. The effects of laparoscopic vs. open gastric bypass for morbid obesity: a systematic review and meta-analysis of randomized controlled trials. Obes Rev 20I I; 12(4):254-60

54 Ayloo SM, Addeo P, Buchs NC, et al. Robot-assisted versus laparoscopic Roux-en-Y gastric Bypass: is there a difference in outcomes? World J Surg 201 I;35(3):637-42

Sanchez BR, Mohr CJ, Morton JM, et al. Comparison of totally robotic laparoscopic Rouxen-Y gastric bypass and traditional laparoscopic Roux-en-Y gastric bypass. Surg Obes Relat 55 Dis $2005 ; 1(6): 549-54$
56 Scozzari G, Rebecchi F, Millo P, et al. Robot-assisted gastrojejunal anastomosis does not improve the results of the laparoscopic Roux-en-Y gastric Bypass. Surg Endosc 20I I;597603

57 Hubens G, Balliu L, Ruppert M, et al. Roux-en-Y gastric bypass procedure performed with the daVinci ${ }^{\circledR}$ robot system: is it worth it? Surg Endosc 2008;22(7):1690-6

58 Fourman MM, Saber AA. Robotic bariatric surgery: a systematic review. Surg Obes Relat Dis 20I 2;8(4):483-8

59 Mühlmann G, Klaus A, Kirchmayr W, et al. daVinci ${ }^{\circledR}$ robotic-assisted laparoscopic bariatric surgeryL is it justified in a routine setting? Obes Surg 2003;13(6):848-54

60 Hagen ME, Pugin F, Chassot G, et al. Reducing cost of surgery by avoiding complications: the model of robotic Roux-en-Y gastric Bypass. Obes Surg 20I2;22(I):52-6I

61 Meyer DM, Herbert MA, Sobhani NC, et al. Comparative clinical outcomes of thymectomy for myasthenia gravis performed by extended transsternal and minimally invasive approaches. Ann Thorac Surg 2009;87(2):385-90

62 Toolabi K, Aminian A, Javid MJ, et al. Mid-term results of thoracoscopic thymectomy for myasthenia gravis. Neurol India 2009;57(4):402-5

63 Wright GM, Barnett S, Clarke CP. Video-assisted thoracoscopic thymectomy for myasthenia gravis. Intern Med J 2002;32(8):367-7I

64 Hartwich J, Tyagi S, Margaron F, et al. Robot-assisted thoracoscopic thymectomy for treating myasthenia gravis in children. J Laparoendosc Adv Surg Tech A 2012;22(9):925-9

65 Skelly CL, Jackson CC, Wu Y, et al. Thocacoscopic thymectomy in children with myasthenia gravis. Am Surg 2003;69(12): 1087-9

66 Rea F, Marulli G, Bortolotti L, et al. Experience with the "daVinci" robotic system for thymectomy in patients with myasthenia gravis: report of 33 cases. Ann Thorac Surg 2006;8I (2):455-9

67 Marulli G, Rea F, Melfi F, et al. Robot-aided thoracoscopic thymectomy for early stage thymoma: a multicenter European study. J Thorac Cardiovasc Surg 20 I 2; I 44(5): I I 25 -30

68 Marulli G, Schiavon M, Perissinotto E, et al. Surgical and neurologic outcomes after robotic thymectomy in 100 consecutive patients with myasthenia gravis. J Thorac Cardiovasc Surg 20। $3 ;$ I 45(3):730-5

69 Renaud S, Santelmo N, Renaud M, et al. Robotic-assisted thymectomy with daVinci ll versus sternotomy in the surgical treatment of non-thymomatous myasthenia gravis: early results. Rev Neurol (Paris) 2013;169(1):30-6

70 Rückert JC, Ismail M, Swierzy M, et al. Thoracoscopic thymectomy with the daVinci robotic system ${ }^{\circledR}$ for myasthenia gravis. Ann N Y Acad Sci 2008; I 132:329-35

7I Papiashvilli M, Sasson L, Azzam S, et al. Video-assisted thoracic surgery lobectomy versus lobectomy by thoracotomy for lung cancer: pilot study. Innovations (Phila) 20I3;8(I):6-II

72 Hanna WC, de Valence M, Atenafu EG, et al. Is video-assisted lobectomy for nonsmall lung cancer oncologically equivalent to open lobectomy? Eur J cardiothorac Surg 20I3;43(6): II I I-5

73 Lee PC, Nasar A, Port JL, et al. Long-term survival after lobectomy for non-small cell lung cancer by video-assisted thoracic surgery versus thoracotomy. Ann Thorac Surg 20I3;96(3):95|-6I

74 Liang $\mathrm{C}$, Wen $\mathrm{H}$, Guo Y, et al. Severe intraoperative complications during VATS lobectomy compared with thoracotomy lobectomy for early stage non-small cell lung cancer. J Thorac Dis 2013;5(4):5 I3-7

75 Marty-Ané $\mathrm{CH}$, Canaud L, Solovei L, et al. Video-assisted thoracoscopic lobectomy: an unavoidable trend? A retrospective single-institution series of 410 cases. Interact Cardiovasc Thorac Surg 2013;17(1):36-43 
76 Li Z, Liu H, Li L. Video-assisted thoracoscopic surgery versus lobectomy for stage I lung cancer: a meta-analysis of long-term outcomes. Exp Ther Med 2012;3(5):886-892

77 Zhang $\mathrm{Z}$, Zhang $\mathrm{Y}$, Feng $\mathrm{H}$, et al. Is video-assisted thoracic surgery lobectomy better than thoracotomy for early-stage non-small-cell lung cancer? A systematic review and metaanalysis. Eur J Cardiothorac Surg 20I3;44(3):407-14

78 Paul S, Sedrakyan A, Chiu YL, et al. Outcomes after lobectomy using thoracoscopy vs thoracotomy: a comparative effectiveness analysis utilizing the Nationwide Inpatient Sample database. Eur J Cardiothorac Surg 2013;43(4):813-7

79 Jett GK. Thoracic robotics at the Heart Hospital Baylor Plano: the first 20 cases. Proc (Bayl Univ Med Cent) 20I2;25(4):324-6

80 Gharagozloo F, Margolis M, Tempesta B. Robot-assisted thoracoscopic lobectomy for earlystage lung cancer. Ann Thorac Surg 2008;85(6): 1880-5

81 Gharagozloo F, Margolis M, Tempesta B, et al. Robot-assisted lobectomy for early-stage lung cancer: report of 100 consecutive cases. Ann Thorac Surg 2009;88(2):380-4

82 Park BJ, Flores RM, Rusch VW. Robotic assistance for video-assisted thoracic surgica lobectomy: technique and initial results. J Thorac Cardiovasc Surg 2006; I3 I (I):54-9 Jang HJ, Lee HS, Park SY, et al. Comparison of the early robot-assisted lobectomy

83 experience to video-assisted thoracic surgery lobectomy for lung cancer: a single-institution case series matching study. Innovations (Phila) 2011;6(5):305-10

84 Augustin F, Bodner J, Maier H, et al. Robotic-assisted minimally invasive vs. thoracoscopic lung lobectomy: comparison of peri-operative results in a learning curve setting. Langenbecks Arch Surg 2013;398(6):895-901

85 Flores RM, Alam N. Video-assisted thoracic surgery lobectomy (VATS), open thoracotomy, and the robot for lung cancer. Ann Thorac Surg 2008;85(2):S7I 0-5

86 Frumovitz M, dos reis R, Sun CC, et al. Comparison of total laparoscopic and abdominal radical hysterectomy for patients with early-stage cervical cancer. Obstet Gynaecol 2007; I I (I):96-102

$87 \mathrm{Li} \mathrm{G}$, Yan X, Shang H, et al. A comparison of laparoscopic radical hysterectomy and pelvic lymphadenectomy and laparotomy in the treatment of lb-lla cervical cancer. Gynaecol Oncol 2007; I05(I): 176-80

88 Kruijdenberg CB, van den Einden LC, Hendriks JC, et al. Robot-assisted versus total laparoscopic radical hysterectomy in early cervical cancer, a review. Gynaecol Oncol 20II;I 20(3):334-9

89 Soto E, Lo Y, Friedman K, et al. Total laparoscopic hysterectomy versus daVinci ${ }^{\circledR}$ robotic hysterectomy: is using the robot beneficial? J Gynaecol Oncol 201 I;22(4):253-9

90 Pasic RP, Rizzo JA, Fang H, et al. Comparing robot-assisted with conventional laparoscopic hysterectomy: impact on cost and clinical outcomes. J Minim Invasive Gynaecol 2010;17(6):730-8

91 Sarlos D, Kots LA. Robotic versus laparoscopic hysterectomy: a review of recent comparative studies. Curr Opin Obstet Gynaecol 201 I;23(4):283-8

92 Sarlos D, Kots L, Stevanovic N, et al. Robotic compared with conventional laparoscopic hysterectomy: a randomized controlled trial. Obstet Gynaecol 20I2; I 20(3):604-I I

93 Göçmen A, Sanlikan F, Uçar MG. Robot-assisted hysterectomy vs total laparoscopic hysterectomy: a comparison of short-term surgical outcomes. Int J Med Robot 20I 2;8(4):453-7

94 Hsiao KC, Latchamsetty K, Govier FE, et al. Comparison of laparoscopic and abdominal sacrocolpopexy for the treatment of vaginal vault prolapse. J Endourol 2007;2 I (8):926-30

95 Seror J. Yates DR, Seringe E, et al. Prospective comparison of short-term outcomes obtained after pure laparoscopic and robot-assisted laparoscopic sacrocolpopexy. World J Urol 2012;30(3):393-8
96 Judd JP, Siddiqui NY, Barnett JC, et al. Cost-minimization analysis of robot-assisted, laparoscopic, and abdominal sacrocolpopexy. J Minim Invasive Gynaecol 20 I0;17(4):493-9

97 Elliot CS, Hsieh MH, Sokol ER, et al. Robot-assisted versus open sacrocolpopexy: a costminimization analysis. J Urol 2012;187(2):638-43

98 Hoyte L, Rabbanifard R, Mezzich J, et al. Cost analysis of open versus robot-assisted sacrocolpopexy. Female Pelvic Med Reconstr Surg 2012;18(6):335-9

99 Makhoul B, De la Taille A, Vordos D, et al. Laparoscopic radical nephrectomy for TI rena cancer: the gold standard? A comparison of laparoscopic vs open nephrectomy. BJU Int 2004;93(I):67-70

100 Favaretto RL, Sanchez-Salas R, Benoist N, et al. Oncologic outcomes after laparoscopic partial nephrectomy: mid-term results. J Endourol 2013;27(I):52-7

I0I Favaretto RL, Shariat SF, Chade DC, et al. Comparison between laparoscopic and open radical nephroureterectomy in a contemporary group of patients: are recurrence and disease-specific survival associated with surgical technique? Eur Urol 20 I0;58(5):645-5 I

102 Zheng JH, Zhang XL, Geng J, et al. Long-term oncologic outcomes of laparoscopic versus open partial nephrectomy. Chin Med J (Engl) 2013;126(I5):2938-Hyams E, Pierorazio

$103 \mathrm{P}$, Mullins JK, et al. A comparative cost analysis of robot-assisted versus traditional laparoscopic partial nephrectomy. J Endourol 2012;26(7):843-7

104 Panumatrassamee K, Autorino R, Laydner H, et al. Robotic versus laparoscopic partial nephrectomy for tumor in a solitary kidney: a single institution comparative analysis. Int J Urol 2013;20(5):484-9|

105 Lee S, Oh J, Hong SK, et al. Open versus robot-assisted partial nephrectomy: effect on clinical outcome. J Endourol 201 I;25(7): I I8I-5

106 Alemozaffar M, Chang SL, Kacker R, et al. Comparing costs of robotic, laparoscopic, and open partial nephrectomy. J Endourol 2013;27(5):560-5

107 Ferguson JE 3rd, Goyal RK, Raynor MC, et al. Cost analysis of robot-assisted laparoscopic versus hand-assisted laparoscopic partial nephrectomy. J Endourol 20 12;26(8): 1030-7

108 Boger M, Lucas SM, Popp SC, et al. Comparison of robot-assisted nephrectomy with laparoscopic and hand-assisted laparoscopic nephrectomy. JSLS 2010;14(3):374-80

109 Park JW, Choi KH, Yang SC, et al. Cost aspects of radical nephrectomy for the treatment of renal cell carcinoma in Korea: Open, laparoscopic, robot-assisted laparoscopic and videaassisted minilaparotomy surgeries. Korean J Urol 2012;53(8):5 I 9-23

II0 Guazonni G, Cestari A, Naspro R, et al. Intra- and peri-operative outcomes comparing radical retropubic and laparoscopic radical prostatectomy: results from a prospective, randomised, single-surgeon study. Eur Urol 2006;50(I):98-104

III Koutlidis N, Mourey E, Champigneulle J, et al. Robot-assisted or pure laparoscopic nervesparing radical prostatectomy: what is the optimal procedure for the surgical margins? A single center experience. Int J Urol 20|2; I9(|2):|076-8|

II2 Coelho RF, Rocco B, Patel MB, et al. Retropubic, laparoscopic, and robot-assisted radical prostatectomy: a critical review of outcomes reported by high-volume centers. J endourol 2010;24(I2):2003-15

II3 Asimakopoulos AD, Pereira Fraga CT, Annino F, et al. Randomized comparison between laparoscopic and robot-assisted nerve-sparing radical prostatectomy. J Sex Med 2011;8(5):1503-12

114 Porpiglia F, Morra I, Lucci Chiarissi M, et al. Randomised controlled trial comparing laparoscopic and robot-assisted radical prostatectomy. Eur Urol 2013;63(4):606-I4

II5 Lim SK, Kim KH, Shin TY, et al. Current status of robot-assisted laparoscopic radical prostatectomy: how does it compare with other surgical approaches? Int J Urol 20I3;20(3):27I-84 
116 Tewari A, Srivasatava A, Menon M. A prospective comparison of radical retropubic and robot-assisted prostatectomy: experience in one institution. BJU Int 2003;92(3):205-10

117 Minniti D, Chiadò Piat S, Di Novi C. Robot-assisted versus radical prostatectomy: an evidence-based comparison. Technol Health Care 2011;19(5):331-9

Willis DL, Gonzalgo ML, Brotzman M, et al. Comparison of outcomes between laparoscopic vs robot-assisted laparoscopic radical prostatectomy: a study of comparative effectiveness based upon validated quality of live outcomes. BJU Int 2012;109(6):898-905

II8 Laviana AA, Hu JC. A comparison of the robot-assisted versus retropubic radical prostatectomy. Minerva Urol Nefrol 2013;65(3):161-70

119 Close A, Robertson C, Rushton S, et al. Comparative cost-effectiveness of robot-assisted and standard laparoscopic prostatectomy as alternatives to open radical prostatectomy for treatment of men with localised prostate cancer: A health technology assessment from the perspective of the UK National Health Service. Eur Urol 2013;64(3):36I-9

120 Ramsey C, Pickard R, Robertson C, et al. Systematic review and economic modelling of the relative clinical benefit and cost-effectiveness of laparoscopic surgery and robotic surgery for removal of the prostate in men with localised prostate cancer. Health Technol Assess 2012;16(4I):1-313

121 Hyams ES, Mullins JK, Pierorazio PM, et al. Impact of robotic technique and surgical volume on the cost of radical prostatectomy. J Endourol 2013;27(3):298-303

122 Barbash GI, Glied SA. New technology and Healtyh Care Costs - The Case of RobotAssisted Surgery. N Engl J Med 2010;363(8):70I-4

123 Delaney CP, Denagore AJ, Ponsky L. Robot-assisted surgery and health care costs. N Engl J Med 2010;363(22):2175; author reply 2176

124 Van Dierendonck JH, Med Oncologie 2013;3:19-2 |

25 Ezekiel JE. In medicine, falling for fake innovation. Column in The New York Times 2012, may 27 th

126 Levi M. Exnovatie. Column in Medisch contact 2013; march 19th

127 Böhm B, Rötting N, Schwenk W, et al. A prospective randomized trial on heart rate variability of the surgical team during laparoscopic and conventional sigmoid resection. Arch Surg 200I;136(3):305-10

128 Arnetz BB, Andreasson S, Strandberg M, et al. Comparison between surgeons and general practisioners with respect to cardiovascular and psychosocial risk factors among physicians. Scan J Work Environ health 1988; I4(2): I I8-24

129 Van der Schatte ORH, Van't Hullenaar CD, Ruurda JP, et al. Ergonomics, user comfort and performance in standard and robot-assisted laparoscopic surgery. Surg Endosc 2009;23(6): | $365-7 \mid$

130 Wolf JS Jr, Marcovich R, Gill IS, et al. Survey of neuromuscular injuries to the patient and surgeon during urologic laparoscopic surgery. Urology 2000;55(6):83I-6

131 Hubert N, Gilles M, Desbrosses K, et al. Ergonomic assessment of the surgeon's physical workload during standard and robot assisted laparoscopic procedures. Int J Med Robot 2013;9(2): 142-7

132 Klein MI, Warm JS, Riley MA, et al. Mental workload and stress perceived by novice operators in the laparoscopic and robotic minimally invasive surgical interfaces. J Endourol 2012;26(8): 1089-94

133 Heemskerk J, Zandbergen HR, Keet S, et al. Relax! It's just laparoscopy! Surgeon's heart rhythm variability as a measure of mental strain during robot-assisted and conventional laparoscopic cholecystectomy. Submitted.

134 Shukla PJ, Scherr DS, Milsom JW. Robot-assisted surgery and health care costs. N Engl J Med 2010;363(22):2174; author reply 2176
135 Awad MM, Fleshman JW. Robot-assisted surgery and health care costs. N Engl J Med 2010;363(22):2174-5; author reply 2176

136 Ibrahim AM, Makary MA. Robot-assisted surgery and health care costs. N Engl J Med 2010;363(22):2175-6; author reply 2176

137 La Chapelle CF, Jansen FW, Pelger RCM, et al. Robotchirurgie in Nederland. Hoogwaardig bewijs voor effectiviteit ontbreekt. Ned Tijdschr Geneeskd 20|3;157(28):A5 I45

138 Van der Sluis PC, Schreuder HW, Merks BT, et al. Centralisatie van robotchirurgie. Betere resultaten en besparing van kosten. Ned Tijdschr Geneeskd 2013;157(28):A5228

139 Van der Poel HG, Beerlage HP, Klaver SO. Robotchirurgie: pas op de plaats? Ned Tijdschr Geneeskd 2013;I57(28):A6365 


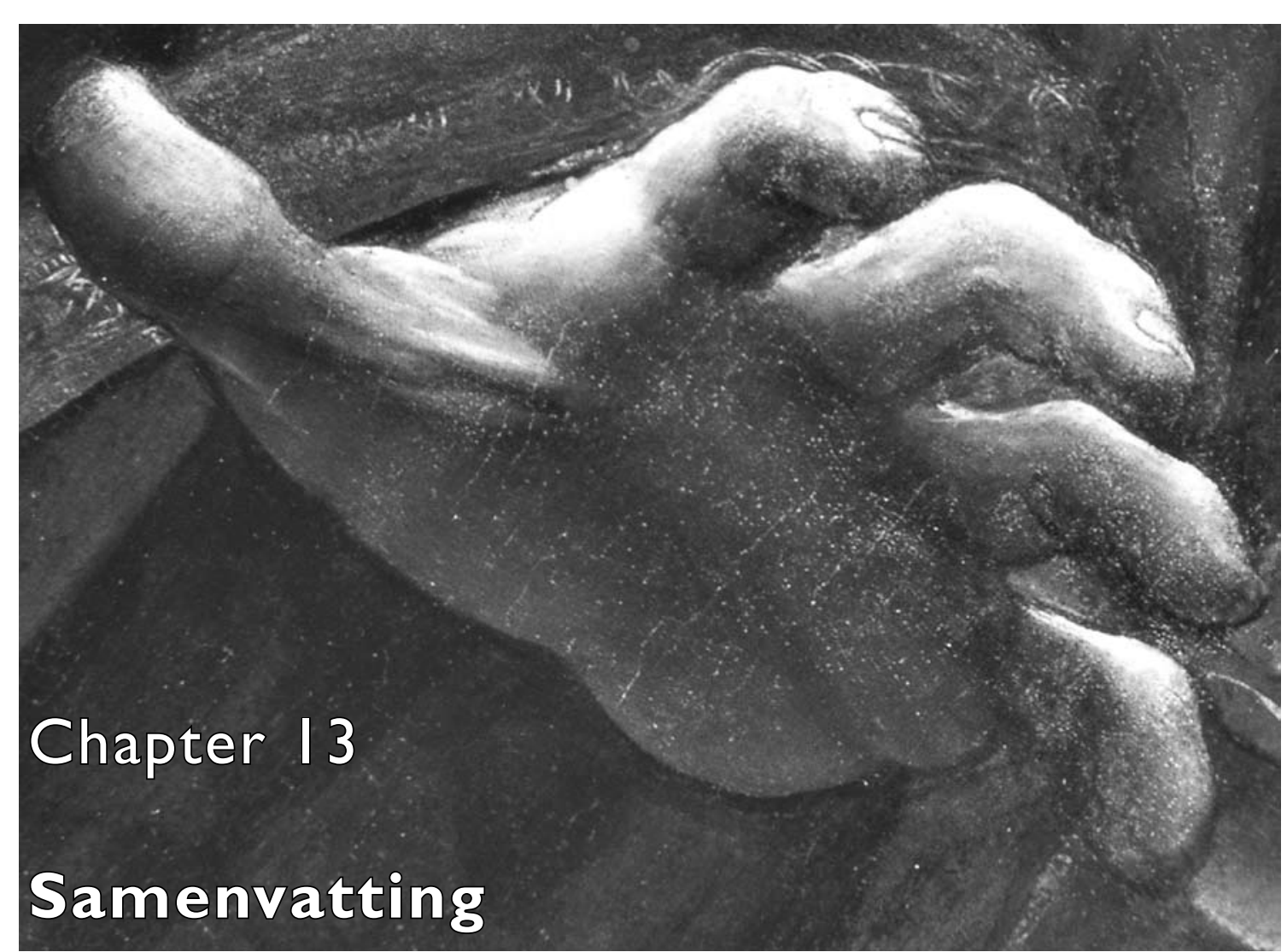

Nederlandse vertaling van hoofdstuk II

DETAIL FROM: VIRGIN OF THE ROCKS OIL ON WOODEN PANEL, I 483-I 486

Virgin Mary raises her left hand above the head of the Christ child in a blessing. 


\section{SAMENVATTING}

De aanvankelijke introductie van laparoscopie in de algemene chirurgische praktijk werd ontvangen met forse scepsis. Drie decennia later is laparoscopie de standaard techniek geworden op meerdere chirurgische gebieden zoals de cholecystectomie. In veel andere chirurgische gebieden is het een aantrekkelijk alternatief geworden voor traditionele open chirurgie die nog steeds aan populariteit wint. Patiënten profiteren van minder postoperatieve pijn, minder pulmonale complicaties, minder littekenbreuken en sneller postoperatief herstel. Echter, chirurgen lijden onder een langere leercurve, verminderde ergonomie en verhoogde intraoperatieve mentale stress.

Robot chirurgische systemen zijn erop gericht om sommige van deze nadelen aan te pakken en mogelijk endoscopische chirurgie te vergemakkelijken. Gebruikmakend van een meester-slaaf concept, verricht de chirurg nog steeds de operatie maar downscaling van bewegingen en tremor filtratie leiden tot een verbeterde handigheid voorbij de mogelijkheden van de menselijke hand. De doelstellingen van dit boekje waren om de rol van robotassistentie in laparoscopische chirurgie te verduidelijken en om te bepalen of en waar het gebruik van robots significante voordelen oplevert. We hebben hiervoor een scala aan studies verricht, zowel in een laboratoriumomgeving als in de klinische praktijk.

In hoofdstuk vier hebben we ons gericht op de voordelen (en nadelen) van de verschillende onderdelen van de daVinci ${ }^{\circledR}$ telemanipulator tijdens het verrichten van laparoscopische taken in een laboratoriumomgeving. We concludeerden dat de meest significante nadelen van conventionele laparoscopie in vergelijking met robot geassisteerde laparoscopie de volgende zijn:

a) Het gebrek aan stereoscopisch zicht

b) Adequaat herstel van de oog-hand-doel-as

c) Het gebruik van rechte, rigide instrumenten met een beperkt aantal vrijheidsgraden (hoewel dit minder significant lijkt)

Grote vooruitgang in laparoscopische chirurgie kan mogelijkerwijs slechts worden verwacht indien deze nadelen adequaat worden aangepakt. Dit lijkt goed mogelijk met gebruikmaking van consolegebaseerde telemanipulator systemen zoals het $\mathrm{daVinci}^{\circledR}$ chirurgisch system, danwel door gebruik te maken van een combinatie van een High Definition stereoscopisch visueel systeem samen met een adequaat herstel van de oog-hand-doel-as. Een mogelijke combinatie zou het Viking ${ }^{\circledR}$ visueel systeem kunnen vormen samen met een handinstrument met zes vrijheidsgraden zoals het Radius ${ }^{\circledR}$ chirurgisch systeem.

Het verschil in leercurve tussen conventionele en robotgeassisteerde laparoscopische chirurgie in een laboratoriumomgeving werd bestudeerd in hoofdstuk vijf. Aangezien het praktisch onmogelijk is om voldoende ervaren chirurgen te vinden met exact evenveel expertise in conventionele laparoscopie als in robotgeassisteerde laparoscopische chirurgie, hebben we onervaren gebruikers geselecteerd. De aanwezigheid van een relatief lange leercurve in conventionele laparoscopie is zeker significant voor de dagelijkse klinische praktijk, aangezien leercurves geassocieerd worden met verlengde operatietijd, verhoogde patiëntmorbiditeit en hogere kosten. Wij zagen dat het gebruik van robotassistentie in laparoscopische chirurgie leidde tot sneller en meer accurate uitvoering van laparoscopische taken. Echter, conventionele laparoscopie vertoonde een steilere leercurve en dus een snellere beheersing van nieuwe vaardigheden. Dit zou kunnen suggereren dat de voordelen van het gebruik van robotassistentie met name aanwezig zijn bij onervaren gebruikers. Of het gebruik van robotassistentie ook daadwerkelijk leidt tot een sneller bereiken van een voldoende beheersingsniveau van nieuw aan te leren chirurgische vaardigheden bij een chirurg, blijft discutabel.

Laparoscopische cholecystectomie (galblaasverwijdering) is één van de meest voorkomende laparoscopische, zoniet de meest verrichtte laparoscopische procedure wereldwijd. Voor cholecystectomie wordt laparoscopie in het algemeen beschouwd als de goudstandaard. In hoofdstuk zes stelden we onszelf de vraag of volledige robot laparoscopische cholecystectomie wel haalbaar zou zijn in de dagelijkse klinische praktijk. Gebruikmaking van de vierde arm van de telemanipulator stelde ons in staat om de operatie te verrichten met een operatieassistent minder. Volledige robot cholecystectomie bleek veilig en haalbaar. Echter, de operatietijd was $3 \mathrm{I}$ minuten langer en de kosten waren toegenomen met $€$ I,| 180.62. Er konden geen significante voordelen worden aangetoond van het gebruik van robotchirurgie voor de patiënt, de chirurg of het ziekenhuis.

Laparoscopie wordt in het algemeen beschouwd als de standaardbehandeling voor anti-reflux chirurgie. Eén van de meest verrichtte anti-reflux procedures op dit moment is de laparoscopische Nissen fundoplicatie. Echter, deze operatie wordt beschouwd als technisch meer uitdagend dan laparoscopische cholecystectomie. Het gebruik van robotassistentie in een dergelijke complexere procedure zou voordeliger kunnen zijn dan het gebruik bij minder complexe procedures als cholecystectomie. In hoofdstuk zeven hebben we patiënten bestudeerd die conventionele laparoscopische of robotgeassisteerde laparoscopische Nissen fundoplicatie ondergingen. Robotgeassisteerde laparoscopische Nissen fundoplicatie bleek veilig en haalbaar in deze studie, maar resulteerde in een toename van de operatietijd van 47 minuten. Costen namen toe met $€ 987.47$ per patiënt. Er kon geen significant voordeel worden aangetoond van het gebruik van robotchirurgie voor de patiënt, de chirurg of het ziekenhuis.

We richtten ons op laparoscopische d'Hoore's rectopexie (endeldarmophanging) voor volledige rectumprolaps in hoofdstuk acht. Deze procedure zou nog meer technisch uitdagend kunnen worden beschouwd vanwege de beperkte werkruimte in het nauwe kleine bekken en de toegenomen noodzaak voor hechten en subtiele weefselmanipulatie. Ook hier bleek robotchirurgie veilig en haalbaar, maar leidde het tot een toename van operatietijd van 39 minuten en een verhoging van de kosten met 557.28. Geen significant voordeel van het gebruik van robotassistentie kon worden aangetoond voor de patiënt, de chirurg of het ziekenhuis.

Om de functionele resultaten op langere termijn na rectopexie te bestuderen, verrichtten we een studie beschreven in hoofdstuk negen. We richtten ons op de lange termijn resultaten en recidiefkans na conventionele open, conventioneel laparoscopische en robotgeassisteerde laparoscopische chirurgie. In onze studie bleek het recidiefpercentage na open chirurgie $2 \%$ vergeleken met $27 \%$ in de conventioneel laparoscopische groep en $20 \%$ in de robotgeassisteerde laparoscopische groep. Het verschil tussen open chirurgie en de minimaal invasieve technieken was significant. Er was geen significant verschil tussen conventionele laparoscopie en robotgeassisteerde laparoscopie. Functionele resultaten, gedefinieerd als een postoperatieve daling van de Wexner Incontinentie score of een afname in IDL score vergeleken met de preoperatieve scores, waren vergelijkbaar in alle drie groepen. Er kon geen significant voordeel worden aangetoond van het gebruik van robotchirurgie.

In hoofdstuk tien hebben we ons focus verlegd van het effect op de patiënt (in termen van veiligheid en complicaties) en samenleving (in termen van kosten) naar de potentiele schadelijke 
effecten van laparoscopie op de chirurg. Dit is een vrij ongebruikelijk onderwerp voor medisch onderzoek. De effecten van nieuw ontwikkelde technieken worden in het algemeen gemeten (zoniet exclusief) gemeten aan de hand van het effect op de patient (in termen van post-operatieve pijnbeleving, complicaties, weefselschade, hersteltijd, functioneel en esthetisch resultaat, kwaliteit van leven en recidiefkans) of ze zij gericht op het gevolg voor de samenleving en het zorgstelsel (in de zin van kosten, operatieduur en opnameduur). We weten echter, dat nieuw ontwikkelde minimaal invasieve technieken mogelijk een voordeel voor de patient opleveren, maar dat ze erg veeleisend, uitputtend en schadelijk voor de chirurg kunnen zijn. Verhoogde geestelijke stress bij de minimaal invasief chirurg is vrij nauw gelieerd aan een verminderde hart ritme variabiliteit (HRV), verminderde gezondheidstoestand en een beperkte levensverwachting. Hoewel negatieve effecten op de gezondheid van de chirurg moeilijk te meten zijn, zijn de lichamelijke effecten van mentale stress goed te meten als een voorloper van stressgeïnduceerde gezondheidsrisico's. In deze klinische studie hebben we de hart ritme variabiliteit van de chirurg gemeten terwijl deze conventionele laparoscopische danwel robotgeassisteerde laparoscopische cholecystectomie aan het verrichten was binnen de omgeving van de dagelijkse chirurgische praktijk. Eerdere studies hadden al laten zien, dat conventionele laparoscopische chirurgie tot een significante verhoging van hart ritme en LF/HF ratio leidt, wat een verhoogde mentale stress suggereert. Het gebruik van robot assistentie tijdens laparoscopische cholecystectomie resulteerde in een significante afname van hart ritme en een stijging van hart ritme variabiliteit tijdens meerdere fasen van de operatie. Dit suggereert een sterke vermindering van intra-operatieve lichamelijke en mentale stress. Op dit moment is interpretatie van dergelijke gegevens nog moeizaam, aangezien de exacte impact van verminderde hart ritme variabiliteit op de gezondheidstoestand van de chirurg moeilijk te meten is. Eerdere studies hebben echter een significante stijging laten zien van potentieel dodelijke gezondheidsproblemen na langdurige blootstelling aan verminderde hart ritme variabiliteit. Deze resultaten suggereren dat chirurgen zich er van bewust moeten zijn dat ze, indien ze proberen meerdere langdurige, uitdagende laparoscopische procedures per dag te verrichten zonder gebruikmaking van robot assistentie, ze waarschijnlijk een verhoogd gezondheidsrisico voor hun patiënten veroorzaken ten gevolge van vermoeidheidsgeïndiceerde chirurgische misstappen, alsmede dat ze zelf een verhoogd gezondheidsrisico lopen.

\section{CONCLUSIE}

De hierboven beschreven studies suggereren dat het gebruik van robot assistentie in een aboratoriumomgeving leidt tot snellere en meer accurate uitvoering van laparoscopische taken. In de dagelijkse klinische praktijk blijken de resultaten van het gebruik van robots echter teleurstellend. Robot chirurgie duurt langer en is duurder. Het meest significante voordeel van het gebruik van robots is mogelijk de verbeterde ergonomie voor de chirurg, en dientengevolge de verminderde mentale belasting van de chirurg. Dit zou potentieel kunnen leiden tot een vermindering van het aantal operatieve complicaties voor de patiënt en een vermindering van potentieel dodelijke gezondheidsproblemen bij de chirurg.

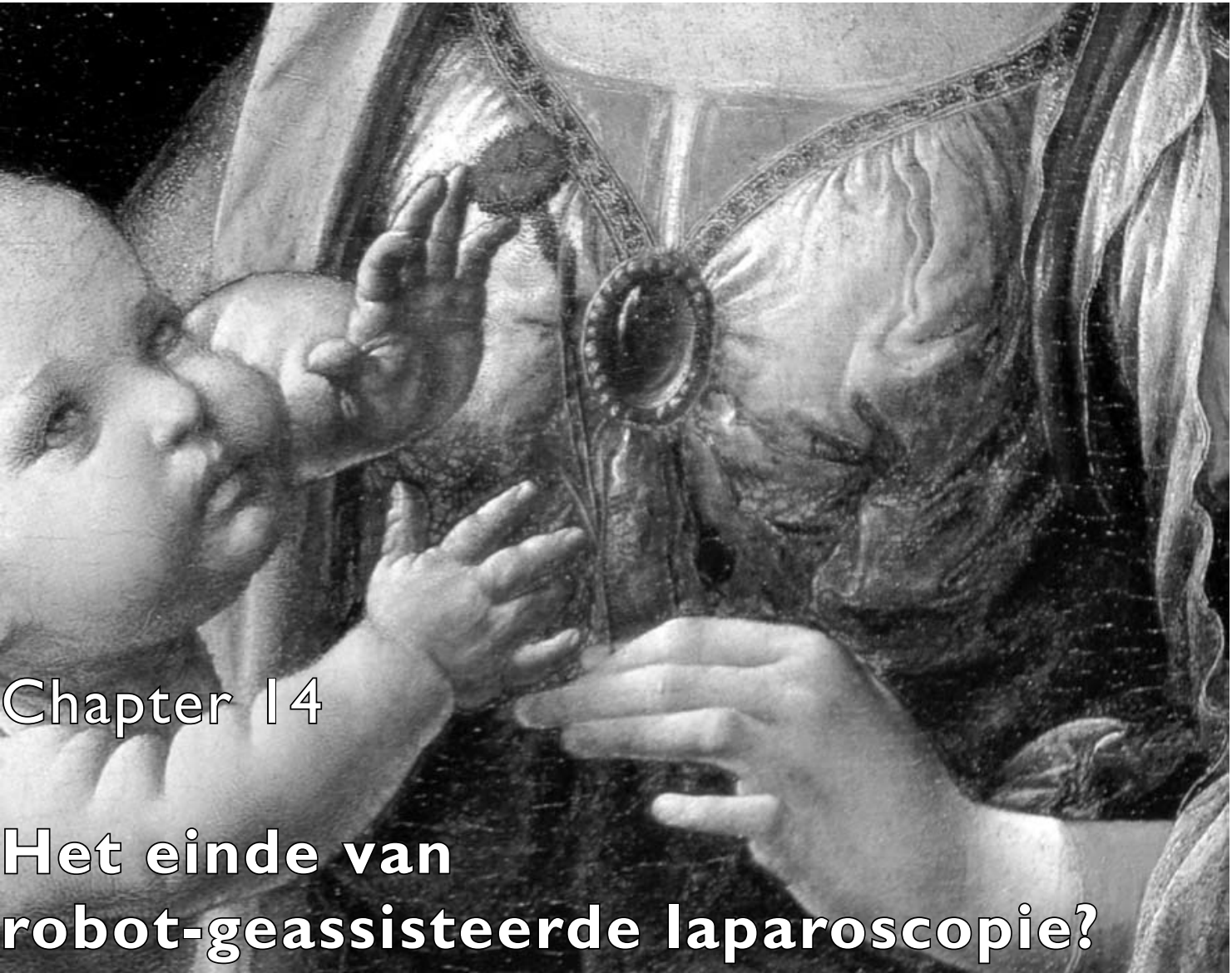

Nederlandse vertaling van hoofdstuk 12
DETAIL FROM: MADONNA OF THE CARNATION

OIL ON WOODEN PANEL, I478-I480

Virgin Mary is seated and wears precious clothes and jewelry. With her left hand she is holding a carnation, interpreted as a healing symbol. 


\section{ABSTRACT}

Robotgeassisteerde laparoscopie wordt gebruikt in een breed spectrum van chirurgische deelgebieden. Echter, de financiële kosten die hiermee gepaard gaan zijn hoog en overtuigend bewijs van superieure resultaten op het gebied van Kwaliteit-van-Leven, kosteneffectiviteit en overleving is niet voorhanden. Mogelijk zijn er kleine voordelen voor de gezondheid van de patient of van de chirurg die het gebruik van robots zouden rechtvaardigen in geselecteerde deelgebieden van de chirurgie. In een tijdperk van wereldwijde economische crisis is de tijd gekomen om een kritische discussie te starten over de vraag of we het gebruik van robotgeassisteerde laparoscopische chirurgie zouden moeten beperken of zelfs zouden moeten verlaten, en ons meer zouden moeten toeleggen op kosteneffectievere methoden om de gezondheidszorg te verbeteren.

\section{INTRODUCTIE}

Het tijdperk van de telemanipulator systemen binnen de minimaal invasieve chirurgie startte met de introductie van het "Automated Endoscopic System for Optimal Positioning" (AESOP). In 1994 werd het systeem toegelaten door de Amerikaanse FDAS als de eerste chirurgische "robot" ooit. Sinds de introductie zijn diverse prototypes van geavanceerde manipulatorsystemen ontwikkeld. Echter, de introductie binnen de chirurgie en het leveren van solide bewijs van haar toegevoegde waarde, blijft moeizaam.

In 2000 werd het "daVinci ${ }^{\circledR}$ Surgical System" goedgekeurd door de Amerikaanse FDA voor gebruik binnen de algemene laparoscopische chirurgie. Op dit moment is het het enige commercieel verkrijgbare "robot"-systeem dat een geïntegreerd stereoscopisch visueel systeem combineert met een gemotoriseerde telemanipulator. De term "robot" lijkt, semantisch gesproken, hier niet op zijn plaats, aangezien dit de aanwezigheid van een geautomatiseerd proces suggereert in plaats van een technisch geavanceerd en op afstand bestuurd geïntegreerd visueel en manipulator systeem. Echter, over de laatste decade is de term zo veelvuldig gebruikt (of misbruikt) binnen het gebied van geavanceerde minimaal invasieve chirurgie om het daVinci ${ }^{\circledR}$ Surgical System te duiden, dat de twee termen in de praktijk de facto synoniem zijn geworden. We zullen in dit manuscript beide termen dan ook door elkaar gebruiken.

Bijna $2000 \mathrm{daVinci}^{\circledR}$ systemen zijn inmiddels wereldwijd geïnstalleerd en het aantal indicaties lijkt snel te groeien in een breed werkgebied, waaronder algemene, cardio-thoracale, kinder- en gastrointestinale chirurgie, urologie en gynaecologie. Het gebruik van het systeem is bewezen veilig en technisch uitvoerbaar, maar de kosten zijn hoog en duidelijke medische voordelen zijn moeilijk te bewijzen. In Nederland alleen al zijn achttien ziekenhuizen over gegaan tot het investeren van grote bedragen voor de aanschaf van twintig robotsystemen. Na ruim tien jaar van uitgebreid gebruik en levend in een tijdperk waar een economische crisis ons dwingt om optimaal gebruik te maken van de ons ter beschikking gestelde fondsen, moeten we iedere cent die we uitgeven aan gezondheidszorg kunnen verantwoorden. De rol van robot assistentie in laparoscopische chirurgie vereist dan ook een kritische evaluatie.

Het introduceren van nieuwe technologieën in de geneeskunde wordt normaliter gedaan om een verbeterde overleving, een verbeterde Kwaliteit-van-Leven of verminderde kosten te bewerkstelligen. Als we de kosteneffectiviteit van robots willen overwegen, zullen we eerst moeten overwegen wat de potentiële voordelen zouden kunnen zijn, en daarna beslissen of deze toegevoegde voordelen wel de extra kosten rechtvaardigen. Als we kijken naar het uitgebreide veld van indicatiestellingen, is duidelijk dat het praktisch onmogelijk is om van iedere operatie in ieder chirurgisch aandachtsgebied te bepalen of de toegevoegde voordelen wel opwegen tegen 
veelvuldig gebruikt, zoals beschreven door André d'Hoore ${ }^{31}$. Deze techniek kent uitstekende lange termijn resultaten en vrij weinig complicaties ${ }^{32-34}$. In het algemeen wordt laparoscopische rectopexie dan ook beschouwd als de goudstandaard.

Het gebruik van robots is bewezen veilig en uitvoerbaar ${ }^{35}$ met een vergelijkbare recidiefkans, complicatiekans en functionele resultaten vergeleken met conventionele laparoscopische chirurgie ${ }^{36}$. De operatieduur lijkt echter langer en de kosten liggen hoger bij het gebruik van robot geassisteerde rectopexie ${ }^{35}$.

Nissen fundoplicatie wordt veelvuldig verricht als een anti-reflux procedure. De laparoscopische Nissen fundoplicatie wordt de laatste jaren in het algemeen beschouwd als de goudstandaard voor anti-reflux procedure en biedt een succesvolle behandeling aan volwassenen en kinderen ${ }^{37}$ potentieel zelfs te verrichten in dagbehandeling. Zowel korte termijn resultaten ${ }^{38}$ als lange termijn resultaten ${ }^{39-41}$ zijn uitstekend terwijl postoperatief herstel sneller is na laparoscopische chirurgie ${ }^{42,43}$ dan na open chirurgie. Littekenbreuken traden significant vaker op na open chirurgie dan na laparoscopische chirurgie ${ }^{44,45}$. introductie van het daVinci ${ }^{\circledR}$ systeem leidt tot vergelijkbare resultaten ${ }^{46}$, maar is duurder ${ }^{47-51}$.

Roux-en-Y Gastric Bypass (RYGB) wordt verricht als een bariatrische procedure. De laparoscopische procedure heeft een enorme vlucht genomen in de afgelopen paar jaren als één van de meest effectieve en meest frequent verrichtte bariatrische ingrepen. In expert centra worden honderden of zelfs duizenden van dergelijke operaties jaarlijks verricht met een lage morbiditeit en mortaliteit. De laparoscopische RYGB resulteert in een sneller postoperatief herstel, kortere opname duur, lagere morbiditeit, lagere mortaliteit en lagere kosten vergeleken met de open procedure en zou dan ook moeten worden beschouwd als de standaard behandeling op dit moment ${ }^{52-54}$.

Het gebruik van robot assistentie leidt tot een vergelijkbaar postoperatief functioneel resultaat en complicaties ${ }^{55}$. Er is geen overtuigend bewijs of het gebruik van het daVinci ${ }^{\circledR}$ systeem leidt to een kortere ${ }^{56}$ of juist langere ${ }^{57-59}$ operatie duur. De kosten die gepaard gaan met het gebruik van robots worden in het algemeen hoger ingeschat ${ }^{58-60}$, hoewel enkele studies lagere kosten suggereren ${ }^{61}$. Dit verschil zou te verklaren kunnen zijn aan een verschil in operatietechniek, een ander gebruik van staplers en andere chirurgische apparatuur, en een verschil in complicatie risico en opname duur.

\section{Thoracale Chirurgie}

Thymectomie voor myasthenie (Myasthenia Gravis) is een invasieve operatie, traditioneel verrich via een transsternale benadering. Gebruikmakend van videogeassisteerde thoracoscopische chirurgie (VATS) kan de procedure net zo effectief worden verricht, maar met een verminderde postoperatieve beademingsbehoefte en een kortere opnameduur in zowel volwassenen ${ }^{62-64}$ en kinderen ${ }^{65,66}$. Het gebruik van het daVinci ${ }^{\circledR}$ systeem is veilig en uitvoerbaar, en leidt tot een sneller postoperatief herstel vergeleken met de transsternale benadering ${ }^{67-71}$. Helaas zijn er geen gerandomiseerde onderzoeken gepubliceerd die de resultaten van traditionele VATS thymectomie vergelijken met die van robot geassisteerde thymectomie.

Lobectomie voor vroeg stadium niet-kleincellig longcarcinoom is een regelmatig verrichtte procedure. De traditionele open benadering met gebruikmaking van een thoracotomie wordt beschouwd als pijnlijk, wat mogelijk bijdraagt aan het frequent ontstaan van pulmonale complicaties en aan de relatief lange opnameduur. VATS-lobectomie is veilig en technisch goed uitvoerbaar ${ }^{72}$, leidend tot vergelijkbare ${ }^{73-76}$ of zelfs betere ${ }^{77-79}$ oncologische resultaten dan na open chirurgie, in combinatie met een sneller herstel.
Het gebruik van robot assistentie is technisch goed te doen ${ }^{80-83}$ en leidt mogelijk tot vergelijkbare ${ }^{84}$, betere of juist slechtere ${ }^{85}$ resultaten. Adequaat gepowerde en goed uitgevoerde studies die VATS lobectomie vergelijken met robot geassisteerde lobectomie, ontbreken helaas ${ }^{86}$.

\section{Gynaecologie}

Hysterectomie wordt gebruikt voor de behandeling van benigne aandoeningen en voor de behandeling van vroeg stadium cervix carcinoom. In het algemeen lijkt de operatieduur voor laparoscopische behandeling langer dan voor open chirurgie, maar het herstel na laparoscopische chirurgie is sneller en het oncologisch resultaat is vergelijkbaar ${ }^{87,88}$. Het daVinci ${ }^{\circledR}$ systeem is hiervoor veelvuldig gebruikt en geëvalueerd. De robot procedure is veilig en uitvoerbaar ${ }^{89}$ en bloedverlies zou mogelijk marginaal minder zijn $^{90}$, maar de operatieduur lijkt langer ${ }^{90-94}$ zonder wezenlijke voordelen in postoperatieve uitkomst vergeleken met conventionele laparoscopische hysterectomie. In het algemeen lijkt robot assistentie significant duurder te zijn ${ }^{91,92,94}$.

Sacrocolpopexie was ontwikkeld als een behandeling van vaginatop verzakking. De abdominale ophanging van de vaginatop resulteert in superieure resultaten vergeleken met transvaginale procedures. Laparoscopische sacrocolpopexie resulteert in significant minder bloedverlies en minder postoperatieve pijn vergeleken met open abdominale chirurgie, en leidt tot een sneller postoperatief herstel ${ }^{95}$. Daarom wordt laparoscopische sacrocolpopexie beschouwd als de standaard. Het is nog onduidelijk of het gebruik van robot assistentie leidt tot een snellere ${ }^{96}$ of juist langzamere ${ }^{97}$ operatieve procedure vergeleken met conventionele laparoscopie. Als de voorbereidingstijd van het daVinci ${ }^{\circledR}$ systeem wordt meegeteld, lijkt de benodigde operatietijd langer. De kosten zijn significant hoger bij het gebruik van robots ${ }^{97}$. In een vergelijking tussen robot geassisteerde sacrocolpopexie vs open sacrocolpopexie lijkt de laatste techniek uiteindelijk de duurste te zijn ten gevolge van een langere opnameduur ${ }^{98,99}$.

\section{Urologie}

Laparoscopische nefrectomie wordt gebruikt als een minder invasief alternatief voor open (en vaak pijnlijke) nierverwijdering bij patiënten met renaalcelcarcinoom ${ }^{100}$, en leidt tot vergelijkbare oncologische resultaten ${ }^{101-103}$. het gebruik van het daVinci ${ }^{\circledR}$ telemanipulator systeem is bestudeerd in voornamelijk kleine en onvoldoende gepowerde studies ${ }^{104,105}$ maar lijkt te resulteren in een langer durende operatie vergeleken met open ${ }^{106}$ of laparoscopische ${ }^{107}$ chirurgie. De resultaten en complicaties lijken vergelijkbaar ${ }^{106-110}$, maar de kosten lijken beduidend hoger ${ }^{104,108-110}$.

Laparoscopische radicale prostatectomie (LRP) voor prostaat kanker is geïntroduceerd als een technisch lastige maar minder invasieve procedure vergeleken met open retropubische radicale prostatectomie (RRP). Het leidt tot minder bloedverlies en vergelijkbare oncologische uitkomsten vergeleken met retropubische chirurgie 'I'. Conventionele LRP wordt echter beschouwd als een extreem uitdagende operatie en relatief weinig urologen zijn in staat om dergelijke chirurgie veilig te verrichten zonder robot assistentie. In een vergelijking van LRP met robot geassisteerde radicale prostatectomie (RARP) zijn de oncologische resultaten vergelijkbaar ${ }^{112-114}$ maar lange termijn effecten van RARP laten mogelijk iets betere resultaten zien als het gaat om urine continentie en erectiele functie I jaar postoperatief ${ }^{14-116}$

Een adequate vergelijking tussen RARP en LRP is moeizaam te verrichten, aangezien veel urologen geen conventionele LRP verrichten. Vergeleken met RRP lijkt het gebruik van de robot te leiden tot vergelijkbare oncologische resultaten $12,116-118$. Postoperatief herstel van potentie en urine continentie zou mogelijk marginaal beter zijn na robot chirurgie ${ }^{19}$ hoewel de wetenschappelijk onderbouwing erg zwak is. In het algemeen wordt RARP beschouwd als duurder dan zowel open als conventionele laparoscopische prostatectomie 20.123 . 


\section{NIEUWE ONTWIKKELINGEN IN}

\section{ROBOT GEASSISTEERDE LAPAROSCOPIE}

Het daVinci ${ }^{\circledR}$ S en Si systeem: de volgende generatie is gearriveerd!

Intuitive Surgical heeft een nieuwe generatie robot systemen ontwikkeld, die een verbeterde manoeuvreerbaarheid en een vergrote werkruimte bieden. Er zijn meerdere voordelen aan het nieuw ontwikkelde daVinci ${ }^{\circledR} S$ en $\mathrm{daVinci}^{\circledR} \mathrm{Si}$ systeem ten opzichten van het huidige standaard $\mathrm{daVinci}^{\circledR}$ system. De nieuwe generatie robot systemen hebben een significante structurele en functionele verandering ondergaan die hun toepasbaarheid beïnvloeden. Enkele van de grootste veranderingen zijn:

- Een vergrote manoeuvreerbaarheid. De armen van het standaard daVinci ${ }^{\circledR}$ systeem bieden een rotatie rond de verticale as (yaw) van 180 graden. Het nieuw ontwikkelde en geoptimaliseerde ontwerp van de instrument arm van het daVinci ${ }^{\circledR} S$ en Si systeem biedt een yaw van 336 graden, waardoor de manoeuvreerbaarheid en instrument werkruimte aanzienlijk worden vergroot. Onder de term "Werkruimte" wordt hier verstaan de totale fysieke ruimte die kan worden bereikt door een Endowrist ${ }^{\circledR}$ instrument indien dit gekoppeld is aan een arm van de "patient side cart". - Langere instrumenten. De nieuw ontworpen instrumenten zijn vijf centimeter langer dan de standaard daVinci ${ }^{\circledR}$ instrumenten. In combinatie met de vergrote manoeuvreerbaarheid leidt het gebruik van deze verlengde instrumenten tot een fors vergrote werkruimte van ruim een factor drie. Om dezelfde anatomie te bereiken als het standaard daVinci ${ }^{\circledR}$ systeem, zijn tegenwoordig minder aanpassingen nodig van de "patient side cart" en van de armen van de robot. - Verbeterde toegankelijkheid van de derde arm. De nieuwe generatie "patient side cart" bevat een derde instrument arm bovenop de kar, waardoor de manoeuvreerbaarheid verbetert en het aantal instrumentbotsingen afneemt.

- Dunnere uitschuifbare armen. De nieuwe generatie "patient side cart" is voorzien van instrument armen met een slanker profiel en telescopisch ontwerp, zodat het aantal intraoperatieve interferenties en botsingen geminimaliseerd wordt.

Het daVinci ${ }^{\circledR}$ Si Surgical System: Single Incision Laparoscopy wordt eenvoudig

Eén van de recente ontwikkelingen op het gebied van laparoscopische chirurgie is de trend om het aantal trocars te minimaliseren tijdens de operatie. Theoretisch zou het gebruik van minder trocars kunnen leiden tot minder postoperatieve pijn en trocar gerelateerde complicaties. In het uiterste geval leidt dit tot een vorm van chirurgie waarbij slechts één trocar wordt gebruikt, in het algemeen aangeduid als "Single-port, Single-access of Single-incision" laparoscopische chirurgie (SILS). Op dit moment wordt SILS met gebruik van conventionele laparoscopische instrumenten beschouwd als technisch erg lastig, met name tengevolgenvan de frequente botsingen van de instrumenten en de beperkte werkruimte. Hoewel er geen overtuigende studies zijn die een significant voordeel van SILS boven conventionele laparoscopie aantonen, neemt de ontwikkeling van deze techniek hand over hand toe. Het gebruik van robots zou nog wel eens onmisbaar kunnen blijken bij het goed uitvoeren van deze technisch lastige SILS procedures. $\mathrm{Het} d \mathrm{daVinci}{ }^{\circledR} \mathrm{Si}$ systeem is speciaal ontworpen om ingezet te worden bij SILS procedures. Het gebruik van deze robot zou kunnen leiden tot een eenvoudigere introductie van deze technisch lastige techniek, waardoor iatrogene weefselschade zou kunnen worden geminimaliseerd en een sneller herstel mogelijk zou kunnen zijn.

Het Firefly ${ }^{\circledR}$ Fluorescence Imaging System: verbeterde visualisatie van cruciale structuren Het standaard daVinci ${ }^{\circledR}$ systeem biedt een scherp High Definition stereoscopisch beeld. Een toename van het aantal pixels (om de scherpte van het beeld te verbeteren) of van de scherm ververs snelheid (om flikkering en vermoeide ogen te voorkomen) wordt in het algemeen beschouwd als niet significant bijdragend om de chirurgische kwaliteit te verbeteren. Een ontwikkeling die wel zou kunnen bijdragen aan het verhogen van veiligheid en verbeteren van chirurgie, is de toevoeging van beeldbewerking. Indien gebruik wordt gemaakt van fluorescentie, kunnen vitale structuren zichtbaar worden gemaakt die eerder niet te zien waren voor het menselijk oog bij het gebruik van eenvoudig wit licht.

Intuitive Surgical heeft een nieuw hulpmiddel ontwikkeld, met de naam Firefly ${ }^{\circledR}$ fluorescence imaging System. Door over te schakelen van conventioneel wit licht naar fluorescentie, kunnen cruciale anatomische structuren zoals galwegen beter zichtbaar worden gemaakt. Dit zou mogelijk kunnen leiden tot veiligere chirurgie en zou onbedoeld iatrogeen galweg letsel kunnen voorkomen. Dit optioneel extra instrument zou bijvoorbeeld gebruikt kunnen worden als hulpmiddel bij SILS cholecystectomie tijdens het gebruik van het daVinci ${ }^{\circledR}$ Si system.

\section{DISCUSSIE}

Sinds de introductie van het daVinci ${ }^{\circledR}$ Surgical System is het aantal robot systemen dramatisch toegenomen over de gehele wereld. Ondanks de uitgebreide expertise in de afgelopen jaren in meerdere deelgebieden van chirurgie, gynaecologie en urologie, is er nog weinig ondersteunend bewijs met betrekking tot de superioriteit van de robot geassisteerde procedures ten opzichte van conventioneel laparoscopische procedures. Goed ontworpen en adequaat gepowerde, geblindeerde en gerandomiseerde onderzoeken zijn schaars en het risico van selectieve publicatie (publication bias) lijkt significant ${ }^{124,125}$.

Historisch gezien is de implementatie van nieuwe medische technieken altijd vooraf gegaan aan de beschikbaarheid van deugdelijke wetenschappelijke bewijsvoering die een dergelijke snelle introductie ondersteunt. Echter, in de huidige situatie met een economische crisis die de economieën verstoort in Europa en (in mindere mate) in de rest van de wereld, zal het niet meer worden geaccepteerd dat dergelijke nieuwe en extreem dure technieken worden geïntroduceerd als standaard behandeling zonder dat er bewijs is geleverd of op $\mathrm{z} / \mathrm{n}$ minst wordt verzameld dat een significante verbetering in overleving, kosteneffectiviteit of Kwaliteit-van-Leven ondersteunt. Het gebruik van robots voegt ongeveer tussen de $€ 600$ en $€ 3000$ euro aan extra kosten toe ten opzichte van een conventionele laparoscopische ingreep. Dit is een forse toename zonder bewijs voor verbeterd resultaat. Onze patiënten en de gemeenschap in het algemeen zouden beter af zijn als we slechts een fractie van dat geld zouden uitgeven aan extra training en verdere differentiatie van chirurgen en chirurgen-in-opleiding, zodat zij veiliger en kosteneffectief laparoscopische procedures kunnen verrichten zonder robot. Kosteneffectiviteit studies zijn onmisbaar voordat wijdverbreid robot geassisteerde chirurgie kan worden geïntroduceerd als standaard behandeling.

Buiten de toegevoegde financiële kosten van robot geassisteerde chirurgie, speelt er een tweede punt van zorg mee, namelijk veiligheid en de verlengde operatieduur. Ondanks het feit, dat het $\mathrm{daVinci}{ }^{\circledR}$ systeem is goedgekeurd door de FDA als chirurgisch instrument voor minimaal invasieve chirurgie, mist het de tactiele terugkoppeling aan de chirurg, hetgeen potentieel een serieus gevaar kan opleveren voor patiënten. Bovendien is er geen overeenstemming over de exacte hoeveelheid extra tijd die een robot geassisteerde operatie duurt ten opzichte van een conventionele laparoscopische operatie. De meeste publicaties laten een langere operatieduur zien bij robot chirurgie en daardoor een verlengde blootstelling aan anesthesiologie-geassocieerde risico's en bijwerken zonder dat er sprake is van een significant voordeel.

Allerlei argumenten worden gebruikt om de huidige trend van toenemend gebruik van robots te verklaren. Het specifieke verzoek van de patient wordt vaak gebruikt als een argument, of als een excuus, voor het toenemend gebruik van robot systemen. Zelfs in professionele literatuur werd recent geponeerd:" Goed ontworpen, gerandomiseerde gecontroleerde onderzoeken die 
conventionele laparoscopie vergelijken met robot geassisteerde laparoscopie bestaan (nog) niet. Dat is helaas een gepasseerd station. Op dit moment zijn dergelijke onderzoeken onuitvoerbaar aangezien onze patiënten robot geassisteerde laparoscopie zullen kiezen op basis van de informatie die momenteel voorhanden is" 126

Echter, in een tijdperk van "Evidence-based medicine" kan een dergelijk verzoek van een patient niet gehonoreerd worden als het niet ondersteund wordt door adequaat bewijs. De bron van een dergelijk verzoek van een patient is waarschijnlijk gelegen in industrieondersteunde of ziekenhuisondersteunde marketing en is niet gelegen in het beperkte bewijs van klinische superioriteit zoals nu beschikbaar. Prof. dr IA Broeders stelt:" In landen waar het gezondheidszorg systeem commerciëler is dan in Nederland, wordt de daVinci ${ }^{\circledR}$ robot gebruikt als een hulpmiddel voor marketing"|26. Het lijkt echter niet onaannemelijk dat exact datzelfde marketing potentieel wordt gebruikt (of misbruikt) in ons land, hoewel mogelijk op een iets kleinere schaal. Alleen op het gebied van minimaal invasieve radicale prostatectomie voor prostaatkanker, lijkt wetenschappelijk onderzoek een heel klein potentieel voordeel te suggereren op het gebied van betere seksuele functie en mogelijk betere urine continentie na het gebruik van robot chirurgie. Of een dergelijk marginale potentiële verbetering in seksuele functie van een individuele 70 jarige patient een dergelijke grote toename van kosten in de gezondheidszorg rechtvaardigt, zou onderwerp moeten zijn van een open debat.

Een tweede argument dat een significante rol lijkt te spelen in de hedendaagse Nederlandse medische gemeenschap, is de angst om achter te blijven. Medische professionals voelen een continue drang om de zorg die zij leveren te verbeteren/ ze zijn constant op zoek naar nieuwe technieken en methodes. leder risico om trendsetter of "early adjuster" te worden en te blijven resulteert in de angst om aansluiting te missen en achter te blijven in belangrijke ontwikkelingen. Dit klinkt wellicht iets overtrokken, maar het is zeker geen onrealistische angst. De huidige ontwikkelingen in het Nederlands gezondheidssysteem stimuleren competitie tussen verschillende zorgaanbieders en dragen bij aan een dergelijke angst.

Allerlei organisaties waaronder de Nederlandse Inspectie voor de gezondheidszorg,

Zorgverzekeraars en patiëntenorganisaties hebben een houding ontwikkeld waarin grote

kwantiteit gelijk wordt gesteld aan hoge kwaliteit. Er worden minimale aantallen van

specifieke soorten operaties per ziekenhuis en per chirurg vereist in de hoop hiermee zorg te differentiëren en verbeteren. Ondanks een wetenschappelijk gebrek aan ondersteunend bewijs voor dergelijke regels ondervinden veel ziekenhuizen moeilijkheden in het behalen van de minimaal vereiste aantallen van dergelijke operaties, met als risico dat deze ziekenhuizen specifieke zorg niet meer mogen gaan leveren, onafhankelijk van de daadwerkelijke kwaliteit van de geleverde zorg. Ziekenhuizen worden direct bedreigd in hun voortbestaan, en hetzelfde geldt voor de banen van medisch personeel dat in deze instellingen werkt. Een onvermogen om voldoende aantallen patiënten aan te trekken (desnoods gebruikmakend van een sterk marketing instrument zoals een robot) kan het verschil maken tussen een bloeiend tertiair verwijzingscentrum en een gemarginaliseerde kliniek balancerend op de rand van bankroet. Dit is geen theoretisch doemscenario voor kleine ziekenhuizen, maar de dagelijkse praktijk. Alleen een gezondheidssysteem dat weigert om de extra kosten van robot chirurgie te vergoeden voor alle indicaties waar de toegevoegde waarde niet voldoende wetenschappelijk onderbouwd is, zou het realistisch gebruik van het $\mathrm{daVinci}^{\circledR}$ systeem stimuleren waar het medisch zinvol is.

Het robot systeem zou gebruikt worden als en onderzoeksinstrument en (waarschijnlijk voor een beperkt aantal indicaties) als een geavanceerd chirurgisch instrument, niet meer hoofdzakelijk als een marketinginstrument. Het huidige vergoedingensysteem leidt tot een situatie waarbij relatie kleine ziekenhuizen ophouden met het aanbieden van allerlei soorten specifieke zorg, leidend tot een vergroting van de grotere ziekenhuizen en dus een tweedeling van soorten ziekenhuizen. Alleen een paar zeer grote medische centra, verzekerd van voldoende aantallen patiënten, kunnen eenvoudig de drang weerstaan om deel te nemen aan een wedloop van 'valse innovatie' of 'pseudo-innovatie', zoals dit genoemd werd door de internist-oncoloog Ezekiel Emanuel in de New York Times ${ }^{127}$. In het Academisch Medisch Centrum Amsterdam werd de bewuste keuze genomen om niet te investeren in robot chirurgie. De directeur stelde:" Dergelijke valse innovaties, of beter genaamd exnovaties, zouden niet geïmplementeerd moeten worden in een effectief en efficiënt gezondheidssysteem". ${ }^{28}$.

Een derde argument om het gebruik van robots te verdedigen, is de aanwezigheid van grote potentiële voordelen van stereoscopische vergroting, vergrote precisie, mogelijke schaalverkleining van handbewegingen, tremorfiltratie en bewegingen van de tip van het instrument die de mogelijkheden van de menselijke hand overtreffen. Dit zou potentieel kunnen leiden tot betere operatie resultaten in de toekomst. In een echte open wetenschappelijke omgeving zou aan nieuwe en veelbelovende technologieën de mogelijkheid moeten worden geboden om ontwikkeld ruimte te krijgen voor ontwikkeling binnen een gezonde kritische context. En ja, wij geloven zeker dat nieuwe technologieën ontwikkeld moeten worden en zorgvuldig moeten worden geïntroduceerd in de medische praktijk. Het is zeker niet onze intentie om technische en wetenschappelijke vooruitgang binnen de medische wereld tegen te gaan. In tegendeel. Het is ons streven om een wetenschappelijk kader te creëren waar de ons ter beschikking staande beperkte financiële middelen zorgvuldig worden gespendeerd, leidend tot een optimale effectiviteit van iedere cent die uitgegeven wordt aan gezondheidszorg en aan onderzoek. Juist daarom is het zo belangrijk dat, zolang als er geen bewijs is van superioriteit van het gebruik van robots, de introductie van deze zeer dure technologieën beperkt blijft tot onderzoeksfaciliteiten binnen goed ontworpen onderzoeksprojecten en niet uitgebreid wordt naar de normale dagelijkse praktijk. $\mathrm{Er}$ is geen enkel goed argument om te verdedigen waarom nieuwe chirurgische technologieën niet onderworpen zouden moeten worden aan dezelfde strikte regels als die ook gelden voor nieuw ontwikkelde medicatie. Goed gepowerde studies zijn en blijven onmisbaar voordat het wijdverbreid gebruik van robot geassisteerde laparoscopie kan worden gerechtvaardigd.

Een vierde veelgehoord argument is dat de kosten van robot chirurgie zullen dalen bij toegenomen gebruik. Tijdens de introductie van conventionele laparoscopische chirurgie in de late 1980's werden de initieel verhoogde kosten voor laparoscopie beschouwd als een potentiële hindernis. Dertig jaar later heeft conventionele laparoscopie uitgebreid bewezen om kosteneffectief te zijn in allerlei deelgebieden binnen de chirurgie. We zouden nu niet dezelfde foutieve aannames moeten maken als toen, door teveel te focussen op de kosten van aanschaf van initieel dure apparatuur, terwijl de grote kostenbesparingen voor het maatschappij ten gevolge van een verkorte opnameduur, verminderde wond gerelateerde kosten, verminderde kosten voor pijnstilling en verkort ziekteverlof over het hoofd worden gezien. We willen zeker niet ontkennen dat de kosten voor robot chirurgie waarschijnlijk zullen verminderen in de loop der tijd en met toegenomen ervaring. Of een dergelijke kostenreductie echter op termijn zal leiden tot kosteneffectieve behandeling, blijft discutabel. Tijdens de introductie van conventionele laparoscopie in de 80 er jaren van de twintigste eeuw veranderde de ingreep significant van een open procedure naar minimaal invasieve chirurgie, potentieel leidend tot kleinere wonden, minder pijn, minder wondinfecties, minder littekenbreuken, minder pulmonale complicaties en longontstekingen, een sneller herstel en een kortere opnameduur. De initieel hoge kosten van de laparoscopische ingreep konden dan ook potentieel worden terugverdiend met grote te verwachten besparingen. Bij de introductie van de robot wordt een nieuwe en dure minimaal invasieve benadering aangeboden voor veel indicaties als een alternatief voor reeds bestaande conventionele minimaal invasieve chirurgie. In dat geval verandert de operatieve procedure wel, maar de potentiële voordelen in termen van kleinere wonden, minder pijn, sneller herstel en kortere opnameduur 
lijken afwezig. Dit maakt het vrij onwaarschijnlijk dat de kosten voor robot chirurgie lager zullen uitvallen dan de kosten voor conventionele laparoscopie. Alleen bij de radicale prostatectomie, waar de conventionele laparoscopie technisch erg lastig blijkt en zelden wordt gezien als een viabele optie, lijkt de robot geassisteerde minimaal invasieve operatie het alternatief voor open chirurgie en kunnen er dus wel dergelijke potentiële voordelen verwacht worden.

Een laatste (en zelden vernoemd) argument zou kunnen zijn, dat de voordelen voor de patiënt misschien beperkt zijn, maar dat de voordelen voor de chirurg groot zijn. Laparoscopisch opererende chirurgen lijden niet slechts aan een hoge belasting van mentale stress ${ }^{129}$, ze lijken ook te lijden aan een verhoogd risico op stress gerelateerde gezondheidsproblemen vergeleken met andere zorgprofessionals ${ }^{130}$. Het lijkt er dan ook op, dat de minimaal invasief chirurg vecht voor de gezondheid van zijn patiënt, maar hierbij zijn eigen gezondheid riskeert. Tijdens robot chirurgie leidt het uitstekende zicht en de verbeterde ergonomie tot een ervaring bij de chirurg van verminderde fysieke en mentale stress ${ }^{131}$. Dit zou kunnen leiden tot minder lage rugpijn, nek en schouderpijn ${ }^{132-134}$, verminderde vermoeidheid en verminderde stress gerelateerde gezondheidsrisico's voor de chirurg. Studies in een trainingsomgeving hebben een significante stijging in hartritme variabiliteit tijdens robot chirurgie laten zien in vergelijking met conventionele chirurgie, wat een lager niveau van mentale stress suggereert in de robotgroep ${ }^{|3|}$. Wij verrichtten een klinische studie die een indrukwekkende stijging in hart ritme variabiliteit liet zien tijdens het gebruik van robot chirurgie, wat suggereert dat er minder mentale stress is vergeleken met conventionele laparoscopie. Dit was zelfs meetbaar tijdens laparoscopische cholecystectomie, een operatieve procedure die in het algemeen als weinig mentaal belastend wordt beschouwd voor de chirurg ${ }^{135}$. Tijdens technisch meer uitdagende procedures zoals laparoscopische rectumresectie en laparoscopische radicale prostatectomie zou het positieve effect van het gebruik van robots op de aanwezigheid van mentale stress, indrukwekkender kunnen worden verwacht. Helaas blijft het lastig om het exacte effect te meten van een bepaalde hoeveelheid werk gerelateerde mentale stress op het ontstaan van multifactoriëel veroorzaakte (maar deels stress geïnduceerde) negatieve gezondheidseffecten zoals hoge bloeddruk, hartinfarct, acute hartdood en suikerziekte.

Tot op heden wordt het nog als onconventioneel of zelf vernieuwend beschouwd, om veel geld te investeren in de ontwikkeling van nieuwe chirurgische technieken die de gezondheid van de chirurg verbeteren in plaats van de gezondheid van onze patiënten. Als we het gebruik van robots echter niet meer blijven zien als een totaal nieuwe operatietechniek, en er mee omgaan zoals met ieder voorzorgmaatregel ter bescherming van werkgerelateerde ziekte, dan zou het gebruik van robots voor sommige ingrepen in de toekomst net zo normaal kunnen worden als het gebruik van operatie handschoenen en jas. Chirurgen gebruiken die voorzorgsmaatregelen al tijden om zichzelf te beschermen tegen overdraagbare aandoeningen. Dergelijke beschermingsmaatregelen hoeven niet te leiden tot een betere overleving of Kwaliteit-van-Leven van onze patiënten en zijn hoogstwaarschijnlijk niet kosteneffectief. Ze beschermen de werknemers in de gezondheidszorg echter tegen werkgerelateerde ziekten. Zo lang overtuigend bewijs (nog) niet geleverd is, dat de gezondheidsclaims van verdedigers van het gebruik van robots ondersteunt, zullen de hiermee gepaard gaande forse kostenstijgingen helaas niet geaccepteerd kunnen worden

\section{CONCLUSIE}

Op dit moment is het bewijs van een beter resultaat na robot geassisteerde chirurgie voor zowel de patient als de chirurg niet overtuigend. De Nederlandse Zorgautoriteit (NZa) heeft gesteld:" Al het wetenschappelijk bewijs is consistent. Robot geassisteerde laparoscopische prostatectomie is net zo effectief als conventionele laparoscopische en open prostatectomie,

en moet dus vergoed worden". De NZa geeft echter niet aan of de extra (en waarschijnlijk onnodige) kosten die gepaard gaan met het gebruik van robots, ook vergoed moeten worden. De individuele verzekeringsmaatschappijen volgen hierin een divers beleid. Sommige van de grootste verzekeraars, zoals Achmea en Menzis, hebben besloten om de standaard open en conventioneel laparoscopische prostatectomie volledig te vergoeden, maar ze weigeren om extra vergoedingen uit te keren voor het gebruik van robots. Andere verzekeraars zoals Centrale Zorgverzekeraar (CZ) blijven doorgaan met het financieel ondersteunen van ziekenhuizen bij de aanschaf, onderhoud en gebruik van robots. Dit verschil leidt tot een ongelijkheid in de behandeling van patiënten met dezelfde ziekte, wat niet aan te bevelen lijkt. Het blijkt echter moeizaam of vrijwel onmogelijk om tot consensus te komen in een nationale richtlijn. leder debat over gezondheidszorg waarin gesuggereerd wordt dat een bepaalde nieuwe dure techniek niet zou moeten worden vergoed vanwege financiële argumenten, leidt tot extreem gevoelige reacties bij het publiek uit angst om een tweederangs of zelfs insufficiënte behandeling te krijgen 124, 125, 136138. Een open en eerlijke publieke discussie over of robot chirurgie zou moeten worden vergoed, en onder welke omstandigheden, is hoogst naadzakelijk in Nederland. Op dit moment staat een dergelijk debat nog in de kinderschoenen ${ }^{139-141}$. Ongeldige argumenten zoals eerder vermeld worden veelvuldig gebruikt door autoriteiten op het gebied van chirurgie om andere doelen na te streven, zoals het beschermen van hun persoonlijke intellectuele, tijd- en financiële investeringen in robot chirurgie.

Als we eindelijk serieus worden in onze pogingen om de snel groeiende kosten in de Nederlandse gezondheidszorg te beperken tijdens een tijdperk van financiële crisis, en als we echt de beste medische zorg willen leveren die we ons kunnen veroorloven, dan kunne we slechts één conclusie trekken hier. De extreem toegenomen kosten staan implementatie van robot chirurgie als standaardbehandeling nu niet toe. Het gebruik van robot geassisteerde chirurgie moet beperkt worden tot goed ontworpen en adequaat gepowerde gecontroleerde onderzoeken. De gebieden waar robot chirurgie de beste kans heeft om voordeel te laten zien, zijn beperkt. Onderzoeksprojecten zouden dan ook het best beperkt moeten blijven tot de volgende onderwerpen:

I) Het gebruik van het standaard daVinci ${ }^{\circledR}$ systeem in het verbeteren van de Kwaliteit-van-Leven, zenuwsparend opereren, seksuele functie, urine continentie en oncologisch resultaat bij technisch lastige procedures zoals minimaal invasieve radicale prostatectomie en rectumresectie.

2) Het gebruik van het standaard daVinci ${ }^{\circledR}$ systeem in het verminderen van mentale en fysieke stress bij de chirurg tijdens het verrichten van dergelijke technisch uitdagende laparoscopische procedures. Het meten van mentale belasting en van haar effecten op de lichamelijke gezondheid van de chirurg zou erg interessant zijn om te beoordelen of een robotgeïnduceerde vermindering van mentale stress ook daadwerkelijk leidt tot een bescherming tegen potentieel dodelijke werkgerelateerde gezondheidsrisico's.

3) De voordelen van verbeterde manoeuvreerbaarheid en vergrote werkruimte bij het gebruik van de nieuwe generatie daVinci ${ }^{\circledR}$ S and Si chirurgische systemen.

4) De implementatie van het $d a V i n c i{ }^{\circledR}$ Si systeem tijdens het verrichten van "SILS".

5) De implementatie van het Firefly ${ }^{\circledR}$ fluorescentie systeem, om visualisatie van cruciale anatomische structuren mogelijk te verbeteren en zo het risico op iatrogeen galweg letsel tijdens (SILS of conventionele) laparoscopische chirurgie te voorkomen met gebruikmaking van het daVinci ${ }^{\circledR}$ Si systeem 
Buiten deze gerandomiseerde gecontroleerde onderzoeken, zou het erg interessant en mogelijk verhelderend kunnen zijn als er een nationale registratie zou worden opgezet voor dergelijke geavanceerde laparoscopische chirurgie, analoog aan of zelfs georganiseerd door het Dutch Institute for Clinical Auditing (DICA). Een dergelijke registratie zou in ieder geval de radicale prostatectomie, rectumresectie en cystectomie moeten bevatten met registratie van zowel open, conventioneel laparoscopische als robot geassisteerde laparoscopische ingrepen. Een dergelijke registratie zou kunnen worden gebruikt voor het vervolgen en evalueren van de rol van robots binnen de laparoscopische chirurgie. Tot dergelijk onderzoek is uitgevoerd en registratie is verricht, en kijkend naar de ongelofelijke recente chirurgische ontwikkelingen in robot geassisteerde chirurgie, wordt het duidelijk dat de snelheid van technische ontwikkeling dramatisch veel sneller gaat dan de snelheid van de wetenschappelijke onderbouwing van haar (kosten)effectiviteit.

Historisch gezien is de implementatie van nieuwe technieken in de geneeskunde altijd sneller gegaan dan het beschikbaar worden van data om deze implementatie te verantwoorden. Deze kloof tussen nieuw ontwikkelde chirurgische mogelijkheden enerzijds en wetenschappelijk onderbouwde effectieve standaard chirurgische zorg anderzijds, lijkt vandaag de dag echter groter dan ooit. Als we goede medische zorg betaalbaar willen houden voor onze patiënten, zullen we keuzes moeten (durven) maken. Goede vergelijkende studies over kosteneffectiviteit zijn onmisbaar voordat robot chirurgie kan worden aangeboden als standaard behandeling. Tot die tijd geloven wij sterk dat het gebruik van robots zou moeten worden beperkt wot goed ontworpen onderzoeken en nationale registraties gericht op eerder genoemde onderwerpen.

Betekent dit, dat we het einde suggereren of promoten van deze veelbelovende techniek, hoofdzakelijk gebaseerd op financiële gronden? Dat doen we zeker niet. Is dit het eind van robot geassisteerde laparoscopische chirurgie? Dat hopen wij zeker niet. Wij geloven oprecht dat de huidige technische ontwikkelingen grote potentiële voordelen zouden kunnen bieden en zouden kunnen leiden naar succesvolle en kosteneffectieve robot geassisteerde chirurgie in de nabije toekomst, of tot de ontwikkeling van laterale spin-off zoals stereoscopische conventionele laparoscopie en de verdere ontwikkeling van geavanceerdere handinstrumenten. Als we Sir Winston Churchill mogen aanhalen:" Dit is niet het einde. Het is nog niet eens het begin van het einde. Misschien, is dit slechts het einde van het begin."

REFERENTIES zie bladzijde II4

\section{DANKWOORD}

Eindelijk is mijn proefschrift af. Het doen van een promotie-onderzoek tijdens een opleiding chirurgie en later naast het werk in een maatschap chirurgie vergt aardig wat inspanning. Voeg daar nog een verhuizing naar Roermond, een verbouwing van een huis, een huwelijk en een tweetal kinderen aan toe, en het moge duidelijk zijn dat er wat zweetdruppels gevloeid hebben. Geen enkel proefschrift schrijft zich zelf tenslotte. Zonder allerlei mensen tekort te doen door ze niet bij naam te noemen, zijn er een paar mensen die zeker niet onvermeld kunnen blijven.

Allereerst wil ik dr N. D. Bouvy bedanken. Beste Nicole, ik bedank je voor je onaflatend optimisme en tomeloze enthousiasme. leder voorstel voor een onderzoek en iedere versie van een artikel werden verwelkomd met een positieve instelling. Als het aan jou had gelegen, hadden we jaren geleden al een nietje door een bundeltje artikelen geslagen. Ik hoop dat je het met me eens bent dat het toevoegen van het artikel over hart ritme variabiliteit wel echt wat heeft toegevoegd. De definitieve versie heeft weliswaar wat langer geduurd heeft, maar het is het hopelijk wel waard geweest.

Prof. dr C.G.M.I. Baeten. Beste Cor, dank voor je onuitputtelijke stroom aan verhalen over geneeskunde, geschiedenis van Maastricht of wat dies meer zij. Een onderhoud met jou was niet altijd even to-the-point maar wel altijd gezellig en onderhoudend.

Prof dr. J. J. Jakimowicz. Beste Jack, ik wil je bedanken voor de wellicht ouderwetse, maar zeer bewonderenswaardige leermeester die je voor me was. Wars van de nieuwe opleidingseisen met portfolio- en KKBterreur was je prima in staat om de essentie van een top-chirurg te laten zien. De rust die je uitstraalde en de uiterst subtiele manier waarmee je de handen van enthousiaste assistenten wist bij te sturen leidde niet alleen tot een mooi operatief eindresultaat maar ook tot een hoop trots en vreugde bij ons assistenten. Opereren met jou was een feest. Ik ken geen ander chirurg die zo goed voldoet aan de omschrijving van "the eyes of a hawk, the heart of a lion, but the hands of a lady".

Reinier zandbergen. Beste Reinier, je begon als co-assistent op de afdeling chirurgie en we hadden al snel een klik. Toen ik je voor het eerst (en volgens de Leidsche regels uitermate reglementair) binnen de muren van het azM tegen de grond neerzooide en toen jij kort daarna je eerste motorrijles op mijn motor doormaakte, hadden we beide nog geen idee dat we samen tot enigszins serieus onderzoek zouden komen. $\mathrm{lk}$ wil je bedanken voor je gezelligheid op congres in bijvoorbeeld Venetië en je enthousiasme en inzet om van de hartritme studie iets leuks te maken.

Marieke Koenen. Beste Marieke, ik weet dat het regelen van de benodigde operatieprogramma's je heel wat bloed,zweet en tranen gekost heeft. Dank voor je hulp. Zonder jou was dit boekje nooit afgekomen.

Arthur Bouwman en Sander Keet, dank voor jullie hulp bij het analyseren van de hartritme gegevens. Na pogingen aan diverse instellingen in binnen- en buitenland had ik de hoop eigenlijk al min of meer opgegeven, tot ik min of meer toevallig op jullie artikel over hart ritme variabiliteit kwam. $\mathrm{Na}$ mijn informatief mailtje ontmoette ik direct een warm Amsterdams welkom en inspirerend enthousiasme.

Martijn, JG en Maddy, jullie hadden af en toe meer vertrouwen in een goede afloop van deze schrijfmarathon dan ik. 
Als laatste (maar wellicht belangrijkste) wil ik natuurlijk het thuisfront bedanken. Martien, bedankt voor je enorme steun tijdens de vele keren dat ik moedeloos en gefrustreerd weer niet verder leek te komen. En dank natuurlijk voor je geduld tijdens de vele uren dat ik met mijn boekje bezig was en jij er min of meer alleen thuis voor stond. Thijs en Laura, jullie bedankt voor de nieuwe, onbevangen blik waarmee ik tegen allerlei dingen aan heb leren kijken. Zelfs zoiets alledaags als het langsrijden van een trein (wat toch wel vaker gebeurt als je langs een spoorbaan woont) blijkt te kunnen leiden tot een uitbarsting van vreugde en enthousiasme, voor degene die er oog voor heeft. De schoonheid der vrijster blijkt vaak gelegen in 's vrijers oog.

\section{CURRICULUM VITAE AUCTORIS}

Jeroen Heemskerk werd geboren op 25 oktober 1972 in Alphen aan den Rijn. Hij bracht het grootste deel van zijn jeugd door in Veldhoven en volgde middelbare school aan het Van Maerlantlyceum in Eindhoven. In 199| startte hii aan zijn studie Geneeskunde aan de RijksUniversiteit Leiden. Datzelfde jaar werd hij ook lid van studentenvereniging Quintus en van het Leidsch Heerendispuut Houphnyx.

In 1996 begon hij aan zijn coschappen in Nederland, Suriname en Ghana. Hij behaalde het artsexamen in 1998. $\mathrm{Na}$ anderhalf jaar gewerkt te hebben als arts-assistent thoraxchirurgie in het VU Medisch Centrum Amsterdam, begon hij als arts-assistent algemene chirurgie in het St Elisabeth Ziekenhuis te Willemstad, Curaçao. In het jaar 200 kwam hij terug naar Nederland en begon als arts-assistent in het Maastrichts Universitair Medisch centrum, alwaar hij aan zijn opleiding begon in 2002. Hij vervolgde zijn chirurgische training in 2004 in het Catharina Ziekenhuis Eindhoven. Gedurende deze jaren ontwikkelde hij een grote liefde voor de

minimaal invasieve chirurgie, resulterend in meerdere onderzoeksprojecten op het gebied van

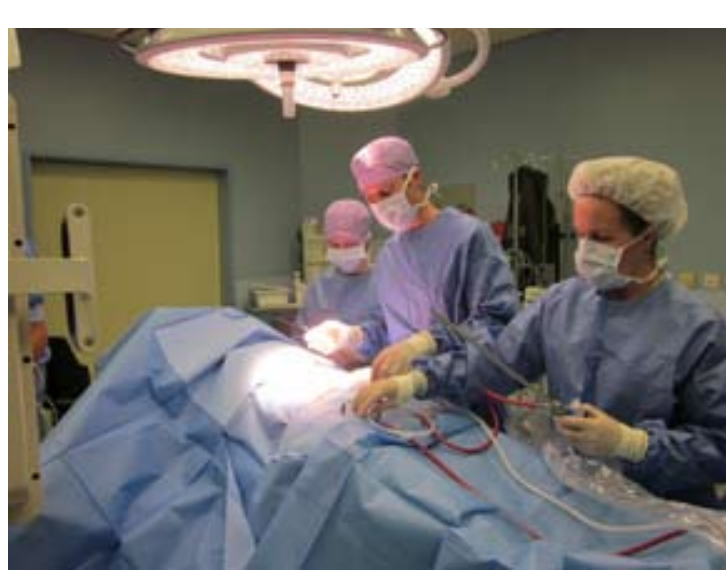
geavanceerde laparoscopie. In dezelfde tijd ontwikkelde hij een nog grotere liefde voor zijn Martien (buiten werktijd aangeduid als "dushi”), resulterend in een huwelijk en twee schatten van kinderen, Thijs en Laura.

Sinds 2008 is hij werkzaam als gastro-intestinaal chirurg en chirurg-oncoloog in het Laurentius Ziekenhuis te Roermond. Buiten deze klinische werkzaamheden en enkele nieuwe onderzoeksprojecten, wordt hij door verpleging en kinderen geschoold in de beheersing van de midden-Limburgse taal, met opvallend weinig succes.

foto boven: de auteur tijdens laparoscopische totaal extraperitoneale plastiek. zelfs (of misschien wel juist) zonder de aanwezigheid van een chirurgische robot lijkt deze minimaal invasieve ingreep relatief

snel, eenvoudig en veilig te verrichten.

foto rechts: de auteur en zijn publiek verdiept in andermans werk. Ondanks de matige wetenschappelijke onderbouwing en onrustige lay-out lijken de oplage, impact factor en de publiekswaardering wellicht hoger dan van het boekje dat voor u ligt.

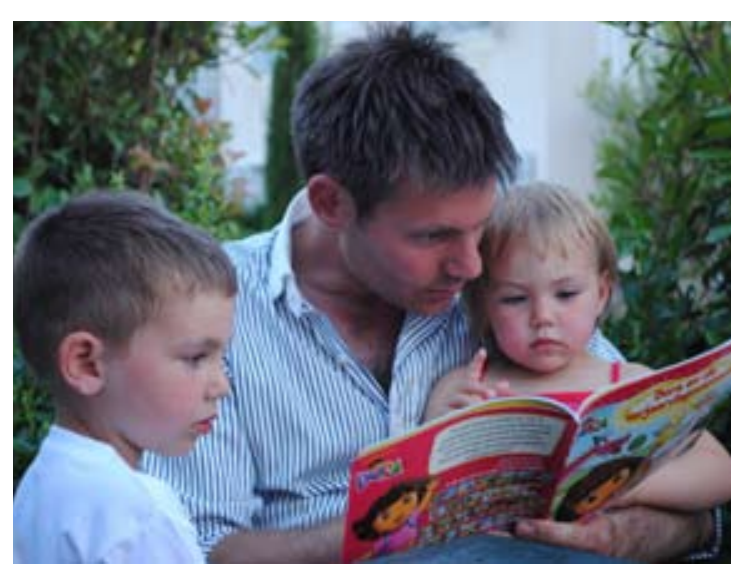




\section{PUBLICATIELIJST}

Heemskerk J, Kitslaar P. Acute compartment syndrome of the lower leg: retrospective study on prevalence, technique and outcome of fasciotomies. World J Surg 2003;27(6):744-747.

Heemskerk J, Sie GH, Van den Neucker AM et al. Extreme short bowel syndrome in a full-term neonate- a case report. J Pediatr Surg 2003;38(II):1665-6.

Heemskerk J, Baeten CGMI. Intestinal blood loss due to GIST. Dig Surg 2005;22(3):I5I.

Heemskerk J, van Empel I, Jakimowicz JJ. Tunga Penetrans. A case report and review of the literature. Acta Chir Belg 2005;105(5):548-50.

Heemskerk J, Van Dam R, Van Gemert WG, Beets GL, Greve JWM, Jacobs MJHM, Bouvy NB. First results after Introduction of the four-armed daVinci Surgical System in fully Robotic Laparoscopic cholecystectomy. Dig Surg 2005;22(6):426-431.

Heemskerk J, Zandbergen RH, Maessen JG, Greve JWM, Bouvy ND. Advantages of advanced laparoscopic systems. Surg Endosc 2006;20(5):730-3.

Heemskerk J, Stultiens GN, Tan I, van er Veen AH, Nieuwenhuijzen GAP. Papillary carcinoma in a thyroglossal duct. Acta Oncologica 2006;45(3):332-4.

Heemskerk J, van Gemert WG, Greve JWM, Bouvy ND. Robot-assisted versus conventiona laparoscopic Nissen Fundoplication: a comparative retrospective study on costs and time consumption. Surg Laparosc Endosc Percutan Tech 2007;17(I): I-4.

Buzink SN, Koch AD, Heemskerk J, Botden SMBI, Veenendaal R, Goossens RHM, de Ridder H, Schoon EJ, Jakimowicz JJ. Acquiring basic endoscopic skills by training on the GI Mentor II. Surg Endosc 2007;21(1 I): 1996-2003

Koch AD, Buzink SN, Heemskerk J, Botden SMBI, Veenendaal R, Jakimowicz JJ, Schoon EJ. Expert and construct validity of the Simbionix GI Mentor II endoscopy simulator for colonoscopy. Surg Endoscopy 2007;22(1):158-62

Heemskerk J, van Gemert W, Bouvy ND. Learning curves of robot-assisted laparoscopic surgery compared with conventional laparoscopic surgery: an experimental study evaluating skill acquisition of robot-assisted laparoscopic tasks compared with conventional laparoscopic tasks in inexperienced users. Surg Laparosc Endosc Percutan Tech 2007; I7(3): I7I-4

Heemskerk J, de Hoog DENM, van Gemert WG, Baeten CGMI, Greve JWM, Bouvy ND. Robotassisted versus conventional laparoscopic Rectopexy for rectal prolapse. A comparative study on costs and time. Dis Colon Rectum 2007; 50(1 I):1825-30

Heemskerk J, de Hingh I. pneumatosis intestinalis, mesenteric venous gas and portal venous gas. Dig Surg 2008;25(2):85-6
Buzink SN, Botden SM, Heemskerk J, Goossens RH, de Ridder H, Jakimowicz IJ. Camera Navigation and tissue manipulation: are these laparoscopic skills related?. Surg Endosc 2009;23(4):750-7

Heemskerk J, Nienhuijs SW. Gallstone ileus as first presentation of a gallbladder carcinoma. J Gastrointest Liver Dis. 2009;18(2):253-4

De Hoog DENM, Heemskerk J, van Gemert WG, Baeten CGMI, Greve JWM, Bouvy ND. Recurrence and functional results after open versus conventional laparoscopic versus robotassisted laparoscopic rectopexy for rectal prolapse: a case-control study. Int J Colorectal Dis. 2009;24(I0):| $20 \mid-6$

Koopmans NG, Kwee HW, Heemskerk J. Acute appendicitis with goblet cell carcinoid. Ned Tijdschr. Geneeskd. 2010;154:AII54

Dunink R, Veldkamp J, Nienhuijs S, Heemskerk J. Secondary healing versus midline closure and modified Bascom natal cleft lift for pilonidal sinus disease. Scand J Surg 201 I; 100(2):1 10-3

Heemskerk J, BouvyND, Baeten CGMI. The end of robot-assisted laparoscopy? A critical appraisal of scientific evidence on the use of robot-assisted laparoscopic surgery. Surg Endosc. Geaccepteerd voor publicatie in Surg Endosc

Janssen N, Heemskerk J, Willig AP, Toebosch SM. Rectal polyp caused by Schistosomiasis Haematobium. Geaccepteerd voor publicatie in J Gastrointest Liver Dis.

Göttgens KW, Heemskerk J, van Gemert WG, Smeets RR, Stassen LP, Beets G, Baeten CGMI, Breukink SO. Rectovaginal fistula: First results using collagen matrix biomesh by minimal invasive approach. Geaccepteerd voor publicatie in Tech Coloproctol.

Van Zwieten G, de Goede EB, van der Laan RT, Heemskerk J. A typical case of bouveret's Syndrom, or not? Geaccepteerd voor publicatie in J Gastrointest Liver Dis

Heemskerk J, Zandbergen HR, Keet SWM, Martijnse I, Montfort G, Peters RJA, Svircevic V, Bouwman RA, Baeten CGMI, Bouvy ND. Relax, it's just laparoscopy! A prospective randomized trial on heart rate variability of the surgeon in robot-assisted versus conventional laparoscopic cholecystectomy. Aangeboden voor publicatie. 
$1 4 4 \longdiv { 5 }$ 